perennials raises the possibility of differences in cold-acclimating ability between juvenile vs. mature (flowering) phases. This study investigated the yearly cold hardiness $(\mathrm{CH})$ changes of rhododendron populations and examined the relationship between leaf freezing tolerance (LFT) and physiological aging. Naturally acclimated leaves (January) from individual plants (parents- $R$. catawbiense and $R$ fortunei, $\mathrm{F}_{1}, \mathrm{~F}_{2}$, and backcross) and $\mathrm{F}_{1}$ population generated from $R$. catawbiense and $R$. dichroanthum cross were subjected to controlled freeze-thaw regimes. LFT was assessed by measuring freeze-thaw-induced ion leakage from leaf discs frozen over a range of treatment temperatures. Data were then plotted with a sigmoidal (Gompertz) curve by SAS, to estimate $T_{\text {max }}$ - the temperature causing maximum rate of injury. $T_{\text {max }}$ for the 30- to 40-year-old parental plants (catawbiense, fortunei, and dichroanthum) and the $\mathrm{F}_{1}$ 'Ceylon' (catawbiense $\mathrm{x}$ fortunei) were estimated to be about $-52,-32,-16$, and $-43^{\circ} \mathrm{C}$, respectively. These values were consistent over the 3 -year evaluation period. Data indicated the $\mathrm{F}_{2}(50$ seedlings) and backcross ( 20 seedlings) populations exhibited significant, yearly $T_{\text {max }}$ increment (of $\approx 5-6^{\circ} \mathrm{C}$ ) from 1996 to 1998 as they aged from 3 to 5 years old. $A$ similar yearly increase was observed in the $12 F_{1}$ progenies (compared 2 to 3 years old) of catawbiense $x$ dichroanthum cross. The feasibility of identifying hardy phenotypes at juvenile period and research implications of age-dependent changes in $\mathrm{CH}$ will be discussed.

\section{6 \\ Seasonal Effects on Growth of Olneya tesota following Root Pruning}

Chris A. Martin * and L. Brooke McDowell; Department of Plant Biology, Arizona State University, PO Box 871601, Tempe, AZ 85287-1601

Seedlings of Olneya tesota A. Gray (desert ironwood) were grown in 12-L containers filled with a peatmoss and pumice substrate $(1: 1 \mathrm{v} / \mathrm{v})$ for 3 months under simulated summer or winter Sonoran Desert conditions in a walk-in growth chamber. Growth room irradiance $\left(550 \mathrm{mmol} \cdot \mathrm{m}^{-2} \cdot \mathrm{s}^{-1}\right)$ was provided with an even mixture of mercury vapor and high-pressure sodium high-intensity discharge lamps. Growth room air temperature and relative humidity were ramped hourly to approximate typical summer or winter weather conditions based on mean seasonal climatological data for Phoenix, Ariz. For simulated summer conditions, maximum/minimum air temperature range was $40 / 28{ }^{\circ} \mathrm{C}$ and maximum/ minimum relative humidity range was $25 \% / 12 \%$. Photoperiod was $16 \mathrm{~h}$. For simulated winter conditions, maximum/minimum air temperature and relative humidity were $20 / 5^{\circ} \mathrm{C}$ and $80 \% / 35 \%$, respectively. Photoperiod was $10 \mathrm{~h}$. After 2 months, desert ironwood root systems were cleaned of substrate by floatation in a water bath, pruned to a length of $15 \mathrm{~cm}$, repotted, and then grown for an additional month under the same conditions. Only $41 \%$ of desert ironwood survived root pruning under summer conditions compared with a $100 \%$ survival rate under winter conditions. For surviving desert ironwood, shoot and root extension growth was significantly greater under summer conditions.

\section{7}

\section{Determining Suitable Chilling Conditions for Deciduous Fruit} Trees in Iraq

Makki A. Al-Kahafaji ${ }^{\star}$, The Arab Bank for Economic Development in Africa(BADEA) P.O. Box 2640, Khartoum, Sudan

This study was conducted during two season (1993-1994) to formulate a suitable mathematical model to determine optimal chilling conditions for deciduous fruit trees from different areas of Iraq (Baghdad, Diyala, Karbala, and Naynawa). A hygrothermograph was utilized to record the average chilling temperature: Baghdad (571), Diyala (874), Karbala (548), and Naynawa (1206). Temperature information gathered 1982-1994 from weather forecasting records also proved beneficial to our study. The model designed for this project was then used to measure optimal chilling conditions of deciduous fruit trees in 11 areas of Iraq: 1000-1200 h in northern areas (Douhook, Sulaymaniyah, Arbeel Naynawa); 700$800 \mathrm{~h}$ in the north central areas (Al-Taameen, Salah al din, Diyala), 500-600 h in the middle and south centeral areas (Baghdad, Karbala, Babil, Al-Najaf, Wasit), and $200 \mathrm{~h}$ in the southern areas (Al Qadissiyah, Thi-qar, Misan, Basrah). The chilling temeperature differences recorded in the central areas were due primairly to variations in water surface and plant coverage. Temperature proved to be the determining factor for chilling hours accumulations recorded during the growing seasons.
338

Timing of Onion Bulb Formation under Field Conditions in New York in Relation to Temperature, Photoperiod, and Cultivar

H.C. Wien ${ }^{\star}$, B.S. Orenstein, and L.A. Elerbrock; Cornell University, Ithaca, NY 14853

Although it has been known since the 1930s that long photoperiods and high temperatures hasten bulb formation in onions, the time at which onion cultivars under field conditions in New York start forming bulbs has not been previously reported. In the 1997 and 1998, onion cultivars were seeded in three commercial onion production areas at normal early spring planting dates. In 1998, a timeof-planting study was carried out in lthaca, N.Y., in which three transplanted crops and three direct-seeded crops were established at monthly intervals beginning at the end of March. Bulb ratios (bulb diameter : neck diameter) were measured at 2-week intervals during the season in all plantings. Initiation of bulbs (assumed to occur 3 weeks before bulb ratio reached 2) was then related to the photoperiod and air temperature up to that point. A comparison of early, mid-season, and late cultivars indicated that bulbs are initiated in commercial plantings in New York at close to the longest day of the year (15.6 h), at a time when mean temperature is still rising. In the time of planting study, delay of planting resulted in fewer days from emergence to bulb initiation and a reduction in growing degree-day accumulation. If planted later than 15 June, some cultivars failed to initiate bulbs, but others, such as 'Quantum' and 'Winner', initiated bulbs but did not mature them. The results indicate that photoperiod appears to be the primary factor for the initiation of bulbs, but that bulb initiation can be modified strongly in some cultivars by temperature.

\section{9}

Postharvest Physiological and Physico-chemical Responses of Jute (Chorchorus olitorius Linn.) to Various Temperature Conditions

Artemio Z. Tulio, Jr. ${ }^{* 1}$, Kimiko Ose ${ }^{2}$, Kazuo Chachin ${ }^{1}$, Yoshinori Ueda', and Hiroyuki Yamanaka'; ${ }^{3}$ College of Agriculture, Osaka Prefecture University, Sakai, Osaka 599-8531, Japan; ${ }^{2}$ Otani Women's Junior College, Tondabayashi, Osaka 584-8522, Japan; ${ }^{3}$ Hagoromo Junior College, Sakai, Osaka, 592-8344, Japan

The physiological and physico-chemical responses of jute, a tropical green leafy vegetable, to several temperature conditions were determined during postharvest storage. Jute were sourced from wholesale market and harvested from the university farm, packed in low-density polyethylene bags and stored at 1 to $30^{\circ} \mathrm{C}$ and 1 to $20^{\circ} \mathrm{C}$, respectively, before it was analyzed for postharvest quality changes. There was no significant difference in the time-temperature tolerance of both leaves in all treatments. At $1^{\circ} \mathrm{C}$ and $8{ }^{\circ} \mathrm{C}$, both jute showed high sensitivity to chilling injury, which manifested by browning of the stems, darkening of young and mature leaves, wilting, and excretion of slimy substances. These symptoms developed within 3 to 9 days at $1{ }^{\circ} \mathrm{C}$ and 5 to 13 days at $8^{\circ} \mathrm{C}$, and it seems related with the decrease of ortho-diphenol content. The chlorophyll fluorescence of jute measured in terms of $F_{v}: F_{\text {max }}$ ratio decreased before the onset of browning and remained at lower levels during development of chilling injury at 1 and $8{ }^{\circ} \mathrm{C}$. The ethylene concentration decreased after increasing for 1 day at $8^{\circ} \mathrm{C}$ and before chilling injury occurred at $1^{\circ} \mathrm{C}$. However, at 15,20 , and $30^{\circ} \mathrm{C}$, both jute were more susceptible to yellowing with chlorophyll degradation and abscission of leaves due to senescing effect of high-temperature storage. Senescent symptoms were evident within 1 to 5 days at $30^{\circ} \mathrm{C}$ and 3 to 7 days at 15 and $20^{\circ} \mathrm{C}$. Jute with stems partly immersed in water during storage had lower respiration rates at 1 and $8{ }^{\circ} \mathrm{C}$ due to its sensitivity to chilling injury manifested by wilting of leaves within 1 to 4 days of storage.

\section{0}

Postharvest Life of Antirrhinum majus L. as Influenced by Number of Stomata per Cut Flower Stem

Kenneth R. Schroeder" and Dennis P. Stimart; Department of Horticulture, University of Wisconsin, 1575 Linden Dr., Madison, WI 53706

Leaf impressions were made from two short-lived ( 4 and $5 \mathrm{~d}$ ) inbreds, alonglived (11 d) inbred, and their hybrids ( 8 and 9 d) of Antirrhinum majus L. using Super Glue and glass microscopeslides. Leaves weretaken from mid stem, pressed on glass slides (under side down), spread with a small amount of Super Glue, set for 3 to $4 \mathrm{~s}$. Then, the leaf was peeled off leaving a permanent impression in the glue. Slides were placed under a microscope equipped with a video imaging 
system and computer images were taken to facilitate counting of stomatal complexes. Number of stomata ranged from 10,400 to 21,300 per $\mathrm{cm}^{2}$ of leaf. A LICOR LI-3100 area meter (LI-COR, Inc. Lincoln, Neb.) was used to measure total leaf area of $40-\mathrm{cm}$ cut flower stems of each accession. Stomata per flowering stem ranged from 1,074,000 to 2,282,000, with the long-lived inbred having the fewest stomata, the hybrids intermediate with $11 \%$ to $21 \%$ more, and the shortlived inbreds having $40 \%$ to $113 \%$ more stomata per stem. It appears long postharvest life of $A$. majus is associated with flowering stems with fewer stomata per cut stem.

\section{1}

\section{Carbohydrate Concentration in Antirrhinum majus L. Flower, Leaf, and Stem Tissue}

Kenneth R. Schroeder" and Dennis P. Stimart, Department of Horticulture, University of Wisconsin, 1575 Linden Dr., Madison, WI 53706

A phenol-sulfuric acid assay was used to quantify non-specific neutral carbohydrates in Antirrhinum majus L. flowering stems of three inbreds and their hybrids. Flowering stems $40 \mathrm{~cm}$ long were harvested with five to six florets open and flower, leaf, and stem tissue separated, freeze-dried, and finely ground. Carbohydrates were extracted from the tissue with $95 \%$ ethanol in a $70{ }^{\circ} \mathrm{C}$ water bath and combined with a $5 \% \mathrm{w} / \mathrm{v}$ phenol solution and concentrated sulfuric acid. Glucose equivalents were determined with a spectrophotometer at absorbance of $490 \mathrm{~nm}$. Averaged over tissue type, results were genotype dependent, ranging from 213 to $291 \mu \mathrm{g}$ glucose equivalent per $\mathrm{mg}$ dry tissue with $\mathrm{LSD}_{0.05}=13$. Flowers had the highest concentration of $340 \mu \mathrm{g} / \mathrm{mg}$ dry tissue, foll owed by stems, then leaves with $36 \%$ and $38 \%$ lower concentrations, respectively. Carbohydrate concentrations in two inbreds were compared when grown under cool $\left(16^{\circ} \mathrm{C}\right)$ and warm $\left(29^{\circ} \mathrm{C}\right)$ conditions. A genotype $\mathrm{x}$ environment interaction exists with inbred 3 exhibiting no reduction, $6 \%$ increase, and a $45 \%$ reduction in carbohydrate concentration when grown in warm conditions, while inbred 2 exhibited $15 \%, 23 \%$, and $37 \%$ reductions for flowers, leaves, and stems, respectively. Overall, there were $10 \%$ and $21 \%$ reductions in carbohydrate concentration for inbreds 2 and 3 , respectively, when plants were grown under warm conditions.

\section{2}

\section{Shading Influences the Growth and Development of Pawpaw} Seedlings Grown Outside

Kirk W. Pomper*, Snake C. Jones, and Eddie B. Reed; Land-Grant Program, Atwood Research Facility, Kentucky State University, Frankfort, KY 40601-2355

In an effort to determine the optimal light level for growing pawpaw [ Asimina triloba (L.) Dunal] seedlings outside, seedlings were germinated in a greenhouse until the two- to three-leaf stage, at which time they were placed outside and shade treatments were imposed that reduced incident light intensity by $30 \%$, $55 \%, 80 \%$, and $95 \%$. Control seedlings were left unshaded outside. A randomized block design was used, with 20 replicate seedlings in each experimental treatment per block. Plants were destructively harvested 11 weeks after the start of the experiment. After 11 weeks, the height and number of leaves per seedling were about $35 \%$ higher with light to moderate shading (30\%, $55 \%$, and $80 \%$ ) than in control (unshaded) seedlings. Shoot and leaf dry weights of seedlings grown in 30\%, 55\%, and $80 \%$ shade were almost 2-fold greater than control plants. Root dry weight of seedlings in $30 \%$ and $55 \%$ shade was 2 -fold higher than in control plants. Total plant biomass was greatest in the $30 \%, 55 \%$, and $80 \%$ shade treatments, about 2-fold higher than control plants. Total leaf areaper seedling increased significantly with up to $80 \%$ shading. Seedlings growing under $95 \%$ shading had fewer and smaller leaves and reduced biomass production compared to control plants. There was a trend for shaded plants to display a higher leaf chlorophyll content than control plants. Overall, the best seedling growth was achieved in the $30 \%$ and $55 \%$ shade treatments outdoors.

\section{3}

\section{Emergence of Five Lettuce Cultivars using Seeds Developed in Different Seasons}

Lynze Greenwood", Janice M. Coons, Henry R. Owen, Lisa Ferguson, and Ronglin Wang; Biological Sciences Department, Eastern Illinois University, Charleston, IL 61920

Lettuce (Lactuca sativa) is one of the most important U.S. fresh-market vegetables with year-round consumption. For winter markets, lettuce is produced in the southwestern states with plantings in early fall when soil temperatures are high. Seed germination of lettuce, however, is inhibited by soil temperatures over $25^{\circ} \mathrm{C}$. The objective of this study was to test the emergence and growth of five lettuce cultivars using two seedlots produced in winter or summer to provide information for improving stand establishment at high temperatures. Seeds of five cultivars ('Empire', 'Parris Island Cos', 'Waldmann's Green', 'Prizehead', and 'Dark Green Boston') produced in Yuma, Ariz., during summer or winter months were used. Seeds were planted in a greenhouse mix in plastic trays and grown in a growth chamber at $23,25,30$ and $35^{\circ} \mathrm{C}$. After 4 weeks, number of emerged plants, number of leaves, height, fresh weight, dry weight, and leaf area were measured. At lower temperatures $\left(23\right.$ and $25^{\circ} \mathrm{C}$ ), more plants emerged and plants developed more rapidly than at higher temperatures $\left(30\right.$ and $\left.35^{\circ} \mathrm{C}\right)$. More plants emerged of 'Empire' and 'Parris Island Cos' than of 'Waldmann's Green' or 'Dark Green Boston'. Growth varied greatly for the different cultivars. At $35^{\circ} \mathrm{C}$, only 'Empire' winter seed emerged. At other temperatures, summer seed lots generally were better than or equal to winter seedlots. This information suggests that seeds developed during the summer are morevigorous at emergence than those developed during the winter.

\section{4}

Dormancy Breaking and Germination of Liriope spicata Lour. Ki Sun Kim* and Ji Ny Lee; Department of Horticulture, Seoul National University, Suwon 441-711, Korea

There are many ground covers native to Korea. Liriope spicatais very promising for landscaping purposes due to its waxy and dark-green foliage fragrant and pink flowers, as well as fruit. However, seeds harvested during late fall do not germinate at all if they are sown in spring. Thus, series of experiments were conducted to undestand the physiological mechanism of dormancy breaking and germination of Liriope spicata Lour. seeds and to determine the effective methods for enhancing seed germination. Fruit were harvested in October through December. Depulped seeds germinated rapidly, indicating that one or more inhibitors may be present in the pulps of fruit and/or seeds. $\mathrm{GA}_{3}, \mathrm{NaOCl}, \mathrm{NaOH}$, and $\mathrm{H}_{2} \mathrm{SO}_{4}$ treatments and dry cold treatment had no effect on germination, whereas wet, cold seed treatment for at least 30 days promoted germination up to $75 \%$ within 15 days. Optimum conditions for germination was continuous dark and $25 / 20^{\circ} \mathrm{C}$ alternate temperature conditions. Extracts from pulps and seeds showed a strong inhibition effects on the germination of lettuce seeds, indicating that germination inhibitors are present in pulp and seeds. Since extracts from naked seeds did not show inhibition, inhibitory substances are thought to be present in pulp and seedcoat. Pulp and seeds were extracted with water and methanol and autoclaved at $115^{\circ} \mathrm{C}$, followed by bioassay experiments. Germination inhibitors were found water soluble and heat stable by series of bioassay experiments. Diluted extracts 4 to 8 times still maintained inhibitory effects. Optimum seed harvesting time was from 22 Nov. to 1 Dec., where seed germination was high without additional seed treatments. Total phenolic compounds and ABA contents of pulp and seeds decreased by wet cold seed treatment. Changes in total phenolic compounds and ABA in from October through December were correlated with germination during the seed development. When contents of total phenolic compounds and ABA were high, seeds did not germinate at all, while low contents resulted in good seed germination.

\section{5}

\section{Seed Germination of Inland Saltgrass}

Judy Harrington* and Scott Reid; Department of Horticulture and Landscape Architecture, Colorado State University, Fort Collins, CO 80523

Distichlis spicata var. stricta (Torrey) Beetle is a native grass that tolerates salt, high pH, and some heavy metals. It has been proposed for use in several challenging environments, including mine spoils and salt-impacted areas of golf courses, but its widespread use has been hindered by several factors, one of which is seed dormancy. Dormancy appears to be coat-imposed and can be overcome by scarification in relatively young seed lots. Thirteen-year-old seeds germinated better without scarification. Seeds were tested at several constant and alternating temperatures. Temperatures around $30^{\circ} \mathrm{C}$ seemed to give the highest percentage germination, approaching the viability that was shown by tetrazolium chloride tests for each seed lot. Alternating temperatures increased the germination of unscarified seeds but not as much as scarification did. Light appears to be unnecessary for germination. 


\section{6}

Effects of Gibberellic Acid and Seed Location on Seed Germination of Echinacea pallida

Ali O. Sari, Mario R. Morales* , and James E Simon; Center for New Crops and Plant Products, Purdue University, West Lafayette, IN 47907-1165

Echinacea pallida, one of the three medicinal Echinacea species native to North America, is generally wildcrafted, and low and uneven seed germination are obstacles to its widespread cultivation. Nonstratified $E$ pallida seeds were treated with 2500,3500 , and $4500 \mathrm{mg} / \mathrm{L} \mathrm{GA}$ to increase seed germination. Treated seeds were directly germinated at $25^{\circ} \mathrm{C}$ and $25 / 15^{\circ} \mathrm{C}(14 / 10 \mathrm{~h})$ or stored at 5 and $10^{\circ} \mathrm{C}$ for 4,8 , and 12 weeks before germination at the same temperatures. Seed germination across treatments was higher at $25^{\circ} \mathrm{C}(19 \%)$ than at $25 / 15^{\circ} \mathrm{C}(14 \%)$. Application of 2500,3500 , and $4500 \mathrm{mg} / \mathrm{L} \mathrm{GA}_{3}$ significantly increased seed germination rate and total seed germination of nonstratified seeds of $E$. pallida and resulted in $44 \%, 50 \%$, and $63 \%$ total seed germination, respectively, while untreated control seeds germinated at only $9 \%$. The effect of $\mathrm{GA}_{3}$ as a germination stimulant increased with cold storage, with maximum germination (83\%) occurring after seeds were treated with $4500 \mathrm{mg} / \mathrm{L} \mathrm{GA}_{3}$ and an 8-week cold storage period at $10^{\circ} \mathrm{C}$. The effect of cold storage periods of 4,8 , and 12 weeks and cold storage temperatures of 5 and $10^{\circ} \mathrm{C}$ on seed germination were generally similar. Seeds collected from the upper rows of the seed heads germinated significantly higher $(10.6 \%)$ than those collected from the lowest seed rows $(2.4 \%)$.

\section{POSTER SESSION 8 (Abstr. 347-365) Postharvest Physiology \& Food Science}

\section{Thursday, 29 July, 1:00-2:00 p.m.}

\section{7}

1-MCP and $\mathrm{CO}_{2}$ Reduction of Ethylene Response on Snapdragon

R. St.Hill" and D.P. Murr, Department of Plant Agriculture, Horticultural Science Division, University of Guelph, Guelph, Ontario, Canada N1G 2W1

Recent advances in technology have made the snapdragon, Antirrhinum majus L., a promising florist crop in North America and potentially on the Ontario market. $\mathrm{CO}_{2}$ is a known inhibitor of ethylene action, but its effects tend to be difficult to interpret based on the variable responses of plants to this gas. Recently, a gaseous ethylene analog has been shown to inhibit certain ethylene responses of cut flowers, such as wilting in carnations and flower abscission of cut phlox. This cyclic olefin, 1-methylcyclopropene (1-MCP), is thought to bind irreversibly to the ethylene receptor sites, thereby preventing or delaying ethylene responses. In the experiments undertaken, the potential of $\mathrm{CO}_{2}$ and $1-\mathrm{MCP}$ were investigated for their ability to enhance vase life and to reduce shattering and wilting of snapdragons. Flowers were sealed in $\approx 0.2-\mathrm{m}^{3}$ chambers encased in 6 -mil polyethylene and exposed to elevated $\mathrm{CO}_{2}(5 \%$ or $10 \%)$ or $1-\mathrm{MCP}(20-200 \mathrm{~nL} / \mathrm{L})$ for 6 to $24 \mathrm{~h}$ at $20^{\circ} \mathrm{C}$. The flowers were then exposed to continuous ethylene of $0-20 \mu \mathrm{L} /$ L. Following exposure to 5 or $20 \mu \mathrm{L} / \mathrm{L}$ ethylene, 1-MCP reduced shattering $\approx 2$ to 3-fold compared to $\mathrm{CO}_{2}$ treatment. 1-MCP did not prevent the wilting response but delayed it by $\approx 2$ days. $\mathrm{CO}_{2}$-treated flowers exhibited a more rapid decline in net percent open florets from days 3 to 5 post-treatment. Despite the ability of 1 MCP to reduce shattering, in the absence of exposure to continuous ethylene, it has limited effectiveness on wilting compared to $\mathrm{CO}_{2}$.

\section{8}

Mineral Nutrient Composition of Edible Parts of the Daylily Plant Johnny Carter", Bharat P. Singh, and Young W. Park; Agricultural Research Station, Fort Valley State University, Fort Valley, GA 31030

In the United States, the common daylily is cultivated as an ornamental. However, in other countries, such as China and Japan, it is an important food crop. With this in mind, a study was conducted to determine the mineral nutrient content of edible parts (flower buds, flowers and tubers) of the daylily plant. Edible parts were analyzed for $\mathrm{P}, \mathrm{K}, \mathrm{Ca}, \mathrm{Mg}, \mathrm{Mn}, \mathrm{Fe}, \mathrm{B}, \mathrm{Cu}, \mathrm{Al}$, and $\mathrm{Na}$. Results of this study showed that flower buds had significantly higher level of $P$ and $M g$ than tubers and flowers. The $\mathrm{K}$ and $\mathrm{B}$ concentration in flower buds were similar to flowers, but significantly greater than in the tubers. The respective Zn concentra- tions in flowers and flower buds were $32 \%$ and $23 \%$ greater than those in the tubers. There was no difference in the $\mathrm{Mn}$ concentration among the edible parts. Tuber contained significantly higher contents of $\mathrm{Ca}$ and $\mathrm{Cu}$ than the flowers and flower buds. It also had 10.6-, 14.3-, and 2.8-times greater concentration of Mn, $\mathrm{Al}$, and $\mathrm{Na}$, respectively, than the combined average flower buds and flowers. From this study, daylily appears to have potential as a nutritious food source for human consumption.

\section{9}

\section{Studies on Postharvest Performance of Cut Racemes of Big Bend Bluebonnet}

W.A. Mackay*, D. Sankhla, T.D Davis, and N. Sankhla; Texas A\&M University Research and Extension Center, 17360 Coit Rd., Dallas, TX 75252- 6599

Racemes of Big Bend bluebonnet (Lupinus havardii Wats.), a winter annual native to far west Texas with attractive blue flowers, are currently being produced commercially as a specialty cut-flower crop. Our studies indicated that the key determinants of postharvest longevity and performance are flower abscission and flower senescence, both of which can be influenced by ethylene. Therefore, this study was undertaken to evaluate the role of some ethylene biosynthesis inhibitors (aminooxy acetic acid = AOA; cobalt $=\mathrm{CO}^{++}$; salicylic acid $=\mathrm{SA}$ ) and an ethylene action inhibitor (silver thiosulfate $=$ STS) on flower abscission and flower senescence of bluebonnet racemes. Depending on the concentration used (10 $\mu \mathrm{M}-1 \mathrm{mM}), \mathrm{AOA}$ and $\mathrm{CO}^{++}$exhibited variable effects on flower abscission, flower senescence and vaselife. SA (10-100 $\mu \mathrm{M})$ slightly delayed senescence but did not affect abscission, while higher levels of $S A(500 \mu \mathrm{M}-2 \mathrm{mM})$ slightly promoted abscission and also significantly enhanced the senescence of flowers on cut racemes. The effects of SA were found to be pH-dependent. However, STS nearly eliminated flower abscission and enhanced vaselife. The results also demonstrated that the abscission of bluebonnet flowers, in particular, is highly sensitive to ethylene.

\section{0}

\section{Quality Changes of Spinach Stored in Controlled and} Modified Atmospheres

Ma. Teresa Martinez-Damian ${ }^{1}$ and Marita I. Cantwel ${ }^{2}$; ${ }^{1}$ IREGEP, Colegio de Posgraduados, Montecillo, C.P. 56230 Edo. de Mexico; '2 Dept. Vegetable Crops, University of California, Davis, CA 95616

Spinach is not packed commercially in modified-atmosphere packaging due to difficulties in maintaining beneficial conditions during distribution, wheretemperature fluctuations can occur. However, low $\mathrm{O}_{2}$ and high $\mathrm{CO}_{2}$ atmospheres can be useful to retard yellowing and deterioration. In two experiments we studied developing and full-size leaves stored at $7.5^{\circ} \mathrm{C}$ in air and controlled atmospheres of $0.5 \% \mathrm{O}_{2}+10 \% \mathrm{CO}_{2}$ and $5 \% \mathrm{O}_{2}+10 \%$ or $20 \% \mathrm{CO}_{2}$. Subjective quality evaluations (visual quality, decay, discoloration, off-odors, and yellowing) and objective evaluations $\left(\mathrm{L}^{*} \mathrm{a}^{*} \mathrm{~b}^{*}\right.$ color values, chlorophyll, $\mathrm{pH}$ and titratable acidity, ammonia, and ethanol and acetaldehyde) were conducted every 3 days during 15 days. The developing leaves had higher visual quality and lower off-odor scores during storage than did the full-size leaves. In air storage, leaves were below the limit of sal ability by day 12 . The atmospheres containing $10 \% \mathrm{CO}_{2}$ were similarly effective in maintaining the visual quality and greenness of the leaves, and reduced off-odors in developing but not full-size leaves. The $20 \% \mathrm{CO}_{2}$ atmosphere resulted in some leaf damage. Ammonia concentrations increased during storage, with lowest and highest concentrations in leaves stored in air and $20 \% \mathrm{CO}_{2}$, respectively. Tissue $\mathrm{pH}$ only slightly increased from 6.5 in air-stored samples, but increased notably during storage in the controlled atmospheres. At 2.5 and $7.5^{\circ} \mathrm{C}$, a plastic film providing a $5 \% \mathrm{O}_{2}$ and $6 \% \mathrm{CO}_{2}$ atmosphere resulted in better quality spinach than that obtained with either a $10 \% \mathrm{O}_{2}$ and $3 \% \mathrm{CO}_{2}$ package atmosphere or the commercial perforated polybag.

\section{1}

Use of Promalin ( $\mathrm{GA}_{4+7}$ and BA) Sprays to Prevent Cold Storage-induced Leaf Yellowing and Abscission in 'Stargazer' Hybrid Lilies

Anil P. Ranwala $a^{* 1}$ and William B. Miller'; ' 1 Department of Horticulture, Clemson University, Clemson, SC 29634; '2Department of Floriculture and Ornamental Horticulture, Cornell University, Ithaca, NY 14853

Our previous research has demonstrated preventive effects of foliar sprays of growth regulators containing $\mathrm{GA}_{4+7}$ (ProVide or Promalin) on cold storage- 
induced leaf yellowing and abscission in 'Stargazer' hybrid lilies. Further research was conducted to investigate the effective concentrations of Promalin and appropriate timing of promalin sprays. Lilies at "puffy bud" stage were sprayed with promalin at concentrations of $10,25,50$ or 100 ppm (each $\mathrm{GA}_{4+7}$ and $\mathrm{BA}$ ) just before placing them at $4{ }^{\circ} \mathrm{C}$ for 2 weeks in darkness. Promalin concentrations of $25 \mathrm{ppm}$ or above completely prevented cold storage-induced leaf yellowing occurring during the poststorage evaluation phase in a simulated consumer environment, whereas $10 \mathrm{ppm}$ sprays only partially prevented it. Foliar spray of Promalin (100 ppm each $\mathrm{GA}_{4+7}$ and $\mathrm{BA}$ ) just before storage at $4{ }^{\circ} \mathrm{C}$ for 2 weeks was compared with spraying 2 or 4 weeks before cold storage. While spraying 2 weeks before storage prevented leaf yellowing to the same extent observed in plants sprayed just before cold storage, spraying 4 weeks before storage had very little preventive effect on leaf yellowing. To investigate the effectiveness of promalin sprays with different cold storage durations, puffy-bud stage plants were stored at $4^{\circ} \mathrm{C}$ for $1,2,3,4$, or 5 weeks in darkness with or without promalin sprays (100 ppm each $\mathrm{GA}_{4+7}$ and $\mathrm{BA}$ ) before storage. Longer cold storage durations increased the severity of leaf yellowing occurring during poststorage phase. Although promalin was able to prevent leaf yellowing completely up to 2 weeks of cold storage, beyond 3 weeks of cold-storage, effectiveness of promalin diminished with no apparent preventive effect on plants stored for 5 weeks.

\section{2}

\section{Heat Treatment Enhances the Development of Mealiness in Peaches and Nectarines}

D.M. Obenland* and F.R Ryan; Horticultural Crops Research Laboratory, USDA ARS, Fresno, CA

Previous work by our group has demonstrated the potential feasibility of using high-temperature forced-air (HTFA) treatment for insect disinfestation of nectarines. Fruit quality of nine cultivars tested was unaffected following the application of a HTFA treatment targeted against Mediterranean fruit fly. In an extention of this work, we examined the effect of this treatment on peach and nectarine cultivars that have differing reported susceptibilities to the development of mealiness to determine if HTFA treatment has any effect on the occurrence of this disorder. Fruit were exposed to HTFA over $4 \mathrm{~h}$ until the fruit center registered a temperature of $47.2^{\circ} \mathrm{C}$, then stored at $5^{\circ} \mathrm{C}$ for 1 to 3 weeks and $2 \mathrm{~d}$ at $23^{\circ} \mathrm{C}$, at which time the fruit were visually evaluated for symptoms of mealiness. 'Summer Bright', 'Ryan Sun', and 'Elegant Lady', cultivars susceptible to the development of mealiness, showed a $66 \%, 24 \%$, and $66 \%$ increase in the incidence of mealiness, respectively, due to HTFA treatment. 'Summer Grand', a cultivar classified as nonsusceptible, did not develop mealiness in the absence of HTFA treatment, while $81 \%$ of the HTFA-treated fruit of this cultivar were classified as mealy following 2 weeks of storage. Enhancement of mealiness in stonefruit by heat is a very detrimental effect that must be carefully considered in the development of HTFA treatments for these commodities.

\section{3}

Flavor, Sensory, and Postharvest Evaluations of Commercial- vs. Tree-ripe Fresh-cut 'Bounty' Peaches

John C. Beaulieu' ${ }^{* 1}$, Karen L. Bett', Elaine T. Champagne', Daphne A. Ingram', James A. Miller', and Ralph Scorzz;; 'United States Department of Agriculture, Agricultural Research Service, Southern Regional Research Center, 1100 Robert E. Lee Blvd. New Orleans, LA 70124; '2United States Department of Agriculture, Agricultural Research Service, Appalachian Fruit Research Station, 45 Wiltshire Rd, Kearneysville, WV 25443

Many consumers do not buy peaches due to the fuzzy skin and seed stone and because out-of-season peaches do not possess optimum tree ripe flavor. The feasibility of using a non-browning freestone peach to deliver high-quality fresh-cut products was investigated. Changes in fresh-cut flavor, texture, and postharvest attributes of commercial-ripe (CR) vs. tree-ripe (TR) harvested and shipped 'Bounty' peach was assessed. Fresh-cut CR wedges had an initial firmness of $20.9 \mathrm{~N}$, whereas TR wedges had $11.2 \mathrm{~N}$. On day 2, firmness decreased roughly $3 \%$ to $12 \%$ and $35 \%$ to $45 \%$ for CRand TRwedges held at $1{ }^{\circ} \mathrm{C}$, respectively. By day 5, CR wedges hardened (24.5 N) whereas TR did not return to their initial firmness; increasing marginally through day 7 . Sensory panel hardness for CR did not change through storage, but with TR wedges, hardness decreased through day 2 then increased until day 7. Little variation was noted in the initial soluble solids for CR vs. TR wedges (11.7, vs. $11.4^{\circ}$ Brix, respectively). After 7 days storage, ${ }^{\circ}$ Brix decreased $7.5 \%$ to $12 \%$ in CRand $4.5 \%$ to $12 \%$ in TRwedges. Yellow flesh color $\left(b^{*}\right)$ decreased in all $C R$ and TR treatments through storage.
Flavor compounds in expressed juice were analyzed by solid phase microextraction with GC-MS. Several peaks were identified that may be associated with flavorrelated changes that occurred during storage. For example, low molecular weight acetates and $6 \mathrm{C}$ compounds almost disappeared during storage, whereas short chain fatty acids, lactones, and palmitic acid increased markedly through storage. In TR, the "fruity" descriptor decreased throughout storage and "sweet aromatic" increased slightly (day 2) then decreased through day 7.

\section{4 \\ Development of Off-flavor in Melting Flesh and Nonmelting Flesh Peach Genotypes}

Yasar Karakurt, Donald J. Huber*, and Wayne B. Sherman; Horticultural Sciences Department, POBOX 110690, University of Florida, Gainesville, FL 32611 0690

Some nonmelting flesh (NMF) peaches develop a characteristic off-flavor during postharvest ripening. A study was conducted using NMF genotypes from the Univ. of Florida breeding program to investigate the off-flavor development in melting flesh (MF) and NMF peach genotypes and to determine the compositional changes associated with the development of off-flavor during postharvest ripening at $8^{\circ} \mathrm{C}$. The study revealed that there were certain chemical components that were consistently associated with the occurrence of off-flavor. Generally, there was a significant increase in total soluble phenolics, polyphenoloxidase (PPO) activity and ethanol content with the increase in the percentage of off-flavored fruit with time in storage at $8{ }^{\circ} \mathrm{C}$ in NMF genotypes examined. However, total sugars and total soluble solids decreased significantly during the storage period. These changes in chemical composition of NMF genotypes were not observed in MF genotypes, which did not show off-flavor development. Moreover, highly significant linear correlations were detected between off-flavor development and soluble phenolics, PPO activity, ethanol content, total soluble solids, and sugars in Fla. 92-21C and USDA 87P285, which had the highest percentage of offflavored fruit. Specifically, soluble phenolics, chlorogenic acid, PPO activity, and ethanol were positively correlated, but soluble sugars and soluble solids were negatively correlated with the off-flavor development. Thus, it is suggested that the accumulation of soluble phenolic compounds and ethanol, and the reduction of soluble solids and sugars contribute to the of off-flavor in NMF genotypes.

\section{5 Effect of UV-C on Ripening and Postharvest Quality of Peaches}

Robert C. Ebel* Floyd M. Woods, and Dave Himelrick; Department of Horticulture, 101 Funchess Hall, Auburn University, Auburn, AL 36849

Brown rot of peaches is one of the most devastating diseases that can occur before and after harvest. There has been extensive research that has shown that ultraviolet light (UV-C) kills the fungus that causes brown rot. However, it is has not been determined whether UV-C will also change ripening and fruit quality. We applied UV-C to 'Loring' peaches that were harvested 10 days before normal harvest. We intentionally picked the fruit early because we wanted to make sure the fruit had not entered the climacteric. The fruit were treated with UV-C and ethylene, skin color, firmness, and soluble solids were measured. We also held fruit at three storage temperatures to determine whether there may be an interaction between UV-C treatment and storage temperature. Ethylene was slightly higher for UV-C treated fruit at $70^{\circ} \mathrm{F}\left(20^{\circ} \mathrm{C}\right)$ and $55^{\circ} \mathrm{F}\left(12^{\circ} \mathrm{C}\right)$, but not at $40^{\circ} \mathrm{F}\left(4^{\circ} \mathrm{C}\right)$. However, there was very little effect on firmness and soluble solids. There was a slight delay in development of red blush. UV-C had little effect on ripening and peach fruit quality.

\section{6}

Leatheriness and Mealiness of Peaches, Their Biochemical Characteristics Related to Fruit Maturity and Storage

\section{Temperature}

Zhiguo $\mathrm{Ju}^{* 1}$, Yousheng Duan ${ }^{2}$, and Zhigiang Ju'; ${ }^{2}$ Tree Fruit Research Lab, USDAARS, 1104 N. Western Ave., Wenatchee, WA 98801; ${ }^{2}$ Dept. R\& D, EurekaBiotech. Co. China

'Huangjin' peaches were harvested at immature, mature, and over-mature stages according to ground color and firmness evaluations, and were stored at 0 , 5 , and $10^{\circ} \mathrm{C}$, respectively. After 4 weeks of cold storage, immature fruit developed a higher percentage of leatheriness but a lower level of mealiness than mature fruit. Over-mature fruit did not develop leatheriness, but developed a higher 
percentage of mealiness than mature fruit. Fruit stored at $5{ }^{\circ} \mathrm{C}$ developed more mealiness than fruit stored at $0^{\circ} \mathrm{C}$ for the same period of storage, while fruit stored at $0^{\circ} \mathrm{C}$ developed more leatheriness than fruit stored at $5^{\circ} \mathrm{C}$. When stored at $10^{\circ} \mathrm{C}$, fruit did not develop any leatheriness or mealiness regardless of maturity. Compared with juicy and mealy fruit after the same period of cold storage, fruit with leathery symptoms were significantly firmer following 4 days at $20^{\circ} \mathrm{C}$. 1-Aminocyclopropane-1-carboxylate oxidase (ACO) activity, 1-amino-cyclopropane-1-carboxylic acid (ACC) content, and polygalacturonase (PG) and $\beta$-galactosidase (GAL) activity were lower, and insoluble pectin content was higher, in leathery fruit than that in juicy and mealy fruit. Mealy fruit were as soft as juicy fruit after ripening at $20^{\circ} \mathrm{C}$ for 4 days. Their ACO, PG, and GAL activity; ACC; and insoluble pectin content were similar. Results indicated that leatheriness is atypical chilling injury but mealiness is not.

\section{7}

\section{Combinations of $\mathrm{GA}_{3}$ and AVG Delay Fruit Maturity, Increase} Fruit Size, and Improve Storage Life of 'Feicheng' Peaches

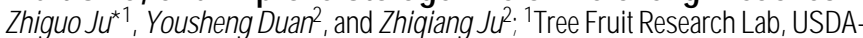
ARS, 1104 N. Western Ave., Wenatchee, WA 98801; ${ }^{2}$ Dept. R\& D, EurekaBiotech. Co., China

'Feicheng' peach is a favorite cultivar in China due to is large size and high eating quality. However, its storage quality is poor and its market life is relatively short. Different combinations of $A V G$ and $G A_{3}$ applied at various stages of fruit development were evaluated to prolong market life of this fruit. A combination of 80-100 mg/L AVG and 80-100 mg/L GA at the end of pit hardening gave the best results. This treatment retarded the change in ground color, loss of firmness, and reduction in acidity by 2 to 3 weeks. Since harvest was delayed, soluble solid content increased compared with the control that was harvested earlier. Fruit size increased significantly on treated trees. During 6 weeks of storage at $0{ }^{\circ} \mathrm{C}$, ethylene evolution increased and fruit firmness decreased slowly in control fruit, but in $\mathrm{AVG}+\mathrm{GA}_{3}$-treated fruit, they did not change from the low initial levels. At the end of storage, control fruit developed a high percentage (83\%) of tissue browning and mealiness after warming at $20{ }^{\circ} \mathrm{C}$ for 4 days, but the $\mathrm{AVG}+\mathrm{GA}_{3}$-treated fruit ripened normally and developed much less $(16 \%)$ tissue browning and mealiness. Our results showed that the market life of 'Feicheng' peaches can be prolonged by at least 4 weeks by using the $\mathrm{AVG}+\mathrm{GA}_{3}$ treatment to delay harvest and improve storage quality.

\section{8}

\section{Quality of Fresh-cut Onions}

M. Khatoon ${ }^{* 1}$ and A. Hakim²; ${ }^{1} 805$ Prince Avenue, Apt "A", Tifton, GA 31794, USA; ${ }^{2}$ Department of Horticulture, University of Georgia, Coastal Plain Experiment Station, Tifton, GA 31793, USA

Sweet onions (Allium cepae) were diced or sliced, ringed with sodium hypochloride solution (50 ppm) for about $2 \mathrm{~min}$, and drained. After that, they were packaged in perforated polyethylene package and stored in an air and controlled-atmosphere $\left(2 \% \mathrm{O}_{2}\right.$ and $\left.5 \% \mathrm{CO}_{2}\right)$ room at $1{ }^{\circ} \mathrm{C}$ for 5 and 10 days. Weight loss, fungus infection, surface discoloration, flavor and taste, ethanol content, TSS, pH, firmness, and electrolyte leakage were determined after storage. Based on weight loss, fungus infection, surface discoloration, flavor and taste, ethanol content, TSS, pH, firmness, and electrolyte leakage, controlled-atmosphere storage, onions diced exhibited better quality retention than those that were stored in air. The overall quality of discs was better than slices. Onion stored for 10 days showed higher weight loss, more fungus infection and surface discoloration, offflavor, bad taste, higher ethanol content, lower TSS content, less firm and higher electrolyte leakage than those stored for 5 days. So, the quality of fresh-cut onion disks can be maintained properly in a controlled atmosphere with reduced oxygen and elevated carbon dioxide up to 10 days.

\section{9}

Firmness and Force Relaxation Characteristics of Tomatoes Stored Intact or as Slices

Tianxia Wu and Judith A. Abbott" ; Horticultural Crops Quality Laboratory, U.S. Department of Agriculture, Agricultural Research Service, Beltsville, MD 207052350

We compared the firmness and force relaxation characteristics of tomato flesh harvested at six maturity stages and stored intact or as 7 - $\mathrm{mm}$ slices for 0 to 20 days. Three measurements were made on outer pericarp and columella tissue. $\mathrm{A}$ 4-mm cylindrical probe provided more consistent firmness measurements (lower percent CV) than a 6.4-mm spherical probe at harvest, and distances of $3 \mathrm{~mm}$ were more consistent than $1 \mathrm{~mm}$. Following loading, stress relaxation was recorded for $10 \mathrm{~s}$. Stored tomato samples were tested only with the 4-mm cylindrical probe and distance of $3 \mathrm{~mm}$. Firmness was taken as the maximum force $\left(F_{\max }\right)$ in the loading portion, usually occurring at $3 \mathrm{~mm}$. $F_{\text {max }}$ of freshly harvested tomatoes ranged from 15 to $2 \mathrm{~N}$ for mature green and red tomatoes, respectively. $\mathrm{F}_{\text {max }}$ was closely correlated to area, slope, and force at first peak, i.e., all four parameters measured the same physical property, and was moderately correlated $(R>$ 0.9 ) to forces at specific relaxation times. Tomatoes stored intact generally had lower CVs than that of those sliced before storage, although there was little difference in average firmness $\left(F_{\text {max }}\right)$ between the two at a given storage time. A threeparameter model was developed to fit the relaxation curves. There was little correlation between $\mathrm{F}_{\max }$ and the three relaxation characteristics $(R=0.6$ to 0.0$)$, i.e., the relaxation characteristcs measured different physical properties than did $F_{\text {max }}$. The responses of the relaxation characteristcs over storage time were dependent on the initial maturity of the tomatoes, but their values usually differed significantly between tomatoes stored intact or sliced, with tomatoes sliced before storage generally having higher values.

\section{0}

\section{Quality Deterioration of Fresh-cut Onions}

Andrés F. López Camelo ${ }^{1}$ and Marita Cantwel/ ${ }^{* 2} ;{ }^{1}$ INTA E.E.A. Balcarce, Buenos Aires, Argentina; ${ }^{2}$ Mann Laboratory, University of California, Davis, CA 95616

A study on quality changes of fresh-cut onions under different temperatures and handling conditions was conducted. High-quality onions were peeled and diced into $1 \times 1 \mathrm{~cm}$ pieces. Replicated (3) experimental units $(150 \mathrm{~g}$ ) were stored for 20 days in glass jars in a humidified air flow under the following conditions: 0,5 , and $10^{\circ} \mathrm{C}$. To simulate rough handling, onion pieces were rolled with a rolling pin with enough pressure to induce some damage and stored at $5{ }^{\circ} \mathrm{C}$. Objective (color, soluble solids, and dry and fresh weights) and subjective (visual quality, decay, aroma, and discoloration) measurements were taken every 5 days. Fresh and dry weights as well as soluble solid content decrease with storage time and temperature, but decay and development of off-odors increased. An overall browning was observed at the higher temperatures. Colorimeter readings indicate that $b^{*}$ and chroma increased with storage and temperature, while $a^{*}$ values decreased. No definite trends were observed in $L^{*}$ values, and no major differences were found in the hue, although hue tend to be higher with lower temperatures. Rough handling resulted in a faster quality deterioration rate in comparison with pieces stored at the same temperature. At $0{ }^{\circ} \mathrm{C}$, diced onions could be stored satisfactorily for 20 days, although some quality changes took place. At $5{ }^{\circ} \mathrm{C}$ visual quality may be acceptable after 10 days of storage, but discoloration started to show up after 5 days, reducing acceptability. Storage at $10^{\circ} \mathrm{C}$ only is possible for very short periods of time. Rough handling increases the rate of quality deterioration.

\section{1}

\section{Quality Changes During Storage of Intact and Fresh-cut Cantaloupe Melon}

Silvina I. Portela and Marita I. Cantwel/ ${ }^{\star}$; Dept. Vegetable Crops, University of California, Davis, CA 95616.

Although minimal processing increases the perishability of products, largely due to microbial decay, quality changes may be similar between tissues from intact produce and fresh-cut pieces. This study compared pulp quality changes of intact cantaloupe melons and of sanitized fresh-cut pieces $(1.8 \times 3-\mathrm{cm}$ cylinders) during storage in air at 2.5 (cv. Corona) and $5^{\circ} \mathrm{C}$ (cv. Corona and Durango) for 15 days. Quality evaluations included subjective (visual quality, decay, translucency, aroma, off-odor) and objective (color, firmness, SSC) measurements. At $5^{\circ} \mathrm{C}$, visual quality of the pieces was below the limit of sal ability by day 15 due to decay, whereas pulp from stored melons was excellent. Pulp from intact melons did not suffer from development of translucency as did the fresh-cut pieces. At $5^{\circ} \mathrm{C}$, pulp from intact fruit had higher aroma scores than pieces, but there were no differences in off-odor scores. At $2.5^{\circ} \mathrm{C}$ there were no differences in the subjective quality measurements of pulp from intact or fresh-cut pieces. Pulp from intact fruit had higher chroma (at 2.5 and $5{ }^{\circ} \mathrm{C}$ ) and $\mathrm{L}^{*}$ (only at $5^{\circ} \mathrm{C}$ ) than the pieces after 6 or 15 days, depending on the variety. There were no differences in hue between intact and fresh-cut pulp. Pulp from intact and fresh-cut pieces had similar firmness changes and SSC during storage at 2.5 and $5{ }^{\circ} \mathrm{C}$. We conclude that pulp of intact fruit and fresh-cut pieces had similar quality up to 15 days at 
$2.5^{\circ} \mathrm{C}$; but at $5^{\circ} \mathrm{C}$, the fresh-cut pieces lost intrinsic quality (visual quality, aroma, and color) before the pulp of intact fruit did.

\section{2}

Prolonging the Shelf-life of Fresh-cut Tomato Slices through Modified Atmosphere and Low Temperature

Ji Heun Hong ${ }^{*}$ and Ken Gross; Horticultural Crops Quality Laboratory, Plant Sciences Institute, Beltsville Agricultural Research Center, Agricultural Research Service, USDA, 10300 Baltimore Avenue, Beltsville, MD 20705-2350 USA

Fresh-cut produce continues to be a rapidly growing industry. However, there is little information available on storage conditions for many commodities, particularly for fresh-cut tomato slices. A major problem with fresh-cut tomato slices is their short shelf-life. The best method to extend shelf-life is refrigerated storage, preferably around 4 to $5^{\circ} \mathrm{C}$. Unfortunately, tomato tissue is susceptible to chilling injury at such temperatures. Experiments were conducted to compare changes in quality of slices from red tomato ( Lycopersicon esculentum Mill.) fruit during storage at 5 or $10^{\circ} \mathrm{C}$ under various modified-atmosphere conditions. In this study, we used the fourth uniform slice from the stem end and analyzed for various quality attributes during the storage period. At both 5 and $10^{\circ} \mathrm{C}$ storage temperatures, ethylene concentration in containers sealed with Film A (oxygen transmission rate of 60.3 or $77.9 \mathrm{ml}$ per hour per $\mathrm{m}^{2}$ at $1 \mathrm{~atm}$ and $99 \%$ relative humidity at 5 or $10{ }^{\circ} \mathrm{C}$, respectively) was higher than that sealed with Film B (oxygen transmission rate of 87.4 or $119.4 \mathrm{ml}$ per hour per $\mathrm{m}^{2}$ at $1 \mathrm{~atm}$ and $99 \%$ relative humidity at 5 or $10^{\circ} \mathrm{C}$, respectively), during storage. In addition, chilling injury, as measured by percent of slices showing some water soaked-areas, in containers sealed with Film B was higher than that of slices in containers sealed with Film A. The percent of visible fungal growth of slices was roughly correlated with the degree of chilling injury, as measured by the percent of slices showing some water soaked-areas. After 13 days of storage at $5{ }^{\circ} \mathrm{C}$, slices stored in containers with a beginning atmospheric composition of $12 \% \mathrm{CO}_{2} / 1 \% \mathrm{O}_{2}$ were firmer, compared to slices given the other treatments. After 9 days of storage at $10^{\circ} \mathrm{C}$, no visible fungal growth was observed on slices in containers with a beginning atmospheric composition of $12 \% \mathrm{CO}_{2} / 1 \% \mathrm{O}_{2}$ or $12 \% \mathrm{CO}_{2} / 20 \% \mathrm{O}_{2}$. However, slices in containers with a beginning atmospheric composition of air, or $4 \% \mathrm{CO}_{2} / 1$ or $20 \% \mathrm{O}_{2}$ and $8 \% \mathrm{CO}_{2} / 1$ or $20 \% \mathrm{O}_{2}$ did show visible signs of fungal growth at $25 \%, 33 \%, 46 \%, 29 \%$, and $100 \%$ of infected slices, respectively. Slices in containers given all treatments, with the exception of $12 \% \mathrm{CO}_{2} /$ $1 \% \mathrm{O}_{2}$, had visible fungal growth after 15 days of storage at $5^{\circ} \mathrm{C}$. Slices in containers containing eight slices had less chilling injury and visible fungal growth than those containing four slices. Chilling injury of slices stored in completely enclosed plastic containers, similar to those commonly observed in grocery food stores, was over 7-fold higher than chilling injury observed in slices containers covered with Film $\mathrm{A}$ after 12 days of storage at $5{ }^{\circ} \mathrm{C}$. However, there were no significant differences in the amounts of the volatiles we measured, i.e., ethanol, ethyl acetate, hexanol and hexanal, between the two container types. These results suggested that modified-atmosphere packaging storage can extend shelflife, as well as inhibit chilling injury in fresh-cut tomato slices.

\section{3}

\section{UV-C Irradiation Reduces Decay and Improves Quality of Fresh-cut Squash}

M. Erkan ${ }^{1}$, C.Y. Wang ${ }^{* 1}$, and D.T. Krizek ${ }^{2},{ }^{1}$ Horticultural Crops Quality Lab., ${ }^{2} \mathrm{Cli}-$ mate Stress Lab., ARS, U. S. Department of Agriculture, Beltsville, MD 207052350

Exposure of fresh-cut zucchini squash (Cucurbita pepo L., cv. Tigress) to ultraviolet-C (UV-C) irradiation for 1,10 , or 20 min significantly reduced microbial counts and severity of decay during subsequent storage at 5 or $10^{\circ} \mathrm{C}$. However, the respiration rate and ethylene production of the slices were not affected by the UV-C treatments. Slight UV-C damage (reddish brown discoloration) was detected on the surface of 10- and 20-min treated slices after 12 days of storage at $10^{\circ} \mathrm{C}$. Slices stored at $5^{\circ} \mathrm{C}$ did not show UV-C damage. Chilling injury was not observed until after 20 days of storage at $5^{\circ} \mathrm{C}$. The symptoms of chilling injury appeared as dried sunken brown spots on the surface of cortex tissue. UV$\mathrm{C}$ treatments did not affect the degree of chilling injury during storage at $5 \mathrm{C}$. The storage quality of fresh-cut zucchini squash was improved by UV-C exposure primarily because of the retardation of microbial growth and reduction of decay. The influence of UV-C irradiation on sugar and organic acid contents of the freshcut zucchini squash will also be discussed.

\section{4}

Controlled-Atmosphere Storage of Fresh-cut Spinach at Various Temperatures

Hidemi Izumi*, Tetsuya Nakatani, and Hiroki Ogikubo; Faculty of Biology-Oriented Science and Technology, Kinki Univ., Naga, Wakayama 649-6493, Japan

'Sunbest' spinach leaves were stored in air or controlled atmosphere (CA) containing $3 \%, 6 \%$, and $10 \% \mathrm{CO}_{2}$ combined with $0.5 \% \mathrm{O}_{2}$ at 0,10 and $20{ }^{\circ} \mathrm{C}$. Carbon dioxide production and $\mathrm{O}_{2}$ consumption of spinach leaves decreased in CA by about $50 \%, 40 \%$, and $65 \%$ relative to those in air at 0,10 and $20{ }^{\circ} \mathrm{C}$ respectively. The rates in the different $\mathrm{CA}$ were similar. The respiratory quotient (RQ) of spinach leaves held in CA was slightly higher than that held in air at 0 and $20{ }^{\circ} \mathrm{C}$. CA inhibited the growth of aerobic mesophilic bacteria and lactic acid bacteria at all temperatures, with the inhibition being greater in $6 \%$ or $10 \% \mathrm{CO}_{2}$ with $0.5 \% \mathrm{O}_{2}$. The ascorbic acid content at the end of storage was higher in spinach leaves held in air than in $\mathrm{CA}$ at all temperatures except $10 \% \mathrm{CO}_{2}$ with $0.5 \% \mathrm{O}_{2}$ at $20{ }^{\circ} \mathrm{C}$. A slight or no off-odor was emitted by all spinach leaves. At $20{ }^{\circ} \mathrm{C}$, spinach leaves held in $6 \%$ and $10 \% \mathrm{CO}_{2}$ with $0.5 \% \mathrm{O}$ developed more off-odor than those in air. These results indicate that the $\mathrm{CA}$ of $3 \%-10 \% \mathrm{CO}_{2}$ and $0.5 \% \mathrm{O}_{2}$ was beneficial in reducing respiration rate and microbial growth of spinach leaves at 0,10 , and $20^{\circ} \mathrm{C}$ but accelerated ascorbic acid loss at all temperatures and induced off-odor at $20^{\circ} \mathrm{C}$.

\section{5}

Induced Modified Atmosphere Maintains Quality of Packaged Fresh-cut Honeydew Cubes

Jin-He Bai* and Alley E Watada, USDA/ARS, Bldg. 002, Beltsville, MD 20705-2350

A study was made to determine if induction of modified atmosphere at the time of packaging would be of a benefit to the quality of fresh-cut honeydew cubes because the desired gas levels are not attained immediately or at all during the short holding period in modified-atmosphere packages. Fresh-cut honeydew cubes (2-cm cube) were placed in a plastic container underlaid with a water absorbent packet and the container was sealed with a film. The film is coextruded polystyrene and polyethylene (Cryovac), which had oxygen transmission rates of 1448 and $1903 \mathrm{ml} / \mathrm{m}^{2}$ per day per atm at $5^{\circ} \mathrm{C}$ and $10^{\circ} \mathrm{C}$, respectively. The sealed packages were given one of the following three treatments: 1) the packages were allowed to form their own natural modified atmosphere (nMAP), 2) the internal atmosphere of the packages was flushed with a gas mixture of $5 \% \mathrm{O}_{2}+5 \% \mathrm{CO}_{2}$ (iMAP), 3) the film was perforated with a needle to have ten $1.5-\mathrm{mm}$ holes (PFP). The packages were stored at $5{ }^{\circ} \mathrm{C}, 2$ days at $5^{\circ} \mathrm{C}$, and transferred to $10^{\circ} \mathrm{C}$ or at $10^{\circ} \mathrm{C}$ for $2,4,7,9$, or 11 days. Quality attributes and microbial population were analyzed after each holding period. The average gas mixture equilibrated to $7 \%$ $\mathrm{O}_{2}$ and $9.5 \% \mathrm{CO}_{2}$ in nMAP, was unchanged from the induced atmosphere in iMAP, and was close to the ambient condition (air) in PFP. Honeydew cubes were marketable on days 11,4 , and 4 when held in nMAP; on days 11,4 , and 7 when held in iMAP; and unsalable on days 9,4 , and 7 when held in PFP at $5^{\circ} \mathrm{C}, 10^{\circ} \mathrm{C}$ or transferred to $10^{\circ} \mathrm{C}$, respectively. Development of water-soaked lesions and sour odor were the main factor affecting marketability of the cubes. The decreasing $\mathrm{pH}$, chroma and 'L' values and increasing hue angle, mesophilic aerobic microrganism, and yeast population was retarded in both of nMAP and IMAP.

95

POSTER SESSION 14 (Abstr. 366-385) Postharvest Physiology \& Food Science

$$
\text { Friday, } 30 \text { July, 1:00-2:00 p.m. }
$$

366

Effects of Postharvest Heat, Methyl Jasmonate Dip, and 1Methylcyclopropene Vapor Treatments on Quality Maintenance and Decay Development in 'Golden Delicious' Apples Robert A. Saftner"', Judith A. Abbott', William S. Conway', and Cynthia L. Barden'; ${ }^{1}$ Horticultural Crops Quality Laboratory, Beltsville Agricultural Research Center, Agricultural Research Service, Beltsville, MD 20705; ${ }^{2}$ Fruit Research Laboratory, Pennsylvania State University, P.O. Box 309, Biglerville, PA 17307

Air heat, methyl jasmonate dip, and vapor treatments with the ethylene action 
inhibitor 1-methylcyclopropene (MCP) were used to evaluate their effects on ripening-related characteristics and susceptibility to fungal decay in 'Golden Delicious' apples (Malus xdomestica Borkh.) through 5 months of storage at $0{ }^{\circ} \mathrm{C}$ and ripening at $20^{\circ} \mathrm{C}$ for 7 days. Preclimacteric fruit were treated with MCP vapor at a concentration of $1 \mu \mathrm{L} \cdot \mathrm{L}^{-1}$ for $18 \mathrm{~h}$ at $20^{\circ} \mathrm{C}, 38^{\circ} \mathrm{C}$ air for 4 days, methyl jasmonate dip at concentrations of $10^{-5}$ and $10^{-4}$ for $3 \mathrm{~min}$ at $20^{\circ} \mathrm{C}$, combinations thereof, or left untreated before storage in air at $0^{\circ} \mathrm{C}$. One set of untreated fruit was stored in a controlled atmosphere of $1.5 \mathrm{O}_{2}$ and $2.5 \% \mathrm{CO}_{2}$ at $0{ }^{\circ} \mathrm{C}$. The MCP treatment and CA storage delayed ripening, as indicated by better retention of green peel color and flesh firmness, and the reduced respiration, ethylene production rates, and volatile (both flavor- and superficial scald-associated) levels that were observed upon transferring the fruit to $20^{\circ} \mathrm{C}$. The MCP treatment followed by air storage delayed ripening more than $\mathrm{CA}$ storage. The heat treatment also delayed ripening but hastened skin yellowing. While methyl jasmonate dips had no significant effect on ripening, they were the only treatments used that reduced the incidence of postharvest decay and discolored the surface of some fruit. The results indicate that MCP may provide an effective alternative to CA for maintaining quality during cold storage and ripening. The results also indicate that methyl jasmonate dip treatment may reduce postharvest decay of fruit while maintaining fruit quality.

\section{7}

\section{Ripening Control of Pyrus communis L. Fruit with 1-MCP}

R.S. Mueller ${ }^{* 1}$, D.P. Murr ${ }^{1}$, and L.J. Skog ${ }^{2} ;{ }^{1}$ Horticultural Science Division, Department of Plant Agriculture, University of Guelph, Guelph, Ontario, N1G 2W1, Canada; ${ }^{2} \mathrm{HRIO}$, Department of Plant Agriculture, University of Guelph, Vineland Station, Ontario, LOR 2E0, Canada.

1-Methylcyclopropene (1-MCP), a gaseous synthetic cyclic hydrocarbon, has been shown to have potential to become an important new tool in controlling the response of plants sensitive to ethylene. Due to its irreversible binding to the ethylene receptor(s) and its subsequent prevention of the physiological action of ethylene for extended periods, 1-MCP may prove also to have effective commercial application in the control of ethylene effects in detached organs such as fruit. Our objective was to investigate the effectiveness of 1-MCP in controlling ripening in pear. Two commercial cultivars (Bosc, Anjou) and one numbered cultivar from Agriculture and Agri-Food Canada's breeding program (Harrow 607) were harvested at commercial maturity. Immediately after harvest, fruit were exposed for $24 \mathrm{~h}$ at $20^{\circ} \mathrm{C}$ to $1-\mathrm{MCP}$ ranging from 0 to $100 \mu \mathrm{L} \cdot \mathrm{L}^{-1}$ then placed in air at 0 ${ }^{\circ} \mathrm{C}$ and $90 \%$ relative humidity for 5 and 10 weeks. Following treatment and after 5 weeks storage plus a 7- or 14-day post-storage ripening period, fruit softening and ethylene evolution were inhibited and fruit volatile evolution was reduced significantly by exposure to $1-\mathrm{MCP}$ at or above $1.0 \mu \mathrm{L} \cdot \mathrm{L}^{-1}$ in all three cultivars. Concentrations exceeding $1.0 \mu \mathrm{L} \cdot \mathrm{L}^{-1}$ were required to maintain initial firmness and inhibit ethylene production after 10 weeks storage in air. Evolution of alphafarnesene and 6-methyl-5-hepten-2-one was related to low temperature stress and chlorophyll loss as a result of ripening, respectively, and were affected by 1 MCP exposure. The pattern of evolution and amounts of other volatiles was al so affected by $1-\mathrm{MCP}$ treatment. These results indicate a huge potential for commercial use and application of 1-MCP in controlling fruit ripening and senescence.

\section{8}

\section{Responses of 'd'Anjou' and 'Bartlett' Pear Fruit to Posthar-} vest 1-Methylcyclopropene (MCP) Treatment

Xuetong Fan, Luiz Argenta, and James Mattheis*; USDA, ARS, 1104 N. Western Ave., Wenatchee, WA 98801

'Bartlett' and 'd'Anjou' pear fruit were treated after harvest with MCP at 0 , $0.01,0.1$ or $1 \mathrm{~mL} \cdot \mathrm{L}^{-1}$ and then stored at $1^{\circ} \mathrm{C}$. After storage, half of the fruit was continuously exposed to $10 \mathrm{~mL} \cdot \mathrm{L}^{-1}$ ethylene for 7 days in a flow-through system at $20^{\circ} \mathrm{C}$. A treatment concentration effect was evident for both respiration and ethylene production, all MCP concentrations reduced respiration and ethylene production by 'd'Anjou' and 'Bartlett' fruit compared to controls. Fruit quality changes in 'd'Anjou' and 'Bartlett' fruit were delayed by MCP treatment. Firmness and titratable acidity were higher through 4 months storage for 'Bartlett' fruit treated at the two higher MCP rates. After 2 months, 'Bartlett' fruit treated at the two higher MCP rates remained green, but, after 4 months, all fruit were yellow. Loss of firmness and titratable acidity was also reduced following MCP treatment of 'd'Anjou' fruit. Yellowing of 'd'Anjou' fruit was prevented by MCP treatment, even when fruit were exposed to ethylene after removal from storage. Poststorage eth- ylene exposure did not overcome the effects of MCP. Development of superficial and senescent scald was prevented by MCP treatment.

\section{9}

Relationship Between Ethylene Production and Accumulation of Cuticular Constituents in 'Delicious' Apples During Fruit Ripening at Room Temperature

Zhiguo Ju*1 and William J. Bramlage'; 'USDA, ARS, Tree Fruit Research Lab, 1104 North Western Avenue, Wenatchee, WA 98801; ${ }^{2}$ Department of Plant and Soil Sciences, University of Massachusetts, Amherst, 01003

Developmental changes in total cuticle and cuticular constituents were studied with 'Delicious' fruit. Total wax $\left(0.31 \mathrm{mg} / \mathrm{cm}^{2}\right)$ and total cutin $\left(0.54 \mathrm{mg} / \mathrm{cm}^{2}\right.$, including carbohydrate polymers) were low in young fruit. They increased during fruit growth and reached 1.41 and $2.47 \mathrm{mg} / \mathrm{cm}^{2}$ of fruit peel at harvest, respectively. During fruit ripening at $20^{\circ} \mathrm{C}$, total cutin did not change, but total wax increased rapidly and reached $2.15 \mathrm{mg}^{\bullet} \mathrm{cm}^{-2}$ at 6 weeks. The increase of cuticular wax paralleled the increase of internal ethylene in fruit. Wax was separated by column chromatograph into four portions, hydrocarbons and wax esters, free alcohols, free fatty acids, and diols. More than half of the diols was ursolic acid. During fruit development, more hydrocarbons and diols accumulated in cuticle than free fatty acids and alcohols. During fruit ripening, all of the four portions increased, coincident with the climacteric rise in ethylene, but the increase rates of free fatty acids and alcohols were higher than those of other portions. Aminoethoxyvinylglycine (AVG, $220 \mathrm{mg}^{\bullet} \mathrm{L}^{-1}$ ) preharvest treatment inhibited internal ethylene synthesis to below $0.5 \mu \mathrm{L} \cdot \mathrm{L}^{-1}$ during 6 weeks at $20^{\circ} \mathrm{C}$, and also inhibited wax accumulation. Ethephon $(200 \mathrm{mg} / \mathrm{L})$ preharvest treatment increased ethylene production and accelerated wax accumulation. $\alpha$-farnesene accumulation coincided with increased internal ethylene and paralleled free fatty acid and alcohol accumulation.

\section{0}

\section{Alternative Coating Formulations for Apples and Their Effects on Quality}

V. Alleyne*, EA. Baldwin, and R. D. Hagenmaier, USDA Citrus \& Subtropical Products Lab, Winter Haven, FL 33881

Experimental formulations of candelilla, zein, and polyvinylacetate (PVA) were investigated as alternatives to commercial apple-coating formulations of shellac and carnauba wax. Coatings or a deionized water control were applied to 'Red Delicious' apples. Effects on quality attributes, internal atmospheres, sensory flavor, and volatile composition were evaluated. Treated fruit were stored at $5{ }^{\circ} \mathrm{C}$ for 7 days followed by 14 days at $21^{\circ} \mathrm{C}$. Zein and PVA formulations exhibited gloss levels comparable with commercial formulations. Although shellac-coated apples maintained the highest gloss over the 21-day storage period, gloss of zein-coated apples was comparable to shellac after fruit were removed from storage at $5{ }^{\circ} \mathrm{C}$. On removal from cold storage there was no difference in firmness among coated and uncoated apples, but, after a 14-day period at $21^{\circ} \mathrm{C}$, shellac-coated fruit were significantly firmer than all other treatments. Shellac- and candelilla-coated apples contained higher $\mathrm{CO}_{2}$ than uncoated fruit and lower $\mathrm{O}_{2}$ than all coated fruit except those coated with PVA. PVA-coated apples contained significantly higher ethylene than uncoated fruit. Candelilla coating was most effective in reducing weight loss while PVA and zein had no effect. Shellac and carnauba coatings reduced weight loss relative to uncoated fruit. There were no differences in perception of sweetness, acidity, off-flavor, and overall flavor. Effects of coating formulations on apple flavor volatile composition will be discussed.

\section{1}

\section{Enhancing Anthocyanin Production and Maturity Uniformity of Apples Without Over-ripening}

Zhenyong Wang* and David R. Dilley; Horticulture Department, Michigan State University, East Lansing, MI 48824

Multiple harvests are often necessary to achieve maximum yield of wellcolored high-quality apples. This is true for most cultivars, and particularly for 'Gala'. Multiple harvests add significantly to the cost of producing apples. We tested our hypotheses that anthocyanin production of ReTain ${ }^{\mathrm{TM}}$-treated apples may be enhanced by ethephon without overly stimulating other ripening processes and ReTain ${ }^{\mathrm{TM}}$ may promote uniform maturation of apples within and between trees by delaying maturation and ripening processes. Experiments were conducted with 'Gala', 'Empire', and 'Jonagold' apples at the MSU CHES in 1997 
and 1998 employing the rootstock/training systems research plot. Treatments were 1) ReTain ${ }^{\mathrm{TM}}$ (50g/ac.) applied 3 to 4 weeks before harvest, 2) ReTain ${ }^{\mathrm{TM}}$ followed by ethephon (3/4 pt/ac.) applied 1 to 2 weeks before harvest, 3) ethephon, and 4) control (Silwet ${ }^{\circledR}$ L-77 surfactant only). ReTain ${ }^{\mathrm{TM}}$ applied al one delayed the onset of the ethylene climacteric and red color development of 'Gala' apples. ReTain ${ }^{\mathrm{TM}}$ followed by ethephon delayed the onset of the ethylene climacteric and red color development at the commercial harvest date was not significantly affected. Similar results were obtained with the 'Empire' and 'Jonagold'. Results with ReTain ${ }^{T M}$ and ReTain ${ }^{\text {TM }}$ + ethephon in 1998 on 'Gala', 'Empire', and 'Jonagold' apples were more profound than in 1997; we attribute this to less environmental stress on the trees, which were well-irrigated in 1998. The ripening-related effects of treatments were reflected in the storability of fruit 1997 in air and particularly during CA storage where the action of ethylene in ripening can be attenuated. ReTain ${ }^{\mathrm{TM}}$ - and ReTain ${ }^{\mathrm{TM}}$ + ethephon-treated fruit were still at preclimacteric ethylene levels after 6 months in CA with excellent retention of flesh firmness and shelf-life, while ethephon and control fruit had higher ethylene levels and softened more during storage and shelf-life evaluation.

\section{2}

\section{1-MCP-mediated Ripening Changes in 'McIntosh' Apples}

H.P.V. Rupasinghe ${ }^{* 1}$, D.P. Murr', and G. Paliyath ${ }^{2} ;{ }^{1}$ Horticultural Science Division, Department of Plant Agriculture, ${ }^{2}$ Department of Food Science, University of Guelph, Guelph, Ontario, Canada N1G 2W1

'McIntosh' apples were treated at $20^{\circ} \mathrm{C}$ with $0.0,0.01,0.1,1.0,10$, and 100 ppm 1-methylcyclopropene (1-MCP; EthylBloc ${ }^{\mathrm{TM}}$ ) a day after harvest for $18 \mathrm{~h}$ and stored at $0^{\circ} \mathrm{C}$ in air. Apples were also continuously exposed to 0.0 and 25 ppm 1-MCP under controlled atmosphere $\left(\mathrm{CA} ; 0{ }^{\circ} \mathrm{C}\right.$ in $4.5 \mathrm{kPa} \mathrm{CO}$ and $3 \mathrm{kPa}$ $\mathrm{O}_{2}$ ) by re-establishing the initial concentration at week 9 and 17. The threshold concentration of $1-\mathrm{MCP}$ at $20^{\circ} \mathrm{C}$ to inhibit de novo ethylene production in apple fruit was determined to be $1.0 \mathrm{ppm}$. Interestingly, the ethylene antagonist completely inhibited $(99.67 \%)$ ethylene production in apples, which were removed from $0^{\circ} \mathrm{C}$ in air and $\mathrm{CA}$ after 9 weeks and held at $20^{\circ} \mathrm{C}$ up to 6 days. Overall, ethylene production was 10- to 100-fold less in apples treated with $1 \mathrm{ppm}$ and above 1-MCP than in untreated apples. 1-MCP-treated apples showed less softening; fruit firmness was 2-4 Lb higher compared to untreated apples. Total soluble solids of apples was not affected by 1-MCP treatment. Total hydrophobic volatiles, including the sesquiterpene hydrocarbon $\alpha$-farnesene, from apples measured by SPME/GC showed an inverse relation to 1-MCP concentration. Contents of $\alpha$ farnesene and its putative superficial scald-causing catabolite, conjugated triene alcohol, in the skin were reduced $60 \%$ to $90 \%$ by 1 -MCP. However, 1 -MCP did not suppress the incidence of scald or other disorders, e.g., stem cavity, browning and brown core, in 'McIntosh' apples.

\section{3}

Phenolics and Lipid-soluble Antioxidants in Fruit Cuticle of Apples and Their Antioxidant Activities in Model Systems Zhiguo Ju' and William J. Bramlage2; 'USDA, ARS, Tree Fruit Research Lab, 1104 North Western Avenue, Wenatchee, WA 98801; ${ }^{2}$ Department of Plant and Soil Sciences, University of Massachusetts, Amherst, MA 01003

Phenolics were extracted from fruit cuticles of 'Delicious', 'Golden Delicious', 'Empire', and 'Cortland' apples, using either cuticular wax scraped from fruit peel or enzyme-isolated cuticles. The concentrations of free phenolics in fruit cuticle ranged from 8 to $45 \mathrm{mg} \cdot \mathrm{g}^{-1}$, and bound phenolics ranged from 50 to $110 \mathrm{mg}^{\bullet} \mathrm{g}^{-1}$ in these cultivars. Free cuticular phenolic concentrations in the four cultivars were in the order 'Golden Delicious' > 'Delicious' > 'Empire' > 'Cortland'. In a linoleate emulsion (oil-in-water) system, diphenylamine (DPA, lipophilic) displayed higher antioxidant activity than methanol-extracted cuticular phenolics (hydrophilic). In an $\alpha$-farnesene-hexane (bulk oil) system, however, antioxidant activities of methanol-extracted cuticular phenolics were higher than that of DPA. Lipid-soluble antioxidants (LSAs) from cuticle displayed higher activity in the linoleate emulsion system than in $\alpha$-farnesene-hexane system. Only about $10 \%$ to $15 \%$ of the total LSA activity in fruit peel was detected in isolated fruit cuticle. Among the four cultivars, LSA activity in epidermal and hypodermal cells was similar in 'Golden Delicious', 'Empire', and 'Cortland' apples, while 'Delicious' had lower activity.

\section{4}

Evidence that $\alpha$-farnesene Biosynthesis during Fruit Ripening is Involved in Ethylene-regulated Gene Expression Zhiguo Ju* and Eric A. Curry; USDA, ARS, Tree Fruit Research Lab, 1104 North Western Avenue, Wenatchee, WA 98801

In 'Delicious' and 'Granny Smith' apples, fruit did not produce $\alpha$-farnesene until internal ethylene reached about $1 \mu \mathrm{L} \cdot \mathrm{L}^{-1}$. The correlation between internal ethylene and $\alpha$-farnesene production was highly significant $\left(r^{2}=0.71\right.$ and 0.76 , respectively) and fitted the exponential growth equation. Aminoethoxyvinylglycine (AVG) inhibited both internal ethylene and $\alpha$-farnesene production, while ethephon stimulated them. When applied to discs from preclimacteric fruit peel, cycloheximide and actinomycin $D$ inhibited ethylene and $\alpha$-farnesene production. In discs from AVG-treated fruit, ethephon induced $\alpha$-farnesene synthesis. Cycloheximide, actinomycin $D$, and silver ion counteracted the stimulation effect of ethephon. When added to discs from preclimacteric fruit peel or AVG-treated fruit peel, hydroxymethylglutarc acid, meval onic acid lactone, and farnesyl pyrophosphate induced $\alpha$-farnesene synthesis, which was not affected by cycloheximide or actinomycin $\mathrm{D}$.

\section{5}

Mono-, Di-, and Tri-acylglycerols and Phospholipids Inhibit Scald Development in 'Delicious' Apples

Zhiguo Ju*1, Yousheng Duan' ${ }^{2}$, and Zhiqiang Ju'; ${ }^{1}$ Tree Fruit Research Lab, USDAARS, 1104 N. Western Ave., Wenatchee, WA 98801; ${ }^{2}$ Dept. R\& D, EurekaBiotech. Co., China

Effects of different plant oils (soybean oil, corn oil, olive oil, peanut oil, linseed oil, and cotton seed oil) and oil component emulsions on scald development in 'Delicious' apples were studied. Prestorage treatment with commercial plant oils reduced scald development, but was not as effective as $2000 \mathrm{mg} \cdot \mathrm{L}^{-1}$ diphenylamine (DPA) after 6 months of cold storage. Different oil components played different roles in affecting scald. At $6 \%$ or $9 \%$ concentrations, neutral lipids (mono-, di-, and tri-acylglycerols), and phospholipids inhibited scald to the same level of $2000 \mathrm{mg} \cdot \mathrm{L}^{-1}$ DPA treatment. Free fatty acids partially reduced scald, while $\alpha$-tocopherol at $3 \%$ or higher concentrations accelerated scald development. There were no differences in scald inhibition between unsaturated neutral lipids and saturated neutral lipids or among the different acylated neutral lipids. When $\alpha$-tocopherol was stripped from plant oils, the stripped plant oils at $6 \%$ or $9 \%$ controlled scald to the same level of $2000 \mathrm{mg} \cdot \mathrm{L}^{-1}$ DPA treatment. Emulsions of $6 \%$ or $9 \%$ neutral lipids, phospholipids, or stripped plant oils did not induce greasiness on fruit skin. Fruit treated with lipids, phospholipids, or stripped plant oils looked greener and fresher compared with the control by the end of storage.

\footnotetext{
376 Cuticular Phenolics and Scald Development in 'Delicious' Apples

Zhiguo Ju $u^{* 1}$ and William J. Bramlage2; ${ }^{1}$ USDA, ARS, Tree Fruit Research Lab, 1104 North Western Avenue, Wenatchee, WA 98801; '2Department of Plant and Soil Sciences, University of Massachusetts, Amherst, MA 01003

Effects of fruit maturity, aminoethoxyvinylglycine (AVG) and 2chloroethylphosphonic acid (ethephon) preharvest treatments, and storage conditions on cuticular phenolic concentration, $\alpha$-farnesene oxidation, and scald susceptibility of 'Delicious' apple were studied. Advanced maturity and ethephon reduced scald. AVG totally inhibited scald when the AVG-treated fruit were stored in low-ethylene room $\left(<1 \mu \mathrm{L} \cdot \mathrm{L}^{-1}\right)$. In commercial room (ethylene $>5 \mu \mathrm{L} \cdot \mathrm{L}^{-1}$ ) however, AVG did not reduce scald. Advanced maturity and ethephon did not alter $\alpha$-farnesene accumulation but significantly reduced conjugated triene (CT281) formation. AVG reduced $\alpha$-farnesene and CT281 accumulation to very low levels in low-ethylene room but not in commercial room. Both advanced maturity and ethephon increased free phenolics in fruit cuticle, while AVG reduced them. Free cuticular phenolics increased during early storage in ethephon-treated and control fruit but not in AVG-treated fruit. Overall, free phenolics in fruit cuticle negatively correlated with formation of CT281 and scald susceptibility of apples. Neither fruit maturation nor AVG or ethephon treatment significantly affected lipid-soluble antioxidant concentration in fruit cuticle.
} 


\section{7}

\section{Differential Human Antiplatelet Activity of Selected Allium Thiosulfinates}

W.H. Briggs ${ }^{*}$, H. Xiao, K.L. Parkin, and I.L. Goldman; Departments of Horticulture and Food Science, University of Wisconsin, 1575 Linden Dr., Madison, WI 53706 USA

The acute syndromes associated with many human diseases of the cardiovascular system such as myocardial infarction, angina, and some forms of stroke are caused by thrombosis. Platelet aggregation plays a central role in thrombus formation. Dietary intake of inhibitors of aggregation may provide protection against these disorders, which effect millions of Americans. Previous research in our laboratory has shown that juice from onion (Allium cepa) inhibits platelet aggregation ex vivo. Various sulfur-containing compounds are largely responsible for the distinctive aromas, flavors, and platelet inhibitory actions of onion. Among these is the thiosulfinate (TS) family of compounds formed upon maceration of the vegetable. In this study, several pure Allium compounds were evaluated for antiplatelet activity. TSs were synthesized in model reaction mixtures containing the enzyme allinase and S-alk(en)yl-L-cysteine sulfoxides (ACSOs), their natural precursors, or purified from garlic juice. Antiplatelet activity of each compound was determined by dose response using whole blood from human donors. A minimum of $0.4 \mathrm{mM}$ methyl methaneTS, a compound found in freshly cut onion and garlic (Allium sativum), was needed to significantly inhibit aggregation relative to a non-TS control. By contrast, a lower concentration $(0.05 \mathrm{mM})$ of 2 propenyl 2-propeneTS (allicin) and propyl propraneTS, compounds found in garlic but not onion, was required. The garlic compound methyl 2-propeneTS significantly inhibited at $0.2 \mathrm{mM}$. These data imply a role of alk(en)yl groups in TS antiplatelet efficacy. Variability in ACSO-derived TS composition in cut onion tissue may explain differential antiplatelet activity of onion cultivars. Results from this investigation suggest that ACSO and TS composition profiles may be useful for evaluating the medicinal value of Alliums.

\section{8}

\section{Does Exposure to Hormic Dose of UV-C Light Affect the Ripening of Tomato Pericarp Disc?}

S. Kalantari ${ }^{\star}$, G. Samson, J. Makhlouf, and J. Arul; Horticultural Research Center, Pavillon de líEnvirotron, Universitè Laval, Quèbec, Canada, G1K 7P4

The application of ultraviolet light on fruit and vegetables is a promising new method to control storage diseases and to delay the onset of senescence. In this investigation, we studied the effects of hormic dose $\left(1,4\right.$ Merg $\left.\cdot \mathrm{cm}^{-2}\right)$ of UVradiation on the ripening of tomato pericarp discs by measuring different characteristics of ripening and senescence during storage. We observed that UV-treatment induced significant delays of the red color development, chlorophyll degradation, and lycopene production compared to control discs. UV-treatment also retarded the decline of the chlorophyll-a fluorescence ratios $F_{v}: F_{m}$ and ${ }^{*} F: F_{m}$, two characteristics related, respectively, to the maximum and operational quantum yield of photosystem II electron transport. Furthermore, the climacteric ethylene peak was delayed in the treated discs. However, UV-treatment did not alter textural changes, and the respiratory climacteric peaks were observed concomitantly for both treated and untreated tomato discs. However, the respiratory rate was consistently higher in treated discs. These results indicate that UV irradiation of tomato pericarp discs delays some processes of ripening associated with chloroplast to chromoplast transition whereas other ripening processes seem unaffected.

\section{9}

\section{Biochemical Barriers Induced by UV Light and Botrytis cinerea in Postharvest Tomato}

Marie-Therese Charles, Alain Goulet, Francois Castaigne, and Joseph Aru**; Department of Food Science and Horticultural Research Center, Laval University, Sainte-Foy, Quebec, Canada G1K 7P4

Hormic dose of ultraviolet light $\left(3.7 \mathrm{~kJ} \cdot \mathrm{m}^{-2}\right)$ induced disease resistance in tomato fruit. The biochemical nature of induced resistance by UV light was investigated by histochemical techniques. Ultraviolet light induced plasmolysis of the epicarp and few mesocarp cell layers, and collapse of these cell layers led to the formation of cell wall stacking zone (CWSZ). The treatment also stimulated the biosynthesis of phenolic compounds (Prussian blue reaction) in the epicarp and mesocarp cells. Biochemical reinforcement of the cell wall through lignification (Maule test) and suberization (berberine fluorescence) was also induced. These responses originating from the activation of phenylpropanoid path were princi- pally localized in the CWSZ and were induced before inoculation by $B$. cinerea. The intensity of these responses was significantly increased in UV-treated tissue in response to infection. These responses were also induced in the inoculated control tissue but were either less substantial (phenolics, lignification, and suberization) or delayed.

\section{0}

\section{Chlorophyll Fluorescence and Prediction of 'Iceberg' Lettuce} Shelf-life

R. Andrew Schofield ${ }^{* 1}$, Jennifer R. De曰 ${ }^{2}$, and Dennis P. Murr ${ }^{3}{ }^{1}$ Division of Horticultural Science, Department of Plant Agriculture, University of Guelph, Guelph, ON, N1G 2W1, Canada; ${ }^{2}$ Agriculture and Agri-Food Canada, Horticultural Research and Development Centre, 430 Boul. Gouin, Saint-Jean-sur-Richelieu QC, J3B 3E6, Canada; ${ }^{3}$ Division of Horticultural Science, Department of Plant Agriculture, University of Guelph, Guelph, ON, N1G2W1, Canada

Chlorophyll fluorescence responds to a range of environmental stresses that affect horticultural crops. This technique has been used successfully to evaluate the quality of commodities after exposure to a number of postharvest stresses such as chilling, heat, and atmospheric stress. As well, chlorophyll fluorescence measurements have been incorporated as the main characteristics in shelf-life prediction models. Our objective was to evaluate the use of chlorophyll fluorescence measurements at harvest to predict the shelf-life of 'Iceberg' lettuce. It was hypothesized that storage potential is influenced by the degree of stress induced by field conditions and that different cultivars, although grown under the same conditions, experience varying degrees of stress that can be detected by fluorescence measurements at harvest, even in the absence of visual differences in quality. The utility of fluorescence measurements was limited by inconsistencies in the development of the heads, such as maturity and leaf formation, and by variation among different areas of the same leaf. Fluorescence data from a homogeneous group of heads revealed that the variation associated with different areas of the same leaf was larger than that associated with measurements from different heads. Also, fluorescence readings from one leaf differed from those taken from any non-adjacent leaves. These sources of variation, along with strong cultivardependant differences in the fluorescence signal, were quite large, and hence, any trends in fluorescence measurements related to storage potential were not observed. Therefore, chlorophyll fluorescence at harvest does not appear to be a good predictor of lettuce storability.

\section{1}

\section{Differential Leaching of Anthocyanins during Thermal} Processing of Selected Black Bean (Phaseolus vulgaris L.) Genotypes

George L. Hosfield ${ }^{*}$ and Clifford W. Beninger; USDA, Agricultural Research Service, SBRU, East Lansing, MI 48824

Seed coat color in dry bean (Phaseolus vulgaris L.) is determined by the presence or absence of tannins, flavonoids, and anthocyanins. Black beans contain three main anthocyanins that are responsible for their black seed coat color: delphinidin 3-0-glucoside, petunidin 3-0-glucoside, and malvidin 3-O-glucoside. Leaching of anthocyanins occurs in many black bean genotypes during thermal processing (i.e., blanching and cooking). Black beans that lose their dark color after processing are unacceptable to the industry. Since the marketability of black beans can be adversely affected by thermal processing, an experiment was conducted to ascertain whether pigment leaching was due to qualitative or quantitative changes in anthocyanins during processing. Four black bean genotypes that showed differential leaching of color were investigated. 'Harblack' retains most of its black color after processing while 'Raven' loses most of its color. 'Black Magic' and 'Black Jack' are intermediate between 'Harblack' and 'Raven' in processed color. Bean samples $(119 \pm 1.5 \mathrm{~g})$ of the four genotypes were thermally processed in $100 \times 75$ - $\mathrm{mm}$ tin cans in a pilot laboratory. Seed coats were removed from the cooked beans, freeze-dried, and placed in solutions of formic 10 acid : 65 water : 25 methanol to extract anthocyanins. The extracts were analyzed by HPLC. Although all genotypes retained some color, there were no detectable anthocyanins in seed coats of the cooked beans. In a second experiment, raw beans of each genotype were boiled in distilled water for 15 minutes. All four genotypes lost color during boiling, but 'Harblack' retained most of its color and had a five-fold higher concentration of the three anthocyanins than did the other genotypes. 'Harblack' may retain color better than other black beans because of physical characteristics of the seed coat. 
1-Methylcyclopropene Prevents Development of Ethylenepromoted Postharvest Physiological Disorders of Carrot,

\section{Broccoli, and Lettuce}

Xuetong Fan and James Mattheis*; USDA, ARS, 1104 N. Western Ave,.Wenatchee, WA 98801

Carrots, broccoli, and lettuce were treated with air, continuous ethylene, 1methylcyclopropene (MCP), or a combination of MCP before continuous ethylene. The respiration rate of ethylene-treated carrots reached a maximum 4 days after treatment and remained higher compared to controls through 16 days at $10^{\circ} \mathrm{C}$. Ethylenetreatment also resulted in an accumulation of isocoumarin. Treating carrots with MCP before ethylene exposure inhibited the increase in respiration rate and accumulation of isocoumarin. MCP treatment reduced broccoli respiration and yellowing compared to controls, indicating that ethylene is involved in the senescence of broccoli. Ethylene exposure stimulated respiration and yellowing of broccoli. Treatment with MCP before continuous ethylene exposure negated the ethylene effects. MCP also inhibited respiration and russet spotting of lettuce stored in ethylene-containing atmospheres. The results indicate MCP can be used to block ethylene-induced isocoumarin accumulation (associated with bitterness) in carrots, yellowing in broccoli, and russet spotting in lettuce.

\section{3}

\section{WITHDRAWN}

\section{4}

Modified-Atmosphere Packaging of Fresh Produce to Prevent Generation of Anaerobic Environments

Michael Wendorf", Nazir A. Mir, and Randolph M. Beaudry, Department of Horticulture, Michigan State University, East Lansing, MI 48824

Broccoli tissue, ranging in weight from 7 to $21 \mathrm{~g}$, was sealed in packages made from low-density polyethylene (LDPE) of various thickness and permeability to establish a range of $\mathrm{O}_{2}$ levels in the package headspace. A pouch containing either hydrogen peroxide $\left(\mathrm{H}_{2} \mathrm{O}_{2}\right)$ or water as a control was also sealed in the package. For packages that developed anaerobic atmospheres, inclusion of $\mathrm{H}_{2} \mathrm{O}_{2}$ permitted the maintenance of aerobic conditions for up to 3 days at ambient room temperature. These results suggest that the plant tissue is able to actively metabolize the $\mathrm{H}_{2} \mathrm{O}_{2}$ vapor to generate $\mathrm{O}_{2}$, which will prevent the development of low- $\mathrm{O}_{2}$ conditions in packaged produce, even under conditions of elevated storage temperature.

\section{5}

Honey Dew Fruit Senescence is Regulated by Polyamine Inhibition of Lipid Peroxidation

Gene Lester" , USDA/ARS/Kika de la GarzaSARC, 2301 South International Blvd., Weslaco, TX78596

Polyamines are effective scavengers of activated oxygen free radicals produced by lipoxygenase (LOX) and phospholipase-D (PL-D). Activated oxygen free radicals cause peroxidative damage to membranes and hasten senescence. Exogenous polyamine spermidine (SPD) compared to spermine (SPM) at $1 \mathrm{mM}$ or no polyamine was an effective inhibitor of honey dew (Cucumis melo L. var. inodorus) membrane peroxidation, as determined by malondialdehyde (MDA), following dark incubation for 6 or 48 hours of fully abscised fruit hypodermal mesocarp tissue. MDA levels in SPD-treated tissue was lowest in both 6 and 48 hours compared to SPM or no polyamine. SPD was effective in slowing lipid peroxidation as MDA was highly negatively correlated with the loss in total chlorophyll, plasma membrane $\mathrm{H}+$ pumping ATPase activity, and microsomal phospholipid content ( $r=-0.89,-0.64$ and -0.57 , respectively). Both LOX and PL-D enzyme activities were not correlated with the total chlorophyll and microsomal membrane phospholipid losses or MDA levels, demonstrating that these enzymes act indirectly in the degradation of membranes through the production of lipid peroxidating free radicals. The results also demonstrate that the effect of polyamines as anti-senescence compounds is through direct inhibition of lipid peroxidation and not by affecting LOX or PL-D free radicle production.

\section{POSTER SESSION 23 (Abstr. 386-400) Postharvest Physiology \& Food Science}

\author{
Saturday, 31 July, 1:00-2:00 p.m.
}

386

\section{Volatiles of $E$ coli 0157:H7 and Foodborne Pathogen \\ Detection on Strawberry Fruit}

K. Yü, T.R. Hamilton-Kemp, D.D. Archbold, M. Newman, and B.E. Langlois; Departments of Horticulture and Landscape Architecture and Animal Sciences, University of Kentucky, Lexington, KY 40546-0091

Strawberry fruit were inoculated with the human pathogen $E$ coli $0157: \mathrm{H7}$, and the bacteria were recovered from the fruit over a 3-day period of storage at room temperature. The bacterial population was maintained on fruit when the inoculation level was relatively high and increased when the inoculation level was low. The volatile metabolites of $E$ coli $0157: \mathrm{H} 7$ growing on plate count agar (PCA) and on inoculated strawberry fruit were collected by a headspace trapping system and analyzed by gas chromatography and GC-mass spectrometry. E coli 0157:H7 grown on PCA produced a variety of volatile compounds including indole as a major component and a series of methyl ketones. A nonpathogenic $E$. coli also produced these compounds. However, there was not an appreciable amount of indole collected from E. coli 0157:H7 inoculated strawberry fruit as compared to the large amount of volatiles produced by the fruit. Strawberry fruit were able to capture over $95 \%$ of the vapor phase indole fed to them from a neat source.

\section{7}

Carbon Dioxide Enrichment in Mamoncillo Fruit (Melicoccus bijugatus Jacq.) during Storage

Juan E Manzano-Mèndez* and Damaso Bautista; Universidad Centoccidental Lisandro Alvarado, P.O. Box 815, Posgrado de Horticultura, Decanato de Agronomia, Barquisimeto - Estado Lara 3001, Venezuela S.A.

Mamoncillo fruit, which are very perishable, were harvested at mature ripening stage and stored at gas atmospheres containing of $5.1 \% \mathrm{CO}_{2}, 5.6 \%$ oxygen and $89.3 \%$ nitrogen, during 17 days at 10 and $15 \pm 2{ }^{\circ} \mathrm{C}$. Characteristics studied were the percent soluble solid content, pH, tritatable acidity (expressed as citric acid), reducing sugars, and total sugars. The SST content showed values ranged between $20.37 \%$ to $22.30 \%$, which were high values, but did not show significant differences in the treatments. The pH values were between 3.4 and 3.8 and were highly significant in the interaction between temperature and storage time. The tritatable acidity reported values from 0.99 to 2.24 (as percent citric acid), which had similar behavior in the fruit treated or not with $\mathrm{CO}_{2}$. Reducing sugar values were between 7.79 and $17.99 \mathrm{~g} \cdot 100 \mathrm{~g}^{-1}$ (in base to fresh weight), with highest values at higher storage temperature without $\mathrm{CO}_{2}$ atmosphere. Sometimes these fruit could be sweeter, such as in this case where the total sugar reached the highest values from 12.92 to $20.64 \mathrm{~g} \cdot 100 \mathrm{~g}^{-1}$, resulting in higher value fruit stored during 3 weeks with $\mathrm{CO}_{2}$ treatment at $15 \pm 2{ }^{\circ} \mathrm{C}$. Fruit kept good conditions during 3 weeks stored at $15 \pm 2^{\circ} \mathrm{C}$.

\section{8}

Measurement of Strawberry Fruit Firmness and Drip-loss

Patrick P. Moore*, Dept. of Horticulture and Landscape Architecture, Washington State University, Puyallup, WA 98371

Strawberry fruit of 16 clones was harvested from 45 plots in 1997. Fruit from 35 plots, 12 of the clones sampled in 1997 plus four additional clones, was harvested in 1998. Fruit was harvested on three to five dates in 1997 and three to seven dates in 1998 with 160 samples in 1997 and 165 samples in 1998. Fruit firmness was determined for five fruit from each plot at each harvest with a penetrometer and fruit from the same harvest was sliced, sugared, and frozen. Drip loss was determined later for the frozen, sliced samples. There were statistically significant correlations between firmness and drip-loss $(r=-0.27, n=160, P<$ 0.01 in 1997 and $r=-0.44, n=165, P<0.001$ in 1998); however, firmness did not adequately predict drip-loss. There was considerable variation in drip loss from harvest to harvest, which was associated with weather conditions or precipi- 
tation/irrigation. The drip loss in 1997 was not significantly correlated with the drip loss for the same plots in $1998(r=-0.26, n=24$, ns); however there was a significant correlation between firmness in 1997 and $1998(r=0.52, \mathrm{n}=24, P<$ 0.05). These findings have implications for evaluation of fruit in a strawberry breeding program for a processing industry.

\section{9}

Volatile Profile of 'Marion' Blackberry

P. Perkins-Veazie ${ }^{* 1}$, C. Finn ${ }^{2}$, and E. Baldwin ${ }^{3} ;{ }^{1}$ USDA-ARS, Lane, OK 74555; ${ }^{2}$ USDA- ARS, Corvallis, Ore.; ${ }^{3}$ USDA-ARS, Winter Haven, Fla.

Oregon produces most of the processing blackberries in the United States. 'Marion' blackberry ( Rubus hybrid) is a trailing, thorny plant type with fruit highly prized for its unique flavor and superior processing quality. Blackberries developed in other parts of the United States grow well in Oregon but differ in flavor from 'Marion' fruit. 'Marion' blackberry plants are thorny and highly susceptible to freeze injury; growers desire a thornless, higher yielding, and more winter tolerant plant with similar fruit flavor and quality. This experiment was done to identify volatiles unique to 'Marion' that may be incorporated into new germplasm. Forty-two volatile peaks were identified in blackberries using headspace gas chromatography and known standards. Ethylacetate and trans-2-hexenol were present in very low amounts and nerilidol was present in an unusually high amount in fresh 'Marion' homogenates relative to other blackberry cultivars. Nerilidol is a volatile commonly associated with raspberry flavor and may come from the raspberry germplasm in the breeding background of 'Marion'. It appears that the flavor of 'Marion' fruit results from proportional differences in several volatile compounds rather than the presence of volatiles unique to this cultivar.

\section{0}

\section{Controlled-Atmosphere Tents for Storage of Fresh Blueber-} ries in Conventional Refrigerated Rooms

Jerry C. Leyte ${ }^{1}$ and Charles F. Forney ${ }^{2 *},{ }^{1}$ Agricultural Engineer, Nova Agri Associates Ltd., Port Williams, N.S. BOP 1T0, Canada; ${ }^{2}$ Storage Physiologist, Agriculture and Agri-Food Canada, Atlantic Food and Horticulture Research Centre, 32 Main St., Kentville, N.S., B4N 1J5, Canada

A plastic tent was designed and constructed for the controlled atmosphere (CA) storage of fresh blueberries. The CA tent was suspended from pallet racking in a standard cold room and held two standard pallets stacked 6 feet high with flats of packaged blueberries. The tent was sealed with two air-tight zippers and a small water trough, resulting in an air-tight chamber that successfully maintained $\mathrm{CA}$ storage environments. The CA tent was easily set up and removed to allow flexibility in use of storage space. To provide efficient use of storage space, tents could be stacked two or three high on pallet racking. The tent was easily loaded and unloaded by a single person using a forklift. CA tents provide an economical alternative to traditional CA rooms for the storage of small quantities of fresh blueberries and allows greater flexibility in marketing than traditional CA storage rooms. CA tents are suitable for the storage of other fresh produce that benefits from CA environments.

\section{1}

Compression Bruising Alters the Strawberry Volatile Profile

Douglas D. Archbold*, Ann M. Clements, T.R. Hamilton-Kemp, and R.W. Collins; Department of Horticulture and Landscape Architecture, University of Kentucky, Lexington, KY 40546-0091

Prior work indicated that volatile compounds produced by macerated strawberry fruit occurred at levels capable of affecting pathogen development. To determine if a less-severe injury, such as bruising, would alter the volatile profile of strawberry fruit, the headspace volatiles from ripe 'Tribute' strawberry fruit were sampled with SPME fiber during the 15 min immediately following and from 75 to 90 min following application of a compression bruise. The compression bruise was applied with a force gauge, and fruit were kept in a closed bottle at room temperature during the study. Of the 14 major volatile products consistently produced by all fruit, acetate esters derived from hexanal, (E)-2-hexenal, and (Z)-3hexenal increased most, over $50 \%$, in response to bruising during the first interval. During the later interval, bruised fruit produced over $50 \%$ more (E)-2-hexenyl acetate and hexyl acetate than control fruit. Most notably, the ratio of levels of $(E)$ 2-hexenyl acetate produced by bruised compared to control fruit were the highest among all 14 major volatiles, over $150 \%$ more after 15 min and $270 \%$ more at 90 min. Headspace levels of the 6 -carbon acetate esters declined for both control and bruised fruit between 15 and $90 \mathrm{~min}$, while levels of the other major volatiles increased. The other 11 volatile compounds were commonly identified aroma volatiles. Headspace levels of some of these were also higher from bruised than control fruit. In particular, headspace levels of ethyl butyrate were increased by bruising $13 \%$ after $15 \mathrm{~min}$ but over $100 \%$ after 90 min, the most of any volatile product other than $(E)$-2-hexenyl acetate.

\section{2}

\section{Postharvest Quality Of Eastern North American Strawberry Cultivars during Short-term Storage}

Rumphan Koslanund* and Douglas. D. Archbold; Department of Horticulture and Landscape Architecture, University of Kentucky, Lexington, KY 40546-0091

Strawberry cultivars grown for "pre-picked" markets need to maintain quality during short-term postharvest storage in contrast to those destined for "U-pick" harvest. However, very little information is available on berry qual ity during postharvest storage of cultivars grown in matted-row culture in eastern North America. To determine how rapidly berry quality may change and identify cultivars bestsuited for pre-picked markets, the postharvest performance of 16 cultivars grown in matted rows was compared. Berries were sampled at harvest, after 3 days of $4^{\circ} \mathrm{C}$ storage within sealed plastic bags, and after 3 subsequent days at $20^{\circ} \mathrm{C}$ Quality traits assessed included fruit firmness, color, titratable acidity, $\mathrm{pH}$, soluble solids, and percent weight loss. At harvest, berry quality varied by cultivar and from early to late harvest dates. Berry quality changed very little during $4{ }^{\circ} \mathrm{C}$ storage. During the subsequent $20^{\circ} \mathrm{C}$ storage, berry quality traits changed more for some cultivars than others. In particular, soft fruit at harvest and/or a rapid decline in berry firmness indicated that several cultivars were not suited for shortterm storage. Based on the cumulative data, several cultivars can be identified as better suited for pre-picked markets.

\section{3}

The Potential of Saprophytic Yeasts Antagonistic to Aspergillus flavus in Reducing Aflatoxin Contamination of Tree Nuts S.-S.T. Hua*, J.L. Baker, and M. Flores-Espiritu; USDA, ARS, Western Regional Research Center, 800 Buchanan Street, Albany, CA 94710

California is the major state for producing almonds, pistachios, and wal nuts, with a total market value of $\$ 1.6$ billion. Both domestic and export markets of these nuts presently allow a maximum level of aflatoxin $B$ contamination in the edible nuts to be $20 \mathrm{ppb}$. Even very low degrees of infection of the nuts by $A$. flavus can result in aflatoxin levels above the mandatory standards. Biological control to reduce the population of and to inhibit the biosynthesis of $A$. flavus in orchards may be useful to decrease infection and thus aflatoxin content in the edible nuts. Certain saprophytic yeasts were shown to effectively compete with postharvest fungal pathogens such as Penicillium expansum and Botrytis cinerea. The potential of saprophytic yeasts to reduce aflatoxin contamination in tree nuts has not been hitherto extensively explored. A safe visual bioassay for screening yeasts antagonistic to $A$. flavus has been developed. The nor mutant of $A$. flavus has a defective norsolorinic acid reductase and blocks the aflatoxin biosynthetic pathway, resulting in the accumulation of norsolorinic acid, a bright red-orange pigment. We used the nor mutant in the assay to screen yeasts strains for their ability to inhibit aflatoxin production by visually scoring the accumulation of this pigment as well as the growth and sporulation of the fungus. Yeast strains that reduced the red-orange pigment accumulation in the nor mutant were identified and shown to inhibit aflatoxin biosynthesis of several toxigenic strains of $A$. flavus.

\section{4}

\section{Ripening and Postharvest Behavior of Fruit of Two} Hylocereus Species (Cactaceae)

Avinoam Nerd", Fania Gutman, and Yosef Mizrahi; Ben-Gurion University of the Negev, P.O. Box 653, Beer-Sheva 84105, Israel

Fruit growth and ripening and the effect of various storage temperatureson fruit quality were studied in Hylocereus undatus and $H$. polyrhizus growing in Beer-Sheva (Israeli Negev desert) under greenhouse conditions. Dimensional growth of the fruit had a sigmoid pattern with a negligible growth after the onset of peel color change. The first change in peel color was recorded 24-25 $\mathrm{d}$ after anthesis in H. undatus and 26-27 d after anthesis in H. polyrhizus. In both species, peel color turned fully red 4-5 days after first color change (mean temperature for the study period was $26.6 \pm 2.1^{\circ} \mathrm{C}$ ). Parallel to color changes the content of pulp, SSC and soluble sugars increased while firmness and the content of 
starch and mucilage decreased. The surge in acidity before color change indicated the beginning of ripening processes. In $\mathrm{H}$. polyrhizus fruit, which have a red-violet pulp, the pigment increased in parallel to the development of peel color. The fruit were proved nonclimacteric, and when harvested at close to full color, they kept their marketing quality at least 2 weeks at $14^{\circ} \mathrm{C}$ or 1 week at $20^{\circ} \mathrm{C}$. Storage at $6^{\circ} \mathrm{C}$ is not recommended because fruit transferred from $6^{\circ} \mathrm{C}$ to room conditions lose their firmness and flavor rapidly. In $\mathrm{H}$. undatus chilling injury symptoms appeared.

\section{5}

Storage Disorders of Araza Fruit (Eugenia stipitata Mc. Vaugh) Related to Postharvest Treatments

M.S. Hernandez',2, H.E. Arjona', O. Martinez', and J.P. Fernandez-Trujillo*3; ${ }^{1}$ Facultad de Agronomia, Univ. Nacional de Colombia, P.O. Box 14490 Santafè deBogota, Colombia; 2 Instituto Amazunico de Investigaciones Cientlficas SINCHI, P.O. Box 340.291 Santafè de Bogota, Colombia; ${ }^{3}$ Dept. Fruit and Vegetable Science, Cornell University, Ithaca, NY 14853 USA

Araza (Eugenia stipitataMc Vaugh) is a plant from the Myrtaceae family originated from Amazonia. The postharvest behavior of its promissory fruit has been sparingly studied. Weight loss, softening, decay, and chilling injury (skin scald) at temperatures below $10-12^{\circ} \mathrm{C}$ limits its shelf-life to less than 10 days. The application of calcium pretreatments slightly improved flesh firmness after 7 days at $20^{\circ} \mathrm{C}$ and resulted in skin injury, particularly at concentrations higher than $4 \%$ $(\mathrm{w} / \mathrm{v})$. A warming treatment of 6,12 or $18 \mathrm{~h}$ at $20^{\circ} \mathrm{C}$ was applied to fruit after $6 \mathrm{~d}$ storage at $10^{\circ} \mathrm{C}$. Treated fruit had less scald, suppressed decay, and ripened normally after a total of 2 weeks of storage and a shelf life of 3 days.

\section{6}

Suppression of Green Mold on Grapefruit during Refrigerated Storage in Altered Atmospheres

Krista C. Shellie*; USDA-ARS, Weslaco, TX 78596

Green mold, a predominant disease of citrus fruit, develops when spores of Penicillium digitatum infect extant wounds in fruit epidermal tissue. Development of green mold during shipping limits the distance grapefruit can be surface transported. The objective of this research was to evaluate whether altering the atmosphere during refrigerated storage could suppress development of green mold. In the first two experiments, growth of green mold was evaluated after fruit were stored in ultra-low oxygen $(0.05$ or $1 \mathrm{kPa})$ at 14,16 , or $18^{\circ} \mathrm{C}$ for up to 21 days. In the last two experiments, grapefruit were stored for 14 or $21 \mathrm{~d}$ at 12,13 , or $14^{\circ} \mathrm{C}$ in atmospheres containing 2, 5, or $10 \mathrm{kPa}$ oxygen with or without 2,5 , 10 , or $20 \mathrm{kPa}$ carbon dioxide. In all experiments, grapefruit were inoculated with 10 or $20 \mu \mathrm{L}$ of a spore suspension of $P$. digitatum. Decay progression after storage was monitored by measuring the diameter of the lesion in $\mathrm{cm}$ at the demarcated site of inoculation or by subjectively rating percent decayed fruit surface area. Grapefruit not inoculated with $P$. digitatum had no visible symptoms of green mold. Grapefruit stored under controlled atmosphere had less fruit surface covered with mycelium (5\% to $64 \%$ ) than grapefruit stored in air. Inoculated grapefruit stored in $0.05 \mathrm{kPa}$ oxygen for up to $14 \mathrm{~d}$ at 14 or $18^{\circ} \mathrm{C}$ had no visible symptoms of green mold upon removal from cold storage, but developed a characteristic green mold lesion after 5 additional days of storage in air at ambient temperature. Results suggest that refrigerated controlled-atmosphere storage combined with wax and a fungicide can enhance control of green mold during shipping.

\section{7}

\section{Simple Ripening Model of Sapote Mamey (Pouteria sapota) Fruit}

Juan C. Diaz-Perezz" ${ }^{* 1}$, Silvia Bautista', and Ramon Villanueva2; ' 1 Dept. of Horticulture, Coastal Plain Experiment Station, Univ. of Georgia, Tifton GA 31793-0748; ${ }^{2}$ Dept. of Biotechnology, Ceprobi, National Polytechnic Institute, 62730 Yautepec, Morelos, Mexico

Sapote mamey is a sweet and aromatic tropical fruit that is very perishable. It is a climacteric fruit and has high rates of respiration and ethylene production. Maturity indices for this commodity are difficult to define because fruit show few changes in external appearance as they ripen. The fruit flesh, however, shows large changes in color, firmness, and sugar content measured as soluble solids content (SSC). The objective was to model fruit ripeness from measurements of SSC. We selected SSC because it is easy to measure and because sweetness is an important quality attribute in sapote mamey. Typical values of SSC range from $12 \%$ (immediately after harvest) to $30 \%$ to $35 \%$ (ripe fruit). A linear-plateau model was used to describe the changes in SSC over time of ripening fruit kept at different temperatures. The model assumed that, as fruit ripened, SSC increased at a linear rate reaching a maximum of $30 \%$ SSC at the ripe stage after which SSC changed little. From the model we cal culated the rate of fruit ripening and the time to reach the ripening stage ( $30 \% \mathrm{SSC})$. The rate of ripening showed a quadratic relationship with storage temperature. Fruit kept at 27,25 , or $20^{\circ} \mathrm{C}$ ripened 3.5 , 5 , or 7 days after harvest. The model can be used to estimate when fruit will reach the ripe stage, as long as we know the initial SSC and storage temperature. This model was constructed from data obtained over 2 years from fruit grown in the state of Morelos, Mexico. It is still to be tested for its applicability on fruit from other growing regions.

\section{8}

\section{Effects of Insecticidal Controlled Atmospheres at High Temperature on the Quality of Mango Fruit}

Ehadi M. Yahia* and Dora Ortega; DIPA, Facultad de Química, Universidad Autónoma de Querétaro, Querétaro, QRO, 76190, Mexico

We have shown in research work also presented in this meeting that insecticidal controlled atmospheres at high temperatures are very efficient in causing in vitro mortality of eggs and third instar larvas, and in vivo mortality of third instar larvas of Anastrepha ludens and A. obliqua. In this work we are reporting on their effect on the quality of mango fruit. Fruit of the cultivar 'Manila' were exposed to $0 \% \mathrm{O}_{2}+50 \% \mathrm{CO}_{2}$ at $40,42,43,44,45,46,47,48$, and $49^{\circ} \mathrm{C}$ and $50 \%$ relative humidity for $160 \mathrm{~min}$, after which they were stored at $10^{\circ} \mathrm{C}$ for 20 days and evaluated at different intervals. Fruit exposed at $44^{\circ} \mathrm{C}$ or more had heat injury, while those exposed at $43^{\circ} \mathrm{C}$ or less did not show any injury and had similar or better quality than the control. On the basis of our previous results on insect mortality and on the resulted fruit quality reported here (heat injury, color, texture, weight loss), we conclude that $0 \% \mathrm{O}_{2}+50 \% \mathrm{CO}_{2}$ at $43^{\circ} \mathrm{C}$ or less for 160 min can be used for the control of $A$. ludens and $A$. obliquain mangoes.

\section{9}

The Mortality of Artificially Infested Third Instar Larvas of Anastrepaha ludens and $A$. obliqua in Mango Fruit with Insecticidal Controlled Atmospheres at High Temperature Ehadi M. Yahia ${ }^{* 1}$, Dora Ortega', Alejandro Martinez, and PamelaMoreno'; ' ${ }^{1}$ IPA, Facultad de Química, Universidad Autónoma de Querétaro, Querétaro, QRO, 76190, Mexico; ${ }^{2}$ Planta Moscafrut, DSVG-SAGAR, Chiapas, Mexico

Previous work in our laboratory and also reported in this meeting has indicated that insecticidal controlled atmospheres at high temperatures $\left(0.5 \% \mathrm{O}_{2}+\right.$ $50 \% \mathrm{CO}_{2}$ at $44-55^{\circ} \mathrm{C}$ and $\left.50 \% \mathrm{RH}\right)$ are very effective in causing in vitro mortality of eggs and third instar larvas of Anastrepaha ludens and $A$. obliqua. This work is a follow up that evaluated the effect of such atmospheres on the in vivo mortality of third instar larvas artificially infested in mango. Atmospheres evaluated included $0 \% \mathrm{O}_{2}+50 \% \mathrm{CO}_{2}$ at $35,37,39,40,42,43,44,45,46,47,48$, and $49^{\circ} \mathrm{C}$ for $160 \mathrm{~min}$. Treatments at $35-40^{\circ} \mathrm{C}$ caused $100 \%$ mortality of larvas of $A$. obliqua, but not of $A$. ludens. Temperatures of 42 to $49^{\circ} \mathrm{C}$ caused $100 \%$ mortality of larvas of both species. Statistical analysis to calculate the probit 9 will be discussed.

\section{0}

\section{Effects of Hot Air Treatments on the Postharvest Physiology} and Quality of Mango Fruit

E.M. Yahia ${ }^{* 1}$, A. Mondragon ${ }^{1}$, M. Balderas ${ }^{1}$, P. Santiago ${ }^{2}$, and L. Lagunez ; 'DIPA, Facultad de Química, Universidad Autónomade Querétaro, Querétaro, QRO, 76190, Mexico; ${ }^{2} \mathrm{CIIDIR}$, Oaxaca, Mexico

Heat treatments have several potential positive effects in fruit, including insect and decay control, amelioration of chilling injury, and delay of ripening and senescence. Hot water treatment $\left(46.1^{\circ} \mathrm{C}\right.$ for $65-90$ min, depending on fruit weight) has been used in Mexico and some other countries as a quarantine insect control treatment for mangoes. Hot air treatments can provide several advantages compared to hot water in regard to installations, costs, reduced injury, and compatibility with other systems such as controlled atmospheres. In this work we have investigated the effect of hot air treatments at 44 to $48^{\circ} \mathrm{C}$ and $50 \%$ relative humidity for 160 and $220 \mathrm{~min}$, on the physiology and quality of 'Manila' and 'Óro' mango fruit stored at $10^{\circ} \mathrm{C}$ and $85 \%$ relative humidity for up to 4 weeks. No injury was observed in both cultivars exposed for $160 \mathrm{~min}$, but some injury was 
observed when fruit were exposed for $220 \mathrm{~min}$. Some of these fruit also failed to ripen. Heat treatment (especially for $160 \mathrm{~min}$ ) delayed ripening of fruit, as measured with color and texture changes, compared to the control. Heat treatment changed the protein composition of the fruit and affected the activity of peroxidases.

\section{ORAL SESSION 1 (Abstr. 401-405) Vegetable Crops: Crop Physiology}

401

\section{Assessing Crop Canopy Development Using a Digital, Red/ Near-infrared Band Ratioing Camera}

D.W. Peters, J.P. Mitchel/ ${ }^{*}$, R.E. Plant, and B.R. Hanson; University of California, Davis, CA 95616

Current methods of making crop cover estimates are time-consuming and tend to be highly variable. A low-cost, digital, red/near-infrared band ratioing camera (Dycam Inc., Chatsworth, Calif.) and accompanying software (S. Heinold, Woodland Hills, Calif.) were eval uated for estimating crop cover. The camera was tested using a set of images having leaf areas of known sizes with different crop, soil, and lighting conditions. In the field, camera-based crop cover estimates were compared to light bar measured estimates. Results indicate that the camera and image analysis software are capable of estimating percent crop cover over a range of soil, crop, and lighting environments. Camera-based crop cover estimates were highly correlated with light bar estimates (tomato $r^{2}=0.96$, cotton $r^{2}$ $=0.98$ ). Under the conditions tested, the camera appears to be a useful tool for monitoring crop growth in the field.

\section{2}

Lettuce Seed Germination and Endo-mannanase Activity are Stimulated by Ethylene at High Temperature

Warley M. Nascimento, Daniel J. Cantliffe*, and Donald J. Huber; Horticultural Sciences Dept., Univ. of Florida, PO Box 110690, Gainesville, FL 32611-0690

Temperatures above $30^{\circ} \mathrm{C}$ may delay or inhibit germination of most of commercial lettuce cultivars. Ethylene enhances lettuce seed germination at high temperatures. Enzyme-mediated degradation of endosperm cell walls appears to bea crucial factor for lettuce germination at high temperature. The galactomannan polysaccharides in lettuce endosperm cell wall are mobilized by endomannanase. The role of endo-mannanase during germination of lettuce seeds at high temperature $\left(35^{\circ} \mathrm{C}\right)$ and the possible role of etlene in enzyme regulation were investigated. Seeds of thermotolerant ('Everglades'-EVE) and thermosensitive ('Dark Green Boston'-DGB) lettuce genotypes were incubated at 20 and $35^{\circ} \mathrm{C}$ in water, $10 \mathrm{mM}$ of 1-aminocyclopropane-1-carboxylic acid (ACC), or $20 \mathrm{mM}$ of silver thiosulphate (STS). Also, seeds were primed in an aerated solution of polyethylene glycol (PEG), or PEG+ACC, or PEG+STS. Untreated seeds germinated $100 \%$ at $20^{\circ} \mathrm{C}$. At $35^{\circ} \mathrm{C}$, EVE germinated $100 \%$, whereas DGB germinated only $33 \%$. Seed priming or adding ACC during imbibition increased germination of DGB to $100 \%$ at $35^{\circ} \mathrm{C}$. Adding STS during imbibition led to a decrease in germination at $35 \% \mathrm{C}$ in EVE and completely inhibited germination of DGB. Priming with STS led to reduced germination at $35 \% \mathrm{C}$ of both genotypes. EVE produced more ethylene than DGB during germination at high temperature. Providing ACC either during priming or during germination led to an increase in endo-mannanase activity, whereas STS inhibited mannanase activity. Higher endo-mannana activity was observed in EVE than DGB seeds. The results suggest that ethylene might overcome the inhibitory effect of high temperature in thermosensitive lettuce seeds via weakening of endosperm due to increased endo-mannanase activity.

\section{3}

\section{Promotion of Germination and Seedling Development of Lima Beans (Phaseolus spp.) by Nickel Chloride \\ Cyril E. Broderick*; Delaware State University, Dover, DE 19901}

Delaware is among the largest producers of lima beans in the United States, having more than 10,000 acres in this crop. The plants are raised from seeds, but seeds are notably prone to injury during handling. The seed has little or no endosperm and relies on reserve food materials in the cotyledons. Lima beans are legumes, and the seeds store nitrogenous compounds. Nickel is implicated in nitrogen metabolism, and nickel is now implicated as an essential mineral nutrient element. With the variable rate of germination of lima bean seeds, our objective was set to determine the effect of nickel on seedling development of the lima bean plant. Lima bean seeds were soaked for various periods in 10 solutions from 0 to $500 \mathrm{ppm}$ nickel chloride. Soaking for $1 \mathrm{~h}$ in $100 \mathrm{ppm}$ nickel chloride solution was determined to be the best treatment. The $100 \mathrm{ppm}$ treatment then became the standard treatment for lima bean seeds. Hence, seeds were treated with distilled water of the $100 \mathrm{ppm}$ nickel chloride. The results are that the nickel chloride significantly improved the rate of germination of lima bean seeds. Germination rates were improved from $60 \% \pm 5 \%$ to $76 \% \pm 3 \%$. The total effect of treatments with nickel chloride varied from one batch of seeds to another; however, promotion of germiantion was significant. Osmoregulation and seed priming as well as stimulation of nitrogen metabolism by nickel are possible explanations of the positive effects of nickel chloride.

\section{4}

\section{Cyclic Cold Temperature Stresses Before Transplanting} Influence Cantaloupe Seedling Growth and Earliness But Not Total Yield or Quality

Ahmet Korkmaż and Robert J. Dufault; Clemson University, Coastal Research and Education Center, Charleston, SC, 29414

Cantaloupe seedlings may be repeatedly exposed in the field soon after transplanting to temperatures alternating between almost freezing and optimal temperatures. In the first year of a 2-year study, 'Athena' cantaloupe seedlings were exposed in walk-in coolers to temperatures cycling from $2{ }^{\circ} \mathrm{C}$ for 3,6 , and 9 hours daily to $25^{\circ} \mathrm{C}$ for the rest of the $24-h$ period. Cold stress was repeated for $1,3,6$, and 9 days before field planting. In the second year, transplants were exposed to $2^{\circ} \mathrm{C}$ for 3,6 , and 9 hours for 3,6 , and 9 days before field transplanting. The objective of this study was to determine the long-term effect of early season cold temperature exposure on seedling growth, earliness, yield and quality by simulating the cold/warm alternations possible in the field in coolers. Coldstressed transplants were planted in the field after all risk of ambient cold stress was negligible. In both years, exposure to cycling cold temperatures generally did not effect total productivity and fruit quality, although seedling growth characteristics were reduced in response to longer cold-stress treatments. In the second year, early yield was reduced by exposure to increasing hours of cold stress, but this was not significant in the first year. Therefore, cold temperature stresses occurring in the field at transplanting have negligible effect on yield potential of 'Athena' cantaloupe.

\section{5}

\section{Glycinebetaine Accumulation in Red Beet under Salinity}

Guntur V. Subbarao*1, Raymond M. Wheeler ${ }^{2}$, L.H. Levine ${ }^{3}$, and Gary W. Stutte; ${ }^{1}$ U.S. National Research Council, ${ }^{2}$ NASA Biomedical Office, ${ }^{3}$ Dynamac Corporation, Kennedy Space Center, FL 32899, USA

Accumulation of glycinebetaine occurs in Chenopodiaceae members and is thought to assist in osmotic adjustment and protect cytoplasm from sodium toxicity. Red beet has an ability to tolerate high tissue sodium levels, which may result in increased glycinebetaine production. To test this hypothesis, two cultivars of red beet ['Scarlet Supreme' (SS) and 'Ruby Queen' (RQ)] were grown under nonsaline $(4.75 \mathrm{mM} \mathrm{Na})$ and saline $(54.75 \mathrm{mM} \mathrm{Na})$ conditions in a recirculating hydroponic system for 42 days at elevated $\mathrm{CO}_{2}\left(1200 \mu \mathrm{mol} \cdot \mathrm{mol}^{-1}\right)$ in a growth chamber. Leaf glycinebetaine level, relative water content, and osmotic potential were measured at weekly intervals. Leaf glycinebetaine levels increased with plant age and reached a maximum of $67 \mu \mathrm{mol} \cdot \mathrm{g}^{-1} \mathrm{dw}$ under nonsaline and $101 \mu \mathrm{mol} \cdot \mathrm{g}^{-1} \mathrm{dry}$ weight ( $\mathrm{dw}$ ) under saline conditions at 42 days in $\mathrm{SS}$; in $\mathrm{RQ}$, the glycinebetaine levels reached a maximum of $91 \mu \mathrm{mol} \cdot \mathrm{g}^{-1} \mathrm{dw}$ under nonsaline and $121 \mu \mathrm{mol} \cdot \mathrm{g}^{-1}$ $d w$ under saline conditions by 26 days. The mean glycinebetaine levels were increased over two-thirds under saline conditions in both the cultivars. RQ accumulated significantly higher (37\% more under nonsaline, and $46 \%$ more under salinity) glycinebetaine than SS. The turgid leaf osmotic potential of RQ was consistently higher than SS under nonsaline (2.23 MPa in RQ vs. 1.82 MPa in SS) and saline (2.48 MPa in RQvs. 2.02 MPa in SS) conditions. The results indicate that higher glycinebetaine levels in the leaf could result in better osmotic adjustment, and glycinebetaine accumulation in red beet can vary among cultivars and is strongly affected by external salinity. 
28 ORAL SESSION 2 (Abstr. 406-412) Cross-commodity: Postharvest Physiology, Controlled and Modified-atmosphere Storage

\section{6}

Pyruvate Decarboxylase and Alcohol Dehydrogenase Activities in Sweetpotato under Different Oxygen Atmospheres

Yuehe Huang *, David H. Picha, and Anthony W. Kilili; Dept. of Horticulture, Louisiana State Univ., Baton Rouge, LA 70803

'Beauregard' sweetpotato (Ipomoea batatas L. Lam) roots were maintained under different controlled atmospheres ranging from $0 \%$ to $21 \% \mathrm{O}_{2}$ at $22{ }^{\circ} \mathrm{C}$ in two separate trials for 14 days to study changes in activities of pyruvate decarboxylase (PDC) and alcohol dehydrogenase (ADH). Trial I showed no difference in activities of PDC and $\mathrm{ADH}$ between $0 \%$ and $1 \% \mathrm{O}_{2}$, or among $2 \%, 5 \%$, and $21 \% \mathrm{O}_{2}$. Both PDC and ADH activities were significantly higher at $0 \%$ and $1 \% \mathrm{O}_{2}$ compared to the $2 \%, 5 \%$, and $21 \% \mathrm{O}_{2}$ atmospheres. In trial II, both enzyme activities were lower at $1.5 \% \mathrm{O}_{2}$ than at $0 \% \mathrm{O}_{2}$, but higher than at $10 \%$ and $21 \%$ $\mathrm{O}_{2}$ atmospheres. The combined data of the two trials showed a very strong correlation between PDC and ADH activities $\left(R^{2}=0.86\right)$. In addition, a strong correlation existed between PDC activity and acetaldehyde concentration $\left(P^{2}=0.95\right)$. The maximal activities were at $\mathrm{pH} 6.5$ for $\mathrm{PDC}$ and at $\mathrm{pH} 8.5$ for $\mathrm{ADH}$ in the direction of acetaldehyde-to-ethanol. The results suggest that $1.5 \% \mathrm{O}_{2}$ is the critical point for the transition from aerobic to anaerobic metabolism in CA storage of sweetpotato roots, and PDC is the key enzyme in alcoholic fermentation.

\section{7}

Regulation of Carbon Flux as a Function of $\mathrm{O}_{2}$ and $\mathrm{CO}_{2}$ Atmospheres in Asparagus Tips

S.M. Silva ${ }^{* 1}$, R.C. Herner', and R.M. Beaudry2; ${ }^{1}$ Dept. de Tecnologia Rural, Univ. Federal da Paralba, Bananeiras, PB, 58220 Brazil; ' 2 Dept. of Horticulture, Michigan State Univ., East Lansing, MI 48824

The purpose of this work was to investigate the influence of $\mathrm{O}_{2}$ and $\mathrm{CO}_{2}$ partial pressures on glycolytic carbon flux, phosphorylated intermediates, phosphate, pyrophosphate, and phosporylated nucleotides in asparagus spears tips stores at $1^{\circ} \mathrm{C}$. The effects of $\mathrm{CO}_{2}(0,5,10$, and $20 \mathrm{kPa})$ combined with $\mathrm{O}_{2}$ pressures ranging from 0.1 to $16 \mathrm{kPa}\left(1 \% \mathrm{O}_{2}=1.013 \mathrm{kPaO}\right.$ at $\left.1 \mathrm{~atm}\right)$ were investigated. Spears were enclosed within a low-density polyethylene (LDPE) package (for the $5-, 10-$, and $20-\mathrm{kPa} \mathrm{CO}_{2}$ treatments) having a surface area of $462 \mathrm{~cm}^{2}$ and enclosed in 1.95- $\mathrm{L}$ glass jars. Low $\mathrm{O}_{2}$ enhanced the interconversion of phosphoenolpyruvate (PEP) to pyruvate (PYR) and $\mathrm{F} 6 \mathrm{P}$ to $\mathrm{F} 1,6 \mathrm{P}_{2}$ relative to high $\mathrm{O}_{2}$. When spears tips at $16 \mathrm{KPaO}_{2}$ were compared to those at harvest, little change occurred in the adenylate or phosphate pools. PPi and ATP contents decreased as the $\mathrm{O}_{2}$ partial pressure declined below $16 \mathrm{kPaO}_{2}$. In general, as $\mathrm{CO}_{2}$ increased, $\mathrm{PPi}$ and ATP decreased, while Pi, ADP, and AMP increased. The adenylate energy charge (AEC) declined with a decline in the $\mathrm{O}_{2}$ partial pressure, declining most rapidly below $2 \mathrm{kPaO}_{2}$. Low $\mathrm{O}_{2}$ reduced $A E C$ relative to high $\mathrm{O}_{2}$. Increasing $\mathrm{CO}_{2}$ partial pressure reduced $A E C$, an effect not evident at lower $\mathrm{O}_{2}$. The data suggest low $\mathrm{O}_{2}$ and elevated $\mathrm{CO}_{2}$ impair oxidative phosphorylation and induce nonsustaining carbon metabolism, which may limit asparagus spear survival under $\mathrm{O}_{2}$-deficient conditions.

\section{8}

Atmospheric Oxygen Level Affects 'Beauregard' Sweetpotato Respiration Rate, Fermentation Products, and Sugar

\section{Composition}

Anthony Kilili*, David H. Picha, and Yuehe Huang; Department of Horticulture, Louisiana State University, Baton Rouge, LA 70803

'Beauregard' sweetpotatoes (Ipomoea batatas L. Lam) were stored under a continuous flow of $0 \%, 1 \%, 1.5 \%, 2 \%, 5 \%, 10 \%$, or $21 \% \mathrm{O}_{2}$ (balance $\mathrm{N}_{2}$ ) for 14 days. Respiration rate was significantly lower at $1.5 \%, 2 \%, 5 \%$, and $10 \% \mathrm{O}_{2}$ compared with $21 \% \mathrm{O}_{2}$, while respiration at $0 \%$ and $1 \% \mathrm{O}_{2}$ was higher than at $1.5 \%, 2 \%, 5 \%$, and $10 \% \mathrm{O}_{2}$. Respiration rate at $0 \% \mathrm{O}_{2}$ remained high for several days after exposure to air while that at 1.5\%, $2 \%, 5 \%$, and $10 \% \mathrm{O}_{2}$ increased rapidly to equal that of $21 \% \mathrm{O}_{2}$. Ethanol and acetaldehyde accumulated rapidly at $0 \%$ and $1 \% \mathrm{O}_{2}$ but were lower at the other $\mathrm{O}_{2}$ levels. Ethanol increased 16 - and 4fold after 14 days of storage at $0 \%$ and $1 \% \mathrm{O}_{2}$, respectively, compared to $21 \%$ $\mathrm{O}_{2}$. In addition, acetaldehyde increased 11 - and 8 -fold at $0 \%$ and $1 \% \mathrm{O}_{2}$ respectively, compared to $21 \% \mathrm{O}_{2}$. Sucrose and total sugar concentration increased under low $\mathrm{O}_{2}$ concentration while reducing sugars (fructose and glucose) and $\mathrm{pH}$ decreased.

\section{9}

\section{Controlled-Atmosphere Storage of 'Shinko' and 'Shinsui'} Asian Pears

Yong Seo Park ${ }^{\star 1}$, Clara Pelayo², Betty Hess-Pierce², and Adel A. Kader2 ${ }^{2}{ }^{1}$ Dept. of Horticultural Breeding, Mokpo National University, Chungkye Muan Chonnam, 534-729, Korea; ${ }^{2}$ Dept. of Pomology, Univ. of California, Davis, CA 95616, USA

'Shinko' and 'Shinsui' Asian pears were kept in air, $2 \mathrm{kPa} \mathrm{O}_{2}, 2 \mathrm{kPa} \mathrm{O}+2.5$ $\mathrm{kPaCO}_{2}$, and $2 \mathrm{kPaO}_{2}+5 \mathrm{kPaCO}_{2}$ (balance $\mathrm{N}_{2}$ in each treatment) at $0^{\circ} \mathrm{C}$ or $5^{\circ} \mathrm{C}$ for up to 24 weeks. The three $\mathrm{CA}$ treatments reduced respiration $\left(\mathrm{O}_{2}\right.$ consumption) and ethylene production rates relative to air control pears; these rates were higher at $5^{\circ} \mathrm{C}$ than at $0^{\circ} \mathrm{C}$ and higher for 'Shinsui' than for 'Shinko' pears. While 'Shinsui' pears had a climacteric pattern of respiration and ethylene production rates, 'Shinko' pears produced very small quantities of ethylene and exhibited a non-climacteric respiratory pattern. 'Shinko' pears had a much longer postharvest life than 'Shinsui' pears ( 24 weeks vs. 12 weeks at $0^{\circ} \mathrm{C}$ ). CA treatments had a greater effect on delaying deterioration of 'Shinsui' than 'Shinko' pears, which were more sensitive to $\mathrm{CO}_{2}$ injury and associated accumulation of fermentative metabolites (acetaldehyde, ethanol, ethyl acetate). 'Shinko' pears did not benefit from CA storage and were best kept in air at $0^{\circ} \mathrm{C}$. An atmosphere of $2 \mathrm{kPaO}_{2}$ with or without up to $5 \mathrm{kPa} \mathrm{CO}$ delayed flesh breakdown of 'Shinsui' pears during storage $0^{\circ} \mathrm{C}$.

\section{0}

Interactive Effects of Harvest Maturity, Controlled Atmosphere, and Surface Coatings on Mango (Mangifera indica L.) Flavor Quality

E.A. Baldwin*, T.M.M. Malundo, R. Bender, and J.K. Brecht; USDA Citrus \& Subtropical Products Lab, Winter Haven, FL 33881; U.S. Distilled Products, Princeton, Minn; Fac. Agronomia/UFRGS, Porto Alegre, Brazil; Univ. of Florida, Gainesville, Fla.

Mango fruit, cv. Tommy Atkins, were harvested from two grove sites in south Florida at mature green (MG) and tree ripe (TR) maturities. The fruit were either coated with one of two coatings (NS = Nature Sealß 4000, a polysaccharide coating, or $\mathrm{CW}=$ carnauba wax) or left uncoated (control) and stored in humidified air or held in a controlled atmosphere $\left(\mathrm{CA}=5 \% \mathrm{O}_{2}\right.$ plus $\left.25 \% \mathrm{CO}_{2}\right)$ at $12{ }^{\circ} \mathrm{C}$ for 21 days followed by 2 days in air at $20^{\circ} \mathrm{C}$. There were 12 fruit for each treatment/maturity stage combination replicated by grove site. After storage, the pulp was homogenized for later consumer or descriptive panel analysis. Measurements for total soluble solids (SS), pH, titratable acidity (TA), and flavor volatile compounds were al so made. TR-harvested fruit were sweeter and generally more aromatic than MG-fruit as determined by sensory and/or chemical analysis. NScoated fruit were more sour, bitter, and astringent compared to controls and CAtreated fruit. NS-coated fruit received lower overall consumer scores than CWcoated fruit, but were not different from controls or CA-treated fruit. This was reflected also in descriptive panel ratings. There were no differences based on storage treatment for SS, pH, or TA; however, NS-coated fruit were higher in acetaldehyde, methanol and ethanol compared to control or CA-treated fruit. Correlation and regression analysis showed significant relationships between sensory and chemical data.

411

Elevated Oxygen Atmospheres as a Decay Control Alternative on Strawberry

Annette L. Wszelaki* and Elizabeth J. Mitcham; Department of Pomology, University of California, Davis, CA 95616

Controlled atmospheres have been proven an effective postharvest disease deterrent for strawberries both in transport and storage. However, these treatments do not provide residual protection once the commodity is removed from the atmosphere, and the atmospheres can cause off-flavors in the fruit. Elevated 
oxygen atmospheres are a novel addition to this technology and could potentially provide better decay control without the harmful effects on fruit flavor aspects. Elevated oxygen will potentially discourage microbial growth, as anaerobes grow best under very low oxygen levels and aerobes grow best under atmospheric oxygen. Threshold elevated oxygen levels to prevent Botrytis cinerea growth in vitro and in vivo on strawberry were assessed. Botrytis cultures (mycelial plugs and spores) and fresh strawberry fruit were exposed to $21 \%, 40 \%, 60 \%$, and $80 \%$ oxygen atmospheres at $5{ }^{\circ} \mathrm{C}$ for 5,7 , and $14 \mathrm{~d}$. Growth of cultures from mycelial plugs was evaluated after treatment and during post-treatment incubation by measuring the diameter of the fungus. Spore germination and germ tube elongation were evaluated every $24 \mathrm{~h}$ for 3 days after treatment by counting the number of germinated spores and measuring elongation, respectively. Strawberry quality including firmness, color, soluble solids, titratable acidity, ethylene production and respiration rates, and presence of defects were evaluated upon removal from the elevated oxygen atmospheres as well as after 1,3 , and $5 \mathrm{~d}$ storage in air at $20^{\circ} \mathrm{C}$ simulating market conditions.

\section{2}

\section{Quality of Packaged Fresh-cut Cantaloupe}

A. Hakim ${ }^{\star 1}$, A. Purvis , and M. Khatoon ${ }^{2} ;{ }^{1}$ Department of Horticulture, University of Georgia, Coastal Plain Experiment Station, Tifton, GA 31793, USA; ${ }^{2}$ Department of Horticulture, Bangladesh Agricultural University, Mymensingh, Bangladesh

Cantal oupe at commercial stage of maturity were sliced, i.e., prepared as minimally proceed, rinsed with or without sodium hypochloride solution (50 ppm), and drained. They were stored in perforated polyethylene package $(\mathrm{PE})$ at $1{ }^{\circ} \mathrm{C}$ in air and controlled atmosphere $\left(2 \% \mathrm{O}_{2}\right.$ and $\left.5 \% \mathrm{CO}_{2}\right)$ for 5 and 10 days. Freshcut cantaloupe slices were analyzed initially and after 5 and 10 days of storage for weight loss, lycopene content, fungus infection, flavor and taste, TSS, pH, ethanol, firmness, and electrolyte leakage. Fruit stored in CA exhibited lower weight loss, higher lycopene content, less fungus infection, better flavor and taste, more firmness, higher TSS content, and lower electrolyte leakage than store in air. When compared to fruit treated with sodium hypochloride, lower lycopene content, higher fungus infection, inferior flavor and taste, more softness, and higher electrolyte leakage were detected in fruit that were not rinsed with sodium hypochloride solution. Extended storage time resulted in higher weight loss, increased fungus infection, bad taste, off-flavor, more softness, lower TSS content, and higher leakage value. This study indicates that it is possible to extend the shelf-life of fresh-cut cantaloupe slices from 5 to 10 days if kept at $1{ }^{\circ} \mathrm{C}$ in $2 \% \mathrm{O}_{2}$ and $5 \% \mathrm{CO}_{2}$ in PE package.

\section{ORAL SESSION 3 (Abstr. 413-418) Floriculture: Nutrition \& Substrates}

\section{3}

\section{Investigation of Nutrient Fluxes and Stem Production under} Nutrient Solution Recycling and Three Levels of Nutrition in Alstroemeria

D.R. Edwards* and M.A. Dixon; Department of Plant Agriculture, Horticultural Science Division, University of Guelph, Guelph, Ontario, Canada N1G 2W1

A concern with the greenhouse production of horticultural commodities, particularly those grown in the ground, is the difficulty in managing nutrient runoff. Alstroemeria, a heavy-feeding crop that is nearly al ways grown in soil, were planted into 26.5-L pots with a medium of LECA. Greenhouse experiments were designed to examine flowering stem production, quality, and nutrient flux under nutrient solution reuse (closed system) and with one of three levels of nutrition (EC of 2.1, 1.6 and $1.1 \mathrm{mS} / \mathrm{cm}$ ). Plants in the closed treatments were set on troughs sloped towards separate $24-\mathrm{L}$ reservoirs. The control was an open drainage system fed at $2.1 \mathrm{mS} / \mathrm{cm}$. The reservoirs were kept at a constant volume with the addition of water after every irrigation; nutrients were added to restore the EC to demand levels. Stems were harvested twice per week and the nutrient content of the reservoirs were analyzed biweekly by ion chromatography. Data were analyzed as an RCBD with four treatments and blocks. Analysis of data from the preliminary experiment (29 May to 3 Aug. 1998) indicated number of stems and cymes were similar among treatments. Stem length, dry weight, and number of florets were depressed below the control only in lowest fed treatment. Nutrient application was reduced markedly, by up to 1000 -fold in the closed vs. the open production system.

\section{4}

The Effect of Water Availability on Rose Photosynthesis and Calorespirometric Properties

M. Raviv ${ }^{*}$, J.H. Lieth, and D.W. Burger; Dept. of Environmental Horticulture, University of California, Davis, CA 95616 ( ${ }^{*}$ Permanent address: Newe Ya'ar Research Center, ARO, Israel)

Rose plants (cv. Kardinal, grafted on Natal Brier) were grown in UC mix (42\% fir bark, $33 \%$ peat, and $25 \%$ sand) and in coir. Water tension in the media was maintained within a predetermined narrow range using electronic tensiometers. Whole plant net photosynthesis as a function of the water tension in the medium was determined and the results were later normalized to measured leaf area. Simultaneous measurements of metabolic heat and respiration rate were carried out on detached young ( $F W=10-20 \mathrm{mg}$.) leaflet samples, using differential scanning cal orimeter (model 4100, Calorimetry Sciences, Provo, Utah). Only a small amount of plant material is removed for analyses so the assay is essentially nondestructive for the whole plant. Physical characteristics of the media greatly affect the relationship between water tension and water availability to plants. At similar tension values, water availability is much lower in coir than in UC mix. The effects of water availability on net photosynthesis, metabolic heat rate, and respiration will be discussed in relation to their effect on productivity

\section{5}

\section{Fertilizer Source and Medium Composition Affect Growth of} Moth Orchid

Yin-Tung Wang and Elise A. Konow*; Department of Horticultural Sciences, Texas A\&M University System Agricultural Research and Extension Center, 2415 East Highway 83, Weslaco, TX 78596

Vegetatively propagated Phalaenopsis Atien Kaala 'TSC 22' plants $10 \mathrm{~cm}$ in leaf spread were potted in a medium that consisted of either $100 \%$ fine grade Douglas fir bark or a mixture of $70 \%$ fir bark and $30 \%$ sphagnum peat. Plants were fertigated at each irrigation with $10 \mathrm{~N}-13.1 \mathrm{P}-16.6 \mathrm{~K}(10-30-20), 20 \mathrm{~N}-2.2 \mathrm{P}-$ $15.8 \mathrm{~K}(20-5-19), 20 \mathrm{~N}-8.6 \mathrm{P}-16.6 \mathrm{~K}(20-20-20)$, or a $2 \mathrm{~N}-0.4 \mathrm{P}-1.7 \mathrm{~K}(2-1-2)$ liquid fertilizer at a common $\mathrm{N}$ rate of $200 \mathrm{mg} \cdot \mathrm{L}^{-1}$. After 1 year in a greenhouse plants grown in the bark/peat medium produced more leaves and had heavier fresh weights and larger total leaf areas than those in 100\% bark. In the bark medium, the $20 \mathrm{~N}-2.2 \mathrm{P}-15.8 \mathrm{~K}$ fertilizer resulted in best plants, despite its low $\mathrm{P}$ concentration $\left(22 \mathrm{mg} \bullet \mathrm{L}^{-1}\right)$. When grown in bark/peat, the two fertilizers $(20 \mathrm{~N}$ $2.2 \mathrm{P}-15.8 \mathrm{~K}$ and $20 \mathrm{~N}-8.6 \mathrm{P}-16.6 \mathrm{~K})$ containing urea as part of their $\mathrm{N}$ source $(10 \%$ and $52 \%$, respectively) resulted in plants with $40 \%$ to $50 \%$ heavier shoot fresh weight and $40 \%$ larger leaf area than the other fertilizers. With any given fertilizer, plants had similar root weights in both media. Media and fertilizers had limited or no effect on the concentrations of minerals in the second mature acropital leaves except $P$, the concentration of which nearly doubled in leaves of plants grown in $100 \%$ bark. Water extracts from the bark/peat medium had lower $\mathrm{pH}$, higher $\mathrm{EC}$, and elevated levels of $\mathrm{NH}_{4}-\mathrm{N}, \mathrm{Ca}, \mathrm{Fe}, \mathrm{Na}, \mathrm{Cl}, \mathrm{B}$, and $\mathrm{Al}$ than those from $100 \%$ bark. Exacts from the bark medium did not have detectable levels of $\mathrm{NO}_{3}-\mathrm{N}$, whereas extracts from the bark/peat medium all had similar levels of $\mathrm{NO}_{3}-\mathrm{N}$, regardless of which fertilizer was applied.

\section{6}

\section{Blended Composts and N Rates on Growth of Potted Chry-} santhemum

Catherine S.M. Kü and John C. Bouwkamp; Department of Natural Resource Sciences and Landscape Architecture, University of Maryland, College Park, MD 20742-4452

Potted 'Boaldi', 'Red Akron', and 'Yellow Boaldi' growth performance were evaluated in eight substrates and four $\mathrm{N}$ rates. The substrates included Sunshine Mix 1, Pro Gro 300S, and six compost blends. The compost feedstocks were polymer dewatered biosolids (PDB) blended with poultry litter (PL) or yard wastes (YW) and peat:perlite at final ratios of 4:2:1:1, 3:3:1:1, and 2:4:1:1. Plants received $\mathrm{N}$ at $75,100,150$, or $200 \mathrm{mg} \cdot \mathrm{L}^{-1}$ from $21 \mathrm{~N}-2.2 \mathrm{P}-16.6 \mathrm{~K}$ twice a week. Number of flowers, height, diameter, and grade of plants that received $\mathrm{N}$ at 200 $\mathrm{mg} \cdot \mathrm{L}^{-1}$ treatment were significant better than those received the other $\mathrm{N}$ treatments. For all compost blends, premium-quality plants were produced with $\mathrm{N}$ at 
$200 \mathrm{mg} \cdot \mathrm{L}^{-1}$ treatment and good-quality plants were obtained with the remaining $\mathrm{N}$ treatments. The control substrates produced good quality plants with $\mathrm{N}$ treatments at 150 and $200 \mathrm{mg} \cdot \mathrm{L}^{-1}$, the remaining $\mathrm{N}$ treatments resulted in plants that were only salable at reduced price. 'Red Akron' is a free-branching spray cultivar, had more flowers and branches than the other two cultivars.

\section{7}

\section{Earthworm Castings as a Media Amendment for Poinsettia Production}

Pablo R. Hidalgo* and Richard L. Harkess; Mississippi State University, 117 Dorman Hall, Box 9555, Mississippi State, MS 39762.

An experiment was conducted to determine the effect of earthworm ( Eisenia fetida andrei) castings derived from sheep, cow, or horse manures on the growth of poinsettia (Euphorbia pulcherrima 'Freedom Red'). Poinsettia cuttings were transplanted to $1-\mathrm{L}(15-\mathrm{cm}$-diameter) plastic pots that were filled with castings:peat moss at 1:0, 1:3, 1:1, 3:1, or $0: 1$ by volume for each animal manure evaluated. Plants were fertilized using 200 ppm N from a 15-5-25 (N-P $\left.\mathrm{O}_{5}-\mathrm{K}_{2} \mathrm{O}\right)$ fertilizer applied with the irrigation water. Total bract area and growth index were greatest in those treatments consisting of 3:1 and 1:1 (castings:peat) from sheep and cow manures, 1:0 (castings:peat) from cow manure and for growth index only, 1:0 (castings:peat) from horse manure. For these two characteristics, 100\% sheep manure castings and $100 \%$ peatmoss had the lowest values. The time to anthesis was least when poinsettias were grown in 3:1 or 1:1 castings:peat from sheep and cow manures and 1:3,1:0, or 3:1 from sheep, cow, or horse manure respectively. Anthesis was most delayed when plants were grown in 100\% castings from sheep manure.

\section{8}

\section{Properties of Soils in which Sticherus flabellatus Naturally Occurs}

Melanie C. Cras* and Robyn McConchie; Department of Crop Sciences, Faculty of Agriculture, University of Sydney, N.S.W. Australia, 2006

Sticherus flabellatus (R.Br.) St John, commonly known as Umbrella Fern, is a member of the Gleichenaceae family. Sticherus flabellatus is found on the N.S.W. coast and ranges, Qld, and eastern Victoriain Australia, as well as in New Zealand and New Caledonia. Fronds emerge from underground creeping rhizomes, forming large colonies in sheltered sites in moist gullies and creek banks in open forest. Propagation of the genus Sticherus has previously been relatively unsuccessful. The ferns are difficult to raise from spore and established specimens resent major disturbance to their roots, therefore making them hard to transplant. As a result of these difficulties the properties of the soil in which $S$. flabellatus grows naturally were investigated to determine the specific requirements for successful growth. Soil was collected from naturally occurring stands of $S$. flabellatus growing in a diverse range of sites within and on the periphery of the Sydney Basin. At each site a core of soil ( $12 \mathrm{~cm}$ diameter $\times 12 \mathrm{~cm}$ high) was taken at $\approx 0$, 25 , and $50 \mathrm{~m}$ along a line transect situated within a $S$. flabellatus stand, providing three replicates for each site. Physical and chemical properties were determined for each site. Particle size and consequently soil texture were determined using the hydrometer method. Electrical conductivity $(\mathrm{EC})$ and pH readings were taken in a 1 soil : 5 water solution. $\mathrm{pH}$ readings were also taken in a 1 soil : $5 \mathrm{CaCl}$ solution. Available $\mathrm{P}$ was analysed using the Bray (no. 2) method and organic carbon through colorimetric measurement after dichromate acid digestion. We found that $S$. flabellatus prefers growing in quite acidic soil with an average $\mathrm{pH}$ of 5.2 in a water solution and 4.0 in a $\mathrm{CaCl}$ solution. The $\mathrm{EC}$ readings were also significantly low with a mean reading of $37.0 \mu \mathrm{S} \cdot \mathrm{cm}^{-1}$. Organic carbon was measured at a mean of $2.4 \%$ and available $P$ at $4.1 \mathrm{mg} \cdot \mathrm{kg}^{-1}$ of soil. Using the International Soil Texture Triangle the soil in which $S$. flabellatus is found growing can be classified as sandy. The average sand content was $87.6 \%$, clay $6.8 \%$ and silt $5.5 \%$. These results show that $S$. flabellatus grows naturally in highly acidic, nutrient poor sandy soils that contain only minimal amounts of organic carbon and phosphorus. Therefore this needs to be taken in consideration when trying to successfully propagate the fern.

\section{ORAL SESSION 4 (Abstr. 419-426) Extension: Technology Transfer}

419

Knowledge, Attitudes, and Perceptions of Journalists for Newspapers in Metropolitan Markets in the United States Regarding Food Biotechnology

Tom Andrew Vestal* and Gary E. Briers, Texas A\&M University/Texas Agricultural Experiment Station/Texas Agricultural Extension Service, Mail Stop 2116, College Station, TX 77843

This study enhances knowledge of and information for food systems educators and industry about multiplying their efforts- enlisting collaboration of journalists and the social institution of mass media - in educating consumers about food biotechnology. The focus of this study (diffusion of innovations of food biotechnology) may change behaviors of researchers, agricultural educators, and those in the food biotechnology industry. The researchers investigated journalists' knowledge about, attitudes toward, and perceptions of food biotechnology. Eghty-eight journalists practicing at the nation's largest newspapers and representing "beats" of business, environment, agribusiness, features, food, health/ medical, and science/technology provided data for the study. A researcherdeveloped instrument measured journalists' knowledge, journalists' attitudes (acceptance of genetically modified organisms, acceptance of food biotech practices, effects of biotechnology, level of importance of research, faith in sources, level of importance placed on investigative reporting style, and fear of using food biotechnology), and journalists' perceptions regarding acceptance of food biotechnology as a farm practice. Major findings were journalists' knowledge was low (mean $30.2 \%$ ), most journalists considered genetic modification of plants as "acceptable," journalists had greatest faith in "university scientists" and "health professionals" as sources of biotechnology information, journalists do further investigation and interpretation of information given by sources based on their faith in the source, journalists believed that farmers would accept food biotechnology more rapidly than consumers, journalists with higher perceived scientific knowledge had greater acceptance of genetically modified organisms, journalists with more knowledge about biotechnology saw fewer obstacles to acceptance of food biotechnology; and "Writers" rather than "Editors/Managers" accepted more readily genetically modified organisms, had greater faith in sources, had less fear of using food biotechnology, and perceived a more rapid rate of acceptance of food biotechnology as a farm practice.

\section{0}

Integrating Extension Field Faculty Into Academic Homes: The Oregon State University Experience

J.L. Olsen* and C.D. Boyer; Oregon State University, Dept. of Horticulture, 4017 Ag. \& Life Sci., Corvallis, OR 97331-7304

In 1993, then OSU President John Byrne declared that: "All Extension Service faculty, county agents as well as specialists, will be assigned academic colleges, and will have an academic appointment in the appropriate college." The selection of the academic home would involve a mutual agreement between the individual and the department and would take into consideration the faculty member's academic training, experience, and work assignment. The implementation of this decision was completed by July 1995. In the College of Agricultural Sciences, this assignment of faculty to academic homes was accommodated by adding county agents to the faculty of existing departments. The Dept. of Horticulture faculty numbers nearly doubled, with an increase from 34 to 58 . The department head is now very involved in the annual review and salary administration of extension field faculty. Campus-based faculty are now involved in all of the hiring, promotion, and tenure decisions for extension field faculty and vice versa. Field faculty participate in departmental decision making. The change in the number and diversity of faculty in the department is a unique effort to unify programmatic focus for extension, research, and teaching at OSU. As a work in progress, many issues are being addressed including full faculty participation in the decisionmaking process, communication, evaluation of scholarship, and building departmental community. Successes, pitfalls, and challenges ahead will be discussed and illustrated. 
421

\section{Commonalities of Australian Public Extension Programs}

Mike Murray*; Farm Advisor \& County Director, University of California Cooperative Extension, P. O. Box 180, Colusa, Ca. 95932

A 1995/96 sabbatical leave in Australia was conducted to elucidate trends in public extension programs related to technology transfer or information delivery. Interviews with imore than 500 extension providors and users in seven states or territories were conducted. Based on these discussions, 12 commonalities or recurring themes were identified. These were the delivery of public extension programs through State Departments of Agriculture that also have regulatory responsibilities; decreased public funding for extension programs; clear separations between applied research and extension functions; adoption of purchaser/ provider funding models; poor communication or collaboration between extension and universities; an emphasis on group facilitation programming; difficulties related to extension staff recruitment or retention; diminished clientele support for public extension programs; an emphasis on the sociological aspects of agricultural enterprises; the development of audio-visual educational materials; a movement to assist inefficient producers exit agriculture and; trends toward the privatization of, or cost recovery for, public extension programs.

\section{2}

\section{Digital Video Images and Their Use in Extension Programs}

Charles Marr*; Horticulture Division, Kansas State Univeristy, Manhattan, KS 66506

Digital images are becoming an essential part of computer "slide" presentations, identification of plants and problems from a distant location, and adding visual elements to Web pages. The use of digital video images allows capturing of single frames for individual or sequence photographs as well as "mass" storage of digital images. There are also some uses of short "video clips" to be included in slide or Web presentations. A discussion of digital image quality and demonstration of equipment used will be included in the presentation.

\section{3}

\section{hortIPM: An Interactive Integrated Pest Management} Program

Don C. Wilkerson, Dan R. Lineberger, and Priscilla J. Files*; Department of Horticultural Sciences, Texas A\&M University, College Station, TX 77801

In response to the goals set forth in Target 2000 , a long-range environmental plan for the Texas/Floral Industry developed by the TAMU Nursery/Floral Management Team in cooperation with the Texas Association of Nurserymen (TAN), an interactive, World Wide Web-based integrated pest management program (hortIPM) has been developed for commercial nursery and greenhouse growers. The objective of Target 2000 is to assist growers in initiation of innovative cultural and structural practices, which will result in the following changes by the year 2000: 1) reduce water consumption to 1990 levels; 2) reduce current fertilizer and pesticide usage by $50 \%$; 3) lower current energy consumption by $25 \%$; 4) reduce current solid wastes from agricultural plastics by $75 \%$;5) develop applications for municipal wastes and composted materials for nursery and floral crop production. More so than in any other cropping system, ornamental stock producers apply pesticides on a calendar basis regardless of pest damage to prevent cosmetic injury to their crops, thus reducing their marketability. As justification for this misuse of insecticides, growers cite the extraordinary low damage thresholds associated with their crops. Nursery and floral crops producers that have better access to educational resources and recommendations may be more inclined to follow biologically sound pest management principles. HortIPM is designed as a tool to facilitate access to pest management information and enhance IPM programs already in place. Currently, hortIPM is in the developmental phase, on the cusp of release to a number of sites for preliminary evaluation.

\section{4}

\section{Use of GPS in Golf Course Planning}

Derald A. Harp*; Dept. of Horticultural Sciences, Texas A\&M University, College Station, Texas 77843

A major problem in golf course construction is trying to optimize the use of existing vegetation, especially trees. In North Central Texas, this is made more difficult by the predominance of post oak (Quercus stellata), a tree that declines severely when cultural conditions are modified. The purpose of this project was to create a map using GPS technology of the existing trees, before final planning and construction of the golf course. In addition to the map, a database was created which would be used for future maintenance and management decisions. The GPS equipment consisted of a Trimble PRO-XRS GPS receiver and Trimble TDC-1 data logger and a Laser Atlanta laser rangefinder. Information collected for the database included tree number, latitude, longitude, number, identification, caliper, estimated height, and quality. Quality ratings were defined as 1) specimen, 2) good, 3) fair, 4) poor, 5) unacceptable. Tree numbers were placed on each tree rated above unacceptable, using metal tree tags. Height estimates were made using the vertical offset feature of the GPS equipment. Base maps were created using Pathfinder Office. Hard copy maps were printed, and digital copies were saved in raw and.dxf format for importation into AutoCAD. This map was combined with existing course plans and adjustments were made to save as many specimen trees as possible. Raw information was also imported into a Microsoft Access 97 database. This project created a database and maps that will provide important information in the future, and the development of the course with minimal loss of specimen trees.

\section{5}

Use of Geographic Information System (GIS) to Document Plant Populations for Germplasm Collections

Sandra A. Balch", Cynthia B. McKenney, and Dick L. Auld; Dept. of Plant and Soil Science, Texas Tech Univ., Lubbock, TX 79409-2122

Geographically referenced information is an important aspect in the collection of wild plant species. It provides detailed information about the collection site as well as a method of relocating plant populations. In one project, native plants were collected and analyzed for the presence of gamma-linolenic acid, a valuable fatty acid used in medicinal products. In a second project, native wildflowers were collected and evaluated for potential use as drought-tolerant ornamental landscape plants. All native plants were initially tagged in the spring while in bloom. Each collection site was revisited later for seed collection. Due to a lack of landmarks in the collection area, a GeoExplorer Global Positioning System (GPS) unit was used to capture coordinate data of latitude, longitude, and altitude. This was added to the passport file of each collection site. Differential correction was used to increase accuracy of GPS data to within a range of $10 \mathrm{~m}$. ARC/INFO software was used to assemble, store, and display collection data in map form. This method has been used to document over 300 accessions and identify areas with a high frequency of plants possessing desired characteristics.

\section{6}

\section{Modeling a Flood-Freeze Situation of a Cranberry Bog using} Finite Element Analysis

James R. Altwies $I^{*}$, Beth Ann Workmaster, Joy E. Altwies, Jiwan Palta, and Teryl

R. Roper, Dept. of Horticulture, Univ. of Wisconsin-Madison, Madison, WI 53706

It is commonplace in Wisconsin for cranberry growers to flood their beds to form thick ice during winter to protect the uprights from dangerously low winter air temperatures. However, the specifics of ice thickness and zone temperature within and below the ice vs. surface air temperature have not been studied. We have developed several model s using finite element analysis, a process by which a complex system is divided into finite segments and analyzed individually. All pieces are then recombined into the complete system so a comprehensive picture of the activity of the freezing cranberry bed may be visualized. It was determined that cold surface air temperatures of $-25^{\circ} \mathrm{C}$ and thin ice of $15 \mathrm{~cm}$, soil and gap air temperatures do not drop lower then $-5^{\circ} \mathrm{C}$, which is congruent with data collected from the field. Models on sand beds and peat beds did not show enough difference to be of concern. Temperatures within the ice, where the uprights would be encased, reached $-15^{\circ} \mathrm{C}$ under the cold air regime, which has been proven to be well within the survival range of the dormant buds. 
38 ORAL SESSION 5 (Abstr. 427-431) Vegetable Crops: Crop Production

\section{7}

\section{Factors Determining Consumer Preferences for Colored Bell} Pepper

Chris Frank, Eric Simonne ${ }^{*}$, Robert Nelson, Amarat Simonne, and Bridget Behe; Dept. of Horticulture, 101 Funchess Hall, Auburn University, AL 36849-5408

Most bell peppers produced and consumed in the United States are green in color. However, red, yellow, orange, brown, white, black, and purple bell pepper are also available. While bell pepper consumption has been increasing in the past 10 years, limited information is available on how color, retail price, and vitamin C influence consumer behavior. A conjoint analysis of 436 consumer responses showed that color $(75 \%)$ and retail price $(23 \%)$ were more important than vitamin C (3\%) in shaping consumer purchase decision. Six consumer segments were identified. Segments II to V preferred green bell pepper, while segments I and VI favored the orange and brown color, respectively. Demographic variables were not good predictors of segment membership. However, previous purchases of bell pepper significantly affected the probability of membership in at least one segment. These results suggest that while green is the preferred color, a market exists for orange, red, and yellow peppers. Results on price sensitivity suggest that profits at the retail level are likely to increase by increasing the price of green peppers, and decresing that of the colored ones.

\section{8}

\section{In Search of the Kentucky Tomato}

Brent Rowel ${ }^{*}$, Terry Jones, John Snyder, and William Nesmith; Department of Horticulture and Landscape Architecture, Department of Plant Pathology, N-318 Ag. Science North, University of Kentucky, Lexington, KY 40546-0091

We began trials of vine-ripened, staked tomato cultivars in 1998 to identify a variety suitable for marketing as a premium "Kentucky Tomato". In conversations with marketing specialists at the Kentucky Dept. of Agriculture and merchandising managers at the Kroger Company's regional distribution center, we identified essential qualities of our ideal Kentucky tomato. A carefully selected group of 16 varieties was evaluated at two locations for yields, appearance, quality, disease tolerance, and taste. New varieties were compared with commercial standards like 'Mountain Spring'. Yields of different sizes and grades of marketable fruit were multiplied by appropriate real-market prices for a given harvest date and summarized in a single income-per-acre variable for each variety. Some of the highest yielding varieties in eastern Kentucky ('Fabulous' 'Sunbeam') appeared to have some tolerance to early blight; other varieties in this highest-yielding group included 'Emperador', 'Enterprise', 'Sunleaper', and 'Sunbrite'. All of these had fruit quality we considered acceptable for commercial markets with the exception of 'Sunbrite'. 'Fabulous', 'Emperador', 'Sunleaper', 'SunGem', and 'Sunpride' were the highest yielding varieties in central Kentucky. 'Sunleaper' and 'Sunpride' appeared somewhat tolerant to tomato mosaic virus (ToMV), which occurred at this location. Preliminary taste tests identified six varieties that were evaluated further by consumers at a local farmers' market. 'Mountain Fresh' and 'Floralina' were considered the best tasting varieties overall. The search continues in 1999.

\section{9}

\section{Production of Fresh Baby Corn}

C.A. Miles ${ }^{*}$; Washington State University Cooperative Extension, 360 NW North St., Chehalis, WA 98532

Fresh baby corn is an ideal niche market crop. It is easy to produce and is growing in popularity in the U.S. In 1997 and 1998, we tested 10 corn varieties to determine suitability for fresh baby-corn production in western Washington. By harvesting ears 1 to 3 days after silk emergence, baby corn can be produced from many common sweet corn varieties, including 'Kandy King', 'Bodacious', 'Tendertreat', and 'Custer'. Ear quality characteristics such as length, width, and kernel size and appearance of these common sweet corn varieties were as good as for the variety Baby Corn, a specialty variety produced exclusively for baby corn. The corn variety GH2283, produced in the U.S. for sale of seed to Asia for baby-corn production, produced the best-quality baby corn ears in our trial. Using an in-row spacing of 2 inches, ears of baby corn can be harvested for 4 to 6 weeks, depending on variety, from a single planting. Market criteriafor baby corn are 2 to 4 inches long and $1 / 3$ to $2 / 3$ inch in diameter at the butt end. Delaying harvest of sweet corn varieties for 3 days resulted in ears that were too large for baby corn. Field corn varieties in this trial required close monitoring to meet size criteria and delaying harvest 1 to 2 days resulted in ears that were too large. Harvest of baby corn is all by hand and height of the ear on the plant significantly affects ease of harvest, where dwarf varieties are the least easy to harvest.

\section{0}

\section{Spacing and Subsoiling Affect Yield and Quality of Gobo (Japanese Burdock)}

D.C. Sanders ${ }^{\star 1}$ and W.R. Jester ${ }^{2} ;{ }^{1}$ Dept. of Horticultural Science, North Carolina State University, Raleigh, NC 27695; North Carolina Cooperative Extension Service, Lenoir County, Kinston, NC 28501

During 2 years, 'Takinogawa Long' gobo was seeded with two, three, or four rows per $1.5-\mathrm{m}$ bed at in row spacings of $7.5,15,21.5$, and $30 \mathrm{~cm}$. Total and marketable yield increased with in-row spacing and marketable yield increased with row number, with greatest yields occurring at $15 \mathrm{~cm}$ regardless of row number. Average root weight and yield of forked roots were not affected by row number but increased with in row spacing. Similarly, percent forked roots decreased with more rows per bed. The $15-\mathrm{cm}$ in-row spacing had the greatest yield, but also the greatest weight of culled roots, but none of the populations affected percentage culls. In another study, in-row subsoiling (SS) and in-row banded phosphorus $(\mathrm{P})$ were evaluated. Marketable yield was increased by both SS and $\mathrm{P}$ but did not interact. P increased average root weight. Neither SS or P affected forked root yield or cull root yield, but SS decreased forked roots and increased cull production.

\section{1}

\section{Fruit Sugar and Yield of Three Muskmelon as Influenced by} Spacing and Genotype

F. Kultur, H.C. Harrison* , and J.E. Staub; Univerisity of Wisconsin-Madison, Madison, WI 53706

Muskmelon (Cucumis melo L.) genotypes, Birdsnest 1 ['Qalya' (BN1)] Birdsnest 2 (BN2), and 'Mission' (V) were used to determine the effects of plant architecture and spacing on fruit sugar concentration and yield. The BN1 and BN2 genotypes possessed a highly branched growth habit specific to birdsnest melon types but not characteristic of standard indeterminate vining types (e.g., 'Mission'). Experiments were conducted at the Hancock (sandy soil, $<1 \%$ organic matter) and Arlington (heavy, praire loam soil, $>4 \% \mathrm{OM}$ ) Experimental Farms in Wisconsin. Plant response to two within-row spacings [35 $\mathrm{cm}(72,600$ plants/ ha) and $70 \mathrm{~cm}$ (36,300 plants/ha)] in rows on 210-cm row centers was examined. Genotypes were grown in a randomized complete-block design with four replications at each location and evaluated for primary lateral branch number, fruit number per plant, fruit number per hectare, average fruit weight, yield (g) per plant, yield (MT) per hectare, and fruit sugar concentration. All genotypes produced higher yield, fruit number and sugar concentration on the mineral soil at Arlington compared to the sands at Hancock. The main effect of genotypes was significant for all traits examined. BN1 and V genotypes had greater yield (gram per plant, yield per hectare, and average fruit weight) as well as higher fruit quality (fruit sugar concentration) than the BN2 genotype. Spacing affected all traits examined except primary branch number and fruit sugar concentration. As withinrow spacing increased from 35 to $70 \mathrm{~cm}$, fruit number per plant, yield per plant and average fruit weight increased. However, yield (MT) per hectare and fruit number per hectare decreased. Fertility was adjusted according to soil tests for the two different soil types at the two farm locations.

\section{ORAL SESSION 6 (Abstr. 432-437) Undergraduate Education}

432

Concept Mapping: Helping Students Make Connections in Landscape Design History

Ann Marie VanDerZanden*; Oregon State University, Corvallis, OR 97331-7304

The Landscape Design Theory class at Oregon State Univ. is composed of 
undergraduate students from a variety of majors including, horticulture, housing and interior design, business, criminal justice, and art. This diversity of majors means there is a wide range of student knowledge about the history of landscape design and creates a unique teaching opportunity. To capitalize on this diversity and to encourage student participation, concept or knowledge maps were used at the beginning of the term before the material being covered in class lectures. Students were divided into groups of three and asked to develop a group concept map. They were given major societies or events that occurred in history from about $2000 \mathrm{BC}$ (ancient Egypt) through the early 20th century. Additionally each group was given a list of 20 landscape design elements or features. Initially each group developed a historical timeline. After the timeline was complete they linked the different landscape design elements or features with a historical era thereby creating a map of their understanding of landscape design history. After the landscape design history segment of the class was completed the small groups reconvened and evaluated their initial concept map in light of the recently completed lectures. Each group discussed their original map, what associations were correct, and how they would do it differently with their newfound understanding of landscape design history. A class discussion followed regarding initial perceptions and benefits of this learning activity. This teaching strategy could easily be adapted to a number of other horticulture topics.

\section{3}

Offering a Horticultural Laboratory Experience at a Distance C.B. McKenney*, R.E. Durham, and E.B. Peffley, Department of Plant and Soil Science, Texas Tech University, Lubbock, TX 79409-2122

The horticulture faculty at Texas Tech Univ. has developed an introductory horticulture laboratory course offered asynchronously through several media. A print version has been developed as a traditional correspondence course. Students can also choose to access the course over the World Wide Web with laboratory instruction provided from an accompanying CD-ROM. The course is based on an introductory horticulture textbook and is supplemented by additional information. Students conduct the laboratory exercises at a location of their choice and return photographs or video tapes of their results along with a formal lab report. Self-help exercises, worksheets, and proctored exams are submitted by correspondence or electronically via the World Wide Web. The most challenging aspect of this project was the development of laboratory exercises that ensured adequate experiential learning. This was accomplished by using easily accessible materials for laboratories that would allow students to apply the scientific method. ACD-ROM version of the lab includes compressed video segments used to demonstrate laboratory techniques. Details of these laboratory components and samples of student work will be presented.

434

Using Distance Technology: Inter-institutional Development and Delivery of a Course in Plant Nutrition

Kim Williams ${ }^{1}$, Elen T. Paparozz*2, and Jerry Maranville;

${ }^{1}$ Department of Horticulture, Forestry and Recreation Resources, Kansas State University, Manhattan, KS 66506; Departments of ${ }^{2}$ Horticulture and ${ }^{3}$ Agronomy, University of Nebraska, Lincoln, NE 68583

As universities are required to "right-size," faculty resources of time and expertise are strained as the institution must cater to undergraduate students while providing a complete graduate curriculum. Thus, many institutions are offering more team taught courses. For a new upper-level undergraduate and lower-level graduate course offering in Plant Nutrition and Nutrient Management, the team consists of faculty from two institutions who each bring different expertise into the classroom. The course utilized weekly chat room discussions to bring students into contact with experts from around the United States and the world. Twoway compressed video was used to allow for synchronous lecture delivery and discussion across sites. A Web site was created to facilitate student interaction and provide chat room access. Multiple student evaluations were conducted to separate learning objectives with the effectiveness of using technology. A flowchart will be presented which details the steps and problems/accomplishments encountered in successfully delivering this course via distance technologies, including: funding procurement, determining technological compatibility across institutions, delineation of course content, Web page development, and course evaluations.
435

\section{Addition of Service Learning in Food Crops Curriculum} Revision

Harrison Hughes*; Department of Horticulture \& Landscape Architecture, Colorado State University, Fort Collins, CO 80523

The food crop concentration in the horticulture major was revised in response to discussions with students, faculty, and county agents to emphasis more service learning. A requirement for an internship or practicum was added. The practicum entails the design, maintenance, and data collection of the vegetable and small fruit display gardens. Emphasis will be on sustainable production and on collection of information for use in extension fact sheets for the citizens of Colorado. Other changes include the modularization of the commodity courses to provide greater flexibility and the addition of a capstone course. The capstone course will involve greater interaction with industry in the state and has a requirement for the development of both an enterprise budget as well as a production plan for a commercial operation.

\section{6}

\section{De Novo Synthesis of a Horticulture Teaching Program}

Milton E. Tignor, Jr." and Elizabeth M. Lamb; Horticultural Sciences Department. Indian River Research and Education Center, Univ. of Florida. Fort Pierce, FL 35945-3138.

The Univ. of Florida has had off-campus degree programs for over a decade. In 1998, a new program in a major agricultural region of the state developed under unique circumstances. Community driven support, leadership from local politicians, and guidance from academic administrators resulted in the legislative funding of a new undergraduate teaching program in south Florida. The program offers upper-division courses leading to Bachelor of Science degrees in horticultural science and food and resource economics. Another unique aspect was the partnership formed with local universities necessary to offer the degrees. Locally, Indian River Community College provides lower-division courses and Florida Atlantic Univ. offers four upper-division courses to complete the course offerings for the degrees. Funding was allocated for eight new faculty members with 70\% teaching appointments, four support staff, and anew \$3.7 million teaching complex. In today's academic climate, having eight new faculty members at one time is a rare occurrence that allowed for creative growth on the part of the new teaching program. What was successful and unsuccessful concerning recruitment, advertising, purchasing, advising, collaborative efforts with local colleges, and administration will be discussed. In addition, demographics on the student body will be presented.

\section{7}

\section{Changing Demographics of Nontraditional Students in an Off-campus Horticulture Degree Program}

George E. Fitzpatrick* and Kimberly A. Klock-Moore; University of Florida, Fort Lauderdale Center, 3205 College Ave., Fort Lauderdale, FL 33314

Over the 10-year period of 1987-1997, the demographics of the student population enrolled in the University of Florida off-campus BS degree in horticulture program at Fort Lauderdale have changed. Average student age has increased from 35.5 years to 38.1 years. Age range has increased from 22 to 54 years to 21 to 75 years. Age distribution changes have been most notable. In 1987 , the age of the student population was normally distributed, whereas by 1997 the distribution had become bimodal, with one mode in the age group 26 to 30 and the other mode in the 41 to 45 age group. Estimated median one-way distance traveled to attend classes has not changed significantly, from 13.2 miles (range 3.9-89.8 miles) in 1987 to 14.2 miles (range 1.0-59.8 miles) in 1997. 
53 ORAL SESSION 7 (Abstr. 438-444) Cross-commodity: Postharvest Physiology/ Food Science/Flavor/Nutrition/Quality

\section{8}

\section{Optimization of a SPME Method for Flavor Characterization in Fresh-cut Cantaloupe}

John C. Beaulieu*, Allison K. Rausch, and Elaine T. Champagne; United States Department of Agriculture, Agricultural Research Service, Southern Regional Research Center, 1100 Robert E. Lee Blvd. New Orleans, LA 70124

Fresh-cut melons in many consumer-ready packages are notorious for "wetting" and accumulation of standing juices. These conditions likely create undesirable flavor and aroma changes. We initiated a study to investigate flavor changes in stored fresh-cut cantaloupe. One objective was to optimize solid phase microextraction (SPME) to evaluate organoleptic compounds. Static head-space SPMEanalyses were performed on fresh-cut cantal oupe cubes $(\approx 2.5 \mathrm{~mm}, 5 \mathrm{~mm}$, or $2.5 \mathrm{~cm})$, expressed juice, and homogenized slurries. SPME fiber $(100 \mu \mathrm{m}$ PDMS vs. 75 um Carboxen/PDMS) exposure time (5, 7.5, 10, 12.5, 15, 17.5, 20 $\min$ ) was evaluated at $40^{\circ} \mathrm{C}$ with various head-space : product ratios, plus or minus $\mathrm{NaCl}$ to produce typical chromatograms. Fibers were desorbed in an HP5890 GC with a DB-624 or DB- 5 column for 45 -min runs and an HP6890 GC (DB-5) equipped with a $5973 \mathrm{MS}$ detector for 35 -min runs. Albeit qualitative, the best chromatograms were obtained with 7-ml slurries, stirred with $\mathrm{NaCl}$, exposed to a 10 0 $\mu \mathrm{m}$ PDMS SPME fiber for $12.5 \mathrm{~min}$. The $100 \mu \mathrm{m}$ PDMS fiber produced better chromatograms considering the fact that many important flavor volatiles are low-molecular-weight polar esters and alcohols. These conditions were subsequently used to analyze numerous fresh-cut cantaloupe samples stored various times ( 0 to 9 days). Over 100 peaks were identified, many of which changed through storage and some are suspected as probable agents responsible for undesirable flavor changes. Our analyses are progressing in an attempt to authenticate compounds associated with flavor-related changes in numerous fresh-cut cantaloupe varieties from various growing regions.

\section{9}

\section{Quantification of the Lachrymatory Factor for Onion Flavor} Assessment is Cultivar-dependent

David E. Kopsel/ ${ }^{* 1}$, William M. Randle ${ }^{1}$; and Norman E. Schmidt ; ${ }^{1}$ Department of Horticulture, University of Georgia, Athens, GA 30602; ' 2 Department of Chemistry, Georgia Southern University, Statesboro, GA 30460

The tearing and burning sensations associated with raw onion consumption are caused by (Z,E)-propanethial S- oxide, the lachrymatory factor (LF). The LF is produced from the hydrolysis of S-1-propenyl-L-cysteine S-oxide (PREN), the dominant flavor compound in onions. Current methodology for LF quantification was optimized for Granex-type onions using a2-min incubation time to allow for maximum formation. In this study, data were taken on PREN hydrolysis of 'Dehydrator \#3' and 'Granex 33' at harvest and during storage and were compared to LF formation. 'Dehydrator \#3' PREN hydrolysis was $98 \%$ complete $5 \mathrm{~s}$ after cellular disruption at each sampling date. However, using the 2-min incubation procedure, only $10.25 \mu \mathrm{mol}$ of LF was recovered from the hydrolysis of $30.11 \mu \mathrm{mol}$ of PREN at harvest, thereby underestimating LF for this cultivar. Percent PREN hydrolysis for 'Granex 33' was lower than 'Dehydrator \#3' during the enzymatic reaction at each sampling date, suggesting slower PREN hydrolysis activity. At harvest, $6.96 \mu \mathrm{mol}$ of LF were recovered from $12.54 \mu \mathrm{mol}$ of PREN hydrolyzed. After 2 storage months, however, micromol of LF were equal to micromol of PREN. LF quantification is currently being considered by the onion industry as a direct measurement of gross onion pungency. This data suggests that more optimization of LF quantification is needed before it can be applied to a broad range of cultivar types.

\section{0}

\section{A Comparative Study on Flavor and Nutritional Attributes of 'BetaSweet' Maroon Carrot (Daucus carota L.)}

Carlos A. Lazcano*, L.M. Pike, and K.S. Yoo; Vegetable Improvement Center, Texas A\&M University, 1500 Research Parkway, Suite 120,College Station, TX 77843-2119 A new designer carrot, 'BetaSweet', with high levels of anthocyanin, beta- carotene, and crispy texture was developed by the Vegetable Improvement Center at Texas A\&M Univ. The new carrot contained low levels of low-volatile terpenoids, responsible for the harsh flavor in carrots and high levels of reducing sugars. Carotenoid content increased with carrot maturity and stabilize at 120 days after sowing for orange and maroon genotypes; however, the maroon genotype was 35\% higher than the orange cultivar. Anthocyanin, a cancer preventive compound and not detected in ordinary orange carrots, is present in 'BetaSweet' maroon carrot with $89.8 \mathrm{mg} \cdot 100 \mathrm{~g}^{-1}$ of fresh weight. High percentage of soluble solids and succulence in the maroon cultivar seemed to contribute to the favored sweetness perception by consumers. A consumer taste panel showed a significant difference between orange and maroon genotype for sweetness, texture, and overall carrot flavor.

\section{1}

\section{Best Grapefruit Harvest Time for Potential Health Benefit of Pectin}

Y. Liu' ${ }^{1}$, H. Ahmad ${ }^{2}$, D.T. Gardiner ${ }^{3}$, and B.S. Pati ${ }^{* 1} ;{ }^{1}$ Texas A\&M UniversityKingsville Citrus Center, P.O. Box 1150, TX 78599; '2Department of Chemistry, The University of Texas Pan American, 1201 West University Drive, Edinburg, TX 78539-2999; ${ }^{3}$ Department of Agronomy and resource sciences, Texas A\&M University-Kingsville, TX 78363

Pectin is a class of complex polysaccharides that function as hydrating agents and cementing materials for the cellulose network. Pectin has various health benefits, such as decreasing serum cholesterol levels, alleviating diabetes mellitus, and preventing cancer. It has been reported that the cancer prevention effect is closely related to the structure of pectin (galactose-rich, molecular weight $<10,000$, and methylation degree $50 \%$ to $70 \%$ ). This study was conducted to investigate the variation of grapefruit pectin content due to harvest time. 'Rio Red' grapefruit on sour orange rootstock grown at Texas A\&M Univ.-Kingsville Citrus Center were harvested every 2 months and analyzed for pectin content, galacturonic acid concentration, methylation degree, and neutral sugar composition. Results showed that lamella contains more pectin than flavedo and albedo. In the lamella, the edible section, the uronic acid content ranged from $85 \%$ to $90 \%$ from August to April the following year. Methylation degree increased from August (31.89\%) to April (46.99\%). Total neutral sugar content of lamella pectin decreased from 110.54 to $61.77 \% \mathrm{mg} \cdot \mathrm{g}^{-1}$. Galactose, arabinose, and rhamnose are the major sugar contents of pectin (85\%), and glucose content increased with the season from 3.14 to $13.34 \mathrm{mg} \cdot \mathrm{g}^{-1}$. Molecular weight of pectin was also determined.

\section{2}

Enhancing Citrus Nutraceuticals through Variable Nutrient Rates Bhimanagouda S. Pati ${ }^{* 1}$ and Ashok K. Alva2; ${ }^{2}$ Texas A\&M University-Kingsville Citrus Center, P.O. Box 1150, Wesalco, TX 78599; 2University of Florida, CREC, 700 Experiment Station Road, Lake Alfred, FL 33850

Accumulating epidemiological evidences indicate that citrus phytochemicals have prevented chronic diseases such cancer and heart diseases. To enhance nutraceutical levels, field experiments were conducted using 'Ruby Red' grapefruit on Carrizo citrange rootstock to evaluate the effects of variable fertilizer rates on nutraceutical contents. The trees received annual nitrogen rates from 0 to 280 $\mathrm{kg} \cdot \mathrm{ha}^{-1}$ (using a $1 \mathrm{~N}: 0.25 \mathrm{P}: 1 \mathrm{~K}$ blend) under optimal irrigation schedule. Subsamples of fruit were analyzed for nutraceutical levels. HPLC analysis showed that naringin concentrations of the fruit collected from the trees treated with different levels of nitrogen differ significantly, and naringin levels decreased with increased nitrogen levels. Fruit from the control treatment had $1316 \mathrm{mg} \cdot \mathrm{mL}^{-1}$ of naringin compared to the fruit collected from $280 \mathrm{~kg} \mathrm{~N} /$ ha per year trees (1056 $\left.\mathrm{mg} \cdot \mathrm{mL}^{-1}\right)$. A similar trend was observed with tasteless flavonoid naringenin rutinoside (narirutin). Total vitamin C [ascorbic acid (AA) plus dehydroascorbic acid (DHAA)] content from the fruit collected decreased with the nitrogen levels increased. These results demonstrate that increased fertilizer rates have an influence on the nutraceutical levels; therefore, there is a potential for further investigations on fine tuning the preharvest production programs to improve the nutritional value of the fruit.

\section{3}

Postharvest Physiology and Quality Maintenance of Freshcut Pears

James R. Gorny and Adel A. Kader ; Dept. of Pomology, Univ. of California, Davis, CA 95616

The optimal 'Bartlett' pear ripeness stage for fresh-cut processing based on 
flesh firmness ranges between 44.5 and $58 \mathrm{~N}$ (10 and $13 \mathrm{lbf}$ ). Use of softer pears reduces postcutting life due to flesh browning. Firmer pears may have longer postcutting life but lack good flavor. Dipping pear slices in a mixture of $2 \%(\mathrm{w} / \mathrm{v})$ ascorbic acid $+1 \%(\mathrm{w} / \mathrm{v})$ calcium lactate $+0.5(\mathrm{w} / \mathrm{v})$ cysteine $(\mathrm{pH} 7)$ for $5 \mathrm{~min}$ at $20^{\circ} \mathrm{C}$ extended their shelf-life by inhibiting flesh softening and surface browning during storage at $0{ }^{\circ} \mathrm{C}$ for 10 days. After 3 days at $0^{\circ} \mathrm{C}$, ascorbic acid and cysteine residues dropped below detectable levels, while calcium content was double that of untreated slices. Preliminary sensory evaluation indicate no negative impact on flavor from this dip treatment. Exposure of intact pears to heat (35 or $\left.40^{\circ} \mathrm{C}\right)$ or controlled atmospheres $\left(0.25 \mathrm{kPaO}_{2}\right.$ and $/$ or $\left.40 \mathrm{kPa} \mathrm{CO}\right)$ for 24 or $48 \mathrm{~h}$ did not influence postcutting cut surface browning of pear slices. Storage of 'Bartlett' pears at $-1^{\circ} \mathrm{C}$ in $2 \mathrm{kPaO}_{2}$ (balance $\mathrm{N}_{2}$ ) resulted in longer postcutting life of the slices as compared to those made from air-stored pears at $-1{ }^{\circ} \mathrm{C}$. The longer the storage duration of whole pears, the shorter the shelf-life of their slices was. Fruit size did not affect the postcutting life of the pear slices, provided that they were treated with the ascorbic acid + calcium lactate + cysteine mixture. Untreated slices made from small pears exhibited surface browning faster than those made from large pears.

\section{4}

\section{Changes in Quality and Maturity of Late-season Peaches} (cvs. O'Henry and Nos 21) during Maturation and Ripening G.H. Reginato* and L.E. Luchsinger; University of Chile, Fac. Ciencias Agronomicas, Casilla 1004, Santiago, Chile

Our objectives were to characterize the quality and maturity changes of peach [Prunus persica (L.) Batsch.] fruit cvs. O'Henry and Nos 21 during maturation and ripening and to identify harvest maturity indices by relating nondestructive and destructive variables. After fruit set, 400 fruit of similar diameter and tree position were tagged to follow maturation and ripening on the tree. During commercial harvest, 48 fruit were ramdomly harvested every 4 to 6 days. Ethylene evolution rate (EER) at $20^{\circ} \mathrm{C}$, fresh weight, and peel ground and cover color ( $\mathrm{L}^{*}$, $a^{*}, b^{*}, C^{*}$ and Hue value) were measured to all 48 fruit. Flesh color, firmness at several fruit points, soluble solids (SS), pH, titratable acidity (TA), and SS/TA ratio were measured only to 24 fruit, and the rest were held for up to 7 days at $20^{\circ} \mathrm{C}$ as a ripening period to measure the same characteristics previously mentioned. Pearson correlation coefficients were determined between variables to explore possible harvest maturity indices. The most significant changes occurred in EER and ground color (a* value) for both varieties and fresh weight only for $\mathrm{cv}$. O'Henry. For 'O'Henry' peaches the highest correlation $(P<0.001)$ was obtained between EER-suture firmness $(r=-0.61)$. For cv. Nos 21 the highest correlation was between EER-shoulder firmness $(r=-0.69)$. It was also found that fruit softening occurred mainly in the fruit shoulder for both cultivars. Therefore, no harvest maturity indices could be established for these cultivars.

\section{ORAL SESSION 8 (Abstr. 445-450) Cross-commodity: Sustainable Agriculture}

\section{5}

\section{Solid Matrices for Supporting Plant Growth in Space}

Gary W. Stutte* and Greg Goins; Dynamac Corporation, Kennedy Space Center, FL 32899

In preparation for a spaceflight experiment to measure photosynthesis of wheat (PESTO), four solid media were evaluated for use in the rooting modules of the Biomass Production System (BPS), a new plant growth unit for microgravity. The media were commercial peat-vermiculite (PV) mixture, zeolite developed at Johnson Space (Z/JSC), commercial zeolite developed by Boulder Innovative Technologies (Z/BIT), and arcillite (AR) with slow-release fertilizer. Wheat (cv. USU Super Dwarf) was grown in the media at $1500 \mu \mathrm{mol} / \mathrm{mol} \mathrm{CO}_{2}, 350 \mu \mathrm{mol} \cdot \mathrm{m}^{-2} \cdot \mathrm{s}^{-1}$ PAR, $23^{\circ} \mathrm{C}$, and $75 \%$ relative humidity for 18 to 21 days. Water was delivered to the media through porous tubes imbedded in the media, and NDS pressures of -0.1 to $-0.5 \mathrm{kPa}$ were maintained with either a static or recirculating standpipe. Plant height, leaf area, and fresh mass were determined for each experiment. Results indicated that the AR and Z/BIT media resulted in larger and more uniform plants than Z/JSC or PV at the same NDS pressure. Additional experiments were conducted with AR to evaluate interactions between particle size and NDS pressure. At $\approx 14$ days after planting, there was a loss of NDS prime in $A R>2.0$ $\mathrm{mm}$ when the NDS pressure was less than $-0.3 \mathrm{kPa}$. This resulted in drying of the media and poor plant growth. There was excess water in the media, which resulted in reduced plant size, in AR $<1.0 \mathrm{~mm}$ at NDS pressures more than $-0.3 \mathrm{kPa}$.

\section{6}

Long-term Evaluation of Susceptibility of Selected Prairie Species to the Root Lesion Nematode Pratylenchus penetrans A.W. MCKeown ${ }^{* 1}$, J.W. Potter ${ }^{2}$, M. Gartshore ${ }^{3}$, and P. Carson ${ }^{3}$; University of Guelph, Box 587, Simcoe, Ontario, N3Y 4N5, ${ }^{2}$ Agriculture and Agri-Food Canada, Box 6000, Vineland Station Ontario, LOR2E0, ${ }^{3}$ Pterophylla, R.R. \# 1 Walsingham, Ontario, NOE 1X0, Canada

Because of the need to find plants that suppress root lesion nematodes for use in rotation or cover-crops, 16 native sand-prairie species were evaluated for host status for 6 years. Plants were grown on a Fox sand soil at a local prairie plant nursery. Soil cores were taken in the spring, summer, and fall and assayed for plant parasitic nematodes. Five species supported very low numbers (less than $100 / \mathrm{kg}$ soil) of root lesion nematodes. Brown-eyed Susan (Rudbeckia hirta) had no detectable nematodes for the duration. Switchgrass (Panicum virgatum L.) and Indiangrass (Sorghastrum nutans L., Nash) samples produced detectable nematodes on only two sampling dates over the 6 years and were statistically not different from brown-eyed Susan. Butterfly weed (Asclepias tuberosaL.) al so had very low detectable nematodes as did sand dropseed [Sporobolus cryptandrus (Torr.) Gray.]. New Jersey tea (Ceanothus americanus L.), little bluestem [Schizachyrium scoparium (Michx.) Nash], and big bluestem ( Andropogon gerardi Vitman) were poor hosts with $<200$ nematodes $/ \mathrm{kg}$ soil. Mountain mint (Pycnanthemum virginianum L), wild bergamont (Monarda fistulosa L), horsemint (Monarda punctata L), and dwarf blazing star (Liatris cylindracea L) all had root lesion populations over $3000 / \mathrm{kg}$ soil. Horsemint and wild bergamont plants died out, possibly as a result of nematode infestation. Root lesion nematodes have an extremely wide host range in current agronomic and horticultural crops, and weeds and are difficult to manage using nonchemical means. Indiangrass, switchgrass, big bluestem, and little bluestem have all been used agriculturally for pastures and consequently have potential as beneficial long-term rotation crops for nematode management and soil building.

\section{7}

Nutrient Removal by Five Ornamental Wetland Plant Species Grown in Treatment-production Wetland Biofilters

Thomas C. Holtt, Brian K. Maynard, and William A. Johnson; Department of Plant Sciences, Univ. of Rhode Island, Kingston, Rl 02881

We assessed the capacity for nutrient removal of ornamental water garden plants being grown in treatment-production wetland biofilters. Plant biomass, nutrient uptake, tissue nutrient content, and production potential were compared for five popular ornamental water garden plant species: Typha latifolia L., Iris pseudacorus L., Phalaris arundinacea L. 'Picta', Canna glauca L., and Colocasia esculenta (L.) Schott. Plants were grown in triplicate $0.3 \mathrm{~m}^{2} \times 0.3 \mathrm{~m}$, deep gravelbed mesocosms fed with 20N-20P-20K Peter's fertilizer (Scotts-Sierra Horticultural Products Co., Marysville, Ohio) reconstituted to $100 \mathrm{ppm} \mathrm{N}$. After 120 days, mean species total biomass ranged from 1.4 to $5.6 \mathrm{~kg} \cdot \mathrm{m}^{-2}$, while producing 105 to 206 divisions per square meter. Growth for Canna and Colocasia was greatest, while Typhaproduced the most divisions. Mean tissue $\mathrm{N}$ and $\mathrm{P}$ concentrations ranged from 18 to 29 and 2.1 to $3.0 \mathrm{mg} \cdot \mathrm{g}^{-1}$, respectively. Maximum plant accumulation of $144 \mathrm{~g} \mathrm{~N} / \mathrm{m}^{2}$ and $15.6 \mathrm{~g} \mathrm{P} / \mathrm{m}^{2}$ accounted for $70 \%$ of the $\mathrm{N}$ and $15 \%$ of the $P$ supplied by fertilizer. Mean removal of total $\mathrm{N}$ and $\mathrm{P}$ ranged from $42 \%$ to $90 \%$ and $18 \%$ to $58 \%$, respectively, and was positively correlated with plant biomass. Nutrient removal ability was ranked as Canna = Colocasia > Typha $>$ Iris $=$ Phalaris .

\section{8}

Soil Problems Affecting Date Palm Growth, Yield, and Fruit Quality in Coachella Valley

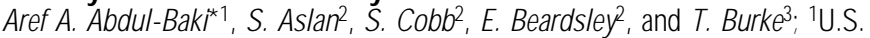
Dept. of Agriculture, BARC, Beltsville, MD 20705; ${ }^{2}$ U.S. Dept. of Agriculture, NARC, Indio Calif.; ${ }^{3}$ Oasis Date Gardens, Thermal, Calif.

A 3-year experiment was conducted to identify problems in Coachella Valley date palm (Phoenix dactylifera) orchards that limit vegetative growth, yield, and fruit quality. Major problems that were identified included soil compaction and 
stratification that restrict water permeation into the root zone, and low fertility as reflected by the low organic - matter content of the sandy soils. To eliminate the impact of these stresses on plant growth, yield, and fruit quality, a no-tillage alternative management system was introduced to replace the conventional practice of tillage that compacts the soil. No-till was coupled with the use of cover crops to enrich the soil with organic matter, fix $\mathrm{N}$, recycle nutrients, and improve water holding capacity of the sandy soil. In al ready established orchards, an additional treatment-slip plowing - was also implemented to loosen the soil at lower depths to facilitate water permeation. The positive effects of the alternative system on the soil, tree growth, yield, and fruit quality will be presented.

\section{9}

\section{Conservation Tillage Row Crop Production in California}

J.P. Mitchel/ ${ }^{* 1}$, W. T. Lanini ${ }^{1}$, S.R. Temple ${ }^{1}$, EV. Herrero ${ }^{1}$, EM. Miyao' ${ }^{1}$ P. Brostrom ${ }^{1}$, $R$. Morse $^{2}$, and F. Thomas ${ }^{3}$; University of California, Davis, CA 95616; ${ }^{2}$ Virginia Polytechnic Institute and State University, Blacksburg, VA 24061; ${ }^{3}$ Cerus Consulting

Conservation tillage (CT) row crop production is currently not widely adopted in California. Recently, however, interest in evaluating the potential of CT systems to reduce production costs and improve soil quality is growing in many areas in the state. In 1997 and 1998, we evaluated four cover crop mulches (rye/ vetch, triticale/vetch, Sava medic, and Sephi medic) in a CT-transplanted tomato system relative to the conventional winter fallow (CF) practice. In both years, yields were comparable to the CF under the tritical e/vetch and rye/vetch mulches. Earthworm populations after 2 years of CT production were increased 2- to 5 fold under mulches relative to the CF system. Soil carbon was increased by $16 \%$ and $6 \%$ after 2 years of CT production under the triticale/vetch and rye/vetch mulches, respectively. Weed suppression under the triticale/vetch and rye/vetch was comparable to the CF with herbicide system early in the season in both years but was maintained through harvest in only one season. Soil water storage (0-90 $\mathrm{cm}$ ) was similar at the beginning of the tomato season in triticale/vetch, rye/ vetch, and fallow plots but was higher under the mulches during much of the last 45 days of the 1998 season. Further refinement of CT practices in California's vegetable production regions is needed before wider adoption is likely.

\section{0}

Impacts of Alternative Cropping Systems on Soil Physical Properties, Crop Productivity and Quality, and Water Management in California's Sacramento Valley

J.P. Mitchel/ ${ }^{*}$, G. Colla, B.A. Joyce, L.M. Huyck, W.W. Wallender, S.R. Temple, P.N. Brostrom, EM. Miyao, and D. Poudel; University of California, Davis, CA 95616

The Sustainable Agriculture Farming Systems (SAFS) Project was established in 1988 to study the transition from conventional to low-input and organic farm management in California's Sacramento Valley. We evaluated the effects of these alternative farming systems on soil compaction, water-holding capacity, infiltration, and water storage in relation to tomato yield and fruit quality within the SAFS cropping systems comparison 10 years after it had been established. Soil bulk density $(0-15,15-30,30-45$, and $45-60 \mathrm{~cm})$ was not significantly different among the farming systems. In situ water-holding capacity at 24,48 and $72 \mathrm{~h}$ after water application was significantly higher in the organic system at all times and depths except $45-60 \mathrm{~cm}$. Cumulative water infiltration after $3 \mathrm{~h}$ in the organic and low-input cover crop-based plots was more than twice that of the conventional system. The more rapid infiltration in the low-input and organic systems resulted in increased total irrigation needs, more water stored in the soil profile throughout the 30 days before harvest, and lower fruit soluble solids and titratable acidity in these systems relative to the conventional system. Yields were not significantly different in the organic, low-input, and conventional systems during either 1997 or 1998.

\section{ORAL SESSION 9 (Abstr. 451-456) Vegetable Crops: Crop Production}

\section{1}

\section{Evaluating Skin-set of the Sweetpotato}

Lewis W. Jett ; Louisiana State University Sweet Potato Research Station, P. O. Box 120, Chase, LA 71324

Skinning of sweetpotatoes [ Ipomoea batatas (L.) Lam] can reduce marketable yield and quality. The 'Beauregard' sweetpotato, despite its consistent high yield and quality, is very susceptible to skinning injury during harvest. A research project was initiated to investigate chemical and mechanical methods to improve skinset of 'Beauregard' sweetpotato. Approximately 14 days before harvest, Desicate II and Enquik (dihydrogen tetraxosulfate) were applied to the sweetpotato vines as a broadcast spray. Mechanical methods evaluated included mowing with a flail-type mower or pulling (vine detachment) 7 days before harvest. Skin-set was measured using a Halderson periderm shear tester fitted to a torquometer. The Enquik + Desicate II treatment significantly desiccated the vines relative to application of Desicate II alone. The skin set testing device was sensitive enough to detect differences between treatments. The highest skin-set reading was obtained from the pulled vine treatment. Marketable yield was not affected by application of any chemical or mechanical treatment. Curing of skinned sweetpotatoes(4 days; $30{ }^{\circ} \mathrm{C} ; 90 \%$ relative humidity) significantly reduced postharvest moisture loss and disease incidence.

\section{2}

\section{Evaluation of Midrib Nitrate-N Tests for Desert Lettuce}

Charles A. Sanchez and M. Peralta; The University of Arizona, Yuma, AZ 85364

Criteria for managing fertilizer nitrogen $(\mathrm{N})$ applications for lettuce (Lactuca sativa L.) based on midrib nitrate- $\mathrm{N}$ analysis were developed 25 years ago. However, this test had not been recently evaluated for the newer cultivars of lettuce currently grown or the higher yield potential now obtained. More recently, quick sap nitrate- $\mathrm{N}$ tests have been correlated to the traditional dry midrib test and preliminary criteria for making diagnosis based on these sap tests have been proposed. Field experiments were conducted at 20 locations across the low desert region of the southwestern United States from 1996-1999 to evaluate the traditional dry midrib and sap nitrate- $\mathrm{N}$ tests. Tissue samples were collected before each sidedress $\mathrm{N}$ application and diagnostic accuracy was evaluated by determining lettuce growth and yield on both $\mathrm{N}$-treated and untreated plots and comparing predicted to actual response. Overall, the variability associated with the quick sap test seemed to limit its application as a predictive $\mathrm{N}$ management tool in the low desert. Although less variable than the quick sap test, the high frequency with which the dry midrib test resulted in incorrect diagnosis suggests that either this test needs revision or that it is an unreliable $\mathrm{N}$ management tool.

\section{3 N Management Strategies Affect Watermelon Yield and N Leaching}

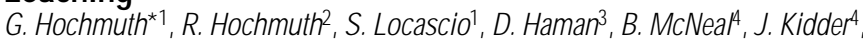
and Jennifer Hornsby ${ }^{2} ;{ }^{1}$ Horticultural Sciences Dept., Univ. of Florida, Gainesville, FL 32611-0690; '2Suwannee Valley Research and Education Center, Live Oak, FL 32060-7434; ${ }^{3}$ Dept. Agric. and Biological Engineering, Univ. of Florida, Gainesville, FL 32611-0570; ${ }^{4}$ Dept. Soil and Water Science, Univ. of Florida, Gainesville, FL 32611-0510.

Nitrate concentrations in the springs and rivers in northern Florida have been increasing, and several state agencies are interested in implementing nitrogen management programs on farms to reduce $\mathrm{N}$ entering the groundwater. Watermelon was grown in the first season of a six-season project under various cultural and fertilization programs to investigate the relationship of $\mathrm{N}$ management with $\mathrm{N}$ leaching. Treatments were a factorial arrangement of two cultural systems (polyethylene mulch with drip-irrigated beds and unmulched, overhead irrigated beds) and three $\mathrm{N}$ fertilization programs [ $\mathrm{N}$ at the extension-recommended rate, $\mathrm{N}$ at the commercial-watermelon-producer rate (1.5 times recommended), or $\mathrm{N}$ at the recommended rate with $50 \%$ of $\mathrm{N}$ from poultry manure]. Nitrate in the soil beneath the watermelon crop was monitored at the 2-m depth with porous-crop suction lysimeters and soil sampling. Yields were greater with the mulch/drip irrigation system compared with the unmulched/sprinkler cultural system; however, fertilization program had no effect on yield. Nitrate- $\mathrm{N}$ concentrations in the soil solution at the 2-m depth with all fertilizer treatments were only slightly elevated $\left(3\right.$ to $\left.5 \mathrm{mg} \cdot \mathrm{L}^{-1}\right)$ above that in the unfertilized soil $\left(<1.0 \mathrm{mg} \cdot \mathrm{L}^{-1}\right)$ early in the season when no rain fell. Later in the season, soil solution nitrate- $\mathrm{N}$ concentrations at the $2-\mathrm{m}$ depth increased to $>50 \mathrm{mg} \cdot \mathrm{L}^{-1}$ with the unmulched treatment and with the greater fertilization rate. Polyethylene mulch, drip irrigation, and recommended $\mathrm{N}$ rate combined to maintain groundwater nitrate- $\mathrm{N}$ concentration below $10 \mathrm{mg} \cdot \mathrm{L}^{-1}$ for most of the production season and only slightly above $10 \mathrm{mg} \cdot \mathrm{L}^{-1}$ during the summer off-season when rainfall was frequent. 
Deficit Irrigation Affects Yield and Quality of Triploid and Diploid Watermelon

D.I. Leskovar ${ }^{* 1}$, P. Perkins-Veazie ${ }^{2}$, and A. Meiri3; ${ }^{1}$ Texas Agricultural Exp. Sta-

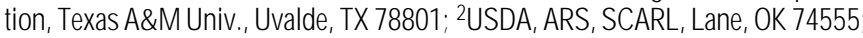

${ }^{3}$ The Institute of Soil and Water, The Volcani Center, ARO, Israel

Water conservation strategies are being investigated for watermelon [ Citrullus lanatus (Thunb.) Matsum. \& Nakai] production in the Winter Garden region of southwest Texas. Our objective was to determine how yield and fruit quality of a triploid (cv. Summer Sweet 5244) and hybrid (cv. Summer Flavor 710) watermelon were affected by irrigation based on evapotranspiration (ET) rates and timing of application during spring. Irrigation treatments included constant 1.0 and $0.5 \mathrm{ET}$, three with varying ET before or after fruit set, and one with cycles of 1.0 and $0.5 \mathrm{ET}$. Fruit quality characteristics were measured at the unripe, ripe, and overripe maturity stages. Water deficit before or after fruit set decreased yield and fruit number. Flesh color was not affected by irrigation at any maturity stage. Soluble solid content at the ripe stage increased only in triploids irrigated with constant $0.5 \mathrm{ET}$ or with $0.5 \mathrm{ET}$ applied after fruit set. Triploid plants exposed to frequent cycles of water deficit set more and smaller fruit than hybrids. These data suggest that triploid watermelon types may have a different acclimation response to drought stress than diploid hybrids.

\section{5}

Response of Irrigated Potatoes to Polyolefin-coated Urea

Francis Zvomuya* and Carl J. Rosen; Department of Soil, Water, and Climate, University of Minnesota, 439 Borlaug Hall, St. Paul, MN 55108

Polyolefin-coated fertilizers are slow-release fertilizers coated with thermoplastic resins that have a temperature-dependent nutrient release pattern. A field study was conducted on a Hubbard loamy sand during 1997 and 1998 at Becker, Minn., to evaluate the effect of polyolefin-coated urea (POCU) fertilizers (Meister, Chisso Co., Japan) on yield and quality of irrigated 'Russet Burbank' potatoes (Solanum tuberosum L.). The coated fertilizers were POCU-50 and POCU-70, which release $80 \%$ of their $\mathrm{N}$ in 50 and 70 days, respectively, at $25^{\circ} \mathrm{C}$, and a 1 POCU-50 : 1POCU-70 mixture. The study compared three soluble urea treatments ( $\mathrm{N}$ at 0,140 , and $280 \mathrm{~kg} \bullet \mathrm{ha}^{-1}$ ) split-applied at planting, emergence, and hilling vs. the same $\mathrm{N}$ rates of coated urea fertilizers applied in a band at planting. In 1997, a season characterized by high leaching, total and large tuber $(>168 \mathrm{~g})$ yields were higher with coated urea sources than soluble urea at equivalent $\mathrm{N}$ rate, but the $\mathrm{N}$ sources gave similar yields in 1998 when leaching was minimal. In both years, doubling the rate of $\mathrm{N}$ as soluble or coated urea from 140 to 280 $\mathrm{kg} \cdot \mathrm{ha}^{-1}$ had no effect on total yield, but increased the marketable yield (tuber size). Yields were higher in 1998 compared to 1997 due to poorer tuber set in 1997. However, the percentage of large tubers was higher in 1997. Specific gravity increased slightly with $\mathrm{N}$ rate but did not differ with $\mathrm{N}$ source at equivalent $\mathrm{N}$ rate. Hollow heart incidence was similar among all treatments in 1997, but it increased with N rate and was similar among N sources in 1998.

\section{6}

An Automatic, Controlled Water-Table Irrigation System for Vegetable Transplant Production

J.W. Buxton* and Wenwei Jia; Department of Horticulture and Landscape Architecture, University of Kentucky, Lexington, KY 40517

The controlled water-table irrigation (CWT) system was evaluated for vegetable seed germination and transplant growth. The system is a modification of capillary mat irrigation except that the mat along one side extends over the edge of the bench into a narrow trough running along the side of the bench. The nutrient solution level in the trough is controlled by a liquid level controller, so it is at a fixed distance below the bench surface. The nutrient solution is drawn by capillarity from the trough upward to the bench surface and then moves by capillarity to the opposite side of the bench. The system automatically maintains a constant air : water ratio in the growing media. Seeds of broccoli, tomato, and pepper were germinated in a 96-cell plug tray and grown to transplanting stage with the CWT system. A factorial experiment consisted of two growing media combined with $\mathrm{CWT}$ treatments of 2 and $4 \mathrm{~cm}$. Excellent germination and high-quality seedlings were produced with all treatments. No differences were observed in growth of seedlings at $2 \mathrm{vs.} 4 \mathrm{~cm}$ or between the two growing media. The CWT system is capable of maintaining a constant uniform water : air ratio in all plug cells on a commercial growing bench. Nutrient solution does not run off the bench. The CWT potentially is an excellent system for the irrigation of vegetable transplants.
56 ORAL SESSION 10 (Abstr. 457-464) Cross-commodity: Genetics \& Breeding

457

Woody Plant Selections and Introductions from North Dakota State University

Dale E Herman* and Lawrence J. Chaput, Dept. of Plant Sciences, North Dakota State University, Fargo, ND 58105

Woody plant improvement research has been an active program at North $\mathrm{Da}$ kota State Univ. (NDSU) for many years. Eghteen cultivars have been introduced since 1986, and $\approx 10$ additional releases are anticipated over the next 6 years. These superior, winterhardy cultivars have increased the inventory of adapted woody plants for landscape use in the northern plains, particularly USDA hardiness zones 3 and 4 . Emphasis will be placed on recent introductions and promising plants for potential future release. An extensive, statewide cooperative evaluation program is conducted at seven sites throughout North Dakota and also at the NDSU Research Arboretum near Absaraka.

\section{8}

Inheritance of Tree Size in Pistachio (Pistacia vera L.)

Chih-Cheng T. Chao', Dan E. Parfitt ${ }^{+1}$, Louise Ferguson', Craig Kallsen², and Joe Maranto ${ }^{2} ;{ }^{1}$ Department of Pomology, One Shields Ave, University of California-Davis, Davis, CA 95616; '2University of California Cooperative Extension, Kern County, Bakersfield, CA 93307

Trunk cross-sectional area from a population of 6192 pistachio trees was used to estimate tree growth from 1995 to 1997 . The narrow-sense heritabilities of trunk cross-sectional area were near zero across multiple locations based on analyses of progenies from 20 half-sib families. However, within individual location, there were values from 0.20 to 0.56 for 1995,1996 , and 1997, respectively. Broad-sense heritability estimates were considerably higher, from 0.36 to 0.64 at multiple locations and 0.51 to 1.35 for individual locations. These results suggest that dominance and significant interaction effects, epistatic and genotype by environment, were important. Breeding strategies should emphasize selection of superior parents based on individual performance, and parents should be selected in the environment in which the progeny are intended to be used.

\section{9}

Inheritance of Alternaria Late Blight [A/ternaria alternata (Fries) Keissler] Resistance in Pistachio (Pistacia vera L.) and Selection for Resistance in the Field and Greenhouse Chih-Cheng T. Chao*1, Dan E. Parfitt', and Themis J. Michailides'; 'Dept. of Pomology, One Shields Ave., University of California-Davis, Davis, CA 95616; 2Dept. of Plant Pathology, University of California-Davis/Kearney Agricultural Center, Parlier, CA 93648

Pistachio (Pistacia veraL.) progeny from the California cultivar improvement program were evaluated at two locations for their resistance to alternaria late blight [Alternaria alternata (Fries) Keissler] from 1995 to 1997. Large differences between seedlings were observed for disease resistance. Narrow sense heritabilities were calculated from half-sib analysis of 20 open pollinated families. Heritabilities of 0.48 and 0.11 at Kearney Agricultural Center were observed in 1995 and 1997, respectively. Narrow-sense heritability estimates were 0.56 and 0.54 at the Wolfskill Experimental Orchard near Davis for 1995 and 1997, respectively. Differences among progeny families to alternaria late blight infection were highly significant and were associated with the female parents. Greenhouse inoculation experiments were not strongly correlated with field results. Fifty-eight highly resistant seedlings were identified for use in future cultivar improvement efforts.

\section{0}

Introgressing Seedlessness from Vitis vinifera into Vitis rotundifolia

Jiang $L u^{*}$ and Lloyd Schell; Center for Viticultural Science, Florida A\&M University, Tallahassee, FL 32311

Vitis rotundifolia(Muscadine grapes), a native species characterized with multiple resistance to grape diseases and insects, are cultivated throughout the south- 
eastern U.S. for fresh fruit and processing. However, the species falls short of consumer's expectation as fresh fruit due to its seediness and thick skin. However, Vitis vinifera, a predominant Vitis species grown worldwide possesses good fruit characteristics such as seedlessness and edible skin but is susceptible to many diseases. Attempts to produce rotundifolia-vinifera hybrids to combine good fruit quality and disease resistance of both into $F_{1}$ hybrids have been made by grape breeders for many years. Limited success was only reported when the $V$. vinifera was used as seed parents. Pollinating seedless vinifera pollen on $V$. rotundifolia stigma was made in 1993 and 1994. More than 20,000 flowers from 34 cross combinations were pollinated. These crosses were made to see if there is any chance to produce hybrids when muscadine grapes were used as female parent and specifically to introgress the seedlessness from European grapes into muscadine grapes. A few hundred seeds were collected from these crosses and germinated in a greenhouse. Two seedlings were clearly distinguished from the others with morphology intermediate between muscadine and the viniferagrapes, while the rest looked straight muscadine grapes derived from possible contaminated pollination. This conclusion was further confirmed by isozyme and DNA markers. One of the seedlings produced from the cross of 'Jumbo' $x$ 'Thompson Seedless' grew vigorously and has been setting fruit since 1996. Fruit are mixture of stenospermocarpic and pathonocarpic seedlessness. Fruit setting and pollen viability test indicated that this hybrid is at least partly self-fertile. Many other characteristics of the hybrid, such as leaves, stems, tendrils, time of budbreak, bloom date, and ripen date are intermediate between muscadine and bunch grapes. The hybrid is resistant to Pierce's disease, anthracnose disease, and downy mildew, which are the limited factor to growing $V$. viniferain the hot and humid southeastern U.S. This is the first report of a seedless hybrid from V. rotundifoliax V. vinifera.

\section{1}

Genetics of the Necrotic Reaction to Lettuce Mosaic in Lettuce Edward J Ryde*; USDA-ARS, US Agr. Res. Sta., 1636 E Alisal St., Salinas, CA93905

Lettuce mosaic has been a serious virus disease for lettuce in all locations worldwide where lettuce has been grown. Consequently, the disease and its virus have been well studied. Lettuce plants react to lettuce mosaic virus in a variety of ways. The most common susceptible reaction is an overall vein clearing and mottling, followed by leaf recurving, leaf distortion, and stunting. However, some susceptible types manifest a mild mottling with little additional distortion. Others develop a necrotic reaction, which may be severe, mild, or seasonal. Finally, there are at least three resistant reactions, most frequently appearing as a systemic infection manifested with restricted yellowish lesions. Research is ongoing to sort out the various reactions and their genetic bases. This report describes the inheritance of the severe necrotic reaction and its relationship to the resistant reaction conferred by the allele mo- 1 . Several previous crosses among necrotic types indicate that the same necrotic allele is operating except that found in 'Bibb'. Several crosses were studied. The cross 'Salinas' (mot.) x 'Crisp As Ice' (nec.) showed that necrotic is due to a single dominant allele. The cross 'Salinas 88' (res.) x 'Maikonig' (nec.) produced three phenotypes in $\mathrm{F}_{2}$, indicating the action of two loci. The crosses PI 251245 (res.) x 'Prizehead' (nec.) and 'Vanguard 75' (res.) x 'Prizehead' disclosed two recombinant phenotypes, mottled and resistant-necrotic. Necrotic is dominant to nonnecrotic in both susceptible and resistant phenotypes. The genes are inherited independently.

\section{2}

\section{Inheritance of Light-Green Flower Color ( $g f$ in Watermelon (Citrullus lanatus)}

Young-Seok Kwon ${ }^{\star 1}$ and Fenny Dane ${ }^{2} ;{ }^{1}$ National Alpine Agricultural Expt. Sta., Pyongchang, Korea 232-950; '2Dept. of Horticulture, Auburn University, AL 36849

Watermelon (Citrullus lanatus Thumb. Matsum. and Nakai) flower petals usually are yellow, but in watermelon line Kw-695, light-green flowers were detected. To study the inheritance of light-green flower color, Kw- 695 plants were crossed with yellow-flowered Korean cultures 'SS-4' and 'Dalgona'. The resulting $F_{1}, F_{2}$, and reciprocal backcross generations were analyzed for flower color. Segregation ratios in the $F_{2}$ and backcross to $\mathrm{Kw}-695$ were 3 yellow : 1 light green and 1 yellow : 1 light green, respectively. Backcross generations to the yellow-flowered parents showed yellow flowers only. These results indicate that inheritance of the light-green flower character in $\mathrm{Kw}-695$ is governed by a single recessive gene. We propose the gf gene symbol for the green flower trait. Kw- 695 plants have large vines with large, light-green leaves. The plants are andromonoecious, have large, oval, bright yellow-green fruit with irregular dark-green stripes, bright yelloworange, inedible flesh with very low sugar content (about $3.2^{\circ}$ Brix), and light-yellow seeds. The trait should be useful as a marker in watermel on breeding programs. Linkages between this trait and other genetic markers in watermelon will be investigated.

\section{3}

Understanding Genetics of Freezing Tolerance: Expression of Freezing Tolerance in the Interspecific $F_{1}$ and Somatic Hybrids of Potatoes

Y.-K. Chen ${ }^{\star 1}$, J.P. Palta', and J.B. Bamberg'; ; ${ }^{1}$ Dept. of Horticulture, Univ. of Wisconsin, Madison, WI 53706; '2USDA/Agricultural Research Service, InterRegional Potato Introduction Station, 4312 Hwy 42, Sturgeon Bay, WI 54235

Wild potato species provide a valuable source of genetic variability for the improvement of freezing tolerance in cultivated potato, Solanum tuberosum (tbr). However, breeding for freezing tolerance by using wild genetic resources has been hampered by contradictory results regarding the genetic control of this trait. Both dominance and recessiveness for this trait have been reported. To explore the genetic control of freezing tolerance, the expression of freezing tolerance was investigated in various interspecific $F_{1}$ and somatic hybrids between hardy and sensitive species. In addition to 2 years of field evaluation, freezing tolerance before and after acclimation was characterized separately under controlled environments to dissect the two independent genetic components of freezing tolerance, namely nonacclimated freezing tolerance (NA) and acclimation capacity (ACC). The expression of freezing tolerance, including NA and ACC, was closer to that of hardy parent, sensitive parent, or approximate parental mean, depending on species combination. However, the expression of freezing tolerance tended to be greater when the hybrids contained more sets of chromosomes from the hardy parent than from the sensitive parent. The significance of hardy : sensitive genomic ratio was further supported by using sexual and somatic hybrids between tbr and $S$. commersonii $(\mathrm{cmm})$ to achieve different genomic ratios without the confounding effect of species. Therefore, we propose that the hardy : sensitive genomic ratio is an important determinant for the expression level of freezing tolerance before and after cold acclimation.

\section{4}

Distribution of Sugars in Sweet Corn

V.M. Russo* ${ }^{1}$ and T. Smith'; ${ }^{1}$ USDA, ARS, SCARL, POB 159, Hwy. 3W, Lane, OK 74555; ${ }^{2}$ Southeastern State Univ., Durant, OK 74701

Sweet corn (Zea mays L.) kernels are sinks, and sugars found in kernels must be translocated from a source. Stalk tissues can act as a source and a sink as sweet corn plants age. Quantity and types of sugars present in various sweet corn tissues during plant development are not well documented. Concentrations of fructose, glucose, sucrose, and their total were determined in the ninth stalk internodes (I9) from the 12-leaf stage (V12) to fresh-market maturity (R3) in sweet corn cultivars carrying either the su1se1, su1, or sh2 endosperm genotype. Developing ears were sampled at tassel emergence (VN) and silking (R1). Kernels and cob tissue were sampled separately at blister stage (R2) and R3. Correlation analysis was performed on concentrations of sugars at all developmental stages. In 19, from V12 to R3, levels of fructose and glucose declined and sucrose increased. In developing ears, concentrations of fructose and glucose increased from VN to R1. Concentrations of sugars in cobs in all cultivars were generally the same at R2 and R3. In kernels from R2 to R3 in the su1se1 cultivar, glucose decreased while the other sugars were unchanged; in the su1 cultivar, fructose decreased while levels of the other sugars stayed the same; and in the sh2 cultivar, fructose decreased, glucose was unchanged and sucrose increased. Correlation analysis suggested that the cultivars moved sugars to the kernels differently. The pattern of movement of sugars to kernels was most complex in the su1se1 cultivar than in the su1, which was more comlex than in the sh2 cultivar. Knowing how sugar content changes in the plant may be used to predict sugar content in kernels.

\section{ORAL SESSION 11 (Abstr. 465-469) Fruit/Nuts: Dormancy \& Flowering}

465

Dormancy Completion-A Dual Response

Amnon Erez" Institute of Horticulture, A.R.O., The Volcani Center, P.O.Box 6 Bet Dagan, 50250, Israel

Most of the works evaluating dormancy completion relies on measuring the 
level of budbreaking or the time needed for buds to break in forcing conditions. In all cases, the evaluation of budbreak is limited to the initial stages of bud opening in both vegetative and floral buds. Very rarely the response of the new growth is determined. It is accepted that dormancy completion of the bud is of a qualitative nature of yes or no. This reasoning led to using excised branches that can not support normally a growing bud but may support the evaluation of the emerging buds. In practice, the effect of breaking bud dormancy is far reaching and has an impact on the development after budbreaking. Growth vigor is a characteristic tied to the rate of dormancy completion in a quantitative manner. After exposure to sufficient chilling growth is rapid and vigorous. When buds are exposed to warm winters, growth is sluggish and poor. Under certain conditions, budbreak may be high, but all vegetative buds will form rosettes. Likewise with floral buds, they may break satisfactorily but will not set normal fruit especially in stone fruit spe cies. In a recent study of bud dormancy inheritance in apricots, budbreak showed a clear dominance of the low chilling characteristic; level of vegetative vigor showed a similar effect to the high and low chilling parents. Thus, two characteristics of dormancy completion should be considered. The first is the level of budbreak and the other is the vigor of the growing vegetative buds and the functionality of the flower buds, as both are affected by the conditions that induce dormancy completion.

\section{6}

Floral Cold Acclimation in Strawberry and Sour Cherry

Christopher L. Owens*, J.F. Hancock, and A.F. lezzoni; Department of Horticulture, Michigan State University, East Lansing, MI 48824

Sour cherry and strawberry are examples of two Rosaceous species that often suffer crop reductions due to spring freezes. Breeding for improved floral freezing tolerance has the potential to mitigate the susceptibility of these plants to spring frosts. In model plant systems, researchers have been able to identify genes that play a role in freezing tolerance by initially searching for $m R N A s$ regulated in response to cold temperatures. To search for cold-responsive freezing-tolerance genes in strawberry and sour cherry, it is necessary to first define their cold acclimation response. To test the hypothesis that sour cherry and strawberry flowers have the ability to cold acclimate, blooming plants were exposed to $4^{\circ} \mathrm{C}$ and $16 \mathrm{~h} \mathrm{light} \mathrm{for} 14$ days. Sour cherry styles and strawberry receptacles from open, fully developed flowers were excised, and electrolyte leakage curves were generated over a range of subzero temperatures. The temperature at which $50 \%$ electrolyte leakage $\left(\mathrm{EL}^{50}\right)$ oCcurred was used to compare treatments. The flowers of two strawberry cultivars were tested for the ability to cold acclimate. Non-acclimated 'Chandler' receptacles had an $\mathrm{E}^{50}$ of $-2.9^{\circ} \mathrm{C}$, while non-acclimated 'Honeoye' had an $\mathrm{E}^{50}$ of $-3.4^{\circ} \mathrm{C}$. Conversely, acclimated 'Chandler' receptacles had an $\mathrm{E}^{50}$ of -7.7 and acclimated 'Honeoye' receptacles had an $\mathrm{E}^{50}$ of $-8.7^{\circ} \mathrm{C}$, both are significantly different from non-acclimated values $(P \leq 0.01)$. Additionally, sour cherry styles were collected from the field at full bloom from a mapping population of 86 individuals from the cross 'Rheinische Schattenmorelle' $x$ 'Erdi Botermo' and acclimated as previously described. The $\mathbb{E}^{50}$ of the 86 progeny ranged from approximately -2.0 to $-6.0^{\circ} \mathrm{C}$.

\section{7}

Overcoming Dormancy, Advancing Budbreak, and Advancing Fruit Maturity in 'Bing' Sweet Cherry (Prunus avium L.): Surfactants/ Dormant Oils + Calcium Ammonium Nitrate or Hydrogen Cyanamide

K.G. Weis', S.M. Southwick ${ }^{* 1}$, J.T. Yeager', M.E Rupert', R.E. Moran', J.A. Grant, and W.W. Coates ${ }^{3}$ ' Pomology Dept. , Univ. of California, Davis CA 95616; ${ }^{2}$ Univ. of California Cooperative Extension, San Joaquin County, Stockton, CA 95205; 3 Univ. of California Cooperative Extension, San Benito County, Hollister, CA 95023

In continuing trials (1995-current), we have used a variety of treatments to overcome inadequate chilling, coordinate bloom, improve leaf out and cropping, and advance/coordinate maturity in sweet cherry, cv. Bing. Treatments have included hydrogen cyanamide (HCN, Dormex) and various surfactants or dormant oils combined with calcium ammonium nitrate (CAN17). Chill hour accumulation, (required chilling for 'Bing' $=850$ to 880 chill hours) has varied greatly in each dormant season from 392 (Hollister, 1995-1996) to adequate, depending both on the season and location (central valley vs. coastal valley). In 1998, 4\% HCN advanced budbreak significantly compared to any other treatment, although other chemical treatments also were more advanced than the untreated control. Dormex advanced completion of bloom $11 \%$ to $40 \%$ more than other treatments, although other dormancy-replacing chemicals were at least $16 \%$ more advanced in petal fall than the untreated control. Dormex contributed to slightly elevated truss bud death, as did 2\% Armobreak + 25\% CAN17. In 1998, fruit set was improved by $2 \%$ Armobreak + $25 \%$ CAN17 (79\%) compared to the untreated control (50\%); all other treatments statistically equaled the control. Fruit set was not improved by Dormex, although bloom was advanced by a few days in this treatment. As fruit set was increased by treatments, rowsize decreased (as did fruit weight), as expected, but no treatment resulted in unacceptable size. In 1997, fruit set was also improved by $2 \%$ Armobreak + 25\% CAN17; however, fruit set was so low overall in that year that no real impact was found. In 1997 and 1998 , $4 \% \mathrm{HCN}$ advanced fruit maturity compared to other treatments, with darker, softer, larger fruit at commercial harvest. These and additional results will be presented.

\section{8}

Effect of Hydrogen Cyanamide (Dormex) and Ethephon (Ethrel) on Fruiting of 'Surecrop' Peaches

Arlie A. Powel/ ${ }^{*}$, James Pitts, and Bobby Boozer; Auburn University, AL 36849

Early flowering of peach in the southeastern United States can result in annual crop loss as a result of late winter-early spring freezes. In peach and other prunus, a fall application of ethephon delays flowering several days; however, delayed harvest and smaller fruit size of certain varieties may occur. Hydrogen cyanamide replaces the late stage of chilling in peach but can also advancebloom and harvest date while maintaing or enhancing fruit size. A randomized complete-block experimental design using 13-year old 'Surecrop' trees was used to evaluate whether hydrogen cyanamide could offset the delayed harvest and smaller fruit size disadvantages of using ethephon without advancing bloom dates. Treatment combinations of ethephon (at 20\%,50\%, and $90 \%$ of required chilling) and hydrogen cyanamide (at $90 \%$ to $100 \%$ of required chilling) were applied as whole-tree foliar sprays to near point of drip. Although not significant, there were trends toward hydrogen cyanamide overcoming both smaller fruit size and delayed harvest induced by ethephon. This agrees with an earlier study using 'Redhaven'. Dormex negated the late flowering effects of ethephon applied at $20 \%$ chilling but did not cause flowering earlier than the control.

\section{9}

Some Citrus Flower Characteristics Limit Bee Preference of Hybrids and Their Pollination

L.G. Albrigo*, R. Russ, R. Rouseff, and R.A. Bazemore; University of Florida, Citrus Research and Education Center, Lake Alfred, FL 33580

Except for 'Orlando' and 'Minneola' tangelos, most citrus hybrids grown in Florida are small-flowered and produced less than half the nectar of largeflowered cultivars. Sugar contents in large- and small- flowered cultivars were not different in 1997, but the concentration of sugars doubled in 1998 over 1997 for small-flowered hybrids, while nectar volume was about one half of that in the previous year. Nectar volume of large-flowered cultivars increased slightly in 1998 compared to 1997. Of four aromatic volatiles measured from headspace over flowers, 'Robinson' and 'Ambersweet' were lowest in total while other cultivars had only some specific differences. Grapefruit flowers produced high limonene levels, while 'Sunburst', 'Fallglo', and 'Valencia' gave off the most myrcene. Bees were tested for flower preference in a round, white screenhouse using a mini-hive and duplicated fresh-cut flower bouquets each day. Bees preferred largeflowered cultivars with more nectar. Some other preferences also were observed. In the field, hedge rows limited cross movement of bees in mature blocks of hybrids, which limits the number of contiguous rows of the preferred cultivar for good pollinization. Timing of bee hive placement was also critical to get bee movement into the intended block because flowering times differ for some cultivars and bees develop inital preferences.

66 ORAL SESSION 12 (Abstr. 470-477) Cross-commodity: Postharvest Physiology/ Temperature Stress

\section{0}

Ethylene Inhibits the Development of Chilling Injury in Fresh-cut Tomato Slices during Storage at Low Temperature Ji Heun Hong* and Ken Gross, Hort. Crops Quality Lab., Plant Sci. Inst., Beltsville Agr. Res. Ctr., Agricultural Res. Serv., USDA, 10300 Baltimore Ave., Beltsville, MD 20705-2350

Experiments were conducted to determine if ethylene influences chilling in- 
jury, as measured by percent of slices showing some water-soaked areas and associated fungal growth in fresh-cut tomato slices ( Lycopersicon esculentum Mill.; cvs. Mountain Pride and Sunbeam). Ethylene concentration in containers without a perforation (perforations were made by piercing the lid of the container forming a $0.7-\mathrm{mm}$ hole) significantly increased during storage at $5{ }^{\circ} \mathrm{C}$, while little or no accumulation of ethylene occurred in containers with from one to six perforations. Chilling injury was greatest in slices in containers with six perforations, compared to slices in containers with one perforation an,d was over 12 -fold greater than that of slices in control containers with no perforations. The percent ofage visible fungal growth of slices was roughly correlated with the degree of chilling injury. An experiment was also performed to investigate the effectiveness of including an ethylene absorbent pad in containers on subsequent ethylene accumulation and chilling injury. While ethylene in the no-pad control increased continually during storage at $5^{\circ} \mathrm{C}$ under modified-atmosphere conditions, no increase in accumulation of ethylene was observed in containers containing ethylene absorbent pads throughout storage with 'Sunbeam' and 'Mountain Pride' tomatoes. The ethylene absorbent pad treatment resulted in a significantly higher percent of chilling injury and visible fungal growth compared with the no-pad control. In studies aimed at inhibiting ethylene production using 1-aminoethoxyvinylglycine (AVG) during storage of slices, the concentration of ethylene in control containers (no AVG) remained at elevated levels throughout storage compared to containers with slices treated with AVG. Chilling injury in controls was 5-fold greater than that in slices treated with AVG. All slices treated with AVG had visible fungal growth, while the percent of slices showing visible fungal growth in no-AVG controls was 54\%. Furthermore, we tested the effect of ethylene pretreatment of slices on subsequent slice shelf-life and quality. In slices treated with ethylene $\left(0,0.1,1\right.$, and $\left.10 \mu \mathrm{L}^{-1}\right)$ immediately after slicing, ethylene production in untreated controls was greater than that of all other ethylene pretreatments. However, pretreatment of slices at 3 days after slicing resulted in a different pattern of subsequent ethylene production during storage. The rate of ethylene production by slices treated with $1 \mu \mathrm{L} \cdot \mathrm{L}^{-1}$ ethylene at 3 days after slicing was greater during storage than any of the other ethylene treatments. With slices pretreated with ethylene both immediately and 3 days after slicing, the rate of ethylene production tended to show an negative correlation with chilling injury.

\section{1}

Tomato Fruit Treated with 1-methylcyclopropene Provide Adequate Non-ripening Controls in Low-temperature Storage Experiments

Domingos P. F. Almeida* and Donald J. Huber; Horticultural Sciences Department, University of Florida, Gainesville, FL 32611

Chilling injury limits the postharvest handling of many fruit and vegetables. In low-temperature storage trials, control treatments typically consist of fruit stored above the injury threshold. Since chilling exposures for tomato fruit often exceed 2 weeks, controls stored above the threshold continue to ripen, confounding comparisons with fruit maintained at low temperatures. In this study, the ethylene action inhibitor 1-MCP was used to arrest ripening to permit more valid comparisons between fruit stored under the two temperature regimes. Mature-green tomatoes were treated with EthylBloc and then stored at 5 or $15^{\circ} \mathrm{C}$ for 2 or 3 weeks after which time the fruit stored at $5^{\circ} \mathrm{C}$ were transferred to $15^{\circ} \mathrm{C}$ to allow the expression of injury symptoms. 1-MCP inhibited ripening of fruit stored at $15^{\circ} \mathrm{C}$ for 2 to 3 weeks. Color, pericarp firmness, and pectin solubilization of MCP-treated fruit stored at 15 ${ }^{\circ} \mathrm{C}$ remained at the values of mature green fruit, validating their use as controls for these physiological characteristics. After 2 to 3 weeks at $15^{\circ} \mathrm{C}, \mathrm{MCP}$-treated fruit resumed normal ripening. Comparing the fruit removed from low-temperature storage with nonripening controls at $15^{\circ} \mathrm{C}$ reveal ed that storage at $5^{\circ} \mathrm{C}$ for 2 to 3 weeks decreased the hue (yellowing) but did not affect chroma or lightness, maintained firmness, and did not affect pectin metabolism. Eectrolyte leakage increased or remained unaffected by cold storage. MCP-treated fruit had slightly higher electrolyte leakage than non-MCP-treated fruit after storage at either 5 or $15^{\circ} \mathrm{C}$. We conclude that MCP-treated fruit provide adequate controls in experiments designed to study many aspects of low-temperature storage.

\section{2}

\section{Effects of Low-temperature Storage on Carbohydrate Metabolism in Potato Tubers}

Robert W. Blenkinsop*, Leslie J. Copp, Alejandro G. Marangoni, and Rickey Y. Yada; Dept. of Food Science, Univ. of Guelph, Guelph, Ont., Canada, N1G 2W1

Following exposure to low temperatures (i.e., $<10^{\circ} \mathrm{C}$ ), potato tubers undergo low-temperature sweetening (LTS), the conversion of starch to sugars. This phenomenon is of great importance to potato chip processors because high levels of reducing sugars lead to undesirable nonenzymatic browning during potato chip frying operations. The purpose of this study was to elucidate the biochemical differences in carbohydrate metabolism between a tolerant (ND 860-2) and a sensitive (Novachip) cultivar during $4^{\circ} \mathrm{C}$ storage. On chilling, there was an increase in the levels of sucrose, fructose, and glucose in both cultivars, with levels being at least 2-fold higher in the sensitive cultivar. Increased levels of ATP and NADH, along with a higher respiratory rate observed in the tolerant tubers, collectively indicate a higher metabolic rate in the LTS-tolerant cultivar. ATP- and pyrophosphate- dependent phosphofructokinase activity was similar in both cultivars. Higher levels of ethanol and lactate were also observed in ND 860-2, suggesting a greater flux of sugars via anaerobic respiration. No significant differences were observed in enzymatic activities in the oxidative pentose phosphate pathway (PPP) or in levels of NADPH, thereby suggesting that the PPP does not play a role in conferring LTS tolerance. Therefore, we propose that LTS-tolerant potatoes may maintain low tissue sugar concentrations via an overall increased metabolism, rather than differing in one specific metabolic step. This increased metabolic rate does not appear to be due to greater enzyme expression (i.e., coarse control) but, rather, to a greater overall flux of carbohydrates through glycolysis and respiration.

\section{3}

\section{Beneficial Effect of Heat-shock Treatments on Lettuce Applied before and after Wounding}

Julio G. Loaiza-Velarde* and Mikal E. Saltveit, Department of Vegetable Crops, Mann Laboratory, University of California, Davis, CA 95616-8631

Changes in phenolic metabolism are induced by minimally processing, which ultimately leads to the browning of lettuce tissue. Phenylalanine ammonia-lyase (PAL, EC 4.3.1.5.) is greatly influenced by storage temperature. Evaluation of PAL activity at temperatures going from 0 to $25^{\circ} \mathrm{C}$ showed that peaks occurred sooner at higher temperatures but at lower levels. Heat-shock treatments $\left(50^{\circ} \mathrm{C}\right.$, $90 \mathrm{~s}$ ) have a protective effect against browning, help to retain greenness of tissue, and decrease the production of phenolics when applied either after or before wounding. To achieve a considerable, beneficial effect from hot water treatments applied after wounding these should not be delayed more than $36 \mathrm{~h}$. The best results for heat-shock treatments before wounding occurred when applied at $\approx 12$ $\mathrm{h}$ before cutting the tissue. Although cycloheximide did reduce PAL activity in a similar pattern as heat-shock treatments, it did not prevent browning itself. Cycloheximide seems to cause some sort of chemical damage that promotes the browning of lettuce tissue. When cycloheximide was applied in combination with heat-shock treatments browning did not occur.

\section{4}

Effect of Vigor and Duration of Chilling on Heat Shockinduced Chilling Tolerance in Cucumber Radicles

Mary E. Mangrich* and Mikal E. Saltveit, Mann Laboratory, Dept. of Vegetable Crops, University of California, One Shields Ave., Davis, CA 95616-8631

Chilling 10-mm cucumber ( Cucumis sativus L. 'Poinsett 76') radicles at $2.5^{\circ} \mathrm{C}$ reduced their subsequent growth during 3 days at $25^{\circ} \mathrm{C}$. The reduction in radicle growth was linear for 1 to 3 days of chilling but then increased substantially until subsequent radicle growth was all but eliminated by 6 days of chilling. Heat shocks of $40^{\circ} \mathrm{C}$ applied for 4 to $12 \mathrm{~min}$ increased chilling tolerance such that 4 days of chilling caused only a $36 \%$ decrease in radicle growth compared to $66 \%$ for seedlings not heat shocked, which brought the response in line with the responses of the non-heat-shocked seeds chilled for 1 to 3 days. Eight-minute heat shocks applied before 5 days of chilling resulted in a $45 \%$ inhibition of subsequent growth, compared to $82 \%$ for chilled non-heat-shocked controls. Heat shocks applied before 3 days of chilling did not result in a significant increase in subsequent growth compared to the non-heat-shocked controls chilled for 3 days. Heat shocks were only able to protect that part of radicle growth that was in excess of the linear decrease in radicle growth. There appears to be two effects of chilling on radicle growth. The first is linear and cannot be affected by heat shocks. The second is much more severe and can be prevented by heat shocks. Seeds were selected for three categories of vigor according to the rate at which their radicles grew to $10 \mathrm{~mm}$. Seeds classified with different vigors neither responded significantly differently to 3 days exposure to $2.5^{\circ} \mathrm{C}$ nor did they respond differently to chilling stress following application of heat shocks. 


\section{5}

Heat Treatments Reduce Irradiation-induced Changes in Phenylpropanoid Metabolism in Grapefruit

R.E McDonald ${ }^{* 1}$, W.R. Miller ${ }^{2}$, and T.G. McCollum; ${ }^{1}$ USDA-ARS, 2199 South Rock Rd., Fort Pierce, FL 34945; ${ }^{2}$ USDA-ARS, 2120 Camden Road, Orlando, FL 32803

Irradiation is being evaluated as a quarantine treatment of grapefruit (Citrus paradisi, Macf.), but it can cause damage to the fruit. We wanted to determine if pre-irradiation heat treatments would improve fruit tolerance to irradiation as they improve tolerance to low-temperature injury. 'Marsh' grapefruit were harvested from interior and exterior canopy positions and irradiated at 0 or $1.0 \mathrm{kGy}$ at a dose rate of $0.148 \mathrm{kGy} \cdot \mathrm{min}^{-1}$ before storage for 4 weeks at $10^{\circ} \mathrm{C}$. Following storage, pitting of flavedo tissue was the most evident condition defect noted as a result of irradiation. Pitting was noted on $15 \%$ and $27 \%$ of irradiated interior and exterior canopy fruit, respectively, whereas there was no pitting on non-irradiated fruit. Temperature conditioning before irradiation decreased the susceptibility of fruit to damage. Pitting was $26 \%, 19 \%$, and $17 \%$ when fruit were held $2 \mathrm{~h}$ at 20 (ambient), 38 or $42^{\circ} \mathrm{C}$, respectively. There was a marked increase in phenylalanineammonia-lyase (PAL) activity following irradiation. Maximum activity $(\approx 18$ fold increase) was attained $24 \mathrm{~h}$ after irradiation. Irradiation-induced PAL activity was reduced significantly by temperature conditioning at 38 or $42{ }^{\circ} \mathrm{C}$. Exterior canopy fruit flavedo contained higher levels of total phenols, including flavanols and coumarins, compared with interior canopy fruit. The deposition of lignin was not related to canopy position. Neither irradiation nor heat treatment had an effect on total phenols or lignin deposition. It seems that irradiation causes a stress condition in the fruit, which leads to pitting of peel tissue. Heat treatment before irradiation reduced the damaging effects of irradiation.

\section{6}

In Vitro Mortality of Eggs and Third Instar Larvas of Anastrepha ludens and A. obliqua with Insecticidal Controlled Atmospheres at High Temperature

Ehadi M. Yahia ${ }^{*}$, Dora Ortega', Alejandro Martinez, and PamelaMoreno2; 'DIPA, Facultad de Química, Universidad Autónomade Querétaro, Querétaro, QRO, 76190, Mexico; ${ }^{2}$ Planta Moscafrut, DSVG-SAGAR, Chiapas, Mexico

In this study, we report on the effect of insecticidal controlled atmospheres at high temperatures on the in vitro mortality of eggs and third instars larvas of $A$. Iudens and A. obliqua. Atmosphere evaluated were air, $0 \% \mathrm{O}_{2}, 13 \% \mathrm{O}_{2}+20 \%$ $\mathrm{CO}_{2}$, and $0 \% \mathrm{O}_{2}+50 \% \mathrm{CO}_{2}$ at $44^{\circ} \mathrm{C}$ for $160 \mathrm{~min}$. Other treatments evaluated included $0 \% \mathrm{O}_{2}+50 \% \mathrm{CO}_{2}$ at $48^{\circ} \mathrm{C}$ for 160 and $220 \mathrm{~min}$ and the same atmosphere at $40,50,51,52,54$, and $55^{\circ} \mathrm{C}$ for $240 \mathrm{~min}$ and at $48^{\circ} \mathrm{C}$ and $55^{\circ} \mathrm{C}$ for 80 , 160 , and $240 \mathrm{~min}$. Both species responded similarly to the treatments applied. Larvas were more sensitive than eggs in both species. A $100 \%$ mortality of larvas of the two species was obtained in $0 \% \mathrm{O}_{2}+50 \% \mathrm{CO}_{2}$ at $48^{\circ} \mathrm{C}$, but there were survivals in eggs of both species. Treatment with $0 \% \mathrm{O}_{2}+50 \% \mathrm{CO}_{2}$ at $55^{\circ} \mathrm{C}$ for 240 min resulted in $100 \%$ mortality in eggs and larvas of both species. Less extreme conditions (temperature and duration of treatment) caused high but inconsistent mortality, probably due to variability in insect population. Statistical analysis for the calculation of probit 9 will be discussed.

\section{7}

Effect of High-temperature Controlled-atmosphere Treatments for Insect Control in 'Bartlett' Pear Fruit

Elizabeth Mitcham*, Lisa Neven and Bill Biasi; Department of Pomology, University of California-Davis and USDA, Wapato, Wash.

High-temperature, controlled-atmosphere treatments were explored for disinfestation of codling moths from 'Bartlett' pear fruit. Fruit were freshly harvested in 1996 and 1997 and sorted for uniformity and absence of defects. Fruit were exposed to forced-heating at $46^{\circ} \mathrm{C}$ for 1,2 and $3 \mathrm{~h}$ in either air or a controlled atmosphere of $1 \%$ oxygen and $15 \%$ carbon dioxide. Fruit were evaluated during ripening at $20{ }^{\circ} \mathrm{C}$ immediately after treatment (1997 only) and after 3 weeks of cold storage at $-1^{\circ} \mathrm{C}$. Fruit were ripened with and without an exogenous ethylene treatment in 1997. Heat treatments, and particularly heat plus CA treatments, slowed fruit ripening, even after fruit had been stored for 3 weeks. The longer the treatment, the greater the inhibition. Fruit from longer treatments were firmer than untreated fruit after 4 days of ripening, but treatment with exogenous ethylene did not overcome the inhibition in the rate of ripening, although fruit from all treatments softened faster. The mortality of codling moths following exposure to the same treatments was also determined. With the heat plus controlled-atmosphere treatments, $100 \%$ mortality was achieved in $2.5 \mathrm{~h}$ with the faster heating rate used in our 1996 experiment, while it took $3 \mathrm{~h}$ to achieve $100 \%$ mortality with the slower heating rate.

\section{ORAL SESSION 13 (Abstr. 478-483) Floriculture: Postharvest Physiology/Plant Growth Regulators}

\section{8}

Preharvest Calcium Application and Its Benefit on Vase Life of Lupinus havardii Watts Cut Flowers

Mario Valenzuela-Vazqueż and Geno A. Picchioni; Dept. of Agronomy and Horticulture, New Mexico State Univ., Box 30003, Las Cruces, NM 88003-0003

Lupinus havardii has gained popularity as a potentially new and unique cut flower species, but its compound, ethylene-sensitive inflorescences (racemes) undergo rapid senescence and deterioration on cutting. The purpose of this study was to evaluate the influence of $\mathrm{Ca}$ culture solution applications on $\mathrm{L}$. havardii cut-flower longevity. Four supplemental Catreatments were incorporated into the nutrient solution $\left(0,2.5,5.0\right.$, and $10.0 \mathrm{mM} \mathrm{Ca}$ using $\left.\mathrm{CaCl}_{2}\right)$, with four replications in arandomized complete-block design. Raceme Ca concentration increased with increasing Ca application, ranging from a low $5300 \mathrm{mg} \cdot \mathrm{kg}^{-1}$ dry weight $(0$ $\mathrm{mM}$ supplemental Ca) to a high of $7500 \mathrm{mg} \cdot \mathrm{kg}^{-1}(10.0 \mathrm{mM}$ supplemental Ca). Calcium application deferred the daily loss in raceme fresh weight (FW) for up to 10 days of vase life in a concentration-dependent manner $(P<0.01)$, with the effect most pronounced between 5 and 9 days following cutting (average $F W$ of $72 \%$ and $83 \%$ of day zero values for the control and $10.0 \mathrm{mM} \mathrm{Ca}$, respectively, with 2.5 and $5.0 \mathrm{mM}$ treatments intermediate). The cut racemes of $L$. havardii are model organs for spatially and sequentially organized postharvest development, with continued, 6-day postcutting life including 4-fold increases in cell permeability of basal, most mature flowers, marginal but significant increases in cell permeability of the most recently expanded flowers, and a $50 \%$ increase in total flowers number resulting from inflorescence expansion. Preliminary data indicate that manipulation of Ca nutrition may be a viable, inexpensive, and environmentally safe alternative to silver-based compounds currently in use for the vase life extension of $L$. havardii inflorescences.

\section{9}

Pulsing and Packing Methods to Reduce Flower Opening of Cut Lilies during Long-distance and Ambient-temperature Transport Young-Sang Lee*1, Yong-Sun Lee', and Chang-Sung Kang ${ }^{2}$; ${ }^{1}$ Dept. of Biological Resources, Soonchunhyang University, Asan, Korea; ${ }^{2}$ Kyonggi Agricultural Research and Extension Service, Hwasong, Korea

The cut Lilium oriental hybrid 'Casablanca' was pulsed with chitosan (MW = 5000-10,000), grapefruit seed extract (GFSE), GA, and sucrose and enclosed with a polyethylene ( $\mathrm{PE}$ ) film of different perforations before packing into a cardboard box. Simulated transport (ST) was conducted by storing plants at $22{ }^{\circ} \mathrm{C}$ for 3 days, and the flower opening and weight loss during ST as well as post-ST floral longevity were evaluated. Pulsing with $600 \mathrm{ppm}$ chitosan effectively reduced open flower percentage and weight loss during ST by $6.5 \%$ and $36 \%$, respectively. The same concentration of chitosan, however, slightly decreased post-ST floral longevity. Adding $8 \%$ sucrose and 100 ppm GA enhanced chitosan effects. In contrast to chitosan, 500 ppm GFSE increased flower opening during ST. Enclosing plants with perforated PE film significantly reduced weight loss during ST, but increased flower opening although no ethylene accumulation over $0.08 \mathrm{ppm}$ was detected in enclosed atmosphere. The opening of flowers during ST also increased in proportion to the time delay between harvest and pulsing.

\section{0}

Evaluation of Potted Anthurium Cultivar Performances under Interior Environments

Jianjun Chen*, R.J. Henny, T. Mellich, R.D. Caldwell, and C.A. Robinson; Department of Environmental Horticulture and Central Florida Research and Education Center, University of Florida, 2807 Binion Road, Apopka, FL 32703

Anthurium cultivars are being produced primarily as cut-flower plants. Whether 
Anthurium can be used as a flowering interiorscape plant is not well documented. Therefore, five finished Anthurium cultivars were evaluated in interior acclimatization rooms under two light intensities provided by cool-white fluorescent lamps for 12 hours daily: $16 \mathrm{mmol} \cdot \mathrm{m}^{-2} \cdot \mathrm{s}^{-1}$ (low light) and $4816 \mathrm{mmol} \cdot \mathrm{m}^{-2} \cdot \mathrm{s}^{-1}$ (high light). Temperature of the rooms was maintained at $24^{\circ} \mathrm{C}$ with a relative humidity of $60 \%$. Total number of open flowers and number of senesced flowers were recorded weekly over 5 months. In addition, plant canopy height and width and total number of leaves were measured monthly. Number of open flowers per week ranged from 1.4 to 4.7 under low light and 2.4 to 6.3 under high light. The cultivar Red Hot showed the best performance with a weekly average flower count of 4.7 under low light and 6.3 under high light. All cultivars continued to produce new leaves, ranging from one to five per month under low light and two to five leaves under high light. Leaves were dark green and shiny under the interior conditions. Growth index of 'Red Hot' increased 31\% under low light and 20\% under high light. Results from this study demonstrate that Anthurium can continue to grow and produce flowers under interior environmental conditions. Variation among cultivars indicates that genetic potential exists for selecting improved cultivars based on interior performance.

\section{1}

\section{Early Applications of Growth Regulators to Bedding Plants}

J.E. Barrett", C.E. Wieland, T.A. Nell, and D.G. Clark; Environmental Horticulture Dept., Univ. of Florida, Gainesville, FL 32611

In some species of bedding plants, rapid hypocotyl elongation during germination makes size control in plug production difficult. Commercial growers often start applying growth regulators as cotyledons are expanding or after the first true-leaves are expanding. Using 'Bonanza Spry' marigolds, we evaluated applying paclobutrazol at sowing and after 3 and 6 days. Sprays at $30 \mathrm{mg} \cdot \mathrm{L}^{-1}$ in a volume of $0.2 \mathrm{~L} \cdot \mathrm{m}^{-2}$ or $3 \mathrm{mg} \cdot \mathrm{L}^{-1}$ in $0.6 \mathrm{mg} \cdot \mathrm{L}^{-1}$ applied at sowing reduced hypocotyl elongation by $25 \%$ and produced more compact plugs. In a second study, plugs of 'Double Madness Rose' petunia, 'Showstopper Orange' impatiens, 'Wizard Rose' coleus, and 'Cooler Rose' vinca were grown in 10-cm pots with a growing medium that did not contain pine bark. Uniconazole was sprayed in a volume of $0.2 \mathrm{~L} \cdot \mathrm{m}^{-2}$ onto the surface of the medium before planting at concentrations of $25 \%, 50 \%$, and $100 \%$ of the label's recommended concentration for each crop. An additional treatment was uniconazol applied 2 weeks after planting at the label concentration. All early applications reduced final plant size compared to the nonsprayed plants. For impatiens, the early application at $25 \%$ of the label concentration produced plants similar to the spray at 2 weeks after planting. For the other crops, the $50 \%$ treatment prodcued plants similar to the spray after planting. The early applicaiton of growth regulators offers the industry an additional stradagy to use for controlling the growth of vigorous bedding plant crops.

\section{2}

Effects of Plant Growth Regulators on Plant Size, Branching, and Flowering in Petunia $\mathrm{x}$ hybrida

Shi-Ying Wang*; PanAmerican Seed Co., 1S861 Green Road, Elburn, IL 60119

Five Wave ${ }^{T M}$ petunias, i.e., 'PurpleWave ${ }^{T M}$, 'Pink Wave ${ }^{T M}$, 'Misty Lilac Wave ${ }^{\text {TMP }}$, and 'Rose Wave ${ }^{\mathrm{TM}}$ ', and two hedgaflora petunias, i.e., 'Dramatica Cherry ${ }^{\mathrm{TM}}$ ', and 'Dramatica Hot Pink ${ }^{T M}$, were investigated to determine the effects of plant growth regulators on plant size, branching, and flowering. Plant regulator treatments consisted of daminozide (B-Nine) spray two times at 7500 ppm, Paclobutrazol (Bonzi) spray two times at $30 \mathrm{ppm}$, paclobutrazol drench at $5 \mathrm{ppm}$, paclobutrazol drench at 5 ppm plus spray at $30 \mathrm{ppm}$, and ethephone (Florel) spray two times at $500 \mathrm{ppm}$. Plant diameter and central stem height were controlled effectively through daminozide spray and paclobutrazol drench. Plant branching was promoted by ethephone and daminozide. However, time to flowering was delayed significantly in the ethephone treatment. The size of the first flower responded to plant growth regulators negatively. The different responses to growth regulators among different types of petunias and different varieties in the same petunia type will be discussed based on the current trial and other separated experiments.

\section{3}

\section{WITHDRAWN}

\section{ORAL SESSION 14 (Abstr. 484-488) Vegetable Crops: Crop Protection}

484

\section{Effect of Viral Infection and Clonal Variability on} Sweetpotato Yield and Quality

Heather L. Wallace*1, Christopher A. Clark², and Don R. La Bonte'; Deparments of ${ }^{1}$ Horticulture and ${ }^{2}$ Plant Pathology and Crop Physiology, Louisiana State University Agricultural Center, Baton Rouge, LA 70803

Virus infections and genetic mutations have been implicated in the decline of sweetpotato yield and quality. Virus-tested mericlones were derived from 12 infected clones of 'Beauregard' sweetpotato by meristem-tip culture. Field studies were conducted to evaluate yield differences between the virus-tested and the virus-infected plants of each respective clone. After a 90-day growing period, the storage roots were harvested, weighed, and analyzed with a colorimeter to gauge color of skin and flesh. Yield was $7 \%$ to $130 \%$ greater in virus-tested mericlones compared to their respective virus-infected clone. Data also show these 12 virustested mericlones vary in yield by up to $118 \%$. This suggests genetic differences between clones greatly affect yield. The virus-tested mericlones also show a more desirable darker-red hue for skin and flesh than the virus-infected clones. The incorporation of virus-tested material into foundation seed programs could potentially increase yield and quality with little added expense to growers, thereby netting a higher return on their crop.

\section{5}

Helping Vegetable Growers Manage Gemini Viruses in Dade County, Florida

Mary Lamberts ${ }^{* 1}$ and Jane Polston'; ${ }^{1}$ Univ. of Florida, Miami-Dade Co. Coop. Ext. Serv., Homestead, FL 33030; ${ }^{2}$ Univ. of Florida, Gulf Coast Research \& Education Center, Bradenton, FL 34203

Florida tomato growers have been managing tomato mottle mosaic virus (TMoV), vectored by the silverleaf whitefly (Bemesia argentifolia) since 1990. Bean growers in the Dade and Palm Beach County area have tried to control bean golden mosaic virus (BGMV) since it entered the area with Hurricane Andrew in 1992. During Summer 1997, tomato yellow leaf curl virus (TYLCV) was found in summer-grown tomatoes in Dade County. In Fall 1997, tomato growers were notified of the new problem and attended a workshop discussing the rigorous control that would be needed to minimize its effects. They instituted scouting and roguing programs in conjunction with appropriate pest management procedures. Dade bean growers worked with the Florida Fruit \& Vegetable Assn. to obtain a Section 18 for imidacloprid. Bean and tomato growers learned about gemini viruses affecting both crops and the distribution of these viruses in the Americas in the fall of 1998. Bean growers have also learned how to use imidacloprid in late 1998/early 1999. Extension methods used and their success will also be discussed.

\section{6}

Growth Responses of Tomato, Pepper, Broccoli, and Corn Grown in Soils Amended with Ammonium Lignosulfonate

Nader Soltani* and George Lazarovits; Southern Crop Protection and Food Research Centre, Agriculture and Agri-Food Canada, 1391 Sandford Street, London Ontario, Canada. N5V 4T3

Ammonium lignosulfonate (ALS) is a liquid waste by-product of pulp and paper industry that may be a source of organic fertilizer. Four plots each of tomato, pepper, broccoli, and corn were set up in a randomized block design on the AAFC-SCPFRC farm in the Spring 1998. Treatments were untreated control, $0.5 \%$ $(\mathrm{v} / \mathrm{w})$ ALS, and $1 \%(\mathrm{v} / \mathrm{w})$ ALS. Soil samples were taken at $0,2,4,8$, and 22 weeks after amendment incorporation and analyzed for $\mathrm{pH}$, microbial population, and water soluble ions. Soil temperature was measured at 8-cm depth. Leaf chlorophyll content was measured at four sampling dates. Tomato and pepper fruit were evaluated for symptoms of diseases. Soil temperature in $0.5 \%$ and $1 . \%$ ALS treatments were 2 and $7{ }^{\circ} \mathrm{C}$ warmer, respectively, than the control. Soil pH was lower in ALS-treated plots. $1 \%$ ALS caused more than 10 -fold increase in bacterial population. Fungal populations in both $0.5 \%$ and $1 \%$ ALS treatments were 10 - to 100 -fold higher than control soil and continued to be higher to the last sampling 
date. Weeds were reduced by more than $50 \%$ by $0.5 \%$ or $1 \%$ ALS treatments. Both ALS rates caused an initial increase in $\mathrm{NH}_{4}, \mathrm{NO}_{3}, \mathrm{NO}_{2}, \mathrm{~K}, \mathrm{Na}, \mathrm{Cl}, \mathrm{PO}_{4}, \mathrm{Ca}$ and $\mathrm{SO}_{4} \cdot \mathrm{NH}_{4}$ and $\mathrm{SO}_{4}$ remained elevated for 22 weeks in both ALS treatments. ALS slightly increased chlorophyll content in tomato, pepper, and corn, but not in broccoli plants. The number of diseased tomato fruit in ALS plots were reduced by $50 \%$ to $70 \%$. Bacterial spot decreased by more than $50 \%$ in both ALStreated plots, while anthracnose declined by $50 \%$ to $75 \%$. There were no significant differences in early and total yield of tomato, peppers, and corn. Early broccoli yield decreased in ALS treatments, while total yield increased over that of control in both ALS treatments.

\section{7}

Assessment of Chemical Induction of Acquired Resistance to Phytophthora Fruit Rot in Field-grown Pickling Cucumber

Priscilla M. Hockin ${ }^{\star}$ and Irvin E. Widders; Department of Horticulture, Michigan State University, East Lansing, MI 48824

Systemic acquired resistance (SAR) is a physiological defense response in plants conferring broad spectrum resistance to pathogens. SAR is inducible through infection by necrotizing pathogens or chemical inducers and involves the systemic activation of defense related genes. Our objectives were to evaluate resistance expression to phytophthora soft rot fruit in cucumber in response to increasing concentrations of 2,6 dichloroisonicotinic acid (INA) and benzo $(1,2,3)$ thiadiazole-7-carbothioc acid S-methyl ester (BTH) by foliar applications. Excised leaves exhibited a resistance response to foliar applications of all concentrations of INA and BTH tested when challenge inoculated with Colletotrichum lagenarium. There was increasing benefit with increasing concentration of each chemical applied. Harvested cucumber fruit, 3.4 to $4.5 \mathrm{~cm}$ in diameter, were challenge inoculated with Phytophthora capsici; there were no significant chemical and rate interactions in terms of internal lesion measurements. Overall, INA consistently reduced lesion size in cucumber fruit. A bioassay conducted on fruit of different maturity levels, as defined by fruit diameter, revealed that larger sized fruit $(4$ to $5 \mathrm{~cm}$ ) were more resistant to fruit rot. Fruit with diameters of 3 to $4 \mathrm{~cm}$ from plots treated with BTH showed little resistance as compared to the control and fruit from the same treatment with diameters of 2 to $3 \mathrm{~cm}$. Fruit from plots treated with INA had at least $50 \%$ reduction in lesion size than the control. It is unclear if these differences were attributable to changes in physiological or anatomical factors. The true importance of these results should be interpreted with caution. Yield studies have not been conducted, and thus, with the experienced stunting, treatment with $100 \mathrm{ppm}$ INA would be expected to lower yield and perhaps fruit quality. Determination of the optimal application regime and other cultural factors will provide broad control of plant diseases.

\section{8 \\ Effect of Oat Extract on Pea Root Rot Pathogen Aphanomyces euteiches \\ M.A. Chandler" ${ }^{* 1}$, V.A. Fritz ${ }^{1}$, F.L. Pfleger ${ }^{2}$, and R.R. Allmaras ${ }^{3}$; Departments of ${ }^{1}$ Horticultural Science and ${ }^{2}$ Plant Pathology, University of Minnesota, St. Paul, MN55108, USA; ${ }^{3}$ Agricultural Research Service, U.S. Department of Agriculture, St. Paul, MN 55108, USA \\ Pea root rot is a serious economic threat to pea production in the Great Lakes region. The primary causal organism is Aphanomyces euteiches Drechs., which is responsible for an estimated 10\% annual crop loss. A fall oat (Avena sativa) rotation before spring pea planting reduces disease severity. To better under- stand the beneficial effect of oat on $A$. euteiches, isolated individual pathogen lifecycle stages of zoospores, mycelium, and oospores were treated in culture with oat extract. Resulting mycelial mats were dried and weighed. Treatment with $90 \%, 70 \%, 50 \%$, and $30 \%$ oat extract resulted in significant spore germination and mycelial growth of $A$. euteiches. In the presence of nutrient solution, oat extract concentrations of $90 \%, 70 \%, 50 \%$, and $30 \%$ significantly enhanced spore germination and mycelial growth of the pathogen. These results demonstrate that the use of oat extract results in dosage dependent germination and growth of $A$. euteiches.}

78 ORAL SESSION 15 (Abstr. 489-494) Cross-commodity: Flowering/P ollination

\section{9}

\section{Detection of Hidden Sectorial Chimeras in Almond Shoots} through Distortions in Flower Symmetry

Thomas M. Gradziel* and Mary Ann Thorpe; Department of Pomology, University of California, Davis, CA 95616

Somatic mutations in shoot growing points, while considered relatively common in many horticultural clones, cannot be detected unless the mutation results in a distinguishable change and comes to occupy sufficient shoot area to be observable. Noninfectious bud-failure (BF) in almond, a genetic mutation which results in failure during early development of vegetative but not flower buds, behaves as a chimera in its incidence within an affected tree and in vegetative progeny from bud-failure prone clonal sources (i.e., vegetative lineage). Early stages of BF development are thought to occur as very limited and so undetected sectorial or mericlinal chimeras. Detection of BF during these early stages would be very valuable for the selection of low-BF source clones for nursery increase. Flower symmetry, as measured by differences in the size of each of the five petals of an almond flower, was evaluated as an indicator of the relative fitness of the individual cell lineages from which different petals were derived. Several hundred flowers from individual clonal sources of the almond variety 'Nonpareil', known to produce either very low, medium, or very high levels of $\mathrm{BF}$ in their vegetative progeny, were tested over 3 separate years. Significant reductions in flower symmetry were consistently observed for medium BF potential clonal sources relative to either low- or high-BF sources despite the lack of any observable BF symptoms in the medium-BF trees tested. Associated with asymmetric-flower-prone sources was a greater number of an easily distinguishable distorted petal morphology. Medium BF-potential sources consistently produced 2- to 3-fold greater numbers of this petal morphology relative to low BF-sources, although the occurrence of distorted petals in both low and medium BF sources limits its use as an efficient field selection tool. Research findings, however, are allowing a more detailed understanding of the developmental ontogeny of "bud-sport" mutations and may have application in the analysis of otherwise hidden chimeras resulting from either somatic mutations or genetic transformation/regeneration schemes.

\section{0}

Toward Conserving a Threatened Orchid (Platanthera praeclara) Margaret From* and Paul E Read; Horticulture Dept., Univ. of Nebraska, Lincoln, NE 68583-0724

Platanthera praeclara, commonly called western prairie fringed orchid, is a showy forb native to seven states and one Canadian province. The species had resisted previous attempts at propagation. Small, isolated populations in the sandhills region of western Nebraska are disjunct and visitation by natural pollen vectors appears to be in decline. Modern cultivation practices and other habitat encroachment factors, including urban development, recreational activities, and natural fluctuations in seasonal water availability all have the potential to exert pressure on current populations. Federal and state permits have allowed a limited hand-pollination study to be conducted on federal land. Hand-pollinated plants showed a greater fruit production compared to control plants receiving no human pollination assistance. Germination studies were conducted using aseptic in vitro techniques. The microscopic seeds possess testa that are extremely hard and resistant to liquid absorption, which presents challenges to germination in vitro. These challenges will be discussed. Alternating cold treatments with room temperatures appeared necessary to promote protocorm development after germination. Three media tested produced varying germination responses. Juvenile plants produced through micropropagation can offer propagules for possible future re introduction efforts of this protected species.

\section{1}

\section{An Evaluation of Dry Particulates as Pollen Diluents for} Supplemental Mass Pollination

Hazel Y. Wetzstein ${ }^{* 1}$ and S. Edward Law2; Departments of ${ }^{1}$ Horticulture and ${ }^{2}$ Biological and Agricultural Engineering, University of Georgia, Athens, GA 30602

Pollination is essential in the production of many agricultural crops. Insuffi- 
cient pollination can lead to reduced yield and lower harvest quality in many fruit and vegetables. Recent declines in insect pollinators and the use of cultural systems where compatible pollen is limiting have caused pollen-related production problems in many crops. Supplemental mass pollination (SMP) may be beneficial in such cases. However, the high cost of pollen may prohibit its use unless pollen is efficiently and uniformly applied. Our objective was to evaluate the feasibility of using selected dry particulate materials as pollen diluents for SMP. Viability was assessed in apple pollen mixed and held with selected powders (i.e., two formulations of Rilsan ${ }^{\circledR}$ nylon, polyester resin, diatomaceous earth, wheat flour, and $\mathrm{CaCO}_{3}$ ). Also, an assessment of inhibitory substances was made using in vitro germination tests with extracts obtained from liquid suspensions of the different particulates. Several powders, viz., Rilsan ${ }^{\circledR}$ nylon formulations, polyester resin, and wheat flour were identified as nontoxic to pollen held for $1 \mathrm{~h}$ as dry pollen : particle mixtures. Likewise, leachates from these diluents had no significant effect on pollen germination. Diatomaceous earth exhibited slight, but statistically significant, inhibitory effects on germination, while $\mathrm{CaCO}_{3}$ completely inhibited germination. The morphology and size of particulates were evaluated using scanning electron microscopy and will be discussed vis-a-vis pollen dispersion and metering requirements.

\section{2}

Storage of Abelia R. Br. Pollen

S.M. Scheiber*, C.D. Robacker, and M.A. Dirr, Dept. of Horticulture, Univ. of Georgia, Griffin, GA 30223

The genus Abelia contains $\approx 30$ species, but $A$. $x$ grandiflora, its cultivars, and $A$. 'Edward Goucher' are the primary taxa grown. The nursery industry has stated that Abelia R. Br. taxa are important economically, and new selections or cultivars with increased cold hardiness, richer pink-rose flower colors, unique foliage colors, and compact habits are desired. Breeding and selection work in the genus is very limited due in part to limited access to germplasm. Pollen storage enables breeders to cross taxa with incongruent flowering cycles, save time and resources by eliminating the need to grow vast amounts of plant material, and incorporate otherwise unavailable germplasm into a breeding program. An experiment was conducted to determine the optimum levels of temperature and humidity for the long-term storage of $A$. chinensis and A. x grandiflora 'Golden Glow' pollen. Temperature and humidity levels were analyzed by incubating undesiccated pollen of a given taxon at four humidity levels $(0 \%, 50 \%, 80 \%$, and $100 \%)$ for $72 \mathrm{~h}$ at $5{ }^{\circ} \mathrm{C}$. Following incubation, the pollen was stored in glass vials at each of the following temperatures: $5,-20$, and $-70^{\circ} \mathrm{C}$. All combinations of temperature and humidity were tested. Pollen viability was assessed after 60 days by in vivo germination tests on styles. Abelia chinensis pollen germinated following storage at all temperature and humidity levels. Pollen of $A$. x grandiflora 'Golden Glow' pollen germinated following all treatments except storage at $-20^{\circ} \mathrm{C}$.

\section{3}

\section{Inducing Polyploidy Pollen in Apple Cultivars}

Yinping Shi ${ }^{*}$, Qiangsheng Wang, Jianming Yang, Congyi Sui, and Qingrong Sun; Shandong Institute of Pomology, Taian, Shandong 271000, P.R.of China

To perform apple polyploid breeding the ways of inducing polyploidy pollen with temperature and chemicals were studied. Materials include 13 diploid cultivars: Red Chief, Dai Hong, Rose Red, Golden Delicious, Mollie's Delicious, Gala, Bella, Jonathan, Fuji, Qiu Kou Hong, and Yan Qing, OBIR-2T-47. Chemicals: Chloroform, N-nitroso-ethylurea. At the beginning of PMC meiosis, fruiting branching groups were covered with plastic bags to raise temperature or were treated with chemical. After covering, temperature during the day increased $2{ }^{\circ} \mathrm{C}$, generally not lower than $0^{\circ} \mathrm{C}$. Whether branches received high temperature or chemicals treatment, polyploidy pollen was induced to produce. The pollen grain of CK is tricolporat, its polar view is triangular, and its diameter almost $40 \mu \mathrm{m}$, showing no difference in size. Rate of empty pollen grain is low. Pollen grains that were treated were different in size, and rate of empty pollen is high, part of pollen grains germinating colporat change into tetracolporat with a few polycolporat, its polar view is square, round, and oval. The diameter of large pollen grains was $45-48 \mu \mathrm{m}$, increased by $11-12 \%$. Giant pollen grain are 50-68 $\mu \mathrm{m}$, increased by $25 \%-70 \%$. Rate of induction is different in different cultivars. For most cultivars, giant pollen grain is $0.3 \%-0.5 \%$. Gala and OBIR-2T- 47 were higher, reaching $2.5 \%-7 \%$. Chemicals caused damage on cultivars. Delicious strains were easily damaged.

\section{4}

Study on the Effects of Different Pollen Grains of Citrus Cultivars on Some Quantitative and Qualitative Characteristics of 'Page' Mandarin in Northern Iran

A. Talaie', B. Goleyn ${ }^{* 1}, Y$. Ebrahimi', and A. Vezvaei'; 'University of Tehran, Karaj, Iran; ${ }^{2}$ Citrus Research Station, Ramsar, Iran

'Page' mandarin is a complex hybrid between 'Minneola' tangelo and 'Clementine' mandarin. Because of self-incompatibility, this cultivar severely needs pollinizers and, if a suitable pollinizer does not exist, it will produce few and small fruit. In this study, the effects of pollen grains of nine cultivars of citrus ['Sour' orange, 'Duncan' grapefruit, 'Sweet' lemon, 'Salustiana' orange, 'Local' mandarin, 'Hamlin' orange, 'Siavaraz III Locan' orange, 'Marrs' orange, and 'Shell' mahaleh (natural hybrid)] on the quantitative and qualitative characteristics of fruit (weight, diameter, length, volume, peel thickness, juice content, developed seeds, undeveloped seeds, total soluble solids, acidity, pH, vitamin C, and percentage of final fruit set) were investigated and evaluated. After artificial pollination and during fruit growth and development, seven times abscission and fruit color and diameter were recorded. Fruit were harvested 29 weeks after pollination and were analyzed. The results showed that this cultivar, in addition to the complete self-incompatibility, has the ability of week parthenocarpy, which results in small and low-quality fruit and also parthenocarpy is induced. 'Page' mandarin is cross-compatible with some cultivars, such as 'Marrs' orange. There is a positive and significant correlation between developed seed number and fruit weight. The pollen of 'Siavaraz III Local' orange has the most effects on percentage of final fruit set. The pollen of 'Shell' mahaleh (natural hybrid) has the most effect of the quantitative characteristics, and the pollen of 'Marrs' orange has the most effects on qualitative characteristics. It was concluded that 'Hamlin' orange is the best pollinizer for 'Page' mandarin in northern Iran. The results of this study were analyzed with the use of a randomized complete-block design.

\section{ORAL SESSION 16 (Abstr. 495-501) Human Issues: Horticultural Therapy}

\section{5}

\section{Prison Master Gardener Program Contributes to Improved} Social and Vocational Skills

Jon H. Traunfeld ${ }^{\star 1}$ and D.M. Kafami2; ${ }^{2}$ Home and Garden Information Center, University of Maryland, 12005 Homewood Road, Elicott City, MD 21042; 'Director of Research, Patuxent Institution, P.O. Box 700, Jessup, MD 20794

Patuxent Institution, a maximum security prison in central Maryland, enlisted Maryland Cooperative Extension (MCE) in 1996 to develop a master gardener (MG) program for inmates as part of its horticultural therapy program. The twin goals are to improve inmate social and coping skills and provide vocational training in horticulture. The program has graduated 30 certified master gardeners over three training cycles. Selected trainees are carefully screened and must complete a preliminary horticulture course before entering the MG program. To earn the MG certificate, inmates receive 65 hours of training, pass a 100-question closedbook exam, and contribute 40 hours of service to the program. The inmates apply their knowledge to a 2-acre garden site that includes a production greenhouse. Placing released inmates in green industry jobs is an important program goal. The program has two unique features: 1) inmates are taught by MG from surrounding counties and MCE faculty. MG volunteers who present subject matter, earn volunteer credit for their participation, gain experience in a horticultural therapy setting, and express a high degree of satisfaction teaching and interacting with inmates. 2) All horticultural crops are produced organically by the inmates (all of whom have a substance abuse history) to demonstrate that life can be nurtured without chemical substances. One self-report research instrument showed that participants had a decreased vulnerability to addiction.

\section{6}

\section{Public Perception in Determining Water Management in Urban Landscapes}

L.L. Lockett", C.B. McKenney, and D.L. Auld; Department of Plant and Soil Science, Texas Tech University, Lubbock, TX 79409-2122

Many segments of private industry use data gathered from public attitude and 
opinion research as an integral part of the planning, program development, and evaluation process. These basic techniques were used to determine public perception of five species of Texas native plants grown at three irrigation rates under xeriscape conditions. Nearly half of the average annual residential water costs go to lawns and gardens. Minimizing the amount of water used in irrigation could provide significant savings of money and a precious natural resource. The complexities of measuring social attitudes, how to develop a valid survey instrument, methods of analyzing survey data, and appropriate interpretation will be discussed. Use of public perception could be a powerful tool in developing water conserving technologies.

\section{7}

Customers in Seven U.S. Markets Assess Service Quality In Traditional and Non-traditional Retail Garden Center Outlets Bridget Behe ${ }^{* 1}$ and Susan Barton'; 'Dept. of Horticulture, Michigan State University, East Lansing, MI 38824; ${ }^{2}$ Dept. of Plant and Soil Sciences, University of Delaware, Newark, DE 19717

SERVQUAL has been demonstrated to be a reliable and valid tool to measure customer perceptions and expectations of service quality. Two previous uses of the survey in the horticulture industry were identified. In Spring 1997, we adapted the SERVQUAL instrument to survey 701 customers of 10 retail garden centers (TR) and four nontraditional retail or mass-merchandise outlets (MM) in seven U.S. markets. Among the seven markets, customers differed on only two of six demographic characteristics: income and number of people residing in the household. Demographic characteristics of TRand MM customers were similar in terms of age (47 and 45 years), people residing in the household (2), percent female respondents (77\% and $73 \%$ ), and family status. Customers differed demographically on 1996 household income (\$50,722 and $\$ 44,753)$. Customers of TR and MM had similarly high expectations for three of five service quality and one product quality dimensions. However, TR customer perceptions were consistently higher on all service and product quality dimensions than MM customers. This yielded consistently higher service quality gaps for MM customers when compared to TR customers. We concluded that TR hold an advantage in these seven markets with higher customer perceptions of product and service quality.

\section{8 \\ School Gardens: Do They Affect Children's Food Preferences and Eating Behaviors?}

Sarah Lineberger" and J.M. Zajicek; Department of Horticultural Sciences, Texas A\&M University, College Station, TX 77843-2133

Nutrition plays an important role in the life of a child because of the impact it has on growth, development, and the ability to learn. One part of proper nutrition is consumption of five fruits and vegetables a day. Currently, children eat an average of 2.5 fruits and vegetables a day, which is only half of the recommended servings. Education is needed to help increase consumption. School gardens are one education tool that can provide active hands-on activities in supportive environments. Through gardening, children learn not only what they should eat but also obtain a greater appreciation for how their food is grown. The main goals of this study were to provide teachers with a guide book for teaching nutrition through horticulture activities and school gardens and to test the effect of gardening on food preferences and eating behaviors of children. A curriculum guide, "Nutrition in the Garden", was developed for teachers to use with their garden containing background information in horticulture and nutrition. Each lesson includes three to four related activities that can be completed with a garden or in the classroom. A pretest/posttest instrument developed by Tom Baranowski, Professor of Behavioral Science, Univ. of Texas MD Anderson Cancer Center, was used to determine students' attitudes toward fruits and vegetables. A24-hour recall food journal was used to determine eating behaviors. Results examine the effects of school gardens on nutritional attitudes and behaviors.

\section{9}

\section{An Annual Children's Garden for Educational Outreach}

Susan D. Schoneweis* ; Horticulture Dept., Univ. of Nebraska-Lincoln, NE68583-0724

Festival of Color, an annual open house and educational outreach event, is sponsored by the UNL Horticulture Dept. and Institute for Agriculture and Natural Resources. In 1995, a children's garden was added to the site to educate, entertain, and motivate families to garden together. Different theme gardens helped over 10,000 attendees learn vegetable and flower culture in 1998. Educational gardens have included: al phabet, pizza, taco, food and fiber, Christmas tree recycling, bees, international cuisine and lemon gardens. Fun themes have included a plant petting zoo, maze, flower "beds," and a bean tepee. Most attendees are adults, so different home gardening topics are demonstrated in the grown-up section of the garden, including fall gardening, tomato caging, reblooming amaryllis, consequences of saving hybrid seed, and edible flowers. Plants are mulched with wood chips or multi-colored ground corn cobs to ease maintenance, conserve water and demonstrate these benefits of organic mulches. Of surveys returned by 541 first-time attendees, $98 \%$ indicated they learned to choose plants based on site/location, $41 \%$ said they learned to identify at least one pest, and $42 \%$ learned to implement water conserving landscape techniques. Of the 298 surveys by repeat attendees, $86 \%$ have learned improved plant selection skills, $63 \%$ now use water more efficiently, and $41 \%$ can identify some pests in the lawn and landscape.

\section{0}

Consumer Viewpoints on Prairie Grass and Wildflower Plantings

Greg L. Davis* and Julie Schimelfenig; Horticulture Dept., Univ. of Nebraska, Lincoln, NE 68583

Public interest in installing landscapes for reduced maintenance remains high. While availability and specification of native and/or adapted landscape plants such as wildflowers and prairie grasses increase, establishment, management, and expectations of such plantings are not well understood. Our objectives in this study were to measure temporal changes of mixed prairie wildflower plantings under various management regimes and to determine consumer expectations and preferences in these plantings. Nine combinations of wildflowers and prairie grasses were planted in June 1997 at the John Seaton Anderson Turfgrass and Ornamental Research Area, Univ. of Nebraska Agricultural Research Development Center near Mead. On-site surveys were conducted during the Festival of Color, a popular outreach event that occurs annually in September at the site. In 1997 and 1998, the festival attracted more than 9000 and 10,500 participants, respectively, of which 750 completed the survey. To determine preferences for planting compositions, plot desirability ratios were calculated from scaled responses. In 1997, respondents preferred the planting composed of only annuals by a ratio of $5.8: 1$ (rated desirable vs. undesirable). This result changed dramatically by the second year, in which the desirability ratio for annuals was $0.3: 1$, while that of the combination of perennials and annuals was $11.2: 1$. Our plant population density and flowering data validate consumers' preference for abundant color. In late summer of the establishment year (1997), the percentage of the plant population in full bloom was highest in the planting of annuals alone as expected and in 1998 was lowest in the annuals.

\section{1}

\section{Viewing Red-flowering Geraniums Altered Fast-beta Brain} Wave Activity and Improved Positive Attention of Lowattentive Female College Students

Eunhee Kim* and Richard H. Mattson; Dept. of Horticulture, Forestry and Recreation Resources, Kansas State Univ., Manhattan, KS 66506

Psychophysiological responses to geranium visual stimuli were analyzed on female college students with low attentiveness. Alpha and fast-beta brain wave activities, electrodermal activities, and skin temperature were measured continuously during a 5-min baseline, a 10-min induced stressor, and a 5-min treatment. Each of 75 female college students viewed a film of a stressful human situation - an induced stressor, then was exposed to a randomly assigned treatment: red-flowering geraniums, nonflowering geraniums, or no plants. Based on responses to the induced stressor, students were placed into non-, mild-, and high-induced stress groups. Regression models of psychophysiological responses to each treatment were developed for over-all stress levels. Non-induced stress female students exposed to red-flowering geraniums in contrast to nonflowering geraniums and no-plants showed greater fast-beta brain wave activity. Greater fast-beta of non-induced stress female students exposed red-flowering geraniums was associated with increased positive attention and not because of increased stressful tension. This conclusion was supported by more positive emotional states self-reported using the Zuckerman Inventory of Personal Reactions. Conclusive findings from over-all stress levels suggest that benefits of viewing redflowering geraniums occur to both nonstress and high stress female college students; red-flowering geraniums improve positive attention of female students with no stress (low attentiveness) and enhance stress recovery of female students with high stress (tension). 
84 ORAL SESSION 17 (Abstr. 502-508) Vegetable Crops: Greenhouse Management/Controlled Environmental Agriculture

\section{2}

Intermittent $\mathrm{CO}_{2}$ Enrichment for Hydroponic Lettuce Production David S. de Villiers", Robert W. Langhans, A.J. Both, Louis D. Albright, Sue Sue Scholl; Cornell University, Ithaca, NY 14853

$\mathrm{CO}_{2}$ enrichment increases efficiency of light utilization and rate of growth, thereby reducing the need for supplemental lighting and potentially lowering cost of production. However, during warmer periods of the year, $\mathrm{CO}_{2}$ enrichment is only possible intermittently due to the need to vent for temperature control. Previous research investigated the separate and combined effects of daily light integral and continuous $\mathrm{CO}_{2}$ enrichment on biomass accumulation in lettuce. The current research was designed to look at the efficiency with which lettuce is able to utilize intermittent $\mathrm{CO}_{2}$ enrichment, test the accuracy with which growth can be predicted and controlled, and examine effects of varying $\mathrm{CO}_{2}$ enrichment and supplemental lighting on carbon assimilation and plant transpiration on a minute by minute basis. Experiments included application of various schedules of intermittent $\mathrm{CO}_{2}$ enrichment and gas exchange analysis to elucidate underlying physiological processes. Same-day and day-to-day adjustments in daily light integrals were made in response to occasional $\mathrm{CO}_{2}$ venting episodes, using an upto-the-minute estimate of growth progress based on an integration of growth increments that were calculated from actual light levels and $\mathrm{CO}_{2}$ concentrations experienced by the plants. Results indicated lettuce integrates periods of intermittent $\mathrm{CO}_{2}$ enrichment well, achieving expected growth targets as measured by destructive sampling. The gas-exchange work quantified a pervasive impact of instantaneous light level and $\mathrm{CO}_{2}$ concentration on conductance and $\mathrm{CO}_{2}$ assimilation. Implications for when to apply supplemental lighting and $\mathrm{CO}_{2}$ enrichment to best advantage and methods for predicting and controlling growth under intermittent $\mathrm{CO}_{2}$ enrichment are discussed.

\section{3}

Evidence for Toxic Effects of Cellulose Acetate in UV Exclusion Studies on 'Ashley' Cucumber Seedlings

Donald T. Krizek* and Roman M. Mirecki; Climate Stress Laboratory, ARS, U.S. Department of Agriculture, Beltsville, MD 20705-2350

Cellulose diacetate has been widely used in UV-B enhancement studies under field and controlled-environment conditions since the early 1970s to remove wavelengths below $\approx 290 \mathrm{~nm}$, without any evidence of toxicity effects. However, while conducting UV-B exclusion studies in window boxes covered with cellulose diacetate (CA) or in Plexiglas chambers lined with CA, there was marginal chlorosis and cotyledon epinasty in 'Ashley' cucumber, which is normally resistant to elevated UV-B, while seedlings exposed to open sunlight and those grown under polyester (PE) film to exclude UV-B were free of visible injury. These findings suggested that the CA filter itself may be causing toxicity. To test this hypothesis, a UV exclusion study was conducted in which CA or Teflon (T), both UV-B and UV-A transmitting films, were used to cover window boxes in the following four combinations (top/bottom): CA/CA, CA T,T/CA, and T/T. When CA was used as the bottom filter (CA/CA and T/CA), the plants showed significantly greater leaf injury and a 2- to 3-fold reduction in growth than when T was used as the bottom filter (CA/T and T/T). These findings suggest that toxicity is caused by CA itself rather than by solar UV-B radiation, possibly as a result of outgassing of phthalates known to be used as plasticizers in the manufacture of CA. Further evidence that $\mathrm{CA}$ was responsible for leaf injury was provided by a companion study in which T was replaced by PE and damage was still observed, although no significant growth effects of CA position were observed.

\section{4}

Detection of Water Stress Using Infrared Imaging

W.C. Lin* , G.S. Block, S. Chen, and D.L. Ehret; Pacific Agri-Food Research Ctr., Agriculture and Agri-Food Canada, POBox 1000, Agassiz, BC VOM 1A0, Canada In commercial production of greenhouse cucumber, moderate water stress is often undetectable until plants show severe wilting. The purpose of this study was to establish a noncontact, early detection method for such moderate stress before visual wilting takes place. An infrared imaging system including an infrared camera, a personal computer, and necessary image processing software was placed in a greenhouse with the camera elevated and viewing the plant canopy. Selected plants, each in a bag of sawdust growing medium, were subjected to water stress by removing irrigation tubes from the growing medium. Theinfrared images obtained from a crop canopy displayed an increase in foliar temperature of stressed plants, which were located among normally watered (control) plants in the same greenhouse. Increased foliar temperatures of stressed plants occurred 1 to 3 days before wilting was observed. When visual wilting occurred, the stress treatment was stopped and irrigation was resumed within the same day. Cucumber plants showed no crop loss after one cycle of moderate stress. Repeated moderate stress caused yield loss. The potential applications of this nondestructive, noncontact detection method in plant science research and in commercial greenhouse production will be discussed.

\section{5}

\section{Analysis of Leaf Development Rates as Affected by Environ-} ment Conditions for Modeling Vegetative Propagation of Sweetpotato

Chieri Kubota*, Ayami Yamaguchi, and Toyoki Kozai; Department of Bioproduction Science, Faculty of Horticulture, Chiba University, Matsudo, Chiba 271-8510, Japan

For vegetative propagation of sweetpotato, single or multi-node leafy cuttings are used as propagules. A quantitative understanding of leaf development and the effects of environment conditions on leaf emergence and expansion rates is important for predicting the number of propagules produced after a given production period. Single-node cuttings each with a fully expanded leaf were grown under two levels of photosynthetic photon flux (PPF, 160 and $250 \mu \mathrm{mol} \cdot \mathrm{m}^{-2} \cdot \mathrm{s}^{-1}$ ) and photoperiod ( 10 and $16 \mathrm{~h} /$ day). The time courses of the number of leaves larger than the standard leaf area (As) were obtained by analyzing the time courses of leaf blade length recorded every day on each leaf. The number of leaves larger than a given As increased almost linearly after the first leaf reached to the As. PPF and photoperiod affected both the duration until the appearance of the first leaf with As and the leaf development rates (leaves per day). The effects of PPF were more pronounced than photoperiod for the development rate of the leaves regardless of As. Results obtained in these experiments were incorporated into our previously developed model, and the number of propagules produced under different environment conditions was predicted. Such techniques need to be used effectively for planning and environment control of vegetative propagation.

\section{6}

Plant Density and Shoot Pruning Management on Yield of a Summer Greenhouse Sweet Pepper Crop

Elio Jovicich*, Daniel J. Cantliffe, and George J. Hochmuth; Horticultural Sciences Dept., University of Florida, 1251 Fifield Hall, POBox 110690, Gainesville, FL 32611-0690

In greenhouse crops, fruit yield and quality can be increased by managing shoot pruning and plant density. The effect of plant population density $(2,3$, and 4 plants $/ \mathrm{m}^{2}$ as function of in-row plant spacings of $66.5,44.3$, and $33.3 \mathrm{~cm}$, respectively), and shoot pruning (one, two, and four main stems) was studied for effects on fruit yield, quality and plant growth of greenhouse-grown sweet pepper (Capsicum annuum L. cv. Robusta) during Summer 1998 in Gainesville, Fla. Red fruit were harvested 84 and 118 days after transplanting (14 Apr.). Additional fruit set was inhibited due to the high temperatures. Marketable yield (number and weight) per square meter increased linearly with plant density and was greater on plants with four stems than in those with two or one stem. Extra-large fruit yield per square meter was not affected by plant density, but was higher in four-stem plants. Total marketable yield and extra-large fruit yields per plant were greatest in the four-stem plants at two plants per square meter. The stem length and the number of nodes per stem increased linearly with the decrease in plant spacing. Stem length and number of nodes per stem were greater in single-stem than in four-stem plants. Number and dry weight of leaves, stem diameter, and total plant dry weight were higher in four- and two- stem plants than in single-stem plants. Results indicated that four plants per square meter pruned to four stems increased marketable and extra-large fruit yield in a short harvest period of a summer greenhouse sweet pepper crop in north central Florida. 
507

Production of Compact Cucumber, Tomato, and Bell Pepper Transplants by Use of Photoselective Plastic Films

Shumin $\mathrm{Li}^{* 1}$, Nihal C. Rajapakse ${ }^{1}$, and Ryu Oi2; ${ }^{1}$ Department of Horticulture, Clemson University, Clemson, SC 29634, USA.; ${ }^{2}$ Organic Performance Materials Laboratory, Mitsui Chemicals, Inc., 1190, Kasama-cho, Sakae-ku, Yokohama 247, Japan

Growth chamber experiments were conducted to investigate the effectiveness of several photoselective plastic films in controlling height of 'Sweet Success' cucumber, 'Mt. Pride' tomato, and 'Capistrano' bell pepper transplants. Four types of treatment films; a control, two far-red light intercepting films (YXE-1 and YXE10), and a red light intercepting film (SXE-1), with $R$ : FR ratios of 1.0, 2.0, 1.6, and 0.8 , respectively, were used as the covering materials of experimental chambers. Photosynthetic photon flux (PPF) was adjusted to be the same in all chambers with cheese cloth. Treatment period for cucumber and tomato was 15 days and that for bell pepper was 20 days. At the end of the treatment, significantly shorter plants were found in both YXE-1 and YXE-10 chambers for all the three tested crops. However, YXE-10 was more effective than YXE-1 in producing compact cucumber, tomato and bell pepper transplants. SXE-4 film produced taller plants than control film. Magnitude of response to filtered light varied with the crop species. Number of leaves was not significantly affected by the light transmitted through photoselective filters, indicating that the height reduction was mainly caused by the reduction in internode length. With the commercial development of photoselective greenhouse covers or shade material in the near future, nursery and greenhouse industry could potentially reduce the cost for growth regulating chemicals, reduce the health risks to their workers and consumers, and reduce environmental pollution.

\section{8}

Ascorbic Acid Content in Tomato and Bell Pepper Fruit during Development, Maturation, and Senescence on the Plant and Relation with Ascorbate Oxidase and Polyamines EM. Yahia ${ }^{* 1}$, M. Contreras-Padilla', and G. Gonzalez-Aguilar'; ' DIPA, Facultad de Química, Universidad Autónoma de Querétaro, Querétaro, 76010; ${ }^{2} \mathrm{CIAD}$, Hermosillo, Sonora, México

Plants were grown in a greenhouse in controlled hydroponic conditions, and fruit were harvested at different intervals from 18 to 94 days from fruit set (DFFS). AsA was higher in pepper than in tomato fruit. In pepper fruit, it increased very fast and reached a maximum at 50 DFFS and then decreased suddenly and reached a minimum about 60 DFFS. AsA in tomato fruit increased slowly and reached a maximum after about 75 DFFS and then declined slowly. The decrease in AsA is correlated with the initiation of ripening and with an increase in the activity of $\mathrm{AAO}$. There was more putrescine in pepper than in tomato fruit. There were no major changes in spermine and spermidine in pepper and spermidine in tomato fruit. However, putrescine in pepper fruit and spermine in tomato fruit increased very early until about 30 to 38 DFFS and then decreased in a manner similar to the decrease in AsA. Putrescine in tomato fruit increased consistently and did not decrease even during the senescence of the fruit. We conclude that AsA decreases in tomato and pepper fruit after 75 and 50 DFFS, respectively, and this decrease is related to an increase in $\mathrm{AAO}$ and a decrease in putrescine in pepper and spermine in tomato fruit.

\section{ORAL SESSION 18 (Abstr. 509-515) Vegetable Crops: Genetics/Biotechnology}

\section{9}

\section{A Glycine-rich Protein from Tomato Involved in Pollen Wall} Formation

Alan G. Smith* and Kenneth J. McNeil; Department of Horticulture, University of Minnesota, St. Paul, MN 55108

The sporophytic tissue of the anther and, in particular, the tapetum, a cell layer surrounding the pollen sac, is know to be essential for the production of pollen. The isolation and characterization of the gene 92B from tomato that encodes an extracellular glycine rich protein (GRP) has been used to further elucidate the role of the tapetum in pollen development. RNA from the 92B gene accu- mulates exclusively in the tapetum. Polyclonal antibodies raised against the 92B GRP detect four proteins in stamens with microspores beginning meiosis. In pollen extracts, the antibodies detect a single protein. Expression of the tomato $92 B$ gene in transgenic tobacco indicates that the four protein products are derived from only the 92Bgene. The 92BGRP is localized to the tapetum, the callose wall of microspore mother cells, the exine (outer wall) of mature pollen, and orbicules. Orbicules are globular bodies derived from tapetal material that form on the tapetum wall and line the exterior of the pollen sac. Expression of 92B antisense RNA resulted in a significant decrease of 92B RNA and protein levels in transgenic tomatoes. This reduction was correlated with a decrease in pollen germination and an abnormal exine morphology. The function of the $92 B$ protein in pollen development and function will be discussed.

\section{0}

Alteration of Fruit Characteristics in Transgenic Tomatoes with Modified Gene Expression of Endo-xyloglucan Transferase

Kiyozo Asada*, Toshiharu Ohba, Shuichi Takahashi, and Ikunoshin Kato; Biotechnology Research Laboratories, Takara Shuzo Co., Ltd, Shiga, Japan

Endo-xyloglucan transferase (EXGT, also called xyloglucan endotransglycosylase, or XET) is a cell wall enzyme catalyzing molecular grafting between xyloglucan molecules, which is essential for expansion and morphological change of plant cells. EXGT gene was first isolated by us from Azuki bean hypocotyl and sequenced and later isolated by several other groups from variety of plants including monocots. In tomato, three genes have been identified, i.e., LeEXGT, tXET-B1, and $t X E T-B 2$. LeEXGT mRNA accumulated transiently in early stage of development (immature green and mature green stage). It accumulated slightly also in breaker stage in which fruit color turns to pink. The peak of LeEXGT mRNA accumulation was $\approx 12$ days after pollination. To elucidate a physiological role of EXGT, especially in fruit development, tomato plants were transformed to produce LeEXGT sense or antisense RNA constitutively using Ti plasmid-based transformation system, and we obtained several lines of plants with different levels of LeEXGT transcripts. In these transgenic tomatoes, fruit size was positively correlated with the level of LeEXGT transcripts monitored at its peak stage of expression. However, the refractive index of tomato fruit sap, which is closely correlated with the total solids contents and reflects the sugar status of the fruit, was negatively correlated with the level of LeEXGT transcripts. These results first represent the evidence that EXGT can control in vivo morphological and biochemical properties of plants by changing the level of its expression. This finding opens the possibility of improvement by transgenic approach of fruit plants, such as melon, watermelon, kiwifruit, and apple, in which sugar contents are important economic characters for evaluation.

\section{1}

Toward Mapping and Cloning Late Blight Resistance Derived from the Wild Solanum bulbocastanum using Potato $+S$. bulbocastanum Somatic Hybrids

James M. Bradeen*, S. Kristine Ness, Geraldine T. Haberlach, Susan M. Wielgus, and John P. Helgeson; USDA-ARS and Department of Plant Pathology, University of Wisconsin, 1630 Linden Drive, Madison, WI 53706 USA

Late blight of potato, caused by the fungal pathogen Phytophthora infestans, is of great economic significance and no important U.S. potato cultivars are reliably resistant. The diploid species Solanum bulbocastanum is highly resistant to late blight, even under extreme conditions, but is sexually incompatible with potato. We have generated potato + S. bulbocastanum somatic hybrids. These hexaploid hybrids are highly resistant to late blight and progeny from two successive backcrosses to cultivated potato are either fully resistant or susceptible. The advanced generations are morphologically similar to potato. We have initiated mapping efforts to identify bulbocastanum chromosomal regions responsible for late blight resistance. Using RFLPs, RAPDs, and AFLPs, we identified a single chromosomal region (i.e., single gene or group of linked genes) on chromosome 8 that accounts for $62.2 \%$ of the observed resistance. The tomato cDNA clone CT88 cosegregates with late blight resistance in our material and was used to isolate a homeologous BAC clone from a $S$. bulbocastanum library. Our current efforts include mapping resistance in both fusion-derived and diploid $S$. bulbocastanum materials via map merging. As markers linked to late blight resistance are identified, we will attempt to convert them to marker forms useful for large-scale breeding efforts. To date, we have successfully converted RAPD and RFLP markers to 
SCAR and CAPS marker forms. Finally, continued fine mapping and BAC clone characterization will enable future map-based cloning efforts.

\section{2}

\section{Copia-like Retrotransposon Sequences in the Ipomoea}

\section{batatas Genome}

Arthur Villordon ${ }^{* 1}$, Don La Bonte ${ }^{1}$, and Robert Jarref ; ${ }^{1}$ Louisiana State University Agricultural Center, Baton Rouge, LA 70803; '2USDA-REE-ARS-SAA-PGRCR, Griffin, GA 30223

The presence of copia-like retrotransposon sequences in sweetpotato [ Ipomoea batatas (L.) Lam.] was investigated. PCR-based amplification using primers to highly conserved copia-like reverse transcriptase sequences produced several products corresponding to the expected target size $(\approx 300 \mathrm{bp})$ that were subsequently isolated and cloned. A random sample of the clones were sequenced and all six reading frames were translated into their corresponding amino acid sequences. Sequence analysis revealed the presence of 22 copia-like reverse transcriptase sequences corresponding to various subfamilies. The presence of several sequence families in the genome is indicative of past or recent transposition activity. Southern blot analysis suggested that these copia-like sequences were present in several hundred copies in the sweetpotato genome. Data also showed retrotransposon insertion polymorphisms between a limited sample of virus-tested and virus-infected sweetpotato clones, indicating putative activity and mobility. This investigation documented the presence of copia-like retrotransposon sequences in the sweetpotato genome. This is an important step in clarifying the possible association between mobile genetic elements and the unusually high incidence of somatic mutations that may result in clonal decline in sweetpotato and other asexually propagated crops. Data presented provides information on the possible use of retrotransposons as genetic markers for sweetpotato crop improvement.

\section{3}

Use of Reverse Transcription PCR (RT-PCR) to Study the Potato Stearoyl-ACP Desaturase (Delta9) Gene Expression at the Transcript Level during Cold Acclimation

Sandra E. Vega* and Jiwan P. Palta; University of Wisconsin-Madison, Department of Horticulture, 1575 Linden Drive, Madison WI 53706-1590

Previous studies in our laboratory both in pine needles and potato leaves have shown evidence of an increase in $18: 2$ (linoleate) in the purified plasma membrane fraction during cold acclimation. This increase was reversible on deacclimation, thereby suggesting a link between the accumulation of $18: 2$ and acquisition of freezing tolerance. These studies suggest that the activity of specific desaturases may be modulated during cold acclimation. This study was aimed at studying the possible involvement of stearoyl-ACP desaturase (delta9) in potato cold acclimation response. Our approach was to study the induction of delta9 desaturase at the transcript level by using potato delta9 desaturase gene specific primers and reverse transcriptase. For this purpose, mRNA from $S$. tuberosum (cold sensitive, unable to acclimate) and $S$. commersonii (cold tolerant, able to cold acclimate) was extracted before and after acclimation. Sequence analysis confirmed that the amplified band was delta9 desaturase. Our results show that there is an increase in delta9 desaturase gene transcripts during cold acclimation and that this increase is associated with the cold acclimation response in potato. These results together with previous reports on the increase in $18: 2$ in the plasma membrane during cold acclimation give more evidence toward the involvement of stearoyl-ACP desaturase (delta9) in the potato cold response.

\section{4}

\section{Consistency of Detected QTL for Bacterial Brown Spot Resistance Using RAPD Markers over Environments in Common Bean}

G. Jung ${ }^{* 1}$, H. Ariyarathne', D.P. Coyne ${ }^{2}$, J. Nienhuis' ${ }^{1}$ S. Hirano ${ }^{1}$, and C. Upper'; ${ }^{1}$ Univ. of Wisconsin, Madison, WI 53706; ' 2 Univ. of Nebraska, Lincoln, NE68583

Bacterial brown spot (BBS), incited by the bacterial pathogen Pseodomonas syringae pv. syringae is important disease of common bean. Phenotypic visual readings of infected areas and a leaf freezing assay estimating the population size of Pss on leaf surface were used for disease assessment for 2 years using $78 \mathrm{RI}$ lines derived from Belneb RR-1 x A55 population grown in Wisconsin. The objectives of this research were to determine the genomic regions of QTL affecting the genetic variation of bacterial brown spot resistance in both assays over 2 years (1996 and 1998) and to determine the size of their genetic effects. In addition, we examined the consistency of detected QTL over environments. Three chromosomal regions associated with QTL for BBS resistance were identified in both assays in 1996 and one chromosomal region was consistently detected over 2 years.

\section{5}

\section{Mapping of Molecular Markers and Seedcoat Pattern} Associated with QTL Affecting White Mold Resistance in Common Bean

Soon O. Park ${ }^{* 1}$, Dermot P. Coyne ${ }^{1}$, James R. Steadman ${ }^{1}$, and Geunhwa Jung2; ${ }^{1}$ University of Nebraska, Lincoln, NE 68583; 'University of Wisconsin, Madison, WI 53706

White mold, incited by Sclerotinia sclerotiorum (Ss), is an important disease of common bean ( Phaseolus vulgaris). Our objective was to identify RAPD markers and seedcoat pattern associated with QTL affecting resistance to Ss isolates 152 and 279 in a molecular marker-based linkage map previously constructed using a recombinant inbred (RI) population from the common bean cross ' $\mathrm{PC}-50$ ' (resistant to Ss) x XAN-159 (susceptible to Ss). White mold reactions were derived from a greenhouse straw test. Continuous distributions for the reactions to Ss isolates 152 and 279 were observed for RI lines, indicating quantitative inheritance. An intermediate $(+0.67)$ Pearson correlation was observed between the reactions to Ss isolates 152 and 279. Low (0.24 and 0.23) narrow-sense heritabilities were found for the reactions to Ss isolates 152 and 279. Three QTL affecting resistance to Ss isolate 152 explained $33 \%$ of the phenotypic variation. Four QTL affecting resistance to Ss isolate 279 explained $54 \%$ of the phenotypic variation. The seedcoat pattern marker $(C)$ on linkage group I was most consistently associated with resistance to Ss isolates 152 and 279, and explained $10 \%$ and $24 \%$ of the phenotypic variation for the traits, respectively. This is the first report on detection of QTL for white mold resistance in common bean. The RAPD markers and seedcoat pattern could be useful in breeding for white mold resistance.

\section{ORAL SESSION 19 (Abstr. 516-523) Fruit/Nuts: Crop Physiology/Plant Growth Regulators}

\section{6}

\section{Predicting Fruit Set and Evaluating the Effects of Chemical Thinners on Apples}

Duane W. Greene*, Department of Plant and Soil Sciences, Univ. of Massachusetts, Amherst, MA 01003

The lack of pollination and the effects of blossom thinners were simulated by enclosing selected 'Mclntosh' apple spurs in super-light insect barrier netting at the pink stage of flower development. Fruit set was recorded and fruit size measured at 2- to 3-day intervals from petal fall until initial set. The effects of lack of pollination or the use of blossom thinners on initial set could not be determined with any degree of accuracy until at least 8 days after petal fall. NAA was applied at $8 \mathrm{ppm}$ when fruit were $8.5 \mathrm{~mm}$ in diameter. Fruit set and fruit size were taken at 2- to 3-day intervals until the end of June drop. Fruit set on NAA-treated trees was greater than that on check trees for 2 weeks following application. Although NAA ultimately did cause significant thinning, it was not until 3 to 3.5 weeks after application that it was possible to determine with accuracy the thinning response to NAA. However, the thinning response to NAA could be predicted within a week after application, since growth of fruitlets that ultimately abscised slowed 4 to 7 days after the application of NAA. A working model to predict effective pollination and the response to chemical thinners in apples will be discussed.

\section{7}

\section{Bloom Thinner Wilthin Decreased Fruit Set and Increased Fruit Yield and Quality of Three Apple Cultivars}

Ejaz Mohammad Ansari", Frank B. Matta, Taqueer Abbas, and Mohammad Baquir; Mississippi State University, Mississippi State, MS 39762

The influence of bloom chemical thinner Wilthin on three apple cultivars (Royal Gala, Blushing Gold, and Ultra Gold) was investigated. Two experiments were 
conducted in 1995 and 1996 to determine the effect of Wilthin at $0 \%, 0.5 \%$, $1.0 \%$, and $1.5 \%$ on fruit length, fruit diameter, fruit weight, yield, juice $\mathrm{pH}$, acidity, SSC, sucrose, glucose, fructose, fruit firmness, and fruit set. Wilthin reduced fruit set of 'Royal Gala', 'Ultra Gold', and 'Blushing Golden' and increased yield of all cultivars. In general, Wilthin increased fruit weight of 'Royal Gala', 'Ultra Gold', and 'Blushing Golden' both years. Wilthin increased fruit length and diameter of 'Royal Gala' and 'Ultra Gold', but it did not affect fruit length of 'Blushing Golden' Wilthin increased fruit juice pH of 'Royal Gala', 'Ultra Gold', and 'Blushing Golden' during both years. Wilthin decreased fruit juice acidity of 'Royal Gala', 'Ultra Gold', and 'Blushing Golden'. In 1995, Wilthin increased SSC of 'Royal Gala' and 'Ultra Gold'. In 1996, Wilthin did not effect SSC of 'Royal Gala' and 'Blushing Golden', but increased SSC of 'Ultra Gold'. Wilthin increased sucrose concentration of 'Royal Gala', 'Ultra Gold', and 'Blushing Golden'. Wilthin did not effect fruit juice glucose concentration of 'Royal Gala' but increased fruit juice glucose concentration of 'Ultra Gold' and 'Blushing Golden'. Wilthin did not influenced fructose content of 'Royal Gala' and 'Blushing Golden' apples. Wilthin increased fructose contents of 'Ultra Gold'. Accel increased fruit firmness of 'Royal Gala', 'Ultra Gold', and 'Blushing Golden' and increased fruit firmness of 'Royal Gala'.

\section{8}

\section{Regulating Fruit Set and Maturity of 'Macoun' Apples}

J.R. Schupp*; Highmoor Farm, University of Maine, Monmouth, ME04259

'Macoun' is a high-value apple cultivar in the northeastern United States that is very difficult to produce. It is difficult to thin and prone to alternate bearing. 'Macoun' is also prone to preharvest drop. Small fruit size, bruising, and lack of red color are additional obstacles to profitable production. The objective of this study was to compare the efficacy of two chemical thinning treatments- accel plus carbaryl, or NAA plus carbaryl - with an untreated control. A second objective was to evaluate the efficacy of ReTain for delaying 'Macoun' fruit maturity and to determine if there was an interaction between ReTain and thinning treatment on fruit characteristics at harvest. Both thinning treatments were effective in reducing fruit set in 1997. Accel plus carbaryl was effective again in 1998, while NAA plus carbaryl over-thinned. Accel increased fruit size in 1997 compared to unthinned controls, and both thinning treatments increased fruit size in 1998. Accel increased fruit firmness in both years. ReTain reduced preharvest drop and delayed fruit maturity both years. In 1997, firmness was greatest for fruit treated with accel and ReTain, while ReTain had no effect on firmness of fruit from NAA thinned trees. ReTain had no effect on fruit firmness in 1998.

\section{9}

\section{The Negative Impact of Sevin XLR Plus Thinner Use on} Apple Fruit Quality under Certain Environmental Conditions

C.R. Unrath*; Dept. of Horticultural Science, North Carolina State University, Mountain Horticultural Crops Research and Extension Center, 2016 Fanning Bridge Road, Fletcher, NC 28732

The use of Sevin XLR Plus in chemical thinning applications at or shortly after petal fall in 1998 resulted in serious negative fruit quality effect, especially on 'Red Delicious'. This negative fruit quality impact was worse in certain Henderson Co., N.C., orchards. Fruit diameter was reduced by $9 \%$, fruit weight was reduced by $22 \%$, misshapen fruit increased by $30 \%$, eliminator fruit ( $<2.25 ")$ increased by $102 \%$, severely stunted fruit $(<2.0 ")$ increased by $317 \%$. Surface russetting increased by $160 \%$ and seed numbers per fruit dropped by $27 \%$. These are "never before seen" fruit quality problems for North Caronlina, which appear to be related to the unusual environmental conditions between full bloom and fruit thinning. Comparing the 30-year weather records, Apr. 1998 was the wettest April on record with twice the average rainfall. There were only two rain free days between bloom and petal fall, and only 9 of the 30 days following bloom were rain-free. Daily lows were at or above while daily highs were below the 30-year average, resulting in an extremely small daily temperature fluctuation. The departure from normal for average daily temperature was highly negative from partial petal fall until 2 weeks post petal fall. Daily relative humidity values for daily minimum, average and maximum were consistently and substantially above 30year average values. It appears that these environmental extremes with Sevin XLR Plus use has an impact on fruit quality. In one 'Golden Delicious' orchard where Sevin formulations could be compared side by side, fruit russetting jumped from $5.3 \%$ with 50 WP to $36.2 \%$ with the XLRPlus formulation.

\section{Methyl Jasmonate Causes Ethylene Production and Abscis- sion in Citrus}

J.K. Burns ${ }^{\star}$, U. Hartmond, R. Yuan, and W.J. Kender; Citrus Research and Education Center, University of Florida, 700 Experiment Station Road, Lake Alfred, FL 33850

Methyl jasmonate ( $\mathrm{Me}-\mathrm{Ja}$ ) is a naturally occurring ubiquitous compound in plants. Me-Ja is considered to be a putative plant hormone because of its effect on plant processes such as senescence, germination, tuber formation, signal transduction, ethylene production, and abscission at low exogenous concentrations. We applied Me-Ja to fruit or whole trees of 'Hamlin' or 'Valencia' orange to determine the potential of this compound as a mature fruit abscission agent. Me-Ja 0 , $1,5,10$, or $20 \mathrm{mM}$ in $0.1 \%$ Kinetic adjuvant) was applied to whole trees with a handgun or boom sprayer rates of 4850 and $1790 \mathrm{~L} \cdot \mathrm{ha}^{-1}$, respectively. Alternatively, tree fruit were dipped in Me-Ja solutions. Fruit drop, leaf drop and ethylene production in both fruit and leaves and fruit detachment force in fruit were monitored at various times up to 2 weeks after application. Me-Ja treatment resulted in increased ethylene production in fruit and leaves 1 to 2 days after application. Fruit detachment force significantly declined 6 to 10 days after application followed by significant fruit drop. Applications of $\mathrm{Me}-\mathrm{Ja}>10 \mathrm{mM}$ resulted in an unacceptable amount of canopy defoliation. The results suggest that Me-Ja has potential as an abscission agent for citrus. Future work will focus on improving uniformity of application and response.

\section{1}

\section{Effects of Apogee on the Growth and Fruit Quality of Three Apple Cultivars in California} Kathy Kelley ${ }^{* 1}$ and Carol Regusci'; ${ }^{2}$ University of California Cooperative Extension, Stanislaus County, Modesto, CA 95358; ${ }^{2}$ BASF Corporation, Salida, Calif.

Apogee at rates of 125 and $250 \mathrm{ppm}$ applied at 2-cm average shoot growth and a split application of 125 ppm applied at 2-cm shoot growth and 2 weeks later reduced vegetative growth of 'Pink Lady', 'Gala', and 'Fuji' in 1997 and 1998. Cultivar response varied with rate and year. Fruit size was significantly increased in 'Gala' at the low rate and split low rate applications and in 'Fuji' at the low and high rate single application in 1998. There was no effect on return bloom or fruit color.

\section{2}

Study on the Effect of $\mathrm{GA}_{4+7}, \mathrm{GA}_{3}$, and Dimethoate on Russeting of 'Golden Delicious' Apple

A. Talaie and J. Mojtahed"; University of Tehran, Karaj, Iran

Skin russet in apple fruit, which causes a considerable decrease in marketing and exporting potentials, is one of the major problems in the word fruit markets. In this project, the effect of $\mathrm{GA}_{4+7}, \mathrm{GA}_{3}$, and dimethoate on russeting of 'Golden Delicious' apple was examined. A complete randomized-block design with 13 treatments and four replications was used. In all treatments, the trees had the same size and medium growth and were homogeneous. The distances between trees were $6 \times 6 \mathrm{~m}$ and the age was 18 years. The total number of trees, including controls, was 52. The 12 treatments were $\mathrm{GA}_{4+7}$ and $\mathrm{GA}_{3}$ with $10 \mathrm{ppm}$ and 20 ppm concentrations in one and two times of spray in petal fall (PF) and PF + 10 days. Dimethoate at a concentration of $0.03 \%$ and $0.05 \%$ in one and two times of spray in $\mathrm{PF}$ and $\mathrm{PF}+10$ days. Fruit russeting was reduced in all treatments except with $\mathrm{GA}_{3}$. The largest decrease of russeting was caused by $\mathrm{GA}_{4+7}$, especially with $20 \mathrm{ppm}$ and also dimethoate with a significant decrease in russeting. Seed number also decreased significantly with $\mathrm{GA}_{4+7}$ and $\mathrm{GA}_{3}$, but dimethoate had no significant effect on TSS, while ACD ratio was decreased significantly by $\mathrm{GA}_{4+7}$ and dimethoate, but $\mathrm{GA}_{3}$ had no significant effect. Compared with the control, the treatment did not show differences with the other characteristics.

\section{3}

\section{Prohexadione-Ca: Induction of Resistance against Bacterial} and Fungal Pathogens in Apple

W. Rademacher" ${ }^{\star 1}$, J.B. Speakman, G. Krack ${ }^{2}$, M. Scholtissek ${ }^{2}$, R. Wolf, J.R Evans $^{3} ;$ S. Roemmelt', and D. Treuttert; 'BASF Agricultural Center, 67114 Limburgerhof, Germany; ${ }^{2 B A S F}$ Analytical Department, 67056 Ludwigshafen, Germany; ${ }^{3 B A S F}$ Corporation, P.O.Box 13528, Research Triangle Park, NC 277093528, USA; ${ }^{4}$ nstitute for Fruit Science, Technical University of Munich, 85350 Freising, Germany

Prohexadione- $\mathrm{Ca}$ (BAS $125 \mathrm{~W}$ ) is currently developed as an inhibitor of ex- 
cessive vegetative growth in apple. In addition to the control of shoot growth, pronounced effects on the incidence of scab (Venturia inaequalis) and fire blight (Erwinia amylovora) are observed that are not due to any fungicidal or bactericidal effect of the compound. Prohexadione-Ca induces marked changes in the metabolism of phenylpropanoids most likely by inhibiting distinct dioxygenases, such as flavanone 3-hydroxylase, which require 2-oxoglutarate as a co-substrate. The content of flavonoids such as luteoliflavan (which does not normally occur in apple tissue) and eriodyctiol is drastically increased reaching levels in the range of $50 \mathrm{mg}$ per gram of dried young shoot tissue. Simple phenols, the identity of which is still unknown, also undergo intense changes. Since phenylpropanoids have often been found to be involved in defense mechanisms of higher plants, further studies on their role in pathogen resistance in apple are justified from these results.

97 ORAL SESSION 20 (Abstr. 524-531) Small Fruit/Viticulture: Production \& Physiology of Raspberries/Blueberries/ Cranberries

\section{4}

\section{Primocane Tipping to Delay 'Heritage' Red Raspberries Harvest Date in Chile}

M. Pilar Bañados ${ }^{\star}$, Carolina Alvarez, and Alejandra Soto; Facultad de Agronomla, Pontificia Universidad Católica de Chile, Casilla 306-22 Santiago, Chile

To evaluate the effect of the time of primocane tipping on harvest date of 'Heritage' red raspberry in the central valley of Chile (southern hemisphere), we tipped primocanes at three dates during the 1996-97 growing seasons: in Nov. 1996 (PN), Dec. 1996 (PD), and Jan. 1997 (PJ). Tipping was done manually at a $1.10-\mathrm{m}$ height. Harvest date, fruit quality, and yield component was evaluated in the control and three tipping dates. A difference of 75 days on the initiation of harvest date was detected among treatments. Harvest date initiation was on 20 Jan. for the control with no tipping and for PN, 3 Mar. for PD, and 4 Apr. for PJ. Fruit of the PN treatment was smaller and lighter than the rest of the treatments; however, little differences in soluble solids, acidity, and pH were detected among treatments. Primocane lateral number was 14 for the control treatment and decreased to seven in tipped primocanes. Lateral length increased largely with tipping treatments: $7.8 \mathrm{~cm}$ in the control, $30 \mathrm{~cm}$ in PN, $29 \mathrm{~cm}$ in PD, and $42 \mathrm{~cm}$ in PJ. Fruit per lateral ranged between 6.2 in control and 12.2 in PD. Yields estimation for the fall production were $8.5 \mathrm{t} / \mathrm{ha}$ in the control, and increased to $12 \mathrm{t} / \mathrm{ha}$ estimated for the PJ treatment. The time of primocane tipping had an important effect on 'Heritage' red raspberry harvest date, lateral length, and estimated yield.

\section{5}

Advanced Development of Split Trellis for Red Raspberry: Cultural Management and Machine Harvest Studies

Stephen F. Klauer*, Chuhe Chen, and J. Scott Cameron; Washington State University Research and Extension Unit, Vancouver, WA 98665

In 1998, yield of the split (ST) vs. conventional trellis was again compared in 'Meeker' red raspberry with work at Vancouver focusing on advanced trellis development and technology transfer. Field testing was expanded from two to five sites in northern (Lynden) and southwestern (Woodland, Ridgefield, WSUV REU) Washington, with a total of eight trials. These tested a variety of widths (28-51 $\mathrm{cm}$ ), crossarm styles, and machine harvesters in fields with varied cultural practices. Four trials were machine-picked, and, in Vancouver, harvest efficiency was studied. For widths $>43 \mathrm{~cm}$, yields were $10 \%$ to $13 \%$ greater for ST in four trials, while widths less than $43 \mathrm{~cm}$ showed no increase. As in previous years, estimated yield potential was 20\% to $59 \%$ higher for ST in three of four trials. Differences between actual/estimated yields were due to several factors, including damage to laterals, harvest inefficiency, and poor early fruit release. Yield potential was greater $(28 \%)$ for ST in a second-year trial, suggesting sustainability. In various trials, numerous data were collected including canopy and primocane measurements, aboveground biomass, light interception and leaf : area, gas exchange, chlorophyll content, fourth derivative spectra, fluorescence, $\mathrm{N}$ content, and tissue for anatomical analysis. Results were similar to last year. Increased light within ST causes earlier and larger canopy growth and fruit development.
There was a large increase in leaf number, leaf area and berry number. Increases in yield were again associated with higher number of lateral/cane. There was no difference in leaf physiological measurements/leaf area between treatments.

\section{6}

\section{Hydrogen Cyanamide Hastens Fruit Development and} Increases Fruit Yield and Berry Size of Blueberry

J.G. Williamson* and EP. Miller; Horticultural Sciences Dept., IFAS, University of Florida, Gainesville, FL 32611-0690

Field-grown 'Misty', 'Star', and 'Southmoon' southern highbush, and 'Climax' rabbiteye blueberry plants were sprayed to drip with $0,7.7$ and $15.4 \mathrm{~g} \cdot \mathrm{L}^{-1} \mathrm{con}$ centrations of hydrogen cyanamide in north central Florida on 17 Dec. 1997 and 6 Jan. 1998. Plants were dormant with slightly swollen flower buds (stage 2) at the times of applications. The extent and earliness of vegetative budbreak were increased by both hydrogen cyanamide sprays. Hydrogen cyanamide also increased mean fruit fresh weights and reduced fruit development periods for 'Misty', 'Southmoon' and 'Climax' but not for 'Star'. Yield response to hydrogen cyanamide was variable among cultivars. Fruit yields of 'Misty' and 'Climax' increased slightly by $7.7 \mathrm{~g} \cdot \mathrm{L}^{-1}$ sprays and decreased significantly by $15.4 \mathrm{~g} \cdot \mathrm{L}^{-1}$ sprays. In that case, increased fruit yields appeared to be the result of greater mean fruit fresh weights while reduced yields resulted from significant flower bud thinning that occurred at the highest spray concentration. Both hydrogen cyanamide spray concentrations increased fruit yield for 'Southmoon' and decreased fruit yield for 'Star' when compared to controls. Spray date had no effect on fruit yield and little effect on fruit development period. Hydrogen cyanamide has potential for increasing fruit quality and earliness of some blueberry cultivars that are grown in the lower southeastern United States.

\section{7}

\section{A Highly Efficient in Vitro Cranberry Regeneration System using Leaf Explants}

Luping Qu*, James Polashock, and Nicholi Vorsa; Blueberry and Cranberry Research Center, Rutgers University, Chatsworth, NJ 08019

We have established a very efficient cranberry regeneration (shoot organogenesis) system from leaf explants using abasal medium consisting of Anderson's salts and Murashige and Skoog (MS) organics supplemented with 1-phenyl-3(1,2,3-thiadiazol-5-yl) urea (TDZ) and $\mathrm{N}_{6}$-( - ??-dimethyallylamino) purine) (2ip). Characteristics examined include combinations of varying levels of three plant growth regulators (TDZ, 2ip, and naphthaleneacetic acid (NAA), explant orientation (adaxial or abaxial side in contact with the media), and leaf position relative to the distal end of the shoot. Genotypes ('Early Black', 'Pilgrim', 'Stevens', 'Ben Lear', and US\#35) differed significantly in regeneration capacity, and there were no genotype by treatment interaction effects. Regeneration occurred on more than $95 \%$ of the explants with 'Early Black' and 'Pilgrim' producing as many as 100 shoot tips per explant with one particular treatment. Emerging adventitious shoots were always observed on the adaxial side of the leaves regardless of explant orientation. However, regeneration was much greater when the adaxial side was in contact with the media. Regeneration efficiency was not significantly affected by leaf position (10 leaves). Elongation of shoot tips began about 2 weeks after the regenerating explants were transferred to the basal medium without hormones and continued for several months. Elongated shoot cuttings rooted readily.

\section{8}

Use of Cultivar and Plant Characteristics as the Basis for Fertilizer Nitrogen Applications in Cranberry (Vaccinium macrocarpon Ait.)

Carolyn DeMoranville*1 and Joan Davenporf; 'University of Massachusetts Cranberry Experiment Station, E. Wareham, MA 02538; ${ }^{2}$ Department of Crop and Soil Science, Washington State University, Prosser, WA 99350

The relationship between yield and applied $\mathrm{N}$ in cranberry has been investigated. Cultivar was important in determining optimum seasonal N rate. Sustained production for the hybrid 'Stevens' required an annual seasonal total of $\mathrm{N}$ at up to $67 \mathrm{~kg} \cdot \mathrm{ha}^{-1}$, higher than was optimal for native selections 'Early Black' and 'Howes'. High N rates were associated with increased fruit rot and vine overgrowth. Optimum $N$ rate varied within cultivar, likely due to variation in soil conditions, but soil $\mathrm{N}$ test results have not correlated well with subsequent yield in cranberry. Soil organic matter content can predict potential $\mathrm{N}$ release, but plant response must also be taken into account. To refine $\mathrm{N}$ rate recommendations, plant charac- 
teristics that might predict $\mathrm{N}$ requirements/status of cranberry were investigated. A standard of $0.9 \%$ to $1.1 \% \mathrm{~N}$ in August tissue has been established for cranberry. To find characteristics that could be used earlier, we surveyed 30 sites for percentage of $\mathrm{N}$ in tissue, length of new growth, SPAD chlorophyll meter ratings, fertilizer N use, and yield. Length of new growth could be used as an indicator of cranberry $\mathrm{N}$ status from June until bloom, being positively correlated with subsequent yield. The SPAD meter proved to be a viable alternative to in-season monitoring of tissue $\mathrm{N}$ during June and July. Readings below proposed standard values indicated the need for $\mathrm{N}$ fertilizer if vegetative growth was in the standard range. Thus, the easily determined factors of upright length and SPAD rating could be used to refine fertilizer rates during the active growing season, while tissue testing for percentage of $\mathrm{N}$ could be used as a "report card" on the fertilizer program at the end of the season.

\section{9}

Relationship of Soil Temperature, $\mathrm{pH}$, and Organic Carbon Content to Nitrogen Release in Cranberry Soils

Joan R. Davenport ${ }^{*} 1$ and Carolyn DeMoranville ${ }^{2} ;{ }^{1}$ Dept of Crop and Soil Science, Washington State University, Prosser,WA 99350; ${ }^{2}$ Cranberry Experiment Station, University of Massachusetts, E. Wareham, MA 02538

Soluble nitrogen (ammonium and nitrate) is released when soil organic matter is mineralized. The amount of $\mathrm{N}$ released by this process depends on the amount of organic matter present and soil temperature. Cranberry ( Vaccinium macrocarpon Ait.) grows in acidic soils with a wide range in organic matter content. To evaluate how soil $\mathrm{N}$ release is affected by soil temperature, intact soil cores were collected from sites that had received no fertilizer and placed in PVC columns. Four different soil types, representing the range of cranberry soils (sand, sanded organic soil, peat, and muck), were used. Each column was incubated sequentially at six different temperatures from 10 to $24^{\circ} \mathrm{C}\left(2.8^{\circ} \mathrm{C}\right.$ temperature intervals) for 3 weeks at each temperature, with the soils leached twice weekly to determine the amount of $\mathrm{N}$ release. The total amount of $\mathrm{N}$ in leachate was highest in organic soils, intermediate in the sanded organic soil, and lowest in the sands. The degree of decomposition in the organic soils was important in determining which form of $\mathrm{N}$ predominated. In the more highly decomposed organic soil (muck), most of the $\mathrm{N}$ was converted to nitrate. The data from this study resulted in the development of two models - one predicting the $\mathrm{N}$ mineralization and the other predicting the proportion of $\mathrm{N}$ in each of the two forms. Key factors for $\mathrm{N}$ release rate were soil temperature, percentage of clay, and organic carbon content. For predicting the proportion of $\mathrm{N}$ as ammonium vs. nitrate, key factors were soil temperature, soil pH, and the distribution of mineral matter in the silt and sand fractions.

\section{0}

Fruitfulness of Evergreen vs. Deciduous Southern Highbush Blueberry after Cross-, Self-, and No Pollination

Ingrith D. Martinez and P.M. Lyrene*; Horticultural Sciences Dept., University of Florida, Gainesville, FL 32611

Fruit set, fruit size, and seed production after hand pollination in a greenhouse were compared for southern highbush blueberry managed in two ways: a) 69 clones were allowed to go dormant and lose their leaves in the field before being dug and subjected to 1000 hours at $5^{\circ} \mathrm{C}$ and b) 26 clones were kept growing in a greenhouse through fall and winter without leaf loss and without chilling to induce flowering on plants that had mature leaves. On each plant in both management systems, some flowers were self-pollinated, some were cross-pollinated, and others had the styles removed before anthesis to prevent pollination. For $>1000$ flowers per pollination treatment on the deciduous plants, fruit set averaged $1 \%$ for no pollination, $46 \%$ for self-pollination, and $76 \%$ for cross-pollination. The corresponding values for the evergreen plants were $23 \%, 59 \%$, and $81 \%$. Parthenocarpic berries averaged $0.37 \mathrm{~g} /$ berry for deciduous plants and 1.01 $\mathrm{g}$ for evergreen plants. Both crossed and selfed berry weights averaged slightly higher for the evergreen plants than for the deciduous plants, but seed number per berry was much lower for the evergreen plants (12 seeds in crossed berries and four seeds in selfed berries) compared to deciduous plants (37 and 8). Southern highbush blueberry plants that flower without going dormant appear to have much higher parthenocarpic capabilities than those that flower after a dormant period.
531

Relating the Accumulation of Heat Units to Changes in the Phenology and Frost Hardiness of Cranberry during Spring Beth Ann A. Workmaster* and Jiwan P. Palta; Department of Horticulture, University of Wisconsin, Madison, WI 53706

Little is known about the growth and development of the cranberry plant (Vaccinium macrocarpon Ait.) in response to air and soil temperatures in the spring. During this period, marked changes in cranberry bud hardiness are known to occur (from -20 to $0^{\circ} \mathrm{C}$ ), with the greatest changes occuring before bud elongation. The ability to predict changes in bud phenology and hardiness in relation to thermal time would be useful to growers in making frost management decisions. To establish a working growth model, canopy air and soil temperatures were continuously recorded in 1996, 1997, and 1998 in a cranberry bed (cv. Stevens) in central Wisconsin. In spring, samples of uprights were randomly collected from several locations within the bed and sorted according to a nine stage bud classification from tight bud to bloom. Controlled freezing tests were performed on uprights from the most advanced stages present that constituted $10 \%$ or more of a sample on a given date. Heat units were calculated from hourly canopy air temperatures. Despite the varied weather conditions over the 3 years, a distinct relationship existed between the accumulation of heat units and the advancement of the crop. Spring 1998 was very early and resulted in the accumulation of more heat units before initial and advanced bud swell was observed compared to the other 2 years. Initial evaluation suggests that soil temperatures between 5 to $10^{\circ} \mathrm{C}$ and photoperiod may play a role in modulating the effect of air temperatures. Further refinement of this model and the predictive value for frost hardiness changes will be discussed.

\section{ORAL SESSION 21 (Abstr. 532-539) Cross-commodity: Postharvest Metabolism/Plant Growth Regulators}

\section{2}

Lovastatin Inhibits $\alpha$-Farnesene Synthesis without Affecting Ethylene Production during Fruit Ripening in Apples Zhiguo Ju* and Eric A. Curry; USDA, ARS, Tree Fruit Research Lab, 1104 North Western Avenue, Wenatchee, WA 98801

At harvest, internal ethylene was $>0.5 \mathrm{~mL} \cdot \mathrm{L}^{-1}$ and $\alpha$-farnesene concentrations were below detectable levels in 'Golden Supreme', 'Delicious', and 'Granny Smith' apples. After 30 days of storage at $20^{\circ} \mathrm{C}$, control fruit produced high levels of internal ethylene and $\alpha$-farnesene. Lovastatin at 100 to $1000 \mathrm{~mL} \cdot \mathrm{L}^{-1}$ did not affect ethylene synthesis, but significantly inhibited $\alpha$-farnesene production. In 'Golden Delicious', ethephon treatment increased ethylene synthesis in lovastatin-treated fruit but did not stimulate $\alpha$-farnesene production. In lovastatintreated fruit peel of 'Delicious' and 'Granny Smith', meval onate (MAL) and farnesyl pyrophosphate (FPP) induced $\alpha$-farnesene production, but hydroxymethylglutaric acid (HMG) did not. The induction of $\alpha$-farnesene synthesis by MAL and FPP was concentration-dependent. Precursor feeding did not affect ethylene production in fruit peel. When high level of $\alpha$-farnesene was detected in fruit peel $(5 \mathrm{~mm}$ thick), it was not found in outer (adjacent to peel) and inner cortex (mid of flesh) tissues. Adding HMG, MAL, and FPP induced $\alpha$-farnesene biosynthesis in both cortex tissues. When lovastatin was added to the feeding solution, MAL and FPP induced $\alpha$-farnesene production but HMG did not.

\section{3}

Metabolic Changes Associated with Strawberry Cultivars with Different Tolerances to High Carbon Dioxide during Storage

J.P. Fernandez-Trujillo*, J.F. Nock, and C.B. Watkins; Department of Fruit and Vegetable Science, Cornell University, Ithaca, NY 14853

Several strawberry fruit cultivars were exposed to air or $\mathrm{CO}_{2}$ at $2{ }^{\circ} \mathrm{C}$ for up to 9 days. Concentrations of fermentation products and organic acids, and activities of pyruvate decarboxylase (PDC) and alcohol dehydrogenase (ADH), were measured. Acetaldehyde, ethanol, and ethyl acetate concentrations accumulated in $\mathrm{CO}_{2}$-treated fruit of 'Honeoye' and 'Kent', but not in 'Cavendish' or 'Annapolis'. We classified the former group of cultivars as intolerant to high $\mathrm{CO}_{2}$ and the latter 
group as tolerant to high $\mathrm{CO}_{2}$. Activities of $\mathrm{PDC}$ and $\mathrm{ADH}$ were higher in $\mathrm{CO}_{2}$ treated than air-treated fruit of the tolerant cultivars but not in the intolerant cultivars. Succinate accumulated in fruit of all cultivars, but concentrations were highest in the tolerant than in the intolerant cultivars. These results will be discussed in relation to mechanisms of $\mathrm{CO}_{2}$ action on fruit metabolism.

\section{4}

\section{1-Methylcyclopropene Extends Shelf Life of Tomato at All} Stages of Maturity

Nazir A. Mir* , Najma Khan, and Randolf M. Beaudry, Dept. of Horticulture, Michigan State University, East Lansing, MI 48824

The effects of 1-MCP on ripening and shelf life in fruit of five classes of maturity (1, mature green; 2 , turning; 3 , half-ripe; 4 , ripe; and 5 , over-ripe) of 'Plum' tomato ( Lycopersicon xesculentum, Mill) at $22^{\circ} \mathrm{C}$ were evaluated. 1Methylcylopropene (1-MCP) reduced the rate of red color development in fruit of all maturity classes. However, the effect was more discernable in fruit with higher hue angle value. Single application of 1-MCP delayed the color development by 10 days. While a second application of 1-MCP at day 10 delayed color development by another 10 days for mature green tomatoes, it did not influence the color change in all other classes of maturity. The effects of 1-MCP on firmness loss were similar to color development. Compared to the control, 1-MCP reduced the ripening-related rate of respiration by approximately $40 \%$. Contrary to this, ethylene production was not affected by 1-MCP application. Potential exists to use 1 -MCP in tomato to reduce ethylene-associated changes in texture and color.

\section{5}

The Potential Benefits of 1-Methylcyclopropene (1-MCP) for Regulating the Ripening and Extending the Storage Life of Avocados

Jiwon Jeong*, Donald J. Huber, and Steven A. Sargent; Horticultural Sciences Department, University of Florida, Gainesville, FL 32611-0690

Ethylene is integrally involved in the ripening of climacteric fruit. The ability to prevent ethylene action, or manipulate fruit sensitivity to ethylene, would provide a powerful means of extending postharvest storage life of these fruit, particularly for those that ripen rapidly and/or that are not tolerant of low-temperature storage. In this study, 1-methylcyclopropene (1-MCP), an inhibitor of ethylene action, was used to investigate ripening, respiration, and ethylene production in avocado fruit. 'Monroe' avocados were treated with 1-MCP (Ethylbloc ${ }^{\circledR}$ ) for $24 \mathrm{~h}$ at $20^{\circ} \mathrm{C}$. The fruit were subsequently stored at 13 or $20^{\circ} \mathrm{C}$. Some fruit were exposed to $100 \mathrm{ppm}$ ethylene at 13 and $20^{\circ} \mathrm{C}$ before or after MCP treatment. As evaluated by flesh firmness, respiration rate, and ethylene evolution, 1-MCP completely inhibited the ripening of avocado fruit stored at 13 and $20^{\circ} \mathrm{C}$ and $85 \%$ relative humidity. Ethylene evolution and respiration rates were dramatically depressed, greater than $95 \%$ and $52 \%$, respectively, by $1-\mathrm{MCP}$. Whereas firmness of control fruit decreased from over $100 \mathrm{~N}$ to $10 \mathrm{~N}$ in as few as 7 days, fruit treated with 1-MCP remained firm $\left(>45 \mathrm{~N}\right.$ ) for periods of up to 3 weeks at $13^{\circ} \mathrm{C}$. Treatment of avocado fruit with 100 ppm ethylene at $20^{\circ} \mathrm{C}$ for $12 \mathrm{~h}$ did not overcome the influence of MCP treatment. Similarly, treatment with ethylene before MCP exposure did not circumvent the effects of the cyclic olefin on ripening. Current studies are addressing the effects of $\mathrm{MCP}$ concentration and exposure time on avocado ripening.

\section{6}

Role of Phospholipase A2-derived Lysophospholipids as Senescence Retardants of Plant Tissues: From Basic Science to Commercial Applications

Stephen B. Ry $u^{*}$ and Jiwan P. Palta; Department of Horticulture, University of Wisconsin-Madison, Madison, WI 53706

Lipids have been thought to be important largely in membrane structure and energy reserve. It is now evident that lipids and lipid-derived metabolites play a role in many critical cellular processes. Recent studies have shown that membrane lipid-based signaling mediated by phospholipases such as phospholipase A2 (PLA2), phospholipase C (PLC), and phospholipase D (PLD) constitutes a crucial step in plant responses to abiotic and biotic stresses. Phospholipases and their products also play a role during plant growth and development. For example, PLA2-derived lysophospholipids acted as growth regulators that retard senescence of plant tissues. Interestingly, the PLA2 products inhibited the activity of PLD, which has been suggested to be a key enzyme responsible for mem- brane lipid breakdown leading to plant senescence. Endogenous levels of lysophospholipids, such as lysophosphatidylethanolamine (LPE), could be increased in castor bean leaf discs by the treatment of auxin $(50 \mu \mathrm{M})$, which is known to be a activator of PLA2. Pretreatment of leaf discs with a PLA2 inhibitor before auxin treatment nullified the auxin effect and rather resulted in accelerated senescence even compared to the nontreated control. Our recent results suggest a potential role of PLA2 products as biologically active molecules mediating hormonal regulation of growth and senescence. One such product LPEis being commercially exploited for retarding senescence and improving shelf life of fruits, vegetables, and cut flowers.

\section{7}

Use of Lysophoshatidylethanolamine (LPE), a Natural Lipid, to Prevent Damaging Effects of Ethephon on Tomato Plants

Mustafa Ozgen* and Jiwan P. Palta; Department of Horticulture, University of Wisconsin, Madison, WI 53706

Ethephon [2-(chloroethyl) phoshonic acid] is used widely to maximize the yield of ripe tomato fruit. However, ethephon causes rapid and extensive defoliation, overripening, and promotes sunscald damage to the fruit. Recent studies from our laboratory have provided evidence that lysophoshatidylethanolamine $(\mathrm{LPE})$ can reduce leaf senescence. We investigated the potential use of LPE to reduce damaging effect of ethephon on tomato foliage. Three month-old tomato plants (variety Mountain Spring) grown in greenhouse conditions were sprayed with $200 \mathrm{ppm}$ LPE (with 3\% ethanol) at 6 and $24 \mathrm{~h}$ before ethephon treatment. After 8 days, plants treated with ethephon alone showed about $80 \%$ foliar damage while plant treated with LPE before ethephon treatment showed about $25 \%$ foliar damage. In a parallel study, LPEtogether with ethephon was found to maintain three to four times greater chlorophyll content in the leaves compared to ethephon al one. Treatments of LPE did not reduce the fruit ripening response by ethephon. Both sources of LPE were effective in preventing damaging effects of ethephon on the foliage. These results suggest that LPE treatments 6 and $24 \mathrm{~h}$ before ethephon application can prevent damaging effects of ethephon on foliage while allowing the acceleration of fruit ripening.

\section{8}

Use of Lysophoshatidylethanolamine (LPE), a Natural Lipid, to Accelerate Ripening and Enhance Shelf Life of Cranberry Fruit Mustafa Ozgen, Senay Ozgen, and Jiwan P. Palta*; Department of Horticulture, University of Wisconsin, Madison, WI 53706

Recent studies from our laboratory have demonstrated that lysophoshatidylethanolamine (LPE) is able to accelerate fruit ripening while at the same time promoting shelf life. LPE is a natural lipid and is commercially extracted from egg yolks and soybeans. We studied the influence of LPE on the pattern of anthocyanin accumulation and storage quality of cranberry fruit ( Vaccinium macrocarpon Ait. cultivar Stevens). For this purpose $2 \times 2-\mathrm{m}$ plots were established in cranberry beds at two separate locations near Wisconsin Rapids. Experiments were conducted in 1997 and 1998 seasons. Plots were sprayed with LPE (extracted from egg yolk and soybean) 3 to 4 weeks before harvest. Spray solution included $200 \mathrm{ppm} \mathrm{LPE}, 3 \%$ ethanol, and $0.1 \%$ detergents (either Tergitol or Sylguard). Fruit samples were taken from a part in the plot periodically to determine the changes in the fruit. The rest of the plots were commercially wet harvested with a machine and stored in cold storage. Marketable fruit were counted at various times of cold storage to determine effect of LPE on shelf life of cranberries. In general, application of LPE from both sources resulted in 20\% to $35 \%$ increase in fruit anthocyanin contents. Also LPE treatment resulted in $10 \%$ to $20 \%$ increase in marketable fruit in cold storage. A postharvest dip of cranberry fruit with $50 \mathrm{ppm} \mathrm{LPE} \mathrm{solution} \mathrm{for} 15 \mathrm{~min}$ also resulted in about a $20 \%$ to $30 \%$ increase in marketable berries during cold storage. The results of this study shows that preand postharvest applications of LPE can add value to cranberry crop including better and more uniform colored fruit, enhance self life, and earlier harvest.

\section{9}

\section{Firmness of Blueberry Fruit Following Storage in Air or Controlled Atmospheres}

Charles F. Forney", Kumudini U.K.G. Nicholas, and Michael A. Jordan; Agriculture and Agri-Food Canada, Atlantic Food and Horticulture Research Centre, 32 Main St., Kentville, N.S., B4N 1J5, Canada

Factors affecting the firmness of 'Burlington', 'Coville', and 'Jersey' highbush 
blueberries (Vaccinium corymbosum L.) during storage in controlled atmospheres or air were characterized. Fruit were stored for up to 9 weeks in 6-ounce plastic clamshells at 0 or $3^{\circ} \mathrm{C}$. Fruit firmness was measured as grams per millimeter of fruit deformation using a FirmTech1 firmness tester (Bioworks, Stillwater, Okla.). Blueberry fruit held in seal ed chambers in $0 \% \mathrm{CO}_{2} / 15 \% \mathrm{O}_{2}$ did not soften during storage. At 0 and $3^{\circ} \mathrm{C}$, fruit firmness of all cultivars increased an average of $30 \%$ after 9 weeks of storage. Changes in fruit firmness varied between cultivars and ranged from no change in 'Coville' fruit held at $3^{\circ} \mathrm{C}$ to an increase in firmness of $9 \mathrm{~g} \cdot \mathrm{mm}^{-1}$ per week in 'Burlington' fruit held at $3^{\circ} \mathrm{C} . \mathrm{CO}_{2}$ inhibited the postharvest firming of blueberry fruit and at higher concentrations induced softening. At $0^{\circ} \mathrm{C}$, fruit firmness decreased below initial values when held in concentrations of $\mathrm{CO}_{2}>12 \%$ for 'Burlington' and $>10 \%$ for 'Coville' and 'Jersey'. At $3{ }^{\circ} \mathrm{C}$, fruit were more tolerant to $\mathrm{CO}_{2}$ and softening occurred at $\mathrm{CO}_{2}$ concentration $>17 \%$ for 'Burlington', and $>12 \%$ for 'Coville' and 'Jersey' fruit. $\mathrm{CO}_{2}$-induced softening was enhanced by increased storage time. $\mathrm{CO}_{2}$ also was effective in reducing fruit decay. After 9 weeks, $2 \%$ and $36 \%$ of fruit held in air at 0 and $3{ }^{\circ} \mathrm{C}$, respectively, were decayed. However, all fruit held in 10 to $25 \% \mathrm{CO}_{2}$ had $<1 \%$ decay. Controlled atmospheres of $10 \%$ to $15 \% \mathrm{CO}_{2}$ reduced decay while maintaining fruit firmness.

\section{ORAL SESSION 22 (Abstr. 540-545) Floriculture: Manipulation of Flowering}

\section{0}

\section{Field-grown Garden Chrysanthemum Responses to Pinching and Plant Date}

Terri W. Starman* and James E Faust; Dept. of Ornamental Horticulture and Landscape Design, Inst. of Agriculture, Univ. of Tennessee, Knoxville, TN 37901-1071

Our objective was to determine the effect of planting date and pinching on flowering dates and plant size of field-grown garden mums. Experiments were conducted in the field during two consecutive growing seasons in 1997 and 1998. In one experiment, 15 to 20 cultivars were planted on five dates (14 May, 4 June, 25 June, 16 July, and 4 Aug.) and received no pinching, one manual pinch 2 weeks after potting, or two manual pinches 2 and 4 weeks after potting. In another experiment, four cultivars were planted at the five dates. Pinch treatments were control, one manual pinch, two manual pinches, one Florel spray at $500 \mathrm{mg} \cdot \mathrm{L}^{-1}$, or two Florel sprays at the same time as the manual pinches but on separate plants. Data were collected for days to first color, first open flower, 10 open flowers, and full bloom. Height and width were measured at 10 open blooms. Although the 1998 season was warmer and caused heat delay, the flowering data followed the same trends as the 1997 experiments. Pinching delayed flowering for the early plant dates. Pinching did not affect plant height or plant width. Planting date affected days to 10 blooms for most early season varieties but not lateseason varieties. Planting early produced larger plants and more uneven flowering and resulted in greater heat delay of heat-sensitive varieties. Florel delayed flowering and increased plant size. We concluded that pinching was not required to produce high-quality garden mums of many new cultivars.

\section{1}

\section{Floral Initiation of Regal Pelargonium Grown at Varying Daily Light Integrals}

Marietta Loehrlein ${ }^{* 1}$ and Richard Craig2; 'Department of Agriculture, Macomb, IL 61455; ${ }^{2}$ Department of Horticulture, Pennsylvania State University, University Park, PA 16802

Nine cultivars of Pelargonium $x$ domesticum representing three germplasm sources were evaluated for the effect of daily light integral on floral initiation. Plants were grown at four daily light integrals: $5,10,15$, or 20 mols/day for a 16 $h$ photoperiod in environmental growth chambers at constant $15.5^{\circ} \mathrm{C}$. Meristems were examined at 50 -mol intervals ( 0 to $350 \mathrm{mols}$ ) for morphological changes associated with floral initiation. Two phenotypes were identified, cultivars with an association between floral initiation and irradiance and those with association between floral initiation and chronological time. Genotypic variation was observed among the cultivars of each phenotype.
542

Influence of Sowing Time and Temperature on Growth and Flowering of Platycodon grandiflorus (Jacq.) A. DC. 'Sentimental Blue'

Donglin Zhang" ${ }^{* 1}$, A.M. Armitage'2, J.M. Affolter ${ }^{2}$, and M.A. Dirr' ${ }^{2}{ }^{1}$ Dept. of Biosystems Science and Engineering, University of Maine, Orono, ME 04469; ${ }^{2}$ Department of Horticulture, University of Georgia, Athens, GA 30602

Platycodon grandiflorus (Jacq.) A. DC. 'Sentimental Blue' can be used as a pot plant and garden perennial. Plants can be grown year-round in a greenhouse as cutting flowers if supplemental heat is provided in the winter. Sowing time did not affect plant growth and flowering. Seeds took 10 to 20 days to germinate at $20-25^{\circ} \mathrm{C}$ day $/ 15-20^{\circ} \mathrm{C}$ night temperatures. As the day/night temperature decreased, time to germination increased and germination rate decreased. Temperature also influenced shoot proliferation and number of basal branches increased as temperature decreased. Plants reached reproductive growth about 20 days after transplanting and took another 20 days to reach full bloom. Open flowers lasted 3-7 days. Cold treatment was not necessary for flowering, but plants were forced into dormancy when provided with $5^{\circ} \mathrm{C}$ for 4 or more weeks. Plants began to emerge 2 to 3 months later and two growth forms, "rosette" and "dwarf", occurred in the second growth cycle. The dwarf form produced one or two stems with six to eight clustered flowers per stem while the rosette form produced an average of 10 stems with one or two flower per stem. For the "rosette" form, each stem could be divided as a new plant.

\section{3}

\section{Flowering and Growth Response to Photoperiod and Cold} Treatment of Arabis sturii Mottet

Donglin Zhang ${ }^{* 1}$, A.M. Armitage ${ }^{2}$, J.M. Affolter ${ }^{2}$, and M.A. Dirr ${ }^{2}{ }^{1}$ Dept. of Biosystems Science and Engineering, University of Maine, Orono, ME 04469; ${ }^{2}$ Department of Horticulture, University of Georgia, Athens, GA 30602

Arabis sturii Mottet (Brassicaceae) has potential as a new crop for American nurseries and may be used as a perennial pot plant. Cold treatment was required for flowering of Arabis sturii and a 6-week cold treatment resulted in the greatest number of racemes and flowers per plant. Increasing or decreasing length of cold treatment resulted in less flowers per plant. Plant height increased as duration of cold treatment increased. Photoperiod had a significant effect on flowering and growth only after plants received 3 weeks or more cold treatment. All plants given a 16-h photoperiod flowered, while only $50 \%$ and $80 \%$ flowered under an 8- or 12-h photoperiod, respectively. A 16-h photoperiod shortened the time to production of flower buds and anthesis and the greatest difference occurred after the 9-week cold treatment. At the 6 -week cold treatment, number of flowers per plant different significantly between long ( 145 flowers) and short day (59). The effect of photoperiod on number of flowers per plant became less as cold treatment increased or decreased. Although photoperiod did not induce flower initiation, it had a tremendous effect on flower development. Many more flowers were produced and plants were taller as photoperiod increased. No significant difference was found in plant dry weight.

\section{4}

\section{Photoperiod and Juvenility Affect Campanula and Lupinus} Flowering Response and Cut Stem Quality

Todd J. Cavins* and John M. Dole; Department of Horticulture and Landscape Architecture, Oklahoma State University, Stillwater, OK 74078-6027.

Campanula medium L. 'Champion Blue' (CB) and 'Champion Pink' (CP) and Lupinus hartwegii Lindl. 'Bright Gems' (LH) were grown in 8- or 16-h initial photoperiods, transplanted when two-three, five-six, or eight-nine nodes developed and placed under 8-, 12-, or 16-h final photoperiods. Greatest flowering percentage $(100 \%)$ for $\mathrm{CB}$ and $\mathrm{CP}$ occurred when plants with two-three nodes were grown in the 16-h final photoperiod. The lowest flowering percentage for CB $(3.3 \%)$ and $\mathrm{CP}(15.7 \%)$ resulted from plants grown in the 8 -h photoperiod continuously (initial and final). $\mathrm{CB}$ and $\mathrm{CP}$ stem lengths $(49.8 \mathrm{~cm}$ ) were longest when grown in the 8-h photoperiod continuously and shortest with the 16 -h initial and 8-h final photoperiods for $\mathrm{CB}(26.5 \mathrm{~cm})$ and the 16 -h photoperiod continuously for $\mathrm{CP}(25.4 \mathrm{~cm})$. Fewest days to anthesis, 134 days for $\mathrm{CB}$ and 145 days for $C P$, resulted from the 16 -h photoperiod continuously and greatest (216 days) from the 8-h photoperiod continuously. LH plants had a high flowering percentage $(99.6 \%$ ) regardless of photoperiod or transplant stage. Stem lengths were longest $(60.1 \mathrm{~cm})$ for $\mathrm{LH}$ plants exposed to the 16 -h photoperiod continu- 
ously and shortest $(46.2 \mathrm{~cm})$ when exposed to the 8 -h photoperiod continuously. LH exhibited a curvilinear response for days to anthesis with the 16-h final photoperiod producing the shortest crop time (166 days) and the 12- $\mathrm{h}$ final photoperiod producing the longest crop time (182 days). The experiment was repeated in 1998/1999 with high intensity discharge (HID) lighting during the initial photoperiod which increased plant quality.

\section{5}

Controlled Flowering of Oenothera fruticosa L. 'YoungiiLapsley' and Stokesia laevis L'Hér 'Klaus Jelitto'

Emily A. Clough", Arthur C. Cameron, Royal D. Heins, and William H. Carlson; Dept. Of Horticulture, Michigan State Univ., East Lansing, MI 48824-1325

Oenothera fruticosa L.'Youngii-Lapsley' and Stokesia laevis L'Hér. 'Klaus Jelitto' are two hardy herbaceous perennials with great potential as pot crops. The vernalization and photoperiod requirements were examined for each species. Plants were cooled for $0,3,6,9,12$, or 15 weeks at $5^{\circ} \mathrm{C}$ with a 9 -h photoperiod. After cold treatment, plants were forced in greenhouses at $20^{\circ} \mathrm{C}$ under a 16 -h photoperiod using high-pressure sodium lamps. The photoperiod requirement was determined by forcing plants at $20^{\circ} \mathrm{C}$ with and without a 15 -week cold treatment at $5{ }^{\circ} \mathrm{C}$ under 10-, 12-, 13-, 14-, 16-, 24-h and 4-h night interruption using incandescent lamps. Plants of Oenothera fruticosa'Youngii-Lapsley' cooled for 0 weeks did not flower. All plants cooled for 3 weeks flowered and time to flower decreased from 53 to 43 days as duration of cold increased from 3 to 15 weeks. 'Youngii-Lapsley' flowered under every photoperiod, but time to flower and number of flowers decreased from 54 to 40 days as photoperiod increased from 10 to $24 \mathrm{~h}$. Percentage flowering of Stokesia laevis 'Klaus Jelitto' increased from 50 to 100 , and time to flower decreased from 112 to 74 days as duration of cold increased from 0 to 6 weeks. Without a cold treatment, plants of 'Klaus Jelitto' flowered only under daylengths of 12,13 , and $14 \mathrm{~h}$. After cold treatment, plants flowered under every photoperiod except $24 \mathrm{~h}$, and time to flower decreased from 122 to 65 days as photoperiod increased from 10 to $16 \mathrm{~h}$. Additional aspects of flowering and the effect of different forcing temperatures will be discussed.

\section{ORAL SESSION 23 (Abstr. 546-550) Floriculture: Crop Production/Crop Protection}

\section{6}

\section{Quantifying the Dose Response of Several Basic Chemicals} on pH of Soilless Media

A.J. Bishko* and P.R. Fisher; Dept. of Plant Biology, University of New Hampshire, Durham, $\mathrm{NH} 03824$

Our objective was to systematically quantify the dose response from applications of several basic materials recommended for raising $\mathrm{pH}$ in acidic media. $\mathrm{A}$ peat $(70 \%)$ /perlite $(30 \%)$ medium was mixed with a pre-plant nutrient charge, a wetting agent, and $0,0.3,0.6,0.9,1.2$, or $1.5 \mathrm{~kg}$ dolomitic hydrated lime/ $\mathrm{m}^{3}$, resulting in a range in initial $\mathrm{pH}$ from 3.4 to 6.4 . Five rates of flowable dolomitic limestone, five rates of potassium bicarbonate, two rates of potassium hydroxide, a supernatant of calcium hydroxide and a distilled water control were applied as single drenches. The medium was irrigated with distilled water when it dried to $50 \%$ container capacity as determined by weight. Media pH and EC of four replicates were tested at 1 day and 1,2, 3, and 4 weeks after application as a saturated media extract. Flowable limestone and potassium bicarbonate both significantly raised medium $\mathrm{pH}$ by up to 2 units compared with the control, depending on concentration. As initial medium pH increased, the effect of the basic chemicals on medium pH decreased. For example, flowable lime applied at $0.5 \mathrm{~L} \cdot 100 \mathrm{~L}^{-1}$ of distilled water increased pH by 2 units at an initial medium pH of 3.4 and by 0.4 units at an initial $\mathrm{pH}$ of 6.4. Potassium hydroxide and calcium hydroxide drenches did not significantly raise $\mathrm{pH}$. Potassium bicarbonate was easier to apply than the suspension of flowable limestone, however both chemicals provide practical methods for raising $\mathrm{pH}$ of soilless media.

\section{7}

Effects of Media Surfactants on Growth and Postharvest Dessication of Impatiens, Petunia, and Spathiphyllum

Robert H. Stamps ${ }^{*}$; CFREC, IFAS, University of Florida, 2807 Binion Road, Apopka, FL 32703-8504

Impatiens 'Dazzler Violet', Petuniax hybrida 'Carpet Blue', and Spathiphyllum 'Ty's Pride' plugs were planted in 10-cm pots containing a commercial peatbased soilless growing medium composed of Canadian 60 peat : 20 vermiculite : 20 perlite (by vol) not treated with surfactant. Growing medium was treated, or not treated, 1) at planting, 2) during production, and/or 3) preshipment with experimental surfactants. The production phase consisted of growing plants on raised benches in a greenhouse until they reached marketable size. Phytotoxicity, plant water use and growth were determined. At the beginning of the postproduction phase, growing medium in all pots was brought to container capacity. Plants were then dried to wilting three times. Water loss and water retained on rewatering and times to wilt and recovery were recorded. Surfactant treatments caused no foliar phytotoxicity and did not delay flowering for petunia or spathiphyllum. However, surfactant treatments delayed flowering for impatiens by $\approx 4$ days. Surfactant treatments increased top growth of petunia but not of the other crops. Postproduction, water retention at rewatering, and times to wilt were increased for petunia and spathiphyllum when they were in surfactant-treated medium. For impatiens, treatments had no effects on water retention or wilting, probably due to the small root systems and limited attendant medium dewatering for this crop. Generally, all three experimental surfactants performed similarly and weekly and preshipment surfactant applications were of no additional benefit compared to a single initial application at planting.

\section{8}

\section{Repeated Applications of Growing Medium Surfactants} Affect Dianthus barbatus Growth and Development

Karen L. Panter* 1 , Steven E. Newman², Amy M. Briggs', and Michael J. RolR; ${ }^{1}$ Department of Plant Sciences, P.O. Box 3354, University of Wyoming, Laramie, WY 82071-3354; ${ }^{2}$ Department of Horticulture and Landscape Architecture, Colorado State University, Fort Collins, CO 80523-1173.

Three application rates of two new growing medium surfactants were tested under two different irrigation systems on Dianthus barbatus plants. The objectives of the study were to determine if either of the surfactants influenced plant growth and development and to determine if surfactant applications decreased irrigation frequencies. The three levels of surfactant tested were $0 \mathrm{mg} \cdot \mathrm{L}^{-1}$ (control), $10 \mathrm{mg} \cdot \mathrm{L}^{-1}$ applied at each watering, and $100 \mathrm{mg} \cdot \mathrm{L}^{-1}$ applied once a week. Each surfactant and rate was tested on hand-watered and ebb-and-flood irrigated plants. D. barbatus plants were grown for 8 weeks in $875-\mathrm{ml}(12.7 \mathrm{~cm})$ pots. Plants were watered when at least one plant per treatment showed visible wilt. Results showed that phytotoxicity symptoms occurred with repeated applications of both surfactants tested, especially at the $10 \mathrm{mg} \cdot \mathrm{L}^{-1}$ rate at each watering. Application of either surfactant at $10 \mathrm{mg} \cdot \mathrm{L}^{-1}$ at each watering decreased plant heights, dry weights, and plant widths, and increased phytotoxicity symptoms over the controls and the $100 \mathrm{mg} \cdot \mathrm{L}^{-1}$ weekly treatments. Fewer waterings were required in surfactant-treated containers.

\section{9}

Imidacloprid Applications for Whitefly Control on Poinsettia Using Ebb-and-flow Systems

Marc van lersel* and Ron Oetting; Departments of Horticulture and Entomology, Georgia Station, The University of Georgia, 1109 Experiment Street, Griffin, GA 30223

Ebb-and-flow systems can be used to apply systemic pesticides to greenhouse crops without worker exposure or runoff. However, there is little information on the efficacy of pesticides applied with ebb-and-flow systems. We are using silverleaf whitefly (Bemisia argentifolii) control on poinsettia (Euphorbia pulcherrima) with imidacloprid as a model system to study pesticide efficacy in ebb-and-flow systems. The objective of this study was to determine the effect of the amount of insecticide taken up by the pot on the efficacy of whitefly control. Different amounts of imidacloprid uptake were obtained by not watering the plants for $0,1,2$, or 4 days before the imidacloprid application. The imidacloprid (132 $g \cdot L^{-1}$ ) was applied once when the roots of the cuttings had reached the side of the pots. These treatments were compared to an untreated control on ebb-andflow and a standard drench application (100 mL) to hand-watered plants. Pots in 
the different subirrigation treatments absorbed 12 to $175 \mathrm{~mL}$ of imidacloprid solution. Four days after the application, leaf tissue of the hand-watered plants contained 8 to 20 times more imidacloprid than the subirrigated plants. Efficacy was determined from the percentage of surviving mature whiteflies after 2 days on the plants and by counting the number of immatures after 2 weeks. Surprisingly, imidacloprid efficacy was better in the subirrigated imidacloprid treatments than in the hand-watered treatment. Whitefly control in all subirrigated imidacloprid treatments was excellent, irrespective of the amount of imidacloprid solution taken up by the pots.

\section{0}

\section{A Naturally Occurring Compound for Controlling Powdery Mildew of Greenhouse Roses}

Steven E Newman ${ }^{* 1}$, Michael J. Roll', and Ronald J. Harkrader2; ' 1 Department of Horticulture and Landscape Architecture, Colorado State University, Fort Collins, CO 80523-1173; ${ }^{2}$ Camas Technologies, Inc., P.O. Box 1357, Broomfield, CO $80038-1357$

Quaternary benzophenanthridine alkaloids (QBAs) isolated from plants in the family Papaveraceae are effective for the control of some fungal diseases. Extracts from Macleaya cordata, a species rich in QBAs, were formulated at 150 $\mathrm{mg} \cdot \mathrm{L}^{-1} \mathrm{QBA}$ for spray application to greenhouse roses infected with Sphaerotheca pannosa var. rosae (powdery mildew). The QBA formulation was applied at 10day intervals. For comparison, copper sulfate pentahydrate, piperalin, and fenarimol also were applied to mildew-infected plants within the same greenhouse at their respective labeled rates. One day after treatment, visible symptoms of mildew infection were reduced $60 \%$ by QBA, whereas fenarimol, copper sulfate pentahydrate, and piperalin reduced the symptoms of infection $50 \%, 75 \%$, and $85 \%$, respectively. Subsequent studies demonstrated that a tank mix of QBA and piperalin provided enhanced control of powdery mildew on rose. Results from this study indicate that QBAs have the potential to be developed as a biorational fungicide for greenhouse use with both fungicidal and fungistatic activity.

\section{ORAL SESSION 24 (Abstr. 551-556) Vegetable Crops: Crop Physiology/ Nutrition}

551

\section{Evaluation of Vegetable Soybeans for Green Bean Yield and Nutritional Quality}

M.S.S. Rao ${ }^{* 1}$, Ajmer S. Bhagsari ${ }^{1}$, and Ali I. Mohamed; ${ }^{1}$ Agricultural Research Station, Fort Valley State University, Fort Valley (FVSU), GA 31030; ${ }^{2}$ Virginia State University, Petersburg, VA 23806.

In Asian countries and among the oriental populations in the United States, vegetable soybeans are consumed much the same way as green peas are consumed. A need exists for developing soybean cultivars adapted to the U.S. environments to take advantage of the economic potential of vegetable soybeans for both domestic and international markets. During 1997, 12 vegetable soybean genotypes of exotic origin and two local U.S. soybean cultivars were evaluated for their agronomic performance in a randomized complete block, with four replications, at the Agric. Res. Stn. FVSU, Ga. At the R6 stage (when the seeds are of full size and still immature), plants from a half-meter-row length were sampled from each plot to estimate green pod and seed yield, and determine the nutritional quality of green beans. Significant differences were observed among genotypes for the agronomic and biochemical parameters studied. The green seed yield ranged from 7.1 (cv. Ware) to $14.0 \mathrm{Mg} \cdot \mathrm{ha}^{-1}$ (cv. Tanbagura). Three cultivars, Tomahamare, Mian Yan, and Tousan-122, produced green seed yields in excess of $12 \mathrm{Mg} \cdot \mathrm{ha}^{-1}$. The number of green pods varied between 1518 (Tanbagura) and $3526 / \mathrm{m}^{2}$ (cv. Hutcheson). The green bean oil and protein contents, ranged from 53.1 to 105.4 and from 354.2 and $418.3 \mathrm{~g}^{\circ} \mathrm{kg}^{-1}$, respectively. Thus, the green seeds contained only $30 \%$ of oil, but $50 \%$ to $80 \%$ of protein normally found in mature soybean seed. The glucose content was between $4.1 \%$ and $7.0 \%$, while the phytate content varied between $0.93 \%$ and $1.3 \%$. The green seed yield was significantly correlated with number of green pods, number of green seeds, and green pod weight. This study showed that some exotic vegetable soybean genotypes may be suitable for production in the southeastern U.S.

\section{2}

\section{The Gradient Concept-Replacing the Soil as the Buffer Component}

C.M. Geraldson ${ }^{*}$; University of Florida, 1111 99th St. NW, Bradenton, FL 34209

The gradient concept is designed with a soluble source of $\mathrm{N}-\mathrm{K}$ banded on the soil bed surface in conjunction with a continuing source of water that synchronizes the nutrient-water input with rate of removal by the root. By placing the $\mathrm{N}-$ $\mathrm{K}$ on the surface rather than conventionally in the bed, nutrient movement to the root shifts from mass flow to diffusion. Nutrients that move by mass flow are a function of water requirement and potentially a source of nutritional instability. With the shift to movement by diffusion, nutrients move independently of the water to replace those removed from the gradient by the root. The gradient with a continuing nutritional stability replaces the variable and limited stability potential of the soil. Commercial tomato yields in Florida more than doubled with the shift to the gradient-mulch procedure. A containerized version of the concept (The EarthBox ${ }^{\top M}$ has been most successful for the home gardener and substantiates the validity of the gradient. Most innovative procedures with the gradient as the buffer component minimize pollution, require minimal management, and use minimal water with microirrigation or an enclosed system. To better understand the gradient concept and utilize the procedure, it may be necessary to consider the procedure as a nutritional paradigm shift.

\section{3}

\section{Nutrient Content of a Model System of Rapid-cycling} Brassica oleracea Responds to Increasing Sodium Selenate Dean A. Kopsel/ ${ }^{*}$, William M. Randle, and Harry A. Mills; Department of Horticulture, University of Georgia, Athens, GA 30602

Brassica species are important economic vegetable crop, and it is possible to enrich them with selenium (Se) to supplement human diets. The health benefits associated with increased Se consumption include cancer suppression, reduced heart disease, and immune system enhancement. Vegetables enriched with Se can serve as excellent delivery systems of organic Se forms, which are more beneficial than traditional Se supplements. The vegetable Brassicas are consumed not only for their flavor, but also for their nutritional content. A heterogeneous population of rapid-cycling $B$. oleracea was used as a model system to study the effects of added selenate-Se on other plant micro- and macronutrients. Plants were grown in nutrient solutions amended with sodium selenate at $0.0,3.0,6.0$, and $9.0 \mathrm{mg} \cdot \mathrm{L}^{-1}$. Leaf tissues were then analyzed for nutrient content. Boron $(P=$ $0.001)$ and iron $(P=0.01)$ content decreased, while selenium $(P=0.001)$, sulfur $(P=0.001)$, and potassium $(P=0.001)$ increased with increasing selenate-Se. Significant quadratic responses were found for calcium $(P=0.02)$, copper $(P=$ $0.05)$, magnesium $(P=0.01)$, and molybdenum $(P=0.01)$. No differences in leaf fresh or dry weight were detected. Changes in plant nutrient content can be expected when Brassicas are enhanced for delivery of beneficial organic Se.

\section{4}

Sequentially Eliminating Sulfate during Onion Growth Affects Its Flavor Characteristics

William M. Randle* and Rachel Snyder, Department of Horticulture, University of Georgia, Athens, GA 30602-7273

Mild onion consumption is increasing in the U.S. The ability to produce mild onions depends on selecting proper cultivars and growing them in an appropriate environment. A major decision in producing onions with mild flavor is determining when to stop applying sulfate to the crop. While adequate sulfur is necessary for good early onion growth, high levels of sulfur increase bulb pungency. A study was conducted where sulfate was eliminated from the fertility program at biweekly intervals during onion growth and development. Mature bulbs were then analyzed for flavor precursors and their biosynthetic intermediates, and pungency. Pungency linearly increased from 3.7 to $5.1 \mu$ mols pyruvic acid from the earliest cut-off date to the latest cut-off date, respectively. While total milligrams of flavor precursors did not significantly change in response to sulfate elimination, the methyl cysteine sulfoxide : 1-propenyl cysteine sulfoxide ratio did. Methyl cysteine sulfoxide concentration decreased in a quadratic manner while 1-propenyl cysteine sulfoxide linearly increased as sulfate fertility was extended in the growing season. Changes in individual precursors will significantly affect flavor perception as well as flavor intensity. 


\section{5}

The Impact of Supplemental Calcium Fertilization during Potato Seed Tuber Production on Subsequent Crop Performance

Christopher C. Gunter* and Jiwan P. Palta; University of Wisconsin-Madison, Department of Horticulture, 1575 Linden Dr., Madison WI 53706

Tuber tissue calcium has been linked to several potato quality characteristics, including internal defects and the susceptibility of tubers to decay by soft rotting Erwinia species. We were particularly interested in studying the relationship between supplemental calcium fertilization during the seed tuber production cycle to raise the seed piece calcium concentration and the impact on crop performance the following season. The role of seed tuber tissue calcium level on seed piece decay, growth, development, and performance of the plant was evaluated for cultivars Russet Burbank, Dark Red Norland, Atlantic, Superior, and Snowden. This study was performed over four growing seasons. Seed tubers were raised with varying calcium and the following season, individual tubers (over 3,000 total for 4 years of study) were sampled for calcium and hand planted in the field. They were evaluated for seed piece decay and total tuber yield during the growing season. Seed tubers raised with supplemental calcium resulted in significantly higher mean calcium content than the control tubers. In general, calcium-raised seed tubers tended to produce a more vigorous main sprout and higher tuber yield. We also found that there are significant differences among these cultivars for the characteristics measured. Consistently, in all three years, 'Atlantic' responded to test conditions with the lowest decay values, and 'Dark Red Norland' consistently showed the highest decay values. This suggests that there may be a genetic component involved in these two responses and these genotypic differences could be exploited to improve cultivated potatoes.

\section{6}

Influence of Supplemental Calcium Fertilization on Potato Tuber Size and Tuber Number

Senay Ozgen ${ }^{*}$, Mustafa Ozgen, and Jiwan P. Palta; Department of Horticulture,University of Wisconsin, Madison, WI 53706

Several recent studies, including from our laboratory, have provided evidence that by improving tuber calcium level, we can improve tuber quality such as low internal defects and better storability. The purpose of this study was to be determine the influence of supplemental calcium fertilization on tuber size and tuber number. For this purpose, plantlets of Solanum tuberosum cv. Russet Burbank raised in tissue culture were planted in 20-L pots filled with sandy loam soil with $\mathrm{pH}$ of 6.9 and soil calcium level of $350 \mathrm{ppm}$. All treatments received same total amount of nitrogen (at the rate of $280 \mathrm{~kg}^{\bullet} \mathrm{ha}^{-1}$ ). Five treatments were evaluated: i) nonsplit nitrogen (from ammonium nitrate), ii) split nitrogen (from ammonium nitrate), iii) split nitrogen + gypsum, iv) split nitrogen (from liquid nitrogen) + calcium chloride, and v) split nitrogen (from calcium nitrate). The total calcium was applied at the rate of $168 \mathrm{~kg} \cdot \mathrm{ha}^{-1}$. Gypsum application was made at 4 weeks after planting, and other sources of calcium were applied on a split schedule (equally split at 4, 6, 8 weeks after planting). Four months after planting, tubers were harvested and evaluated. In general, all calcium treatments had lower tuber number and greater tuber size compared to the nonsplit nitrogen control. The percentage of total A-grade tubers as well as the percentage yield from A-grade tubers was increased by all calcium applications. These results suggest that calcium content I the soil can influence both potato tuber number and tuber size.

111 ORAL SESSION 25 (Abstr. 557-563) Cross-commodity: Biotechnology/Tissue Culture

\section{7}

\section{Genetic Diversity in Wild Strawberry (Fragaria virgininia) of} the Rocky Mountains

Grey Horton ${ }^{\star}$ and Jim Luby; Dept. of Horticulture, Univ. of Minnesota, St. Paul, MN55108

This study of genetic diversity in a wild ancestor of the cultivated strawberry was undertaken to describe patterns of variation in nature, assess worth of existing germplasm collections, and identify promising locations for future collection.
Previous work reported a similar study of octaploid strawberry ranging east to west across North America. This complementary study focused on variation from north to south in the Rocky Mountains. The morphological diversity of 16 populations of Fragaria virgininiawere characterized for morphological and molecular traits. Two clones of each of 133 genotypes from these populations were grown in a common environment in a greenhouse. Eighteen morphological traits, such as leaf area, runner color, and days to flowering, were measured and analyzed with principal components and canonical discriminant analyses. Molecular diversity data were obtained using seven randomly amplified polymorphic DNA primers. Resulting population marker frequencies were also subjected the previously describe anlayses. Differences due to latitude, longitude, and altitude were observed. Implications of the results will be discussed.

\section{8}

Evaluation of Sequence-based PCR Markers in an $\mathrm{F}_{1}$ Pseudotestcross and a $\mathrm{BC}_{1}$ Hybrid Citrus Population

Courtney A. Weber ${ }^{* 1,3}$, Z. Deng ${ }^{2}$, F. Gmitter ${ }^{2}$, and Gloria A. Moore ${ }^{1}{ }^{1}$ Horticultural Sciences Department, University of Florida, Gainesville, FL $32611 ;{ }^{2}$ Citrus Research and Education Center, University of Florida, Lake Alfred, FL 33850; ${ }^{3}$ Present address: New York State Experiment Station, Cornell University, Geneva, N.Y.

Specific primers were designed for 61 cloned RAPD fragments and from 10 Citrus EST sequences for the production of SCAR, CAPS, and STS markers for a Citrus grandis 'DPI 6-4' x Poncirus trifoliata'Rubideaux' $F_{1}$ pseudo-testcross population. Fifteen SCAR, three CAPS, and one EST/STS markers were developed. An additional 17 SCAR and CAPS primer pairs developed at the Citrus Research and Education Center for a Citrus grandis 'Thong Dee' x (Citrus grandis 'Thong Dee' $x$ Poncirus trifoliata 'Pomeroy') $\mathrm{BC}_{1}$ population were screened in the pseudo-testcross population. A total of 27 markers were identified and scored in the pseudotestcross population in which 24 were mapped; 13 in the Citrus parental linkage map on seven linkage groups and 11 in the Poncirus parental map on five linkage groups. In the $\mathrm{BC}_{1}$ population, 20 of 27 markers tested were found to be polymorphic and 13 mapped to seven of nine linkage groups. Of these, 11 were mapped in both populations and could be used for aligning presumed homologous regions on the three linkage maps.

\section{9}

Isolation of an ETR1 Ethylene Receptor Homologue from Peach [Prunus persica (L.) Batsch]

Carole L. Bassett" and Timothy S. Artlip; USDA, ARS, Appalachian Fruit Research Station, 45 Wiltshire Road, Kearneysville, WV 25430

During the past several years, we have been interested in genes and geneproducts involved in various aspects of ripening and maturation in peach (Prunus persica) fruit. The ethylene biosynthetic and signal transduction pathways are of particular interest due to the role of this hormone in such processes. Recently, we isolated a cDNA encoding a homologue of the ethylene receptor ETR1 from a near fully ripe (20-60N) peach fruit cDNA library. This cDNA clone, PpETR1, is nearly $2300 \mathrm{bp}$ in length, with a 5' untranslated region of $268 \mathrm{bp}$, a 3' untranslated region of $150 \mathrm{bp}$, and an ORF of $1881 \mathrm{bp}$, encoding a protein of $70 \mathrm{kDa}$. The cDNA is most closely related to an ETR1 homologue from apple( Malus domestica), i.e., $95 \%$ identity at the amino acid level, but shows considerable similarity to Arabidopsis thalianaETR1, as well. A comparison of the similarity among cloned ETR1 genes from a range of plant species will be presented.

560

Molecular Analysis of the First Intron of the Chalcone Synthase A Gene in Petunia

R.J. Griesbach ${ }^{*}$ and R. Beck; Floral and Nursery Plants Research, US National Arboretum, USDA, ARS, Beltsville, MD 20705-2350

A new method was developed to analyze genetic diversity among Petunia species. The first intron of the chalcone synthase A gene was cloned through the polymerase chain reaction (PCR) and partially sequenced. This sequence was used to dissect the intron into two halves ( $3^{\prime}$ and 5 ' halves). The PCR primers for the $5^{\prime}$ half amplified a single fragment that was the same length for all of the species that were studied. Restriction fragment length polymorphism (RFLP) analysis of the $5^{\prime}$ half resulted in the same number and length of fragments for all the species that were evaluated. The PCR primers for the $3^{\prime}$ half amplified a number of fragments that were characteristic for each species. This research provides a 
new tool for measuring genetic diversity. Genetic diversity measured with this tool should be closely related to evolutionary distance.

\section{1}

Using AFLPs to Examine Genetic Diversity in Umbrella Fern F.J. Keiper" and R. McConchie; Dept. of Crop Science, Univ. of Sydney, NSW, Australia, 2006

Umbrella fern [Sticherus flabellatus (R. Br.) St John] is a successful Australian native foliage product. Currently, all umbrell afern sold on the market is bushharvested. To meet the growing demand for this product on local and international markets, a commercially viable method for its production must be developed, with effective management of the germplasm resource in terms of conservation and exploitation. To manage this resource, breeders require a detailed knowledge of the amount and distribution of genetic variability within the species. Traditionally, plant breeders focus on a combination of agronomic and morphological traits (phenotype) to measure genetic diversity. In umbrella fern there are a limited number of morphological traits, and these are influenced by environmental factors and therefore do not reflect true genetic diversity. To overcome these problems, molecular techniques such as PCR-based DNA markers are used to complement traditional strategies for genotype assessment. DNA markers have the advantages of being independent of environmental effects, as well as being fast, cost-effective, reproducible, and largely accessible to the nonmolecular geneticist. Amplified fragment length polymorphisms (AFLPs) fulfil many of the desirable features of molecular markers, as well as requiring little knowledge of the genome to be investigated. AFLPs have been used widely in the analysis of breeding systems, ecogeographical variation, and genetic variation within and between natural populations. To date there are no published accounts of DNA molecular marker research on umbrella fern. A DNA extraction protocol has been developed for this species, and AFLP markers have been used to analyse genetic diversity within and between natural populations sampled in the Sydney Basin. A large number of polymorphic loci were revealed using 11 primer combinations. The genetic variation detected was partitioned between rather than within populations, suggesting that the mating system in Sticherus is primarily inbreeding. Data will be presented illustrating AFLPs as useful molecular markers for assessing genetic diversity within and between populations of umbrella fern and providing insight on the breeding system used by the species.

\section{2}

\section{Plant Regeneration from Embryo and Cotyledons of Laiyang} Dwarf Cherry

Qingrong Sun*, Yinping Shi, Qiangsheng Wang, and Hongyan Sun; Shandong Institute of Pomology, Taian, Shandong 271000, P.R.of China

Laiyang dwarf cherry (Prunus pseudocerasus Lindl. Var. Laiyang dwary cherry) is an important dwarf type of Chinese cherry. It is both directly used for production and used as rootstock of sweet cherry (P. avium L.). Material used in this study was Laiyang dwarf cherry seed, which is open-pollinated. The fruit surface is sterilized with $70 \%$ ethanol on sterile working table, the seed is removed from fruit, and embryo is taken out of cracking seed shell. Explants include whole embryo, embryo without cotyledons, and cotyledons. Basal media are MS and 1/ 4MS major elements, sugar $30 \mathrm{~g} \cdot \mathrm{L}^{-1}$, agar $5.5 \mathrm{~g} \cdot \mathrm{L}^{-1}$, adjusted $\mathrm{pH}$ 5.8. Hormone used included 6-BA,IBA and 2,4-D for a total eight treatments. Culture temperature was $25^{\circ} \pm 2^{\circ} \mathrm{C}$, and photoperiod was $14 \mathrm{~h}$. Results show 1 ) the plant regeneration rate from cotyledons is highest, second is from embryo without cotyledons, lowest is from whole embryo; 2) when BA is in the range of 0.7 to $5 \mathrm{ppm}$, plant regeneration is higher at a high concentration than that at low concentration; 3) at the same concentration, plant regeneration rate on the medium supplemented with 2,4-D is higher than that on the medium supplemented with IBA; 4) plant regeneration rate is higher on the medium containing cytokinin and auxin is higher than that on the medium only containing cytokinin; and 5) plant regeneration rate of continuous light culture cotyledons is higher than that of first dark culture 2 weeks cotyledons. Effects of light and dark/hormone and explant type on plant regeneration rate is discussed.

\section{3}

Influence of Ultra-high Levels of Carbon Dioxide on Secondary Metabolite Production in Vitro

Brent Tisseratt and Steven Vaughn; USDA-ARS, National Agricultural Utilization Research Center, Peoria, IL 61604

The influence of a wide range of $\mathrm{CO}_{2}$ levels on the growth, morphogenesis, and secondary metabolite production in vitro was evaluated. Shoots of thyme (Thymus vulgaris L.) and a spearmint-peppermint cross (Mentha spicatax Mentha piperita) were grown on MS medium with and without $3 \%$ sucrose under 350 , $1500,3000,10,000$, and $30,000 \mu \mathrm{L} \mathrm{CO}_{2} / \mathrm{L}$ for 8 weeks. Dichloromethane extracts from leafs were analyzed using GC-MS techniques. Prominent peaks were identified by comparison with known standards. Highest growth (i.e., fresh weight) and morphogenesis responses (i.e., leafs, shoots and roots) were obtained when shoots were grown under $10,000 \mu \mathrm{L} \mathrm{CO} / \mathrm{L}$ regardless of whether or not sucrose was included in the medium. Ultra-high $\mathrm{CO}_{2}$ concentrations $(3000 \mu \mathrm{L} \mathrm{CO} / \mathrm{L})$ stimulated secondary metabolite production regardless of whether or not the medium contained sucrose. However, the combination of certain ultra-high $\mathrm{CO}_{2}$ levels (e.g., 3000 to $10,000 \mu \mathrm{L} \mathrm{CO} / \mathrm{L}$ ) and the presence of sucrose in the $\mathrm{me}^{2}$ dium resulted in shoots producing the highest levels of secondary metabolites. These results suggest that in vitro photosynthesis, which is stimulated by ultrahigh $\mathrm{CO}_{2}$ levels, may enhance secondary metabolite production.

\section{ORAL SESSION 26 (Abstr. 564-567) Cross-commodity: Postharvest/Crop Protection/Quality}

564

The Influence of Preharvest Treatments with ReTain ${ }^{\mathrm{TM}}$ (An Ethylene Biosynthesis Inhibitor) on the Fruit Maturation and Quality of 'Royal Gala' Apple in New Zealand

M.D. White ${ }^{* 1}$, D.S. Tustin', K.F. Foote', R.K. Volz', J. Stokes ${ }^{2}$, J. Campbel/2, R. Marshal/ $\beta^{3}$, and C. Howar ${ }^{\beta} ;{ }^{1}$ HortResearch, Private Bag 1401, Havelock North, New Zealand; ${ }^{2}$ HortResearch, Old Mill Road, RD3, Motueka, New Zealand; ${ }^{3}$ HortResearch, Earnscleugh Road, RD1, Alexandra, New Zealand

ReTain ${ }^{\mathrm{TM}}$ is a plant bioregulator containing the active ingredient aminoethoxyvinylglycine (AVG), which inhibits the ethylene biosynthesis pathway. In 1997, the first efficacy studies on 'Royal Gala' apple with ReTain ${ }^{\mathrm{TM}}$ were conducted under New Zeal and conditions in Hawkes Bay. ReTain ${ }^{T M}$ was applied 4 weeks before the anticipated start of harvest on 'Royal Gala' at 850 and 1700 $\mathrm{g} \cdot \mathrm{ha}^{-1}$ with or without adjuvants. ReTain ${ }^{\mathrm{TM}}$ application delayed the onset of 'Royal Gala' fruit maturation between 1 and 2 weeks, resulting in enhanced fruit size and fruit flesh firmness at harvest. The optimum response for delaying the onset of fruit maturation was achieved using ReTain ${ }^{\mathrm{TM}}$ at $850 \mathrm{~g} \cdot \mathrm{ha}^{-1}$ if applied in combination with a wetter. Fruit were also graded for fruit quality and air-stored at $0.5^{\circ} \mathrm{C}$. Fruit after 10 weeks of storage showed no difference in fruit flesh firmness, but all ReTain TM treatments had fruit with less yellow background colour compared with untreated fruit. In 1998, efficacy studies were undertaken in three geographical locations on 'Royal Gala'. ReTain ${ }^{\mathrm{TM}}$ was applied at a rate of 830 $\mathrm{g} \cdot \mathrm{ha}^{-1}$ in combination with Silwet L-77 at $0.1 \%$. All trees with the exception of 'Royal Gala' grown in the Hawkes Bay had not received any ReTain ${ }^{\text {TM }}$ previously. In all regions, seasonal changes in background color and starch pattern index were delayed by ReTain ${ }^{T M}$ treatment. A concurrent delay of an increase in soluble solids concentration and retention of higher flesh firmness were also induced by ReTain ${ }^{\text {TM treatment. }}$

\section{5}

Evaluation of the Massive Use of Magnesium Infiltration to Predict Bitter Pit in Apples

Jorge B. Retamales" ${ }^{*}$, Claudio Valdes ${ }^{1}$, and Verónica Donoso ${ }^{2} ;{ }^{1}$ Centro de Pomáceas, University of Talca, Chile; ${ }^{2}$ Dole Chile S.A.

Bitter pit (BP) is the main physiological disorder of apples in Chile. Its incidence affects pre-and postharvest handling of the fruit and the profitability of this species. Since 1991, its control and prediction have been studied by this research team through field and laboratory trials. The BP incidence is linked to the fruit $\mathrm{Ca}$ concentration; however, fruit $\mathrm{Ca}$ analysis has not adequately predicted $\mathrm{BP}$ incidence in postharvest. Several authors have proposed $\mathrm{Ca} / \mathrm{Mg}$ antagonism, which has been the basis to develop a predictive method through fruit $\mathrm{Mg}$ infilttration (IMG) 40 days before harvest. IMG has been massively used for two seasons in Chile, with 375 samples processed in 1997 and 1170 in 1998. The industry has been increasing its proportion of the samples processed, from 22\% in 1997 to $71 \%$ in 1998 . The most prominent varieties are 'Granny Smith' (GS) > 'Braeburn' 
(BR) > 'Royal Gala' (RG) > 'Red King Oregon' (RKO). The massive use of IMG has obtained predictive capacities ( $r^{2}$ between BP predicted and BP after 3 months regular cold storage) of 0.8 for 'Fuji'; 0.7 for GS, BR, and RG; and 0.58 for RKO. (This reduction in the predictive capacity with regards to the previous research under controlled conditions would, in part, be due to problems in obtaining fruit samples: non-uniform fruit size, inadequate sampling dates, diverse fruit numbers, etc.) Developments are underway to increase the geographical coverage of the service, the predictive capacity of the method for certain cultivars and productive areas and the number of samples processed.

\section{6}

Induction of Defenses Against Pathogens of Fruit and Vegetables by Elicitors

M. V. Bhaskara Reddy" and Joseph Arul; Department of Food Science and Nutrition, and Horticultural Research Center, Laval University, Sainte-Foy, Quebec, Canada, G1K 7P4

Fruit and vegetables are highly perishable and postharvest pathogens are one of the major causes in the early termination of their shelf life. Although synthetic fungicide are effective against postharvest pathogens, they face imminent problems. One alternate approach is the induction of host resistance against postharvest diseases. Wetested the efficacy of chitosan, Milsana ${ }^{\circledR}$, and Bion ${ }^{\circledR}$ on carrot, tomato, potato, green pepper, and strawberries against postharvest fungal and bacterial rots. Chitosan was not only antimicrobial but also induced resistance against postharvest infections of Alternaria, Botrytis, and Erwiniain tomato, green pepper, carrot, and potato. Preharvest sprays of chitosan induced resistance against postharvest infection of Botrytis cinereain strawberries and improved the storage quality. Ultrastructure and cytochemical investigations showed that chitosan not only induced several morphological alterations in B. cinereaand Alternariaalternata inhibiting the production of pathogenic factors by the fungi, but also stimulated various host defense reactions, such as papilla formation and induction of defense enzymes, phytoalexins, and phenols. Application of Milsana ${ }^{\circledR}$, a plant extract, and Bion ${ }^{\circledR}$, an activator of host defenses, protected carrots from postharvest decay by $B$. cinerea. Milsan $a^{\circledR}$ was effective at $4^{\circ} \mathrm{C}$, while Bion ${ }^{\circledR}$ was effective at both 4 and $13^{\circ} \mathrm{C}$ storage temperatures. Thus, there is great potential for defense inducers in postharvest disease control of fruit and vegetables.

\section{7}

Effects of Mancozeb, NOVA, GA, and Yeast-like Fungi on Stylar-end Russeting of Navel Orange

EW. Stover", M. Myers, R.M. Sonoda, and, Z. Guo; Indian River Res. \& Ed. Center, Univ. of Florida, Ft. Pierce, FL 34945

Stylar-end russetting (SER) is a cosmetic defect of Florida citrus fruit most frequently associated with navel orange. SER is evident as spots or streaks of corky tissue that often form a network of intersecting lines. Occurrence of SER is reported to vary widely from year to year, but some orchards have a history of severe SER, with fruit culled annually for this defect. Growers report that SER is typically first evident in August. The cause of SER has not been determined. Reports of yeast-like fungi inducing russet in pome fruit suggest that similar organisms may be implicated in SER. Yeast-like fungi were isolated on acid PDA from navel oranges in an orchard with frequent severe SER. Strains were selected with a wide range of colony morphology, but were not identified taxonomically. These strains, and strains of Aureobasidium pullulans and Rhodotorula glutinis that caused russetting in pome fruit, were grown in liquid suspension and sprayed on navel orange trees with three repeated applications during July and Aug. 1998. No increase in SER was observed on strain-inoculated trees compared to controls. Two broad-spectrum fungicides were sprayed on other navel orange trees to further explore the possibility that fungi may be involved in SER. GA (gibberellic acid) was also applied in this experiment because it can reduce russetting in apples. All applications were made five times at 3-week intervals in June through Sept 1998. SER was assessed in fruit harvested late Sept. 1998. The proportion of fruit with less than $10 \%$ of the surface exhibiting SER was $51 \%$ for controls, increased to $69 \%$ where myclobutanil was applied at $74 \mathrm{mg}$ ai./. L and increased further to $93 \%$ where manganese ethylenebisdithiocarbamate was applied at 1775 $\mathrm{mg}$ a.i./L. GA did not significantly influence SER.

\section{ORAL SESSION 27 (Abstr. 568-575) Floriculture: Greenhouse Management/ Environmental \& Production Technology}

\section{8}

Effect of Twilight and Temperature Difference (DIF) or Temperature Pulse at End-of-day on Height of Easter Lilies Theo J. Blom and David Kerec; Dept. of Plant Agriculture, Hort. Research Inst. of Ontario, Univ. of Guelph, Vineland Station, Ont., Canada, LOR 2E0

Potted bulbs of Lilium longiflorum Thunb. 'Ace', 'Nellie White', and 'Snow White' were grown under either ambient photo period (APP), 8-h photo period using blackout (no twilight) between 1600 and $0800 \mathrm{HR}$ (8PP) or 8PP extended with 1 - $h$ of low-intensity far-red radiation (9PP) at end-of-light period in a greenhouse with either $\mathrm{a}+5^{\circ} \mathrm{C} \mathrm{DIF}$ or $\mathrm{a}-5^{\circ} \mathrm{C} \mathrm{DIF} \mathrm{(=} \mathrm{day} \mathrm{-} \mathrm{night} \mathrm{temperature).} \mathrm{In} \mathrm{a}$ second experiment, Easter lilies were also grown under APP, 8PP, and 9PP regimes with a constant day/night temperature $\left(0^{\circ} \mathrm{CDIF}\right)$ but with either $\mathrm{a}+5^{\circ} \mathrm{C}$ or $-5^{\circ} \mathrm{C}$ temperature pulse for 3 -h during end-of-light period. Each experiment was replicated twice and data was averaged over 2 years. The $+5^{\circ} \mathrm{C}$ DIF regime produced plants which were $19 \%$ taller than under $-5^{\circ} \mathrm{C}$ DIF. Plants grown under APP were $32 \%$ and $25 \%$ taller than under $8 \mathrm{PP}$ in the $+5{ }^{\circ} \mathrm{C}$ and $-5{ }^{\circ} \mathrm{C}$ DIF regimes, respectively. Regardless of the DIF regime, plant height under the $9 P P$ was the same. In the second experiment, there was no significant difference in plant height of plants grown with the $-5^{\circ} \mathrm{C}$ compared with the $+5^{\circ} \mathrm{C}$ pulse at end-of-light period.

\section{9}

\section{Photoselective Filters Affect Flowering and Stem Extension} In Viola xwittrockiana and Pisum sativum

Erik S. Runkle* and Royal D. Heins; Dept. of Horticulture, Michigan State Univ., East Lansing, MI 48824-1325

For many plants, light quality has a pronounced effect on plant morphology; light with a low red $(R, 600$ to $700 \mathrm{~nm})$ to far-red ( $F R, 700$ to $800 \mathrm{~nm}$ ) ratio promotes stem elongation and a high $R$ : $F R$, or blue light (B, 400 to $500 \mathrm{~nm}$ ), suppresses it. In addition, FR light is required for rapid flowering in some species, particularly for long-day plants. Our objective was to quantify how flexible spectral filters, which selectively reduce $F R, B$, or $R$, influence plant height and flowering of the quantitative long-day plants Pisum sativum L. 'Utrillo' and Viola xwittrockiana Gams. 'Crystal Bowl Yellow'. Plants were grown at $20^{\circ} \mathrm{C}$ with reduced FR, B, or Renvironments or with a neutral density control (C) filter. Calculated phytochrome photoequilebria were $0.78,0.73,0.71$, or 0.46 for the altered $\mathrm{FR}, \mathrm{B}, \mathrm{C}$, or Renvironments, respectively. All filter treatments transmitted a similar photosynthetic photon flux. Sixteen-hour photoperiods were created with natural daylight supplemented with high-pressure sodium lamps positioned above filters. Violagrown under the FRfilter never reached $100 \%$ flowering within 8 weeks, and visible bud appearance was delayed by at least 17 days compared to all other filters. The Rand B filters enhanced peduncle length by at least $25 \%$ compared to the $\mathrm{C}$ or FR filters. In Pisum, average internode length was 2.2, 2.9, 3.4, and 3.7 $\mathrm{cm}$ under the $F R, C, B$, and R filters, respectively, all statistically different. Fresh and dry shoot weights were similar under the $\mathrm{C}$ and FR filters but were at least $35 \%$ greater under the $B$ filter and $35 \%$ lower under the R filter.

\section{0}

The Poinsettia Stock Plant Light Environment Impacts Poinsettia Stem Breakage

James E. Faust" and Pamela Korczynski; University of Tennessee, Ornamental Horticulture and Landscape Design, Knoxville, TN 37901

In 1998, 'Freedom Red' poinsettia stock plants were grown outdoors under $0 \%, 60 \%$, and $80 \%$ shade cloth. The stock plants received a single pinch leaving 10 nodes below the pinch. Cuttings were harvested once per week for 3 weeks. The cuttings were propagated, transplanted, pinched, and grown to anthesis in the same greenhouses. After anthesis, the plants were dropped onto a concrete pad from increasing heights ranging from 10 to $70 \mathrm{~cm}$. Stem breakage was recorded each time the plants were dropped. Stem breakage of the finished plants increased as the percentage of shade cloth over the stock plants increased and as 
cutting harvest week number increased. From the Week 1 cuttings, 0\%, 8\%, and $10 \%$ of the lateral stems broke off of plants from the $0 \%, 60 \%$, and $80 \%$ shade cloth treatments when the plants were dropped $20 \mathrm{~cm}$. From Week 2 cuttings, $6 \%, 30 \%$, and $36 \%$ of the lateral stems broke off the $0 \%, 60 \%$, and $80 \%$ shade treatments. From Week 3 cuttings, $0 \%, 29 \%$, and $43 \%$ of the lateral stems broke off of the $0 \%, 60 \%$, and $80 \%$ shade treatments that were dropped $20 \mathrm{~cm}$. Thirtysix percent of the Week 3 cuttings broke off of the $80 \%$ shade treatment plants before anthesis, while none of the lateral shoots broke off of the $0 \%$ shade treatment until the plants were dropped from $40 \mathrm{~cm}$.

\section{1}

\section{Effect of Photothermal Ratio on Poinsettia Plant Quality at Anthesis}

Bin Liu* and Royal D. Heins; Department of Horticulture, Michigan State University, East Lansing, MI 48824-1325

Photothermal ratio (PTR) is defined as the ratio of radiant energy (light) to thermal energy (temperature). The objective of this study was to quantify the effect of PTR during the vegetative (PTR') and reproductive phase (PTR') on finished plant quality of 'Freedom' poinsettia. In Expt. I, plants were grown under 27 combinations of three temperatures, three daily light integrals (DLI), and three plant spacings from pinch to the onset of short-day flower induction and then moved to a common PTR until anthesis. In Expt. II, plants were grown under a common PTR during the vegetative stage and then assigned to nine combinations of one temperature, three DLIs, and three plant spacings after the onset of short-day flower induction. Both PTR' and PTR ${ }^{\mathrm{v}}$ affected final plant dry weight. All components of dry weight (total, stem, green leaf, and bract) responded in a linear way to PTR' and in a quadratic way to PTRv. Stem strength was more dependent on PTRV than PTR'. When PTR ${ }^{v}$ increased from 0.02 to $0.06 \mathrm{~mol} /$ degree-day per plant, stem diameter increased about $24 \%$ while stem strength increased $75 \%$. The size of bracts and cyathia was linearly correlated to PTR', but not affected by PTR' . When PTRr increased from 0.02 to $0.06 \mathrm{~mol} /$ degree- day per plant, bract area, inflorescence diameter, and cyathia diameter increased $45 \%, 23 \%$, and $44 \%$, respectively.

\section{2 \\ Cold Hardiness of Summer and Fall Flowering Evergreen Azalea Hybrids}

Orville M. Lindstrom* and Malgorzata A. Florkowska; Department of Horticulture, The University of Geargia, Georgia Station, Griffin, GA 30223

To date, few summer and fall flowering azaleas exist. Recently, Rhododendron oldhamii, a summer-flowering species, was hybridized with several commercial hybrids. These crosses produced various sizes and colors of flowers that bloom throughout the summer until frost, and again in the spring. However, the cold hardiness level of these azaleas is unknown. Therefore, we evaluated their cold hardiness during several months of the fall and winter. Laboratory cold hardiness tests revealed that there was a range of cold hardiness levels among the new hybrids. 'Fashion' and hybrids 02003 and 4003 tended to acclimate earlier than the others, maintain a good level of midwinter cold hardiness, and retain their hardiness into the early spring. Hybrid 15001 acclimated early and had good midwinter cold hardiness, but lost its cold hardiness in the late winter, while 04003 and 09004 acclimated late in the fall and did not attain a high level of cold hardiness in the winter. 'Lee's Select' and hybrid 08002 seemed to fall between the groups previously mentioned showing intermediate cold hardiness throughout the winter season. The laboratory cold hardiness results were similar with field observations.

\section{3}

\section{Seed Vigor Testing for Small-seeded Flower Species using Computer-aided Image Analysis}

Kay Oakley", Robert Geneve, Sharon Kester, and Patchara Wonprasaid; Department of Horticulture, University of Kentucky, Lexington KY 40546

Standardized seed vigor tests must be developed for greenhouse grown flower species. Current vigor tests used to evaluate large-seeded agronomic crops are generally not useful for evaluating smaller-seeded flower species. One alternative is to use radicle length in seedlings grown under controlled environments as an indicator of seed vigor. For that purpose, a seed vigor test was developed that uses digital images taken using a flat bed scanner to measure radicle length in small-seeded flower species. A novel, cellul ose substrate was used for germinat- ing seeds. It provided similar moisture-holding properties to standard germination blotters used by commercial seed analysts, but is clear. This has allowed for quick image acquisition without removing seedlings from the petri dish. Correlations were made between seedling growth (radicle length, total seedling length, and total seedling area) with other vigor tests (saturated salts accelerated aging) and greenhouse plug flat emergence. For several seed lots of impatiens that varied in initial seed quality, radicle length after 4 days showed good correlations $\left(>P^{2}=0.79\right)$ with other measures of seed vigor for describing seed quality. This system is an improvement over other attempts to use computer-aided assessment of digital images because it provides digital images that do not vary due to external lighting; it uses software that can evaluate radicle length in a petri dish assay that does not require a slant-board for straight radicle growth; it relies on standard germination technics used by every seed lab; it uses a clear substrate to replace the opaque blotter to allow digital images to be taken within the petri dish; and accurate measurements of seedling parts is performed in under 2 min per petri dish.

\section{4}

\section{Capital Investment Analysis of Adopting Zero Runoff}

\section{Subirrigation Systems in Greenhouse Operations}

Wen-fei L. Uva* ${ }^{* 1,3}$, Thomas C. Weiler ${ }^{2}$, and Robert A. Milligan ${ }^{3} ;{ }^{1}$ Dept. of Floriculture and Ornamental Horticulture; ${ }^{2}$ Dept. of Floriculture and Ornamental Horticulture; ${ }^{3}$ Dept. of Agricultural, Resource, and Managerial Economics, Cornell University, Ithaca, NY 14853

Adoption of technology to achieve environmental stewardship and remain competitive is a high priority for greenhouse businesses. Zero runoff subirrigation (ZRS) technology offers great promise to manage fertilizer inputs while improving production efficiency. This study applied economic engineering methodology to quantify costs and returns associated with adopting ZRS systems and compare profitability of producing crops using alternative ZRS systems for greenhouse operations in the northeastern and north central United States. The production models showed that using ZRS systems to grow greenhouse crops can be profitable if growers select a system best suitable for their crop choices. Among the four ZRS systems studied (ebb-and-flow rolling benches, Dutch movable trays, flood floors and trough benches), the Dutch movable tray system returned the highest profit per square foot week (SFW) greenhouse area for small potted plant production $(\$ 0.244 / \mathrm{SFW}$ ), and the flood floor system returned the highest profit when producing large potted plants (\$0.002/SFW) and bedding crop flats ( $\$ 0.086$ / SFW). The trough bench system was least profitable had the lowest profit for the two applicable crop categories-small potted plants $(\$ 0.183 / \mathrm{SFW})$ and large potted plants $(-\$ 0.006 / \mathrm{SFW})$. Sensitivity analysis showed that changes of cost variables generally did not affect the profitability rankings for alternative ZRS systems. Except for labor costs, as the hourly wage increased, the Dutch movable tray system gained advantages for small potted plant and large potted plant production. Among selected costs variables, changes in labor costs and tax rate had the highest impact on the profitability of small potted plant production, and changes in labor costs and initial investment costs had the highest impact on the profitability of large potted plant and bedding crop flat production.

\section{5}

\section{Greenhouse Specialty Cut Flower Production Using Bedding} Plant Flats

John M. Dole* ; Dept. of Horticulture and Landscape Architecture, Oklahoma State University, Stillwater, OK 74078-6027

Three cut-flower species, Ageratum houstonianum 'Tall Blue Horizon', Antirrhinum majus 'Spring Giants Mix', and Helianthus annuus 'Sunrich Orange' were grown in 806,1801 , or 1001 bedding plants flats resulting in 32 (85), 86 (280), and $156(620) \mathrm{cm}^{2}$ (mililiter medium)/plant, respectively. Plants were sown Sept. 1997 (fall), Dec. 1997 (winter), or Mar. 1998 (spring). Increasing area per plant decreased number of stems harvested but increased percent of stems harvested for all species. Increasing area per plant increased stem length and selling price for Antirrhinum and Helianthus; no significant difference was noted for Ageratum. Days to anthesis decreased with later planting for Antirrhinum and Helianthus; however, for Ageratum winter planting had the longest crop time and spring planting the shortest. Gross profit per square meter and square meter per week increased with decreasing area per plant for Ageratum and Helianthus; no significant difference was noted for Ageratum. Gross profit per square meter per week increased with later planting for all species. With all species 806 flats or spring planting required frequent irrigation, which would best be supplied by an auto- 
mated irrigation system. Experiment was repeated in 1998/1999 using Carthamus tinctorius 'Lasting Yellow', Celosia argentea'Chief Mix', Cosmos bipinnatus 'Early Wonder', Helianthus annuus 'Sunbright, Tagetes erecta 'Promise Orange' and 'Promise Yellow', and Zinnia elegans 'Giant Deep Red' and 'Oklahoma Mix'.

\section{ORAL SESSION 28 (Abstr. 576-580) Small Fruit/Viticulture: Production \& Physiology}

\section{6}

Strawberry Yields of Normal vs. "J" Root Plants

Warren E. Bendixen*; Univ. of California Cooperative Extensions, 624 West Foster Road, Santa Maria, CA 93455

Many factors contribute to the reduction of strawberry yields. Field surveys in previous years have shown that the lack of plant vigor associated with poor crown and root systems was the result of "J" root plants. A 1998 strawberry trial was established on 7 Nov. 1997 to evaluate the fruit yield of "J" root plants in comparison with normal roots. A "J" root plant occurs when the workers place the crown at the soil surface, while the other hand then pushes the center of the root into the slotted area, leaving the lower roots near or above the ground surface. The workers used a trowel to plant the normal root plants, place the roots straight down. The variety Camarosa was planted on 64 -inch-wide beds. Each plot was one bed wide and 30 feet long and replicated four times. The strawberry plants were spaced 14 inches apart within the rows and the rows 10 inches apart. Strawberry yields of normal vs. "J" root plants showed the "J" roots reduced yields more early in the season. The March, April, and May yields were harvested as fresh fruit. The normal plants yielded 33,653 lb/acre, compared to $28,411 \mathrm{lb} /$ acre for the "J" roots. The June and July yields were harvested as freezer fruit. The yields for normal plants were $36,421 \mathrm{lb}$ compared to 32,941 for "J" root plants. The season total yields were $70,074 \mathrm{lb} /$ acre for the normal roots compared to $61,352 \mathrm{lb}$ for the " $\mathrm{J}$ " roots, or a $14.2 \%$ yield reduction. In 1998, 10 commercial strawberry fields were surveyed to evaluate the number of "J" root plants. The results showed an average of $54 \%$ of the plants were "J" root plants, with the fields ranging from $25 \%$ to $77.5 \%$.

\section{7}

\section{Strawberry Runner Plant Root Pruning and Subsequent} Growth and Yield in California

Kirk D. Larson*; Department of Pomology, University of California, Davis 95616

Each year, 500,000,000 bare-root plants (crowns) are used to establish strawberry plantings in California. Careful placement of plants in the planting holes is a critical determinant of plant growth and productivity, but large-rooted crowns are difficult to plant correctly. Use of uniform plant material would facilitate proper planting. I conducted a study in 1997-98 to determine the influence of three root pruning treatments on performance of 'Camarosa' bare-root strawberry plants. Crowns were machine-dug from a nursery on 27 Oct. 1997. Two-hundred-forty plants were selected for uniformity of size, and root systems of all selected plants were $>12.7 \mathrm{~cm}$ in length. Root systems of individual plants were randomly subjected to three pruning treatments: nonpruned (NP), pruned to $8.9 \mathrm{~cm}$ in length (P1), or pruned to $4.45 \mathrm{~cm}$ in length (P2). Twenty plants were randomly selected from each pruning treatment, washed, divided into excised and intact root tissues, and dried at $70{ }^{\circ} \mathrm{C}$ for 6 days. Pruning resulted in the removal of $23 \%$ and $78 \%$ of root dry mass for plants in the P1 and P2 treatments, respectively. For each treatment, the 60 remaining plants were established in raised beds at the Univ. of California South Coast R.E.C. in Irvine on 1 Nov. 1997. Experimental design was a RCB, with one 20 -plant plot per treatment in each of three replicate blocks. There was no plant mortality and no difference among treatments in plant canopy diameter in March (mean diam. $=36.7 \mathrm{~cm}$ ). Fruit yields were determined for each plot at weekly intervals from 1 Feb. to 18 Apr. 1998. There was no effect of pruning on yield or fruit size, suggesting that strawberry root systems have considerable regenerative ability.

\section{8}

How Much Cover Crop Affects Plant Growth and Yield Components in 'Selva' and 'Totem' Strawberry (Fragaria $x$ ananassa Duch.) in the Establishment Year

Braja B. Datta* and Ray D. William; Department of Horticulture, Oregon State University, Corvallis, OR 97331

Field experiment on production systems of 'Selva' day-neutral and 'Totem' June-bearing strawberry was established in 1995 on the spring-killed cover crop mulched plots using randomized complete-block design. Seven soil cover treatments consisted of 'Wheeler' rye ( Secale cereale) and 'Micah' and 'Steptoe' barley (Hordium vulgare), 'Micah' residue applied on soil surface, a wedge of perlite (artificial medium) placed next to strawberry row, perlite with 'Wheeler' rye, and no treatment were used. During the early summer, cover crops were replanted between strawberry rows and mowed down after 6 weeks. In both cultivars, plant growth doubled during mid-summer, and 'Micah'on surface produced better growth than the growth in other treatments. No significant difference was found on $\mathrm{CO}_{2}$ assimilation rate $\left(\mathrm{mmol} \cdot \mathrm{m}^{-2} \cdot \mathrm{s}^{-1}\right)$, leaflet length, and number of leaves and runners among treatments $(P \geq 0.1)$. Yield of 'Totem' was ignored during the establishment year. In 'Selva', 'Micah' residue on surface produced 36\% more crowns per plant and the greatest total yield than that of any other treatment. 'Micah' on surface produced $50 \%$ more shoot biomass and $45 \%$ greater yield compared to 'Micah' barley planted in the plot. Total 'Selva' yield was $61 \%$ greater in perlite treatment than the yield in perlite with 'Wheeler' rye and $31 \%$ greater than the control treatment. Comparison of 'Selva' strawberry total yield and average fruit production between cover crops vs. control treatment using non-orthogonal contrast indicated no significant difference might suggests no detrimental interaction between cover crops and strawberry.

\section{9}

Effect of Shoot Positioning, Leaf Removal, Cluster Shading, and Curtain Orientation on Fruit Composition and Primary Bud Cold Hardiness in 'Norton/Cynthiana' Grapevines (Vitis aestivalis)

Sanliang Gu, Susanne Howard*, and Martin K. Walsh; Dept. of Fruit Science, Southwest Missouri State Univ., Research Campus, 9740 Red Spring Rd., Mountain Grove, MO 65711

The effects of shoot positioning, leaf removal, cluster shading, and curtain orientation on fruit composition and primary bud cold hardiness were investigated in mature 'Norton/Cynthiana' grapevines ( Vitis aestivalis) trained to Geneva double curtain (GDC) trellis system. For four years (1995-1998) juice soluble solids content, total titratable acidity, and pH were not affected shoot positioning. Cluster shading, curtain orientation, and leaf removal affected fruit composition at harvest. Fruit from the south-facing curtain of the GDC trellis system had higher juice soluble solid content, $\mathrm{pH}$, and skin pigmentation than fruit from the northfacing curtain. Cluster shading decreased skin pigmentation while cluster shading at the highest level only $(95 \%)$ increased pH and decreased total titratable acidity. Leaf removal, which increases light exposure of the fruit, increased juice pH in the 1997 experiment only. Juice potassium level was decreased by shoot positioning, but not cluster shading or curtain orientation. Cold hardiness of primary buds was affected by these treatments early in the winter, but the differences in primary bud cold hardiness among the treatments diminished toward the end of the dormant season.

\section{0}

\section{WITHDRAWN}

\section{ORAL SESSION 29 (Abstr. 581-587) Fruit/Nuts: Crop Production/Growth Regulators}

\section{1}

Selection and Evaluation of Macadamia Nut (Macadamia integrifolia) Varieties and Hybrids in the Highlands of Kenya L.A. Wasilwa*', N. Ondabu, G.W. Watani, H. Mulli, S. Kirru, A. Nyagah, and Kagiri; Macadamia Nut Res. Project of the Kenya Agr. Res. Inst., Kenya, Africa

Several outstanding macadamia trees (Macadamia integrifolia Maiden and 
Betche, M. tetraphylla L. S. or hybrid of these two species) were selected from orchards established in the 1960s in the central and eastern highlands and evaluated over a period of 10 years. In the thrid year of these evaluations, clones from 30 high-yielding trees (40 to $90 \mathrm{~kg}$ ) were propagated by grafting and trials were established in the central and eastern highlands. Three to five Hawaiian varieties were included as controls. Each trial consisted of five to 10 trees of each clone. Trees were evaluated for vigor, flowering, age of bearing, and yield. From these tests, a subset of 10 of the most outstanding clones were selected and evaluated in 25 field trials located in the Kenyan highlands. Most these clones started to bear 3 years after transplanting. Three distinct flowering patterns have been observed. Ten years after transplanting, yields ranged between 30 to $60 \mathrm{~kg}$ nuts/ tree. The macadamia hybrids and $M$. tetraphylla performed best at the higher elevations (1700-1850 m), M. integrifolia clones performed best at elevations of 1500 to $1750 \mathrm{~m}$. Only two Hawaiian varieties performed well and have been used in the breeding program. Most of the cultivated macadamia trees in Kenya are either M. integrifolia or hybrids. Cultivation of $M$. tetraphyllain Kenya is no longer recommended.

\section{2 \\ Off-season Carambola (Averrhoa carambola L. cv. Arkin) Production under Glass}

Roberto Nuñez-Eliseaand Jonathan H. Crane* ; University of Florida, IFAS, Tropical Research and Education Center, 18905 SW 280th Street, Homestead, Florida 33031

Carambola (Averrhoa carambola L.) is native to the humid tropics of southeastern Asia, where it bears fruit year-round. In south Florida, winter conditions (strong winds and night temperatures below $15^{\circ} \mathrm{C}$ ) repress growth and flowering of the main commercial cultivar, Arkin, and fruit is produced from July to February. Off-season fruit would reach premium prices. We have previously demonstrated that selective pruning stimulates flowering of carambola at any time of the year. However, flowers produced during cool, windy weather have consistently failed to set fruit. This study was conducted in 1994-1995 to determine whether protected cultivation would help obtain off-season fruit. Four-year-old 'Arkin' trees growing in 80-L containers were placed in a glasshouse or outdoors and pruned in November or December to force flowering during December-January. Glasshouse night temperatures during the winter were above $20^{\circ} \mathrm{C}$. All trees flowered in response to pruning. Outdoor trees produced less than one fruit per tree in late March to late April. Glasshouse trees produced 2.3 to 6.1 fruit per tree, 2 to 3 weeks earlier than trees outdoors. In the glasshouse, more than $98 \%$ of fruit were seedless, whereas all fruit produced outdoors were seeded. Production of seedless fruit indoors was achieved in the absence of insect pollinators, and yields were low compared to those of outdoor trees during the summer (at least 25 fruit per tree). We speculate that, under protected cultivation, the use of synthetic bioregulators during anthesis and insect pollinators may help increase production of off-season seedless and seeded fruit, respectively.

\section{3}

\section{Field performance of Grafted Chestnut Cultivars and their Seedlings}

Rachel Byard* and lan A. Merwin; Dept. of Fruit and Vegetable Science, Cornell University, Ithaca, NY, 14853

We planted grafted and seedling chestnuts of six cultivars in Lansing, N.Y., in April 1995 to evaluate performance of the different cultivars in our region and to compare grafted and seedling trees. We used the following cultivars: the Chinese chestnut cultivar Mossbarger (Castanea mollissima) and five interspecific hybrid cultivars [Douglas $1 \mathrm{~A}$ (C. mollissima $\times$ C. dentata), Eaton [C. mollissimax (C. crenata C. dentata) [, Skioka (C. mollissimax C. sativa), Layeroka (open-pollinated daughter of 'Skioka'), and Grimo 142Q (an open pollinated daughter of 'Layeroka')]. Growth was not significantly different between cultivars. There were no notable correlations between trunk cross-sectional area at planting and any measurement after the first year. Significant differences between cultivars were found for mortality, yield, and yield efficiency. 'Eaton' had the lowest mortality rate (2\%) of all cultivars. 'Grimo 142Q' and 'Layeroka' had the highest dry weight yields and the greatest yield efficiencies, although 'Grimo 142Q' had significantly larger nuts than 'Layeroka'. In 1998, the largest nuts (5.2 g) were harvested from 'Mossbarger' and 'Eaton trees'. 'Skioka' had the highest mortality (48\%), lowest yield, lowest yield efficiency, and smallest nut size. In the first 2 years, most grafted trees showed significantly higher yields and greater yield efficiency than seedling trees. By the third year, differences in yield between grafted and seedling trees were no longer significant for most cultivars. Over the 3 years most grafted trees revealed higher mortality and slower growth than seedlings of the same cultivar. Seedlings did not show more variability in measurements than grafted trees of the same cultivar.

\section{4}

The Effects of IBA Hormone Concentration, Cutting Type, and Media on Rooting of Local Hazelnut Cuttings

A Talaie ${ }^{* 1}$ and M.R. Nejatie ${ }^{2} ;{ }^{1}$ University of Tehran, Karaj, Iran; ${ }^{2}$ Tarbiat Modarres University, Tehran, Iran

This work was conducted for the purpose of propagation of hazelnut cuttings, using hard-, semi-hard-, and softwood cuttings produced from 1-year-old suckers of local varieties of hazelnuts from the Alamout-Qazvin area of Iran. The research was carried out in a greenhouse with a mist system at the Faculty of Agriculture of Tarbiat Modarres University. This experiment was based on the complete randomized-block design with a factorial framework and resulted in two levels of $5 \%+1 \%$ according to the Duncan test. The effect of rooting media (sand and pumice), cutting type (hard-, semi-hard-, and softwood), and use of a hormone with five concentrations (control, 1500, 3000, 4500, and 6000 ppm IBA) were investigated. The cuttings, being wounded and treated with hormones on certain beds, were kept in a greenhouse with a mist system. After 4 months, the number of rooted cuttings, mean number of roots per rooted cuttings, total length of roots, mean length of one root, average of dry weights, and average of young shoots were evaluated. The results indicate that the rooting medium and hormone are considerably effective for rooting of the cuttings and is considered as a significant facture. The general conclusion is that the most favorable result is reached with pumice and $4500 \mathrm{ppp} \mathrm{IBA}$. The interaction between rooting medium and hormone on the rooting process was significant, and finally, it was found that there is not a significant relation between callusing and rooting in hazelnut. Also, the wounding is an effective factor for rooting of hazelnut cuttings.

\section{5}

Indole Acetic Acid Reduced Some Adverse Effects of Salt Stress on Date Palm Seedlings

Hameed J. Aljuburi*; ; University of Qatar College of Science, Biology Dept. Botany and Agricultural Programme, P.O. Box 2713, Doha, Qatar

An experiment was conducted at the United Arab Emirates Univ., in Al-Ain, to study the effect of saline water on the growth characteristics of date palm (Phoenix dactylifera L.) seedings cultivar Lulu-salt alone or a combination of $\mathrm{NaCl}$ and indole acetic acid (IAA) or IAA alone were tested with different levels. Then the plant growth characteristics were measured. Hormone did not antagonize the salt effect on shoot length of date palm seedlings. Application of $24 \mathrm{mg} \cdot \mathrm{L}^{-1}$ salt alone or in combination with hormone and $12 \mathrm{mg} \cdot \mathrm{L}^{-1}$ in combination with 0.2 $\mathrm{mg} \cdot \mathrm{L}^{-1}$ IAA significantly increased the root : shoot ratio over the control. Irrigation date palm seedlings with saline water alone or in combination with IAA for 80 days resulted in a significant increase in dry matter (percentage) of leaves with salt symptoms, whereas the number of leaves per seedling were reduced over the control. The results also showed that the irrigation of seedlings with $0.15 \mathrm{mg} \cdot \mathrm{L}^{-1}$ IAA in combination with 24 or $12 \mathrm{mg} \cdot \mathrm{L}^{-1}$ salt alleviated adverse effect of salt by increasing or reducing significantly root length or leaves with salt symptoms percentage over using 24 or $12 \mathrm{mg} \cdot \mathrm{L}^{-1}$ salt alone.

\section{6}

\section{Studies on the Mode of Action of $\mathrm{NH}_{4} \mathrm{NO}_{3}$ as a Spray Additive on Penetration of ${ }^{14} \mathrm{C}-\mathrm{NAA}$ through Isolated Tomato Fruit Cuticle}

Royal G. Fader", Tsuneo Ogata, and Martin J. Bukovac; Department of Horticulture, Michigan State Univ., East Lansing, MI 48824

NAA, a weak organic acid plant growth regulator $\left(\mathrm{pK}_{\mathrm{a}} 4.2\right)$, penetrates the plant cuticle preferentially as an undissociated molecule $(<10 \%$ dissociated at $\mathrm{pH}$ 3.2). We have reported, using a finite dose diffusion system, that $\mathrm{NH}_{4} \mathrm{NO}_{3}$ (AN, $8 \mathrm{mM}$ ) at pH 5.2 (>90\% dissociated) enhanced the penetration of ${ }^{14} \mathrm{C}-\mathrm{NAA}$ through isolated tomato fruit cuticular membranes (CM). AN appears to preferentially enhance penetration of the dissociated NAA molecule over the nondissociated form. A possible mode of action is that AN affects the cuticle matrix, allowing for greater NAA penetration. Acid treatment $(4 \mathrm{~N} \mathrm{HCl})$ of the cuticle, which alters the cuticle's ionic characteristics, resulted in a 10\% reduction in NAA penetration from droplets in the presence of $\mathrm{AN}$. When $\mathrm{AN}(80 \mathrm{mM})$ was included in the receiver solution of the diffusion cell in an effort to infuse the cuticle matrix, NAA 
penetration was not increased compared to when AN was present in the applied droplet. AN (8 mM) also increased NAA penetration through dewaxed tomato cuticular membranes (DCM; $+252 \%$ for DCM vs. $+190 \%$ for CM in $120 \mathrm{~h}$ ). Since AN only enhances NAA penetration when included with the NAA in the treatment droplet, the AN effect may be related to the role of the droplet/deposit (droplet residue) as a donor. This conclusion is further supported with sorption studies, where AN over a 100-fold concentration range $(0.8-80 \mathrm{mM})$ did not increase NAA sorption by tomato fruit CM and where no deposit is present. The role of the physicochemical nature of the deposit, including the chemical/ionic characteristics of any additive (i.e., AN) and active ingredient will be discussed.

\section{7}

Study on Adoptability of Pecan, Carya illinoensis L., under Climatic Conditions of the Safiabad Area of Iran

A. Talaie and A. Khezrian*; University of Tehran, Karaj, Iran

To select proper varieties, several seedlings of Caryaillinoensis (pecan) were imported from the United States about 28 years ago and were planted at the Safiabad Research Center, Iran. Because of the existence of docogamy in pecan, protandrous and protoginous cultivars were first determined. Then, qualitative and some quantitative characteristics were studied in a completely random plant test and, with regard to treatments and repetitions, the total yield of trees, weight of kernel, kernel : bark ratio, oil percentage (fat), protein percentage, and the size of fruit were examined. With regard to all circumstances and statistical results, out of 14 examined varieties, varieties 12 ('Wichita') and 1 ('Gratex') were selected on the basis of their high yields, respectively.

\section{ORAL SESSION 30 (Abstr. 588-595) Fruit/Nuts: Environmental Physiology}

\section{8}

Photosystem II Efficiency and $\mathrm{CO}_{2}$ Assimilation in Response to Light and $\mathrm{CO}_{2}$ in Leaves of Deciduous Tree Fruit

Lailiang Cheng*, Leslie H. Fuchigami, and Patrick J. Breen; Dept. of Horticulture, ALS 4017, Oregon State University, Corvallis, OR 97331

Photosystem II (PSII) efficiency and $\mathrm{CO}_{2}$ assimilation in response to photon flux density (PFD) and intercellular $\mathrm{CO}_{2}$ concentration (Ci) were monitored simultaneously in leaves of apple, pear, apricot, and cherry with a combined system for measuring chlorophyll fluorescence and gas exchange. When photorespiration was minimized by low $\mathrm{O}_{2}(2 \%)$ and saturated $\mathrm{CO}_{2}(1300 \mathrm{ppm})$, a linear relationship was found between PSIl efficiency and the quantum yield for $\mathrm{CO}_{2}$ assimilation with altering PFD, indicating $\mathrm{CO}_{2}$ assimilation in this case is closely linked to PSIl activity. As PFD increased from 80 to $1900 \mu \mathrm{mol} \cdot \mathrm{m}^{-2} \cdot \mathrm{s}^{-1}$ under ambient $\mathrm{CO}_{2}$ (350 ppm) and $\mathrm{O}_{2}(21 \%)$ conditions, PSIl efficiency decreased by increased nonphotochemical quenching and decreased concentration of open PSIl reaction centers. The rate of linear electron transport showed a similar response to PFD as $\mathrm{CO}_{2}$ assimilation. As $\mathrm{Ci}$ increased from 50 to $1000 \mathrm{ppm}$ under saturating PFD $\left(1000 \mu \mathrm{mol} \cdot \mathrm{m}^{-2} \cdot \mathrm{s}^{-1}\right)$ and ambient $\mathrm{O}_{2}$, PSIl efficiency was increased initially by decreased nonphotochemical quenching and increased concentration of open PSII reaction centers and then leveled off with further a rise in $\mathrm{Ci}$. $\mathrm{CO}_{2}$ assimilation reached a plateau at a higher $\mathrm{Ci}$ than $\mathrm{PSIl}$ efficiency because increasing $\mathrm{Ci}$ diverted electron flow from $\mathrm{O}_{2}$ reduction to $\mathrm{CO}_{2}$ assimilation by depressing photorespiration. It is concluded that PSII efficiency is regulated by both nonphotochemical quenching and concentration of open PSII reaction centers in response to light and $\mathrm{CO}_{2}$ to meet the requirement for photosynthetic electron transport.

\section{9}

\section{Summer Pruning Effects on Leaf and Whole Canopy Gas Exchange in Apple Trees}

Kuo-Tan Li* and Alan N. Lakso; Cornell University, NYS Agric. Exper. Sta., Geneva, New York, USA

Summer pruning is primarily used in apples to increase the light penetration into inner canopy to improve fruit color. However, summer pruning may reduce fruit size. We hypothesize that removing heal thy exterior shoots reduces the whole- tree carbon supply in relation to pruning severity. If the crop load (i.e., demand) is high, fruit size and quality will be reduced. The effects of summer pruning on photosynthetic activity and recovery of shaded leaves after re-exposure were monitored on a range of exposures in canopies of 'Empire' apple trees. The photosynthetic ability of leaves was positively related to its prepruning exposure. There was little recovery of photosynthetic activity of shade leaves until late growing season, indicating the re-exposure of shade leaves after summer pruning cannot replace the role of exterior leaves removed by pruning. Whole canopy net $\mathrm{CO}_{2}$ exchange (NCER) was measured on 'Empire'/M9 trees with a commercial range of pruning severity. Reductions in NCER were approximately proportional to pruning severity and \% leaf area removed and were as great as $60 \%$ in the most severe pruning. Canopy light interception decreased slightly. The effects on canopy NCER thus appeared to be primarily related to reduced photosynthetic efficiency and secondarily to reduced light interception.

\section{0}

Growth and Physiological Characteristics of Diploid and Tetraploid Citrus Rootstock Seedlings Grown at Elevated $\mathrm{CO}_{2}$ J.P. Syvertsen ${ }^{* 1}$ J.W Grosser ${ }^{1}$ and L.S. Lee ; ${ }^{2}$ University of Florida, IFAS, Citrus Research and Education Center, Lake Alfred, FL 33850; ${ }^{2}$ Centre for Plant Conservation Genetics, Southern Cross University, Lismore, NSW, 2480, Australia

We grew three diploid (2X) Citrus rootstock seedlings and their autotetraploids (4X) at elevated $\mathrm{CO}_{2}$ to obtain insights into limitations on growth and net gas exchange that have been associated with tetraploidy. Well-nourished Volkamer lemon (Volk), Troyer citrange (Troy), and Cleopatra mandarin (Cleo) were grown in greenhouses at ambient or twice ambient $\mathrm{CO}_{2}$ for 3 months. We measured plant growth, water relations, mineral nutrition, and net gas exchange characteristics of leaves. Overall, tetraploid roots were thicker as $4 X$ had lower root length : dry weight ratio or specific root length (SRL) than $2 X$ roots. Tetraploid plants were smaller and had higher root/shoot ratios, shorter fibrous roots, and lower whole plant transpiration than $2 X$. Tetraploids also had lower leaf $\mathrm{N}$ and $\mathrm{P}$ concentrations on a dry weight basis. Since $4 X$ leaves had thicker leaves (more dry weight per area) than $2 X$ leaves, these nutrient differences disappeared when expressed on an leaf area basis. Elevated $\mathrm{CO}_{2}$ increased plant growth but decreased leaf $\mathrm{N}, \mathrm{P}$, and $\mathrm{K}$ apparently by a growth dilution effect. Elevated $\mathrm{CO}_{2}$ also increased fibrous root thickness, leaf thickness, and net assimilation of $\mathrm{CO}_{2}\left(\mathrm{ACO}_{2}\right)$ but decreased stomatal conductance and transpiration such that leaf water use efficiency increased. There was no effect of ploidy level on $\mathrm{ACO}_{2}$ but $4 \mathrm{X}$ Volk and Troy had lower rates of $\mathrm{ACO}_{2}$ than their diploids at elevated $\mathrm{CO}_{2}$. Hydraulic conductivity of intact root systems (measured in a pressure pot) was correlated to total plant growth but variability obscured effects of $\mathrm{CO}_{2}$ or ploidy on root conductivity. The low SRL of tetraploids were correlated with lower rates of water use and lower leaf nutrient concentrations, which may be operative in determining the growth characteristics associated with tetraploidy.

\section{1}

\section{Potential Use of Infrared Thermometry for the Detection of} Water Stress on Apple Trees

Rita Giuliani* and James A. Flore; Dept. of Horticulture, Michigan State University, East Lansing, MI 48824-1325 USA

Infrared thermometry was applied to estimate the canopy temperature of apple trees with the aim to detect a water stress condition early by remote sensing. The measurements were taken in Michigan during Summer 1998 in a 4-year-old apple orchard. Digital thermo-images of the canopy were taken using a IR imaging radiometer on well-watered trees and trees in a water shortage condition. The images were taken considering the geometrical relationship among camera position, canopy, and sun position. During the measurements, environmental (air and soil) conditions were also monitored. A software program was developed to analyze the thermal data, to show the thermal frequency distribution and to estimate the statistical parameters, which are able to represent the physiological condition of the trees. An increase of the canopy surface temperature (connected to the partial stomatal closure that is affecting the leaf energy balance) was detected early in the non-irrigated plants, compared to the well-irrigated trees, already when physiological responses as photosynthetic activity and fruit growth were not yet negatively affected by water deficit. The study confirms that there are the theoretical basis to use infrared thermometry and digital image processing to early detect the water stress on fruit trees. 


\section{2}

Use of Infrared Thermometry and Heat-pulse Technique for Detection of Water Stress in Apple Trees

L. Lombardini* and J.A. Flore; Department of Horticulture, Michigan State University, East Lansing, MI 48824

The recent development of small portable infrared thermometers has made canopy temperature an easily measured characteristc in the field. Our objective was to correlate a reduction of soil water with foliage temperature and to compare it with other indicators of plant stress $\left(\mathrm{Pn}, \mathrm{E}, \mathrm{g}_{\mathrm{s}}\right.$, leaf expansion, sap flow). During Summer 1998, we evaluated the responses of potted apple rootstocks (cultivars Budagowski 9, M9, and Mark) to soil water deficit. Irrigation was withheld for 7 days, and the canopy temperature $\left(T_{c}\right)$ was measured daily with an infrared camera. $T_{c}$ was al ways higher than air temperature $\left(T_{a}\right)$. $T_{c}$ between control and stress plants began to differentiate from day 3. In Mark, this difference was maintained until the end of the experiment. However, gas exchange in Mark seemed to be less affected by the stress than in the other two cultivars. At day 7, midday stomatal conductance $\left(g_{\mathrm{s}}\right)$ was $38.0,32.3$, and $72.0 \mathrm{mmol} \cdot \mathrm{m}^{-2} \cdot \mathrm{s}^{-1}$ in Budagowski 9, M9, and Mark, respectively (control values varied between 161.6 and 164.3 $\mathrm{mmol} \cdot \mathrm{m}^{-2} \cdot \mathrm{s}^{-1}$ for all the cultivars). Heat-pulse sapflow sensors installed on Mark indicated that the speed of the xylem sap was affected by the stress from day 4 (19-26 cm/h for the controls vs. $15-21 \mathrm{~cm} / \mathrm{h}$ for the stressed plants). Specific details on the physiological data will be presented.

\section{3}

Water Stress Influences Soil/Root Respiration Rate and Root Morphology of Young Apple Trees

Georgios Psarras and lan A. Merwin*; Dept. of Fruit and Vegetable Science, Cornell University, Ithaca, NY 14853

One-year-old potted 'Mutsu' apple (Malus domestica) trees on MM.111 and M. 9 rootstocks were grown outdoors from May to Nov. 1997, under three levels of soil-water availability $(-20,-80$, and $-200 \mathrm{kPa})$, to evaluate the effects of water stress on soil/root respiration and root morphology. At weekly intervals, we measured soil/root respiration using a portable infrared gas analyzer and rootsystem size or functional activity using an electric capacitance meter. These observations were tested as nondestructive methods to estimate relative differences in root size and morphology in situ compared with final dry weight and form of excavated apple rootstocks. Root size-class distributions were estimated by digital imaging and analysis of harvested root systems. Root growth was substantially reduced by water stress; the magnitude of reduction was similar for both rootstocks, but the percentage of shoot growth reduction was higher for MM.111. Root : shoot ratios were higher and average specific respiration rates over the growing season were lower for M. 9 root systems. Water stress increased the root : shoot ratio, specific root length, and carbon costs of root maintenance as indicated by specific respiration rates. Soil/root respiration was more closely correlated than root electric capacitance with actual root system size. The observed $r^{2}$ values between root capacitance and root dry weight were as high as 0.73 , but root capacitance was also confounded by other factors, limiting its usefulness for nondestructive estimation of root size or activity. Rootstock genotype significantly affected root capacitance, which provided better estimates of root dry weight for M.9 than for MM.111.

\section{4}

\section{Effect of Water Stress during the Harvest Period on the} Carbohydrate Reserves of Mature Almond Trees

\section{Gaston Esparza*, Ted M. DeJong, and Steve A. Weinbaum; Department of Po-} mology, UC Davis, One Shields Avenue, Davis, CA 95616 USA

The effect of water stress during the harvest period on carbohydrate reserves at the end of the growing season was studied for mature, field-grown almond trees. The following irrigation treatments were imposed during 1995, 1996, and 1997: a) full irrigation (FI) (irrigation every 3-7 days), b) moderate stress (MS) (18 days of irrigation cut-off), and c) severe stress (SS) (35, 47 , and 53 days of irrigation cut-off for 1995, 1996, and 1997, respectively). Midday stem $\left(\mathrm{Y}_{\mathrm{ms}}\right)$ and predawn leaf $\left(Y_{\text {pd }}\right)$ water potentials were monitored during each season's stress. Three trees of contrasting treatments (FI vs. SS) were excavated on 10 Dec. 1997 and divided into tree components for dry weight and TNC concentration determination. Although there was no significant difference in whole-tree biomass between the excavated Fl and SS trees, total new stem growth of SS trees was half of FI trees. TNC concentrations in the organs of SS trees were significantly reduced compared to FI trees. Total calculated whole tree TNC content for SS trees was $26.1 \%$ less than $\mathrm{Fl}$ trees. The difference in TNC content between $\mathrm{Fl}$ and SS trees was larger for roots (34.9\%) than for the aerial parts (21.1\%) indicating the higher sensitivity of roots for reflecting reserve status. Although roots constituted just $13.4 \%$ of the whole tree biomass, they stored $36.4 \%$ of TNC. Only roots exhibited a clear association between the minimum values of $Y_{m s}$ and $Y_{p d}$ during the season and TNC concentration of 12 non-excavated additional trees that were subsampled at the end of the growing season.

\section{5}

\section{The Cuticular Membrane: A Critical Factor in Rain-induced} Cracking of Sweet Cherry Fruit

Martin J. Bukovac ${ }^{* 1}$, Moritz Knoche ${ }^{2}$, Alicia Pastor', and Royal G. Fader'; ' ${ }^{1}$ Dept. of Horticulture, Michigan State University, East Lansing, MI 48824; ${ }^{2}$ Dept. of Horticulture, Martin-Luther University, 06099 Halle (Saale), Germany

Morphological and physical characteristics of the cuticular membrane (CM) of selected cultivars of sweet cherry (Prunus avium L.) fruit were studied relative to rain-induced cracking. Two characteristics of the $\mathrm{CM}$ may be determinants in rain-induced fruit cracking. The surface morphology and chemistry determine surface wettability and water retention, and the morphology and physicochemical characteristics its water permeability. The fruit epidermis as well as the guard cell walls adjacent to the outer vestibule and stomatal pore are covered by a thin lipoidal CM. Stomata were present at a frequency of 0.1 to 2 per $\mathrm{mm}^{2}$ depending on cultivar and fruit surface position. However, most appeared nonfunctional with many pores partially or completely occluded with wax-like material. There was no evidence of water (containing fluorescein or $\mathrm{AgNO}_{3}$ ) penetration into stomatal pores following surface application or submerging fruit for short periods. There was stomatal pore penetration when submerged fruit were infiltrated by reduced pressure in the presence of $0.1 \% \mathrm{~L}-77$. Preferential sorption of $\mathrm{AgNO}_{3}$ and fluorescein by cuticular ledges and guard cells was noted. The epicuticular wax (ECW) had no significant fine-structure. The CM was isolated enzymatically (cellulase/ pectinase) and found to be 1 to $2 \mu \mathrm{m}$ thick with an area weight of 1.2 to $2.3 \mathrm{~g} \cdot \mathrm{m}^{-2}$, of which $25 \%$ to $40 \%$ was chloroform/methanol (1: 1 by vol.) soluble. Fractionation of the chloroform/methanol fraction indicated the presence of four groups of nonpolar constituents. The fruit surface was moderately difficult to wet, forming contact angles of $85 \%$ to $105 \%$, and with an estimated critical surface tension in the range of 16-24 $\mathrm{mN} \cdot \mathrm{m}^{-1}$. Fruit water loss (transpiration) and uptake on submersion was followed and found to be complex. Transpiration increased with an increase in temperature, and both rate of transpiration and water uptake increased after removal of the epicuticular and cuticular waxes. Pathways of water uptake and the significance of our findings to rain-induced fruit cracking will be discussed.

\section{ORAL SESSION 31 (Abstr. 596-601) Woody Ornamentals/Landscape/Turf: Stress Physiology/Crop Protection}

596

\section{Landscape Design and History Affect Urban Plant Gas} Exchange Parameters

L. Brooke McDowel/* and Chris A. Martin; Department of Plant Biology, Arizona State University, Tempe, AZ, 85287-1601

Effects of landscape design and land use history on gas exchange parameters were evaluated for woody plants in a factorial site matrix of formerly desert or agricultural land uses and xeric or mesic residential landscape designs within the metropolitan area of Phoenix, Ariz. Remnant Sonoran Desert sites and an alfalfa agricultural field functioned as controls. Residential landscapes and the alfalfa field were irrigated regularly. Monthly instantaneous measurements of maximum leaf and stem carbon assimilation (A), conductance (gs), and transpiration ( $E$ ) were made within three replicates of each site type during 1998 and 1999. Measurements were repeated monthly on three woody plant life forms: trees, shrubs, and ground covers. Assimilation fluxes were not related to former land use, but were lower for plants in xeric compared with those in mesic landscapes. Transpiration fluxes were higher for plants in formerly agricultural sites than in formerly desert sites, and were lower in xeric than in mesic landscape design. Compared 
with plants in residential landscapes, $A$ and $E$ fluxes were generally higher for plants in the agricultural control sites and were lower for plants at the desert control sites. Plant instantaneous transpiration efficiency (ITE $=A / E$ ) was higher in formerly agricultural sites than in formerly desert sites but was not affected by landscape design. Patterns of $A, g s$, and shoot temperature at irrigated sites suggest that maximum plant carbon assimilation was not limited by shoot conductance but was more responsive to shoot temperature. Similarities in patterns of ITE between plants in the different landscape design types suggest that xeric and mesic landscape plants do not differ in terms of water use efficiency.

\section{7}

\section{Tree Establishment and Soil Surface Covers}

Garry V. McDonald $d^{*}$ and Michael A. Arnold; Texas A\&M University, Dept. Horticultural Sciences, College Station, TX, 77443-2133

The purpose of this study is to determine the effects of a variety of commonly used soil surface covers on the establishment of Cercis canadensis L. var. texensis (Wats.) Rose. 'Alba'. Containerized 23.3- $\mathrm{L}$ trees were planted into $1.1 \times 1.5-\mathrm{m}$ plots separated by metal landscape edging in $20-\mathrm{cm}$-deep raised beds constructed of exterior treated landscape timbers. Eight soil surface treatments were imposed with five replicates each. Controls included bare soil with no cover. The remaining seven treatments consisted of $8-\mathrm{cm}$ depth of pine bark mulch, Trachelospermum asiaticum (Siebold \& Zucc.) Nakai on 30-cm centers mulched with $8 \mathrm{~cm}$ of pine bark, solid sodded Stenotaphrum secundatum (Walt.) Kuntze, 8 $\mathrm{cm}$ of decorative gravel, $3 \mathrm{~cm}$ of recycled paper mulch, brick pavers underline with $5 \mathrm{~cm}$ of coarse builders sand (brick-on-sand), and seasonal color mulched with $8 \mathrm{~cm}$ of pine bark. The color rotation for summer, fall / winter, and spring is Catharanthus roseus (L.) G. Don, Violax wittrockianaGams., and Petuniax hybrida Hort. Vilm.-Andr., respectively. Preliminary dataindicates that mulching with pine bark resulted in similar or slightly increased trunk diameter growth over that of bare soil. Brick-on-sand and the recycled paper mulch had smaller increases in trunk diameter than the other treatments. Mid-day leaf water potentials of most treatments were similar to bare soil, but the mid-day water potentials of trees mulched with recycled paper were among the most negative. All treatments except brick-on-sand trees recovered as well or better than trees in the bare soil by the next morning. Poor predawn water potential recovery of brick-on-sand trees may be due to the elevated temperatures observed in their root zone. Bare soil, recycled paper mulch, and the annual treatments had the most negative soil moisture tensions on average. The bare soil may be due to increased evaporative loose over mulched soils. The large biomass of vinca as the season progressed may account for the more negative readings in the annual seasonal color plots.

\section{8 \\ Drought Stress Affects Carbohydrate Partitioning in Three Species of Herbaceous Perennials}

Kelly J. Prevete ${ }^{* 1}$, R. Thomas Fernandez ${ }^{1}$, and William B. Miller ${ }^{2} ;{ }^{1}$ Department of

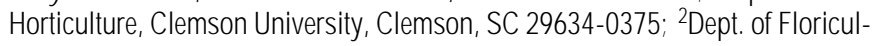
ture and Orn. Hort, Cornell University, Ithaca, NY 14853

Drought stress durations of 2, 4, and 6 days were imposed on Boltonia asteroides 'Snowbank', Eupatorium rugosum, and Rudbeckia trilobato determine the effects on carbohydrate partitioning in the plant. Drought stress was imposed on 19 Sept. 1997 on 1.9-L containerized plants. Plants were planted in the field the day following release from stress. Crown and leaf samples of the three species were collected 21, 23, 25 Sept. 1997 and 30 Jan. and 4 May 1998 and were analyzed for low molecular weight sugars and fructans. The species differed in the time it took for longer chain fructans to break down to shorter chain fructans and low molecular weight sugars (glucose, fructose). The drought tolerant Boltonia and Rudbeckiahad shifts from longer chain to shorter chain fructans by day 4 of stress. Boltoniahad a change in carbohydrate partitioning in the leaf tissue, while Rudbeckia had a change in crown tissue carbohydrate partitioning. Eupatorium did not have a shift in longer chain fructans to shorter chain fructans in crown tissue until day six of stress. The slower shift from longer chain fructans to shorter chain fructans by Eupatorium, compared to Boltonia and Rudbeckia, could explain the lack of drought tolerance of Eupatorium. The shift from high molecular weight sugars to low molecular weight sugars suggests that the higher molecular weight sugars broke down to lower molecular weight sugars in response to drought stress.

\section{9}

Flooding Effects on Stomatal Conductance and Leaf Color Vary among Genotypes of Red and Freeman Maples

James A. Zwack*1, William R. Graves ${ }^{1}$, and Alden M. Townsend ${ }^{2}$; 1 Department of Horticulture, lowa State University, Ames, IA 50011-1100; ${ }^{2}$ U.S. Department of Agriculture, Agricultural Research Service, U.S. National Arboretum, Floral and Nursery Plants Research Unit, 11601 Old Pond Drive, Glenn Dale, MD 20769

We compared two putative Freeman maples ['Jeffersred', (Autumn Blaze ${ }^{\circledR}$ ) and 'Indian Summer'] and five red maples ['Franksred' (Red Sunset ${ }^{\circledR}$ ), 'Autumn Flame', 'PNI 0268' (October Glory ${ }^{\circledR}$ ), 'Fairview Flame', and unnamed selection 59904] for effects of flooding on stomatal conductance. A method for quantifying changes in leaf color that occurred on flooded plants also was developed. Potted plants grown from rooted cuttings in a greenhouse were subjected to 75 days of root-zone inundation (flood treatment) or were irrigated frequently (control treatment). Across genotypes, stomatal conductance of flooded plants initially increased by about $20 \%$ and then fell to and was sustained below $50 \mathrm{mmol}^{-1} \cdot \mathrm{s}^{-2}$. Stomatal conductance of flooded plants of 'Indian Summer' decreased to $20 \mathrm{mmo} \cdot \mathrm{s}^{-1} \cdot \mathrm{m}^{-2}$ after 8 days of inundation, and two of three flooded 'Indian Summer' plants died during treatment. Other genotypes required at least twice this time to display a similar reduction in stomatal conductance, indicating 'Indian Summer' may be particularly flood sensitive. Intensities of red, green, and blue color at a consistent interveinal position were analyzed with Visilog software by using scanned leaf images of the youngest fully expanded leaf of each plant in both treatments. A genotype x irrigation interaction existed for the ratio of green to red intensity. This method provided numerical data that corresponded well to differences among genotypes we observed visually. For example, while flooding did not alter the color of 'Autumn Flame' leaves, the ratio of green to red was three times greater for controls of Autumn Blaze ${ }^{\circledR}$ than for the flooded plants of this cultivar.

\section{0 \\ The Effect of Weed Control Methods on Soil Physical Properties and Plant Growth}

Amy O'Leary ${ }^{\star}$, Paul Henry, and She-Kong Chong; Dept. Plant, Soil and General Agriculture, Southern Illinois University, Carbondale, IL 62901

There has been recent speculation in trade journals that landscape fabrics, while doing an excellent job of weed control, may have a detrimental effect on ornamental plant growth. A study is in progress to investigate the manner in which hardwood mulch and applied landscape fabric affect soil temperature, soil aeration, and water content over 18 months. Two experiments are in progress, one with compost incorporated at $50 \%$ soil volume, the other with no compost incorporation. The experimental design is a randomized complete block with four treatments (mulch, fabric, fabric plus mulch, and control) and four plants per plot. Each plot has been planted with herbaceous perennials so as to allow analysis of treatment effects on plant growth. Soil temperature within plots is monitored on a continual basis. Soil aeration is measured every two weeks using installed oxygen tubes. Water content is measured using time domain reflectometry 24 and $48 \mathrm{~h}$ after a significant rainfall event. Preliminary results suggest that hardwood mulch and landscape fabric are similar in their effect on soil water content 0 to $48 \mathrm{~h}$ after a significant rainfall event. However, after $48 \mathrm{~h}$, hardwood mulch increases soil water retention compared to landscape fabric.

\section{1}

\section{An Evaluation of Sulphosate and Four Glyphosate Formula- tions on Conifers}

Larry Kuhns* and Tracey Harpster; Department of Horticulture, The Pennsylvania State University, University Park, PA 16802

Though glyphosate is considered to be a nonselective herbicide, conifer growers have long known that under certain conditions, they could contact the lower branches of their trees with the herbicide Roundup without injuring them. Species, time of application, rate of application, surfactant, method of application, and pruning wounds are all factors affecting conifer tolerance to glyphosate. Because Roundup was widely used by conifer growers, they were very concerned when the formulation of Roundup was changed to contain a more active surfactant. The new product was marketed under the name Roundup Pro. This change increased its herbicidal activity and raised the possibility that it could damage trees if applied in the same way as Roundup. To determine the tolerance of conifers grown in the northeast to a variety of glyphosate formulations, and sulfosate, a set of studies was established. Roundup, Roundup Pro, Glyfos, Accord, and 
Sulfosate were all applied to field grown hemlock, white fir, Canaan fir, fraser fir, douglas fir, Colorado spruce, and eastern white pine. Rates of 1 to $3 \mathrm{lb}$ active ingredient/A were applied in the fall after new growth was hardened off. In general, it was found that the risk of injuring trees with Roundup Pro is greater than with the old formulation of Roundup. However, in all cases in which Roundup Pro caused more injury than Roundup, the Roundup Pro was applied at $3 \mathrm{lb}$ active ingredient/A. This rate is double the rate recommended for this use. In calibrated, directed spray applications at $1.5 \mathrm{lb}$ active ingredient/A or less, Roundup Pro should be safe for use around the species tested after their growth has fully hardened in the fall.

\section{ORAL SESSION 32 (Abstr. 602-607) Cross-commodity: Sustainable Agriculture}

602

\section{Influence of Tillage and N Source on Gas Exchange in Tomato}

Wayne F. Whitehead" and Bharat P. Singh; Agricultural Research Station, Fort Valley State University, Fort Valley, GA 31030-3298

The purpose of this study was to evaluate the tillage method effects of $\mathrm{N}$ sources on gas exchange (GE) at the flowering, fruiting, and pre-senescence in tomato. Measurements of transpiration $(\mathrm{E})$, stomatal conductance $\left(\mathrm{g}_{\mathrm{s}}\right)$, photosynthesis $\left(\mathrm{P}_{\mathrm{n}}\right)$, and internal leaf $\mathrm{CO}_{2}$ concentration $\left(\mathrm{C}_{\mathrm{i}}\right)$ were reported. The following fall/spring tillage and fertility treatments were applied: 1) fall-fallow/springmoldboard, 2) fall-fallow/spring-moldboard $+90 \mathrm{~kg}^{\circ} \mathrm{ha}^{-1} \mathrm{~N}$, 3) fall-moldboard + hairy vetch/spring-chisel, 4) fall-moldboard + hairy vetch/spring- chisel + 90 $\mathrm{kg} \cdot \mathrm{ha}^{-1} \mathrm{~N}, 5$ ) fall-minimum till +hairy vetch/spring-chisel, and 6) fall-minimum till + hairy vetch/spring-chisel $+90 \mathrm{~kg} \cdot \mathrm{ha}^{-1} \mathrm{~N}$. During the 2 nd week of Apr. 1995, 'Mountain Pride' tomato was transplanted in all plots. Maximum E $\left(11.9 \mathrm{mmol} \cdot \mathrm{m}^{-2} \cdot \mathrm{s}^{-1}\right), \mathrm{g}_{\mathrm{s}}\left(1465.1 \mathrm{mmo} \cdot \mathrm{m}^{-2} \cdot \mathrm{s}^{-1}\right)$, and $\mathrm{P}_{\mathrm{f}}\left(22.23 \mu \mathrm{molCO} / \mathrm{m}^{2}\right.$ per s) occurred at the fruiting and highest $C_{i}\left(301.2 \mu L^{-1}\right)$ at the flowering. Throughout the growing seaon, treatments 5 and 3 affected GE rates the most, while treatments 1 and 3 at flowering affected $C_{i}$ the most. Results indicate that fall moldboard or minimum-till + hairy vetch/spring chisel had greatest influence on GE of tomato.

\section{3}

\section{Cover Crop Mulches for Tomato Production in South Florida as an Alternative to Methyl Bromide}

Gladis M. Zinati ${ }^{* 1}$, Herbert H. Bryan', Waldemar Klassen', and Aref A. AbdulBaki2; 'University of Florida, IFAS, Tropical Research and Education Center, 18905 S.W. 280 St., Homestead, FL 33031; 2U.S. Department of Agriculture, Agricultural Research Service, Vegetable Laboratory, Beltsville, MD 20705-2350

In the quest to produce tomatoes without using methyl bromide, cover crops including sunnhemp, cowpea, hairy vetch, and sorghum sudan were planted on calcareous gravelly soils of southern Florida in Oct. 1998. These crops, singly or in mix, were grown on raised beds for 3 months before they were mowed down with no tillage. Sorghum sudan was plowed down and covered with plastic mulch, a conventional farming practice. In addition, uncropped plots fertilized with $6 \mathrm{~N}$ $2.6 \mathrm{P}-10 \mathrm{~K}$ at 0 or $1124 \mathrm{~kg} \cdot \mathrm{ha}^{-1}$ were either treated with or without methyl bromide chloropicrin and plowed down. 'Sanibel' tomatoes ( Lycopersicon esculentum Mill) were transplanted in two plant densities (one row vs. two rows on a bed) immediately after mowing. Tomatoes were fertigated with $112 \mathrm{~N}$ and $186 \mathrm{~K} \mathrm{~kg}^{\circ} \mathrm{ha}^{-1}$ during the growing season. Sunnhemp biomass alone or in mix with cowpea was higher than any other treatment. Biomass of sorghum sudan and hairy vetch were lowest. Canopy coverage, nutrient content of cover crops, and their effects on tomato growth, nutrient content, and yield will be discussed.

\section{4}

\section{Yield Response of Microirrigated Herbs to Compost Amend-} ment and $\mathbf{N}$ and $K$ Fertilizers on Sand

A. A. Csizinszky", University of Florida, IFAS, Gulf Coast Research and Education Center, Bradenton, FL 34203

Italian parsley (parsley) Petroselinum crispum, summer savory (savory) Satureja hortensis, sweet marjoram (marjoram) Origanum majoranna, and thyme Thymus vulgaris, were evaluated for their yield potential in multiple harvest during the fall-winter-spring (Dec.-May 1997-98). The herbs were grown with the full-bed polyethylene mulch-micro (trickle) irrigation system. Experimental design was a split-plot arranged in three randomized complete blocks. Main plots were two N$\mathrm{P}-\mathrm{K}$ treatments: $\mathrm{ON}-\mathrm{P}-\mathrm{K}$ or $\mathrm{N}$ and $\mathrm{K}$ from a liquid $4 \mathrm{~N}-\mathrm{OP}-3.32 \mathrm{~K}$ fertilizer injected at $0.77 \mathrm{~N}$ and $0.64 \mathrm{~K} \mathrm{~kg} / \mathrm{ha}$ per day. In the subplots, compost was applied in 4 to 8 inches wide band on the pre-bed at $0 x, 1 x, 2 x$, and $4 x$ rates $(1 x=4.5$ t ha $^{-1}$ ). Parsley and marjoram yields in the first three harvests and thyme yields in the first two harvests were similar with $0 x$ compost and $\mathrm{N}+$ Kinjected fertilizers to yields with $3 x$ and $4 x$ compost rates with no injected $N+K$ fertilizers. For the season, yields were higher with injected $\mathrm{N}+\mathrm{K}$ fertilizers with or without compost, than in the compost treated plots with no $\mathrm{N}+\mathrm{K}$ fertilizers.

\section{5}

\section{Evaluation of How Cover Crop, Tillage, and N Fertilization} Affect Nitrogen Sufficiency in Watermelons

Anthony F. Silvernail* and Gary R. Cline; Atwood Research Facility, Kentucky State University, Frankfort, KY 40601

The effects of cover crop, tillage, and $\mathrm{N}$ fertilization on yields of 'Paladin' watermelon (Citrullus lanatus) were analyzed by determining available soil N levels, foliar N content, and relative greenness with a SPAD-502 chlorophyll meter. Analyses from all three analytical procedures identified $\mathrm{N}$ deficiencies in watermelon with their respected measurements. Available soil $\mathrm{N}$ analyses indicated that soil N levels below $40 \mathrm{mg}^{\circ} \mathrm{kg}^{-1}$ at vining caused dramatic decreases in yields, while the level needed to ensure maximal yields during the same period was 100 $\mathrm{mg} \cdot \mathrm{kg}^{-1}$. Results from foliar and SPAD tests indicated that plants with foliar $\mathrm{N}$ levels below $42 \mathrm{~g}^{\circ} \mathrm{kg}^{-1}$ and SPAD readings below 40 SPAD units at anthesis will have suppressed yields. Optimal foliar N levels and SPAD readings required for maximum yields were $50 \mathrm{~g} \cdot \mathrm{kg}^{-1}$ and $48 \mathrm{SPAD}$ units, respectively. The main difference among all three $\mathrm{N}$ testing procedures was that available soil $\mathrm{N}$ analysis was able to detect possible deficiencies two to three weeks before either the foliar or SPAD analysis. Differences in yield between plants from conventionally tilled plots and no-till plots were not significant. However, inorganic $\mathrm{N}$ fertilization significantly increased yields in watermelon following both rye (Secale cereale) and mix cover crop treatments. Watermelon yields of plants following the hairy vetch (Vicia villosa) cover crop treatment showed no response to inorganic $\mathrm{N}$ fertilization. Of the three cover crop treatments, the addition of $\mathrm{N}$ fertilizer had the most effect in the rye treatment.

\section{6}

Effects of Compost and Chicken Manure Soil Amendments on Basil Yield

T.J. Radovich ${ }^{* 1}$, H.R. Valenzuela', B. Kratky ${ }^{1}$, and N.V. Hue ${ }^{2}$; Departments of ${ }^{1}$ Horticulture and ${ }^{2}$ Agronomy, University of Hawaii, Honolulu, HI 96822

To help develop fertilizer recommendations for organic vegetable production in Hawaii, the effects of organic amendments on basil yield were studied in two experiments. The treatments were synthetic nitrogen applied at $100 \mathrm{~kg}^{\bullet} \mathrm{ha}^{-1}$ per crop, organic amendments applied at arate of 8-160 MT• ha ${ }^{-1}$, and an unammended control. Each treatment was replicated four times in a RCB design. In the first experiment, chicken manure was the organic amendment at $8 \mathrm{MT} \cdot$ ha $^{-1}$ with a single basil variety grown. In the second experiment, conducted at the same location immediately following the first experiment, the organic amendment was locally produced compost $(0.3 \% \mathrm{~N})$ applied at 40 and $160 \mathrm{MT} \cdot \mathrm{ha}^{-1}$ with three basil varieties grown. Data taken included soil fertility levels before and after experimental completion, marketable yields recorded weekly over 5-10 weeks, and tissue $\mathrm{N}$ and nitrate sap analysis measured at two to three different plant growth stages. In the first experiment, treatments receiving chicken manure or synthetic N showed similar yields (256-289 g/plant), which were significantly greater than the control (197 g/plant). Tissue N levels were greatest in the synthetic fertilizer treatment $(4.9 \%)$ and lowest in the control $(4.5 \%)$. In the second experiment, there was a differential response by varieties to treatments with respect to yields. Yields from the compost treatments (292-700 g/plant) were equal to or greater than those receiving synthetic fertilizer (320-651 $\mathrm{g} / \mathrm{plant}$ ) and were generally greater than the control (324-532 $\mathrm{g} / \mathrm{plant}$ ). Tissue N levels were greatest in plants receiving synthetic fertilizer $(4.6 \%$ to $4.7 \%)$ and lowest in the control $(4.3 \%$ to $4.4 \%$ ). A positive correlation was found between lab tissue $\mathrm{N}$ levels and nitrate sap analysis determination. 


\section{7}

\section{Estimation of $\mathbf{N}$ Mineralization Rate of Composts and} Manures

T.K. Hartż and J.P. Mitchell; Department of Vegetable Crops, University of California, Davis, CA 95616

The rate of $\mathrm{N}$ mineralization from 35 samples of manure or compost was estimated by both aerobic laboratory incubation and lath house pot studies at Davis, Calif., in 1996-97. Each manure and compost sample was mixed at $2 \%$ by dry weight with a 1 loam soil : 1 coarse sand blend. The amended soil blends were moisture equilibrated under $0.025-\mathrm{MPa}$ pressure then incubated aerobically at constant moisture at $25^{\circ} \mathrm{C}$ for 3 (1996) or 6 months (1997); subsamples were collected monthly (1996) or bimonthly (1997) for mineral N determination. Four-liter pots were also filled with the amended soil blends and seeded with fescue (Festuca arundinacea). The pots were watered but not fertilized for 16 (1996) or 18 (1997) weeks in a lath house at ambient summer conditions. N mineralization from the pot study was calculated from total fescue biomass $\mathrm{N}$ plus mineral $\mathrm{N}$ from pot leachate, minus those quantities in pots of the unamended soil blend. $\mathrm{N}$ mineralization rate estimates from the two techniques were highly correlated $\left(r^{2}\right.$ $=0.79$ ). Green waste composts typically mineralized $<5 \%$ of total $\mathrm{N}$, manure composts $5 \%$ to $10 \%$, and manures (poultry, dairy, and feedlot) $7 \%$ to $20 \%$. After 4 months of incubation, $\mathrm{N}$ mineralization rate (expressed as percent of total $\mathrm{N}$ per month) from the composts and manures was similar to that of the unamended soil blend.

\section{ORAL SESSION 33 (Abstr. 608-613) Woody Ornamentals/Landscape/Turf: Crop Production}

\section{8}

\section{Germination and Early Seedling Growth of Alnus maritima from Its Three Disjunct Populations}

James A. Schrader* and William R. Graves; Interdepartmental Plant Physiology Program, Department of Horticulture, lowa State University, Ames, IA 50011

Genotypic variation and horticultural potential of Alnus maritima [Marsh.] Nutt. (seaside alder), a large shrub or small tree found naturally in only three small, disjunct populations, have not been studied. We examined effects of population of origin and environment on seed germination and the growth and morphology of seedlings. Our first germination experiment showed that 6 weeks of cold stratification applied to half-siblings from Oklahoma optimized germination at $73.2 \%$. When this treatment was applied to multiple half-sib seed sources from all populations in a second experiment, seeds from Oklahoma had a higher germination percentage (55\%) than seeds from both Georgia (31.4\%) and the Delmarva Peninsula (14.7\%). A third experiment showed that growth of seedlings increased with increasing irradiance intensity up to $258 \mu \mathrm{mol} \cdot \mathrm{m}^{-2} \cdot \mathrm{s}^{-1}$, and survival and growth of seedlings from Oklahoma varied with root media. In a fourth experiment, multiple groups of half-siblings from all three populations were grown in one environment to compare variation in growth and morphology within and among populations. Leaves of Oklahoma seedlings were longer (12.8 $\mathrm{cm}$ ) and more narrow (2.15 length : width ratio) than leaves of seedlings from Georgia $(12.0 \mathrm{~cm}$ long, ratio $=1.76$ ) and the Delmarva Peninsula $(11.6 \mathrm{~cm}$ long, ratio $=1.86)$. Seedlings from Oklahoma and Georgia had a higher growth rate (180.7 and $160.0 \mathrm{mg} /$ day, respectively) than did seedlings from Delmarva (130.1 $\mathrm{mg} /$ day), while Oklahoma and Delmarva seedlings were more densely foliated ( 0.72 and 0.64 leaves and lateral shoots per $\mathrm{cm}$ of primary stem, respectively) than those from Georgia $(0.46$ per $\mathrm{cm})$. These differences indicate both divergence among the three disjunct populations and potential to exploit genetic variation to select horticulturally superior A. maritimafor use in managed landscapes.

\section{9}

\section{Micronutrient Fertilization of Container-grown Woody}

Seedlings Essential Regardless of Pine Bark pH

Amy N. Wright", Alex X. Niemiera, J. Roger Harris, and Robert D. Wright, Department of Horticulture, Virginia Polytechnic Institute and State University, Blacksburg, VA 24061-0327

The objective of this study was to determine the effect of micronutrient fertili- zation on seedling growth in pine bark with $\mathrm{pH}$ ranging from 4.0 to 5.5. Koelreuteria paniculata (Laxm.) was container-grown from seed in pine bark amended (preplant) with $0,1.2,2.4$, or $3.6 \mathrm{~kg} / \mathrm{m}^{3}$ dolomitic limestone and 0 or $0.9 \mathrm{~kg} / \mathrm{m}^{3}$ sulfate-based micronutrient fertilizer (Micromax ${ }^{\circledR}$ ). Initial pine bark pH for each lime rate was $4.0,4.5,5.0$, and 5.5 , respectively. Final $\mathrm{pH}$ (week 10 ) ranged from 4.7 to 6.4. Ca and $\mathrm{Mg}$ supply in irrigation water was 10.2 and $4.2 \mathrm{mg}^{\circ} \mathrm{L}^{-1}$. Seedlings were harvested 10 weeks after planting, and shoot dry weight and height were determined. Pine bark solution was extracted using the pour-through method at 3,7 , and 10 weeks after planting. Solution $\mathrm{pH}$ was measured, and solutions were analyzed for $\mathrm{Ca}, \mathrm{Mg}, \mathrm{Fe}, \mathrm{Mn}, \mathrm{Cu}$, and $\mathrm{Zn}$. Shoot dry weight and height were higher in micronutrient-amended bark than in bark without added micronutrients. Lime $\left(1.2 \mathrm{~kg} \cdot \mathrm{m}^{-}{ }^{3}\right)$ increased growth only in the absence of micronutrient additions. In general, adding micronutrients increased pine bark solution $\mathrm{Ca}$, $\mathrm{Mg}$, and micronutrient concentrations. Adding lime increased pine bark solution $\mathrm{pH}$ and $\mathrm{Mg}$ concentration and either had no effect on or decreased solution $\mathrm{Ca}$ and micronutrient concentrations. Regardless of pine bark $\mathrm{pH}$, micronutrient additions resulted in improved growth and adding lime was not necessary.

\section{0}

\section{Evaluation of Sawmill Residue as a Component of Nursery Potting Mix}

Wayne J. McLaurin*, Department of Horticulture, University of Georgia, Athens, GA 30602

The standard mix used by most nurseries consist of a 9 pine bark : 1 sand. With the ever-increasing cost of bark, nurseries are looking for an alternative. Sawmill residue may hold potential utility as part of a potting mix. Although sawmill residue is highly variable, it can serve as soil bulk as well as an organic medium. The purpose of this study was to determine if old sawmill residue not treated by pathogen-free requirement procedures could be used "as is" as part of a nursery soil mix. For this study, a sample, a typical conglomerate of undetermined wood chips, bark, and soil particles, was obtained from an "old pile" (just how old is not known) of sawmill residue. To determine how this sample would function in a nursery bark/sand mix, tests were run on its physical properties of pore space and water-holding capacity. The sawmill residue had the following characteristics: a mean $44.2 \%$ porosity capacity, $23.4 \%$ air space, and $20.8 \%$ water holding capacity. A standard fertilizer and lime amendment package was added to the sawmill residue in the same rates as a regular nursery mix. The sawmill residue and the standard nursery mix were then blended according to the treatment percentages. The treatments were sawmill residue/standard nursery mix 0/100, 10/90, 30/70,60/40, and 100/0. The Ilex crenata 'Compacta' liners were planted into standard 1-gallon nursery pots filling to just below the rim. The pots were randomly placed on a well-drained rock surface in full sun. No additional fertilizer was used and watering was done as needed. Plants were grown for 1 year. Visual assessments were made throughout the growing period and at harvest. There was no visible difference in any of the treatments as far as overall growth was discerned. The plants were of uniform height and width showing consistent, even growth and good leaf color. Root system growth and development were evaluated visually and over all treatments were uniformly good. No root problems were noted. There was not any plant loss in any treatment over the entire study. Each plant was cut at the soil line and dried for 24 hours at $1150^{\circ} \mathrm{C}$. Dry weights were taken after the plant material had cooled for 4 hours. Results were based on four plants per treatment times four replications for a total of 16 plants per treatment. There was not any measurable growth difference in dry weight among treatments $1,2,3$, and 4 [sawmill residue/standard nursery mix $0 / 100$ (41.03 g dry weight), 10/90 (39.83 g dry weight), 30/70 (38.98 g dry weight), 60/ 40 (37.42 g dry weight)]. However, treatment 5 [100/0 (31.03 g dry weight)] was significantly lower when compared to the remaining four treatments. The lower dry weight may be attributed to the $100 \%$ sawmill residue being too heavy and not well-drained enough. However, the roots did not show any damage from being too wet. Further work is being done with the sawmill residue.

\section{1}

From Weed to Wonder: Taming Bitterweed for the Landscape

Michael A. Arnold ; Texas A\&M University, Department of Horticultural Sciences, College Station, TX 77843-2133

Pilot trials were conducted to explore the potential for use of Helenium amarum (Raf.) $H$. Rock as a bedding plant in Texas. Bitterweed is an annual wildflower native to the eastern U.S. It occurs on disturbed waste sites, along railroad tracks, 
roadsides, and in heavily grazed pastures. Bitterweed varies in form from a 15$\mathrm{cm}$-tall spreading mound to an upright oval crown $60 \mathrm{~cm}$ tall. Early growth is in a rosette form. Later foliage is bright green, highly dissected, and attractive. Profusely borne yellow single daisy-like flowers occur from spring to frost, peaking in late summer and fall. The species can survive intense drought and heat. Production responses were tested in 0.06-, 0.13-, 0.16-, and 0.51-L containers in the greenhouse during Summer 1998; then seedlings were transplanted to landscape beds and monitored through fall 1998. Other seedlings from 0.13-L containers were planted to the landscape to determine spacing requirements. Plants were al so grown in an outdoor nursery in larger 2.3- $\mathrm{L}$ containers to test responses to pine bark- and peat-based media. Seedlings from 0.16 - and $0.51-\mathrm{L}$ containers were more effective throughout the growing season in the landscape than seedlings from 0.06 - and $0.13-\mathrm{L}$ containers. Seedlings grown in $2.3-\mathrm{L}$ containers in a 4 pine bark : 1 sand media were larger, flowered more rapidly, and reach a marketable size in a shorter time than seedlings grown in a peatmoss-based media.

\section{2}

\section{Consumers Knowledge, Practices, and Environmental Attitudes on Lawn Care}

Mary Hockenberry Meyer* and Perrin Carpenter, Univ. of Minnesota, St Paul, MN55108

Homeowner surveys conducted in Edina, Minn., showed varying levels of horticultural knowledge on lawn care. A majority of consumers, $75 \%$, knew the value of lawn clippings was equivalent to one fertilization treatment, but $72 \%$ did not know the amount of fertilizer needed for a medium maintenance lawn. A total of $77 \%$ indicated spring as the single best time to control broadleaf weeds, and $39 \%$ thought spring was the best time to fertilize, whereas $48 \%$ indicating fall as the best time to fertilize. Current practices included the following: leaving clippings on the lawn, $75 \%$; bagged and removed clippings, $16 \% ; 83 \%$ apply fertilize in the spring; $67 \%$ fertilize in the fall; $61 \%$ apply herbicides; $74 \%$ mow weekly; $51 \%$ mow at $2-3 "$, but $27 \%$ mow at $1-2 "$. Environmental attitudes were rated on a scale of 1 to 4 , with 1 being strongly agree and 4 being strongly disagree. Consumers strongly agreed that pesticide (1.5) and fertilizer (1.7) applications should be posted in public areas. The statement "A well kept lawn increases property values" also found strong agreement, (1.6). Consumers disagreed that pesticides are not harmful to the environment (3.3) and public health (3.3); while fertilizers were only slightly less harmful to the environment (3.0) and public health (2.9). A $10 \%$ weed population was acceptable (2.2) but $25 \%$ was not (3.3). Areas for consumer education exist in the time and amount of fertilizer, timing of weed control, and mowing height. Because of negative attitudes toward pesticides and fertilizers, recommendations for medium to low input grasses should be well received.

\section{3}

\section{The Methodological Study of Under-soil Heating System} (USHS) for Warm-season Grass

Takashi Miwa* ${ }^{* 1}$, Hisakazu Kihara ${ }^{2}$, and Hideaki Tonogi2; ${ }^{1}$ Research \& Development Institute, Takenaka Corporation, 1-5-1 Ohtsuka, Inzai-shi,Chiba-ken 2701395, Japan; Turf Research \& Technology Support, Turf Business Division, Nichino Ryokka Co., Ltd., Japan

Recently, full-green turf on sports fields in the winter is highly desirable. The negative factor for warm-season grass pitch is its winter dormancy. Winter overseeding (WOS) is one successful method to make turf seem green. However, maintenance cost for WOS turf is relatively expensive and brings some difficulties. Undersoil heating (USH) has been used for cool-season grass pitch or warmseason grass pitch to make turf green in winter. Our objectives were 1) to confirm USH effectiveness for warm-season grass, 2) to make the specified system itself, and 3) to estimate the approximate heat demand. The results indicate that USH can make warm-season grass green and maintain much higher turf quality even in severe winter conditions. Weed invasion, pests, and diseases levels are quite low during the test period. The characteristics needed to create the system include heating pipe spacing and depth, initial media temperature, and required soil temperature. In addition, USH needs a plastic cover for insulation that is light and that air and water can penetrate. Compared with WOS, USH can reduce maintenance fees and procedures, such as preparation for WOS in a fall and transition into spring. Thus, UHS can prolong total playing period. Moreover, it is easy to maintain the higher turf quality and lower maintenance cost than WOS. In the future, we should concentrate on creating more concrete maintenance program for this method.
160 ORAL SESSION 34 (Abstr. 614-619) Fruit/Nuts: Crop Production \& Physiology

\section{4}

Nitrogen Uptake Efficiency of Apple Rootstocks and Scions

Paula B. Aguirre*, Teryl R. Roper, and Armand R. Krueger, Dept. of Horticulture University of Wisconsin-Madison, Madison WI 53706

The uptake efficiency of apple scions and rootstocks has not been studied in the field. Using ${ }^{15} \mathrm{~N}$ (ammonium nitrate, 1 atom $\%{ }^{15} \mathrm{~N}$ ) we compared nitrogen uptake efficiency of 12 rootstocks grafted to one scion (Gala) and of 20 scions on the same clonal rootstock (M.9 EMLA) in orchards located in northeastern Wisconsin. Trees were treated in either Fall or Spring 1998 with $40 \mathrm{~g}$ actual $\mathrm{N}$ per tree applied as a liquid to the soil. $\mathrm{N}$ uptake was assessed by measuring ${ }^{15} \mathrm{~N}$ in leaf and wood tissue taken monthly from June to Oct. 1998. Tissues were oven-dried and analized using a ratio mass spectrometer. Treatment differences were greater among scions with the same rootstocks than among rootstocks with the same scion. Total $\mathrm{N}$ and ${ }^{15} \mathrm{~N}$ content differences were found between roostocks and these values were inversely related to tree size.

\section{5}

\section{Growth Performance of Transplanted Young Apple Trees in Relation to Reserve Nitrogen and Carbohydrates}

Lailiang Cheng* and Leslie H. Fuchigami; Dept. of Horticulture, ALS 4017, Oregon State University, Corvallis, OR 97331

Reserve $\mathrm{N}$ and carbohydrate levels of bench-grafted Fuji/M26 plants were altered by fertigation with seven $\mathrm{N}$ concentrations from 30 June to 1 Sept. in combination with or without $3 \%$ foliar urea application in mid-October. The plants were harvested after natural leaf fall and stored at $2{ }^{\circ} \mathrm{C}$. One set of plants were destructively sampled in January for reserve $\mathrm{N}$ and carbohydrates analysis, and the remaining plants were transplanted into a $\mathrm{N}$-free medium in the spring and supplied with or without $5 \mathrm{mM}{ }^{15} \mathrm{~N}$-ammonium nitrate in a Hoagland solution for 60 days after budbreak. Plants fertigated with higher $\mathrm{N}$ concentrations had higher reserve $\mathrm{N}$ content and lower carbohydrate concentrations. Foliar urea application increased whole plant $\mathrm{N}$ content and decreased reserve carbohydrate concentration at each given $\mathrm{N}$ concentration used in fertigation. Regardless of $\mathrm{N}$ supply in the spring, total new shoot and leaf growth of plants fertigated with $\mathrm{N}$ was closely related to the amount of reserve $\mathrm{N}$ but not reserve carbohydrates. Plants treated with foliar urea had more new shoot and leaf growth than the fertigated controls. By pooling all the data concerning reserve $\mathrm{N}$ used for growth regardless of the spring $\mathrm{N}$ supply, a linear relationship was found between the amount of reserve $\mathrm{N}$ used for new shoot and leaf growth and the total amount of $\mathrm{N}$. We conclude that the growth of apple nursery plants in the spring is mainly determined by reserve $\mathrm{N}$, not reserve carbohydrates. The amount of reserve $\mathrm{N}$ used for new shoot and leaf growth in the spring is dependent on the total amount of reserve and is not affected by the current $\mathrm{N}$ supply.

\section{6}

Rootstock, Strain, Ground, and Fertigated Nitrogen Effects on Tree Growth and Development, Nutrition, and Fruit Quality of 'Fuji' Apple

Esmaeil Fallahi* and Ik-Jo Chun; University of Idaho, Parma Research and Extension Center, 29603U of I Lane, Parma, Idaho 83660

Effects of rootstock and ground and fertigated applied nitrogen on productivity and fruit quality of 'Fuji' apple was studied. In the fertigation portion of this project, treatments were as follows: 1) $22.4 \mathrm{~kg} \mathrm{~N} / \mathrm{ha}$ per year, 2) $89.7 \mathrm{~kg} \mathrm{~N} / \mathrm{haper}$ year, 3) $89.7 \mathrm{~kg} \mathrm{~N} /$ ha per year plus $78.5 \mathrm{~kg} \mathrm{~K} / \mathrm{ha}$ per year; 4) $156.9 \mathrm{~kg} \mathrm{~N} / \mathrm{ha}$ per year; 5) $156.9 \mathrm{~kg} \mathrm{~N} / \mathrm{ha}$ per year plus $78.5 \mathrm{~kg} \mathrm{~K} / \mathrm{ha}$ per year. Fruit had optimum quality when leaf $\mathrm{N}$ concentrations were approximately between $1.9 \%$ to $2.15 \%$ dwt during light-cropping years and approximately between $2.12 \%$ to $2.40 \%$ during heavy-cropping years. Cross-sectional areas of 'Nagafu- 6 Fuji' trees were slightly smaller than those in 'BC-2 Fuji' trees. Preliminary data al so showed that mineral concentrations of leaves from various strains of 'Fuji' do not significantly vary. In 1998, trees from $22.4 \mathrm{~kg} \mathrm{~N} /$ ha zone had lower leaf $\mathrm{N}$, resulting in lower 
leaf area and lower photosynthesis but better fruit color than those with higher $\mathrm{N}$ applications. In 1998, trees on Ottawa-3 had higher yield than those on B.9, M.26, and M.7. Trees on B9 had lower leaf $\mathrm{N}$ and smaller fruit than those on other rootstocks. Fruit on M.7 rootstock were larger, but had the worst color among all rootstocks. Fruit on M.9 had better color than those other rootstocks. Trees with 2.43-m in-row spacing had significantly higher photosynthesis than those of $1.22-\mathrm{m}$ spacing.

\section{7}

Effects of Nitrogen, Potassium, and Irrigation on Postharvest Pitting of White Grapefruit

Huating Dou*1, Ashok Alva², Peter Petracek', Mohamed Ismail', and David Calvert?; ${ }^{1}$ Florida Department of Citrus, ${ }^{2}$ University of Florida, CREC, 700 Experiment Station Road, Lake Alfred, FL 33850; ${ }^{3}$ University of Florida, IRREC, 2199 S. Rock Road, Fort Pierce, FL 34945

Effects of $\mathrm{N}, \mathrm{K}$, and water relation on the incidence and severity of postharvest pitting in white grapefruit were evaluated in two field experiments. In the first experiment, a factorial combination of $3 \mathrm{~N}\left(56,168\right.$, and $\left.336 \mathrm{~kg}^{\bullet} \mathrm{ha}^{-1}\right)$ and $3 \mathrm{~K}$ $\left(52,156\right.$, and $\left.312 \mathrm{~kg} \mathrm{ha}^{-1}\right)$ rates were used with three broadcast applications per year. In the second experiment, there were two irrigation regimes (at $30 \%$ and $60 \%$ depletion of available soil moisture, ASM, content) with three subtreatments of variable $\mathrm{N}$ and $\mathrm{K}$ rates $\left(\mathrm{Kg} \cdot \mathrm{ha}^{-1}\right)$ at $56: 52 ; 112: 104$, and $336: 312 \mathrm{~kg} \cdot \mathrm{ha}^{-}$ 1 . The fruit were harvested three times each season, waxed with shellac wax, and stored at $70^{\circ} \mathrm{F}$ for evaluation of pitting. The pitting incidence was lower at the optimal $\mathrm{N}$ and $\mathrm{K}$ rates than that at the low or high rates. The irrigation at $30 \%$ ASM significantly reduced pitting incidence. The higher incidence of pitting was found in an area in the grove with higher water table. This study suggested that effects of water may play an important role on peel physiology and pitting.

\section{8}

\section{Tree Form and Tree Density Affect Peach Tree Cropping and} Profitability

Richard P. Marini*; Dept. of Horticulture, Virginia Polytechnic Institute \& State Univ., Blacksburg, VA 24061-0327

'Norman' peach trees were trained to the central-leader or open-vase form and were planted at high (740 trees/ha) or low (370 trees/ha) density. A third density treatment was a high/low density, where alternate trees in high-density plots were removed after 6 years to produce alow-density treatment. Annual yield per hectare was $\approx 15 \%$ to $40 \%$ greater for high-density treatments than for lowdensity treatments, but tree form had little influence on yield. Fruit size tended to be greater for low-density than for high-density treatments, but cumulative marketable yield was greatest for high-density and lowest for high/low density treatments. After 9 years, cumulative crop value was higher for open-vase than central-leader treatments $(P=0.12)$, but tree density had less of an effect on crop value $(P=0.21)$. Cumulative costs were highest for high-density treatments, but were not influenced by tree form. Income minus costs was nearly $\$ 4500 /$ ha higher for open-vase than for central-leader trees and net present value was more than $\$ 2000 /$ ha higher for high-density than low-density trees $(P=0.20)$. Open-vase trees were more profitable than central leader trees and should be planted at densities of about 700 trees/ha in the mid-Atlantic region.

\section{9}

\section{Temporal and Spatial Weed Control Effects on Tart Cherry} Orchards

Yahya K. Al-Hinai* and Teryl R. Roper; Dept. of Horticulture, University of Wisconsin-Madison, Madison, WI 53706

This experiment was conducted to determine temporal and spatial weed management characteristics for tart cherry orchards. Annual ryegrass and lambsquarter were planted in tree rows of a 14-year-old tart cherry orchard. Vegetation was controlled with nonresidual herbicides (Gramoxone + B-1956) either all season, May, June, July, August, before harvest, after harvest, or not controlled. Shoot growth measurements showed significantly more growth by trees without weed competition during the entire season, May, June, and before harvest compared to the weedy control and postharvest, July, or August treatments. Weedy early season plots reduced the shoot growth by half. All season, before harvest, May, and June weedfree plots showed higher amounts of leaf $\mathrm{N}$ compared with weedy controls or lateseason treatments. Early season weed control is more important than late season. Vegetation-free areas of $0,2,3$, and $4 \mathrm{~m}^{2}$ were maintained during 1998 by postemergence herbicides. Tissueanalysis showed higher $\mathrm{N}$ concentration in leaves with vegetation controlled to $2 \mathrm{~m}^{2}$ or more compared to the weedy control. The critical vegetation free area for young cherry trees is between 0 and $2 \mathrm{~m}^{2}$.

\section{POSTER SESSION (Abstr. 620-624) Collegiate Branch Poster Competition}

620

\section{Testing Neem Leaf Extract to Control Contamination in Guava Tissue Culture}

J.L. Robbins ${ }^{\star}$, X.Y. Li, and A.K. Yadav, Agricultural Research Station, Fort Valley State University, Fort Valley, GA 31030-4313

Shoot tip explants from field-grown guava ( Psidium guajava L.) trees, which frequently show a high rate of contamination, were cultured on the MS medium with neem leaf ( Azadirechta indicaL.) extract in $\mathrm{H}_{2} \mathrm{O}$. Ten grams of neem powder prepared from crushed dried leaves was made to $200 \mathrm{~mL}$ aqueous solution and was left on a laboratory bench for $24 \mathrm{~h}$. The amber-color neem extract was filtered to separate and discard solid. The liquid was refrigerated until needed. To 950 $\mathrm{mL}$ basic medium in deionized $\mathrm{H}_{2} \mathrm{O}$ containing $25 \mathrm{~mL}$ macronutrients, $5 \mathrm{~mL}$ micronutrients, $5 \mathrm{~mL}$ vitamins, $5 \mathrm{~mL}$ EDTA $+\mathrm{Fe}, 2 \mathrm{~mL}$ BA, $30 \mathrm{~g}$ sucrose, and $7 \mathrm{~g}$ agar, $50 \mathrm{~mL}$ neem extract was added either before or after autoclaving. No neem extract was added to the control. Medium was adjusted to $5.7 \mathrm{pH}$. Unused medium was refrigerated. Shoot tips from actively growing young twigs of fieldgrown L-49 guava trees that showed variable contamination in previous studies were harvested during midmorning hours. Samples were washed in running water and disinfected with 15\% Clorox solution with few drops of Tween-20 for 15 min. There were 20 explants in each treatment. Explants were subcultured a week later. None of the four test studies showed contamination-free cultures from field trees. There was no consistency due to autoclaving neem extract. The neem leaf extract did not show complete elimination of contamination, although it delayed it for few days. It was concluded that neem extract was not effective at concentrations used in getting rid of contamination. Therefore, further investigate effect of neem for this purpose higher concentrations need to be examined.

\section{1}

\section{Effects of Shading Levels on Seasonal Leaf Color in Fire Power Nandina}

Leiah M. Butler" ${ }^{* 1}$, William F. Hayslett', and Robert Harrison'; ' 1 Dept. of Agricultural Sci., ${ }^{2}$ Coop. Agr. Re. Program, Tennessee State Univ., 3500 John A. Merritt Blvd., Nashville, TN 37209

A 24-month experiment was conducted to study the effects of shading levels on the foliage color changes in Fire Power Nandinas. This popular ornamental shrub is the dwarf form of the Heavenly Bamboo, Nandina domestica. It originated in New Zealand, and has vivid green leaf color in the spring and summer months that changes to a fluorescent red as winter approaches. In this experiment light was limited by covering the plots with black woven shadecloth of $43 \%$ and $78 \%$ shade, while allowing the control plots to receive full sunlight. Fifteen shrubs from each plot were randomly selected and 10 leaves per plant in each treatment were taken at 28-day intervals. The leaf color was recorded using a camera attached to a microscope. The results from this study indicate that changes in leaf color may be affected by the change of the seasons. The level of light/ shade that the plants receive may also affect leaf color. The control group turned a bright fluorescent red, the $43 \%$ shade turned a deep red, and the $78 \%$ shade remained a deep green with few leaves turning red. Based on the different hues observed, this research indicates that limiting light has a direct effect on leaf color in this species. The correlation between the amount of sunlight received and the season of the year are the two factors that determine the degree of color change in this ornamental shrub.

622

Toxicity of Indian Mustard (Brassica juncea) and Allyl Isothio-cyanate to Masked Chaffer Beetle Larvae (Cyclocephala sp.)

Ryan R.P. Noble,* C.S. Charron, and C.E. Sams; Department of Plant and Soil Sciences, The University of Tennessee, Knoxville, TN 37901

The development of alternative methods for control of soilborne pathogens is 
imperative since the U.S. Clean Air Act bans the use of methyl bromide after 2005. One possibility is to exploit the pesticidal properties of compounds released by macerated Brassicatissues. In this study, masked chaffer beetle larvae were placed in sealed $473-\mathrm{mL}$ jars with $335 \mathrm{~g}$ of soil amended with $1 \%, 2 \%, 4 \%$, or $8 \%\left(\mathrm{~g}^{\bullet} \mathrm{g}^{-1}\right)$ Brassica tissue. The most prevalent volatile toxic compound of Brassicajuncea (PI 458934) is allyl isothiocyanate (AITC). AlTC production was measured in the jars at $0.25,4,8,24$, and $48 \mathrm{~h}$ using a solid-phase microextraction device (SPME) and gas chromatography. After 7 days, larvae mortality was determined. Control treatments included untreated soil, soil amended with $8 \%$ tomato plant tissue, soil amended with pure AITC, and untreated soil with an atmosphere of $\approx 20 \% \mathrm{O}_{2}$ and $0 \% \mathrm{CO}_{2}$ changing over $48 \mathrm{~h}$ to $2 \% \mathrm{O}_{2}$ and $20 \% \mathrm{CO}_{2}$. AlTC levels were positively correlated to larvae mortality. The estimated lethal concentration for $50 \%$ kill $\left(\mathrm{LC}_{50}\right)$ was $3.6 \mu \mathrm{g} \mathrm{AITC/L}$ soil atmosphere. AITC levels may be influenced by Brassicamass added, soil bulk density, and environmental factors including temperature and moisture. $B$. juncea has a high tissue AITC concentration. However, the mass of Brassicatissue required for insecticidal application against Cyclocephalasp. is also high, between $4 \%$ and $8 \%$ of soil mass. Development and selection of Brassica species that produce higher concentrations of isothiocyanate would increase the effectiveness of Brassicabiofumigation as an alternative to methyl bromide for controlling soilborne insects.

\section{3}

\section{Does the Aquadome Ameliorate Diural Fluctuations}

Kimberly Swenson* and Albert H. Markhart, III; Department of Horticultural Science, University of Minnesota, St. Paul, MN 55108

A major limitation to plant growth in spring is low night temperatures. A variety of plant protection systems have been developed to keep the temperatures around the plant warmer than the ambient air. One system that has been developed for use with individual plants is a double walled stiff plastic tent. The space between the walls can be either filled with water or air. The top of the tent can be either open or closed. The objective of this investigation is to quantify the effect of these protection systems under controlled environmental conditions. Two washtubs filled with wet soil were placed in a controlled environment growth chamber. One tent was placed on the soil surface of each tub. The chamber was programmed to simulate a cold night. Temperatures started at $20^{\circ} \mathrm{C}$ and then decreased to -5 ${ }^{\circ} \mathrm{C}$ at a rate of about $4{ }^{\circ} \mathrm{C} / \mathrm{h}$. During this time, ambient air temperature, jacket temperature, soil temperature, and air inside the tent was measured continuously with self-contained data loggers. Water filled tents delayed the time it took for the inside temperature to reach the outside temperature by 2 hours. There was not apparent effect on soil temperature. The effect of water vs. air-filled jackets and the effect of capping the top will also be presented.

\section{4}

\section{Consumer Perceptions of Landscape Value using Different} Designs, Types of Plant Material, and Plant Sizes

Karl J. Muzii', M. Haque', R.T. Fernandez', B. Behe ${ }^{2}$, and S. Barton ${ }^{3} ;{ }^{1}$ Department of Horticulture, Clemson University, Clemson SC 29634-0375; '2Department of Horticulture, Michigan State University, East Lansing MI 48824-1325; ${ }^{3}$ Department of Plant and Soil Science, University of Delaware, Newark DE197171303

The research contained in this thesis quantifies the difference between actual landscape value and perceived value on the part of homeowners. Pertinent information and necessary data were gathered by surveys interviewing consumers over the age of 18 , who evaluated a set of 16 home landscape photographs. These surveys were conducted at two sites in South Carolina. The study involved three levels of landscape design with varying complexity and cost factors. Four plant material and hardscape combinations were developed for use in each cost design. Finally, the plant material size was categorized as small, medium, or large. Thirty-six design combinations were created. A subset of 16 computer-generated images was selected to simplify the evaluation. Participating respondents answered a questionnaire providing personal demographic information and their evaluations of the 16-image subset. Participants were supplied a base starting price and a photo of the home without landscaping. Responses were analyzed to determine consumer perceptions of value influenced by landscape design style, plant material, and hardscape selection; plant size; and by the difference between perceived value and actual cost to install. Consumer responses for all landscape designs were positive and indicate that consumers consider landscaping an asset to residential value. Participants valued the home on average between. $95 \%$ to $11.3 \%$, depending on the complexity of design, plant material, hardscape, and size combinations. The variance between consumer perception and actual cost of material and labor indicates that consumers undervalue the price of a newly installed landscape where all material and labor costs are priced consistent with professional landscaping averages.

\section{ORAL SESSION (Abstr. 625-631) Collegiate Branch Oral Competition}

\section{6}

\section{Effects of Chemical and Mechanical Height Control in Dendranthema grandiflorum}

Kiffnie M. Holt* and Paul H. Jennings; Horticulture, Forestry, and Recreation Resources Department, Kansas State University, Manhattan, KS 66506

Rooted chrysanthemum cuttings of five cultivars were transplanted into $61 / 2 "$ pots and greenhouse-grown for 7 weeks under natural daylength conditions. Plants were pinched back twice, on the 3rd week and the 5th week following transplanting. At 7 weeks, plants were arranged in a complete randomized-block design with four plants per cultivar per treatment and three replications. Spacing of the pots was kept constant through the duration of the experiment. The chemical group was sprayed with 2500 ppm B-Nine until run-off on the first day of treatment. The mechanical group was brushed 40 times, twice a day, for 5 weeks. The brushing mechanism was adjusted daily to account for growth so as to stimulate only the top 2 to 3 inches of the plant. Measurements of all plants were taken on the first and last day of the mechanical treatment. Data collected included height, internode length, and leaf area. Plants were then allowed to flower under the naturally shortening daylength, and the flowering date was recorded. The chemical and mechanically treated plants were shorter than the controls with a greater response occurring with the cultivars 'Emily' and 'Cheery Emily', which had a more open and upright growth habit. Cultivar response differences and effects on internode length, leaf area, and flowering date were noted and will be discussed.

\section{7}

Using a Toxic Bait and a Trap Crop for the Control of Striped and Spotted Cucumber Beetles and Bacterial Wilt of Cucumbers

Karen M. Meyer ${ }^{* 1}$, James R. Steadman ${ }^{2}$, and Greg L. Davis ${ }^{1} ;{ }^{1}$ Horticulture Dept. 2Plant Pathology Dept., Univ. of Nebraska, Lincoln, NE 68583

The toxic bait, Adios, was tested with the use of a trap crop in a field experiment at the Univ. of Nebraska during Summer 1998. The insecticide contains the secondary plant metabolites known as cucurbitacins that are highly attractive to the striped and spotted cucumber beetles, Acalymma vittatum and Diabrotica undecimuncata howardi, respectively. These beetles serve as the vector of the bacterial pathogen, Erwinia tracheiphila, which causes severe wilting and eventual death of susceptible cucurbits. The objective of the study was to determine whether treatments of Adios, when applied to a flowering trap crop of resistant squash plants, would lure the cucumber beetles away from the susceptible cucumber plants and reduce bacterial wilt. The study compared the effectiveness of a sprayed trap crop, the direct application of Adios to the cucumber plants and no treatment in a randomized complete-block design. A greater number of beetles were attracted to the sprayed and untreated cucumbers compared to the cucumbers surrounded by the treated trap plants. However, significant numbers of dead beetles were found near the sprayed cucumber plants. Untreated plants showed more feeding damage, diminished fruit quality, and an earlier observation date of wilt symptoms as compared to the other treatments. The treated trap plants and the direct application of Adios were effective in delaying infection in cucumbers compared to the untreated plants in the experimental plots. This treatment may be useful to home gardeners.

\section{8}

Influence of Cooling, Long-day Lighting Regime, and Propagule Type on Flowering of Phlox paniculata L. Cultivars

James M. Garner" and Allan M. Armitage; Department of Horticulture, The University of Georgia, Athens, GA 30602-7273

Rooted terminal cuttings and dormant 1-year-old transplants of Phlox 
paniculataL. 'Ice Cap' and 'Red Eyes' were cooled for $0,4,8,12$ or 16 weeks and forced under long-day photoperiod provided by incandescent lights as either a night-interruption (2200-0200 HR) or extended-day (1700-2200 HR). The influence of cooling duration, long-day lighting regime, and propagule type on forcing days to flower, flowering stem counts, and flowering stem length was evaluated in a $3 \times 2 \times 5$ factorial experiment. Cooling accelerated flowering and increased stem yield and length. Days to flower for both cultivars decreased and flowering stems and length increased linearly as cooling increased from 0 to 16 weeks, regardless of lighting or propagule type, but cooling for 8 weeks or more was necessary to produce marketable cut flower stems. Extended-day lighting produced longer stems than night interruption, and stem counts were higher among plants grown from transplants, regardless of cooling duration, lighting regime, or cultivar. Flowering stems from rooted cuttings were generally longer than those from transplants. Cut flower stems of 'Ice Cap' were longer than those of 'Red Eyes', but days to flower and yields for the two cultivars were similar.

\section{9}

\section{Are Trichome Number Related to Parthenolide Content in Feverfew?}

Gretchen Hatch ${ }^{\star}$ and Albert H. Markhart, III; Department of Horticultural Science, University of Minnesota, St. Paul, MN 55108

The concentration of active ingredient in a given dry weight of a medicinal herb is important to the consumer and producer of herbal remedies. Feverfew is a commonly used medicinal herb where the active compound has been identified. There is considerable variability in the amount of the active ingredients in different genotypes of feverfew. Important secondary plant compounds are often produced in the trichomes of leaves. The objective of this investigation is to determine if there is a correlation between the number of leaf trichomes and the level of active ingredient in several feverfew genotypes. Rooted cuttings of feverfew (Chrysanthemum parthenium) genotypes previously characterized for parthenolide content were grown under identical conditions in an environmentally controlled greenhouse. Light and scanning electron microscopy were used to describe and quantify the number and type of trichomes on the youngest fully expanded leaf of each plant from each genotype. The relationship between trichome number and parthenolide content will be presented.

\section{0}

The Effect of Nitrogen Fertilizer Form, Concentration, and Delivery System on the Growth and Plant Quality of Poinsettia

John Ferrel/ ${ }^{\star}$ and Alejandro Ching; Horticulture Program, NW Missouri State University, 800 University Dr., Maryville, MO 64468

Rooted cuttings of poinsettia (Euphorbia pulcherrima willd.ex.klotzch cv. Eckespoint Freedom Red) were grown under 16-h photoperiod in plastic pots ( 6 inches in diameter) containing 1 sand : 1 Metro-Mix 500 (v/v) to determine the response of nitrogen fertilizer forms, concentrations, and delivery methods on plant growth and quality. Plant height, number of lateral shoots, and number of leaves were increased with osmocote $19 \mathrm{~N}-6 \mathrm{P}-12 \mathrm{~K}$ at the rate of $4 \mathrm{gdm}^{-3} \mathrm{com}$ pared to 100-200 ppm of calcium nitrate (foliar spray), 60-100 ppm urea (foliar spray), 80-120 ppm of ammonium sulfate (soil drench), 100-140 ppm of poinsettia 20N-5P-19K (soil drench), and $8 \mathrm{gdm}^{-3}$ of osmocote (slow release), showing superior plant growth. Data show that delivering nitrogenous fertilizers by foliar sprays tends to reduce plant growth with short plant stems and a low number of lateral shoots and leaves compared to soil drench application, with the exception of osmocote $19 \mathrm{~N}-6 \mathrm{P}-12 \mathrm{~K}$ at a rate of $8 \mathrm{gdm}^{-3}$. Plant quality factors such as the number of discolored or dead leaves and the degree of green coloration on the leaves were also affected by the form and delivery system of nitrogenous fertilizers.

\section{1}

\section{Interaction of Genotype and Temperature on the Floral} Initiation of Pelargonium xdomesticum

Laurel L. Anderson* and Laura M. Wakefield; Department of Horticulture, The Pennsylvania State Univeristy, University Park, PA 16802

Pelargonium xdomesticum has great potential as a flowering potted plant. Low-temperature requirements for floral initiation create an obstacle for mass production, and precise temperature requirements for floral initiation vary among cultivars. Our objective was to determine optimum temperature for floral initia- tion of six cultivars: Dandy, Debutante, Empress, Enchantment, Imperial, and Rapture. Four complete experiments were conducted at 1-month intervals beginning Oct. 1998. In each experiment, 120 culture-virus-indexed rooted cuttings were obtained commercially and planted into $15-\mathrm{cm}$ plastic pots. After 1 week, terminals were removed and plants were allowed to grow for an additional 3 weeks. Plants then were subjected to three floral initiation treatments at 12,15 , and $18^{\circ} \mathrm{C}$ for 4 weeks under 16 -h photoperiods in growth chambers. A control group was initiated in the greenhouse. Following initiation treatments, all plants were finished under standard greenhouse conditions, supplemented with HID light. On flowering, plants were evaluated for time to anthesis, number and size of inflorescences, and overall plant quality. The $15^{\circ} \mathrm{C}$ treatment consistently produced the highest quality plants, while the $12^{\circ} \mathrm{C}$ treatment scored lowest with regard to flowering and overall quality. Differences among the cultivars were observed for time to anthesis. 'Imperial' and 'Rapture' flowered earliest, followed by 'Enchantment' and 'Empress', with 'Dandy' and 'Debutante' requiring the most time.

\section{COLLOQUIUM 1 (Abstr. 632-635) Genetic Stability of Transgenes under Field Conditions}

632

\section{Introduction to the Colloquium Genetic Stability of Transgenes under Field Conditions}

Jude W. Grosser*, University of Florida, CREC, Lake Alfred, FL 33850

The genetic engineering of horticultural crops to improve disease/insect resistance, cultivar quality, or other characteristics has become a primary area of focus for many research programs. The technique is attractive because a single beneficial trait can be added to an already successful cultivar without otherwise altering cultivar integrity. However, little information has been available regarding the performance of such transgenic plants in the field, particularly regarding woody perennial crops. The purpose of this colloquium is to provide the latest available information regarding the performance of transgenic plants in the field, covering a wide range of crops including vegetables, woody fruit trees, woody nut trees, and forest trees. Focus will be on the long-term expression of transgenes and promoter efficiency. The information provided should be particularly useful to researchers who are currently designing or performing experiments to improve horticultural crops by genetic engineering.

\section{3}

Field Performance of "Transgenic" Potato, with Resistance to Colorado Potato Beetle and Viruses

David R. Duncan* , David Hammond, Jim Zalewski, John Cudnohufsky, Wojciech Kaniewski, Mike Thornton, Jeffrey T. Bookout, Paul Lavrik, Glennon J. Rogan, and Jennifer Feldman-Riebe; NatureMark (a unit of Monsanto Co.), Mail Zone GG4I, 700 Chesterfield Parkway N., St. Louis, MO 63198

After more than 10 years of research, Monsanto scientists have developed improved seed potatoes that are protected from serious pests, including insects and disease. Thefirst commercial products resulting from this effort were NewLeaf ${ }^{\circledR}$ potatoes derived from 'Russet Burbank' and 'Atlantic' parents. The NewLeaf ${ }^{\circledR}$ product was commercialized in 1995 and contains a gene from Bacillus thuringiensis (variety tenebrionis) (B.t.t.). for the production of the Cry3A protein. Potatoes expressing this gene are completely protected from the Colorado potato beetle (CPB) and need no additional chemical protection for this insect pest. The U.S. Food and Drug Administration (FDA), U.S. Dept. of Agriculture (USDA), and U.S. Environmental Protection Agency (EPA) have all determined that these potatoes are the same in safety and nutritional composition as any other 'Russet Burbank' and 'Atlantic' potatoes. These potatoes have al so been approved by Health Canada, Agri-Food Canada and Agriculture Canada and by Japan and Mexico for food use. Commercial growers across North America have experienced outstanding performance while growing NewLeaf ${ }^{\circledR}$ potatoes 3 years in a row. This level of performance is the result of stable, nonsignificant differences in expression of the Cry3 $\mathrm{A}$ gene. The stable performance, also, is a result of an effective insect resistance management program based on maintaining CPB refuges near NewLeaf ${ }^{\circledR}$ fields, reducing CPB populations, and monitoring for CPB surviving exposure to NewLeaf ${ }^{\circledR}$ potatoes. In 1998 NewLeaf $Y^{\circledR}$ ), conferring resistance to both CPB and 
potato virus $\mathrm{Y}$, and NewLeaf Plus ${ }^{\circledR}$, conferring resistance to CPB and potato leafroll virus will be commercially released.

\section{4}

\section{Mechanism and Stability of Virus Resistance in Transgenic Papaya}

Richard Manshardt ${ }^{* 1}$ and Dennis Gonsalves'; ${ }^{1}$ Dept. of Horticulture, University of Hawaii, Honolulu, HI 96822; ${ }^{2}$ Plant Pathology Dept., Cornell University, Geneva, NY 14456

Transgenic papaya line 55-1 with resistance to papaya ringspot virus (PRSV) originated in 1989 by particle bombardment of cultivar Sunset with the coat protein gene (cp) of mild mutant Hawaii PRSV strain HA 5-1. Hemizygous (+/ cp) RO clones of 55-1 displayed resistance to the virulent Hawaii HA strain in greenhouse tests in New York in 1991 and to local strains in a field trial in Hawaii from 1992 to 1994. In the R, generation produced by crossing the pistillate R0 55-1 with 'Sunset', up to $50 \%$ of the hemizygous transgenic segregants were susceptible to a local Oahu PRSV strain when inoculated as seedlings but not as mature plants. Similar inoculation experiments in New York showed that hemizygous $R_{1}$ transgenics were susceptible in differing degrees to PRSV strains from regions other than Hawaii. Homozygous ( $c p / c p) \mathrm{R}_{2}, \mathrm{R}_{3}$, and $\mathrm{R}_{4}$ populations planted in various locations in Hawaii since 1994 have consistently demonstrated highlevel resistance to local strains at all stages of development. When inoculated in New York with eight non-Hawaii PRSV strains, homozygous $R_{3}$ seedlings were resistant to all but a Thai strain. Transgenic resistance is the result of a complex interaction involving the stage of plant development, transgene dosage, the degree of homology between transgene and challenge virus, and environmental variables. Papaya plants transformed with nontranslatable versions of various $\mathrm{cp}$ genes are also highly resistant to PRSV, indicating that the resistance mechanism operates at the RNA level. No loss of resistance due to the appearance of resistancebreaking virus strains or to transgene inactivation has been noted thus far.

\section{5 \\ Stability of Herbicide Resistance and GUS Expression in Transgenic Hybrid Poplars during Several Years of Field Trials and Vegetative Propagation}

Richard Meilan, Caiping Ma, and Steven H. Strauss*; Department of Forest Science, Richardson Hall, Oregon State University, Corvallis, ORUSA 97331-7501

We assessed the stability of transgene expression in 79 transgenic lines (i.e., transformation events) of hybrid poplars during several years of field trials. The transgenic lines were comprised of 40 lines of hybrid cottonwoods ( $P$. trichocarpa $x P$. deltoides) that were grown at three field sites, and 39 lines of hybrid aspens (section Leuce, $P$. albax $P$. tremula) that were grown at a single field site. All the lines were transformed with a binary construct that included two genes that confer tolerance to glyphosate (GOX and CP4), a gene encoding resistance to the antibiotic kanamycin (nptII), and a visible marker gene (GUS). Agrobacterium tumefaciens was used for transformation; callogenesis and organogenesis occurred under kanamycin selection. In addition to repeated applications of herbicide to test stability of transgene expression, for the first time, we challenged ramets of 40 lines that had not previously been tested for herbicide resistance in their fourth season of vegetative growth. We report on the stability of herbicide resistance and GUS expression and evidence for somaclonal variation in growth and leaf morphology.

\section{COLLOQUIUM 2 (Abstr. 636-642) Organic Horticulture}

\section{6}

\section{Introduction to the Organic Horticulture Colloquium}

Milt McGiffen ${ }^{\star}$; Department of Botany and Plant Sciences, University of California Riverside, CA 92521-0124

Consumption and production of organic food has quadrupled since 1990. Certified organic or pesticide-free produce and other foods are common in most grocery chains. Increased consumer demand and concerns about pesticide use has led to mandates for national standards and local implementation. The Organic Horticulture Colloquium addresses organic certification, production, pest management, consumer demand, education, marketing, and economics. Challenges and results in implementing policy and encouraging change will be related from both national and local perspectives. While the "organic movement" was originally focused on food crops, it has evolved to address issues of pesticide use in non-food horticultural crops as well. This colloquium addresses issues of concern to food and non-food agricultural products.

\section{7}

\section{Implementing Government Mandates for Pest Management} without Pesticides

David C. Frieders* and Jackie Daries; San Francisco Dept. of Agriculture, San Francisco, CA 94124

In Oct. 1996, the San Francisco Board of Supervisors passed an ordinance that became Chapter 39 of the Administrative Code, mandating that City departments adopt integrated pest management (IPM) policies that promote nonchemical approaches to pest management and reduce or eliminate the use of pesticides. Eiminated on 1 Jan. 1997 were 1) category I chemicals (listed by EPA- most toxic; these are products marked "DANGER"); 2) cancer- or reproductive-toxicity chemicals (per State of California Safe Drinking Water and Toxic Enforcement Act of 1986); and 3) possible, probable, or definite human carcinogens (per EPA). Eiminated on 1 Jan. 1998 were category II chemicals (listed by EPA - next most toxic; these are products marked "WARNING"). Eliminated on 1 Jan. 2000 will be category III chemicals (listed by EP- relatively less toxic; these are chemicals marked "CAUTION"), except for a list to be developed by 1 Mar. 1999 of lowtoxicity chemicals commonly used in IPM programs. To date, 10 exceptions have been approved. Several pesticide-free research projects have been embarked on and on-going IPM training is underway for all city employees, both technical and nontechnical. Challenges remain for pesticide regulators and pest managers in implementing policy and encouraging change.

\section{8}

\section{The Economics of Organic Agriculture}

Robin G. Brumfield*; Rutgers University, New Brunswick, NJ 08901

Since World War II, U.S. agriculture has reduced production costs by substituting petrochemicals for labor, often resulting in overuse of agricultural chemicals. Among the adverse results of chemical overuse are increases in certain pests, groundwater and surface water contamination, and surface water run-off. There is a growing perception that consumers bear the risk of pesticide use and farmers reap the profits. For farmers, the short-term risk of losing a crop that is already planted may take precedence over the long-term risks of such things as the pests developing resistance to pesticide, environmental damage, and applicator health risks. Alternative farming programs such as ICM and organic farming allow farmers to reconcile short-term risks and long-term benefits. Before farmers adopt an alternative system, they must be convinced that economic benefits from the alternative farming program surpass the costs incurred. Few studies have compared the cost of producing organic produce vs. using conventional production systems. One study found that net returns were slightly higher in ICM and organic systems that conventional ones. This is because of lower costs when using ICM systems and price premiums for organic crops. These results suggest that there may not be any trade-off between economic efficiency and environmentally friendly farming practices. If the society desires better environmental quality, it will be ready to pay premium price for the organic or ICM-grown vegetables. In a free-market system, farmers will use the market signals in the form of price, and they will produce accordingly.

\section{9}

Organic Alliance

Barbara Duff ; Organic Alliance, 400 Selby Avenue, Suite T, St. Paul, MN 55102

Organics is the fastest growing trend in the food industry, increasing at an annual rate of more than $20 \%$ per year for the past 7 years. In the upper midwestern United States, a pilot project aimed at increasing the sales of organics in mainstream supermarkets has had an even higher success rate. We'll take a look at how this program was developed and implemented and the ways in which consumers, farmers, and grocers were educated about organic food. We'll discuss trends in organics, what consumers want, and how grocers can best promote organic products and increase their sales. 


\section{0}

\section{Sustainable Cropping Systems}

Chad M. Hutchinson* and Milton E. McGiffen; Department of Botany and Plant Sciences, University of California, Riverside, CA 92521-0124

The goals of sustainable agriculture include decreased reliance on synthetic nutrients and pesticides and improved environmental quality for the long-term benefit of the land, livelihood of growers, and their communities. Cropping systems that maximize these goals use alternative fertility and pest control options to produce crops with minimal soil erosion and nutrient leaching. Cropping system elements that can help achieve these goals include: reduced tillage, cover crops, and organic soil amendments. Cover crops are grown before the cash crop and used to replenish the soil with nitrogen and organic matter. Cover crops often also influence pest populations and can be selected based on site-specific growing conditions. Cover crops can be mulched on the soil surface to prevent erosion and weed emergence or can be tilled directly into the soil to incorporate nitrogen and organic matter. Green waste mulch is an increasingly used soil amendment. Many municipalities are encouraging farmers to use green waste mulch in farming systems as an alternative to green waste disposal in landfills. Reduced tillage was once restricted to large-seeded field crops but recent technical advances have made it a feasible option for vegetables and other horticultural crops. Alternative farming practices; however, are still only used by a small minority of growers. Increases in price for organic produce and changes in laws governing farming operations may increase adoption of alternatives to conventional agriculture.

\section{1}

\section{Consumer Demand for Organic Foods}

Gary Thompson*; Department of Ag. \& Resource Economics, University of Arizona, Tucson, AZ 85721-0023

Sales of organic foods at retail have grown at rates from $20 \%$ to $35 \%$ in many countries throughout Europe, Asia, and the Americas during the 1990s. Yet market shares of organic foods remain quite small, less than $5 \%$ of retail value in all countries throughout the world. As mainstream retail outlets have begun to carry and promote organic foods, lack of availability of organic foods has become less of an impediment to consumer demand. The major impediment to continued growth in organic food demand is high price premiums for organic foods over conventional food counterparts. Some of the highest price premiums at retail are displayed by fresh and frozen vegetables and fruit; premiums as high as $250 \%$ for frozen green peas in the United States have been recorded. Indirect evidence in the form willingness-to-pay studies and retail pricing experiments indicate that the majority of consumers will not pay such high price premiums for organic fruit and vegetables. Small market shares at retail tend to corroborate consumers' willingness to pay such high prices. How much prices of organic fruit and vegetables would have to be reduced relative to conventional produce in order to increase market shares of organic produce is not clear.

\section{2}

\section{A Training Series in Organic Farming Systems}

N.G. Creamer ${ }^{* 1}$, F.J. Louws ${ }^{2}$, and K.R. Baldwin'; Departments of ${ }^{1}$ Horticultural Science and ${ }^{2}$ Plant Pathology, North Carolina State University, Raleigh, NC 27695

Consumer demand for organically produced food and the desire by many farmers to eliminate chemical fertilizers and pesticides is increasing the need for research and educational programs to support organic farmers. To date, the landgrant universities and the cooperative extension service have been viewed by organic farmers as unresponsive to this need. The primary reason for the unresponsiveness has been inadequate training and resource materials available to extension agents. In 1998, we conducted an intensive training for agriculture agents in North Carolina. Funding was provided by the USDA SARE Professional Development Program. More than 50 agents participated in a series of workshops that were offered together as a graduate course worth four NCSU credits. Much of the training was conducted on the Organic Unit at The Center for Environmental Farming Systems (CEFS), a 100-acre facility dedicated to research and education in organic farming systems. The hands-on training consisted of lectures, demonstrations, field trips, and class exercises. The topic areas included soil biology/ecology; crop rotation; organic nutrient management; composting; cover crop management; organic weed, insect, and disease management; appropriate tillage practices; organic greenhouse management; marketing organic produce; integrating animals into organic crop production systems; delivery systems for disseminating information to organic producers, and; social and com- munity development aspects of sustainable agriculture. Unique features of the workshops were the interdisciplinary approach to teaching them, and the integration of information about interactions between production factors. The training was very well-received and will serve as a model for future extension programming. A training manual, slide sets, extension publications, and a Web site are being created to further support agents as they conduct programming in their own counties.

\section{COLLOQUIUM 3 (Abstr. 643-649) Applications of Site-specific Management for Horticultural Crop Production}

\section{3}

\section{Site-specific Management for the 21st Century}

Pierre C. Robert * University of Minnesota Precision Agriculture Center, St. Paul, MN55108

The new agricultural system called soil/site specific crop management (SSCM), now more generally named precision agriculture (precision farming) is the start of a revolution in natural resource management based on INFORMATION TECHNOLOGY AND CONTROL: it is bringing agriculture in the digital and information age. New technologies in the early 80 s, particularly the microprocessor, made possible the development in the United States of farm machinery computers and controllers, the electronic acquisition and process of spatial field data to build farm geographic record keeping systems, the production of soil/site specific condition and management maps using GIS, the positioning of machines using GPS, and the development of real-time soil and crop sensors, particularly yield sensors. The concept of precision agriculture originated from a better awareness of soil and crop conditions variability within fields. The variability of soil conditions within parcels in the U.S. has been demonstrated in many ways (soil survey, soil sampling, and remote sensing) for both soil nutrients and soil physical properties (e.g., available water and compaction). It is progressively found that the concept of precision agriculture can be applied to a variety of crops and practices: management technological levels; and farm types and sizes. For example, in addition to grain crops (corn, soybeans, and wheat), applications are now developed for sugar beet and sugar cane, potato, cotton, peanut, vegetables, turf, orchard, livestock, tree plantation, etc. Precision agriculture is still in infancy but it is the agricultural system of the future because it offers a unique variety of potential benefits in profitability, productivity, sustainability, crop quality, food safety, environmental protection, on-farm quality of life, and rural economic development.

\section{4}

\section{Precision Agriculture Technology for Horticultural Crop Production}

Gary T. Roberson*; Dept. of Biological and Agricultural Engineering, North Carolina State University, Raleigh, NC 27695

Precision agriculture is a comprehensive system that relies on information, technology, and management to optimize agricultural production. While used for several years in agronomic crops, it is attracting increasing interest in horticultural crops. Relatively high per-acrecrop values for some horticultural crops makes precision agriculture an attractive production system. Precision agriculture efforts in biological and agricultural engineering at North Carolina State Univ. are currently focused in two functional areas: site specific managment (SSM) and postharvest process managment (PPM). Much of the information base, technology, and management practices developed in agronomic crops have practical and potentially profitable applications in fruit and vegetable production. Mechanized soil sampling, and variable rate control systems are readily adapted to horticultural crops. Postharvest controls are widely used to enhance or protect product quality. These technologies and their applications will be discussed in this presentation. Yield monitors are under development for many crops that can be mechanically harvested. An overview of these developments will be discussed. In addition, low-cost technologies for entry into precision will be presented. 


\section{5}

Using Site-specific Approaches to Advance Potato Management in Irrigated Systems

Joan R. Davenport'; ; Dept. of Crop and Soil Science, Washington State Univ., Prosser, WA 99350

Potato (Solanum tuberosum L.) is grown extensively throughout the Pacific Northwest as a high-value crop in irrigated rotations with other row crops such as wheat (Triticum aestivum L.) and corn (Zea mays L.) - both field and sweet. Center pivots are predominant irrigation systems. Soil texture ranges from coarse sands to finer textured silt loams and silts and can vary within one field, often with very hilly topography. Site-specific management is being evaluated as an approach to help to optimize inputs (water, seed, agricultural chemicals) to maintain or enhance yield and reduce the potential of negative environmental impacts in these farming systems. Currently variable rate fertilizer application technology and harvest yield monitoring equipment are commercially available for these systems. Variable rate seeding and variable rate irrigation water application technologies are developed but not fully commercialized and variable rate pesticide application equipment is in development. At the Irrigated Agr. Res. and Ext. Ctr. in Prosser, Wash., we have a team of research scientists (both university and USDA ARS), interested individuals from local industry, and other key organizations (e.g., local conservation districts) who are working together to evaluate different site specific technologies, improve the ability to use available tools, and to improve decision-making ability by conducting research both on farm and in research plots.

\section{6}

\section{Applications of Site-Specific Management for Tree Fruit} Production

Tim Righetti ${ }^{*}$, Training Coordinator, UAP Northwest, Corvallis, OR. 97331

Our efforts are concentrated on quantifying spatial variability for tree vigor, yield, fruit quality, and profit. We use aerial photography to quantify tree vigor. For mechanically harvested hazelnuts, a prototype weight based yield monitor has been evaluated. This approach may also work for quantifying yield in mechanically harvested sweet cherries. For perishable hand-harvested crops, the GPS locations for individual bar-coded bins can be used to calculate bin density and estimate yield. Bar codes can also be used to track quality in the packinghouse. Since profit depends on yield, size, and packout, it is not always intuitively obvious which areas of an orchard are most profitable. Defining which areas are most profitable, and identifying the problems associated with low-profit areas (poor yield, small size, storage loss, bruising, culls, etc) is an important step. Identifying areas producing fruit that stores poorly is a high priority. An evaluation of low- and high-profit areas may lead to alternate management plans. Anything from investing in more supervision of harvest labor and initiating different pruning regimes to attempts to obtain more uniform tree vigor can be evaluated. By delineating test areas with GPS boundaries, profit data in future years can quantify the success of different management approaches. For example, concentrating expensive inputs on the portion of trees (30\% of total) that may produce the majority of gross returns, while not even harvesting fruit from regions ( $1 \%$ to $5 \%$ of total) that consistently produce poor quality fruit may be a sound strategy.

\section{7}

\section{Aerial Mapping of Grapes for Analysis of Environmental} Stress and Blackleaf Patterns

N.S. Lang ${ }^{* 1}$, J. Silbernagel ${ }^{2}$, E.M. Perry ${ }^{3}$, R. Smithyman ${ }^{1}$, L. Mills', and R.L. Wample'; 'Dept. of Hort. \& L.A., Washington State Univ., Prosser, Wash.; ${ }^{2}$ Washington State Univ.-Pullman, Wash.; ${ }^{3}$ Remote Sensing Group, Environ. Tech. Group, Battelle-Pacific Northwest National Laboratory Richland, Wash.

Blackleaf (a.k.a. chocolate leaf) is of worldwide concern in Vitis due to its negative impact on fruit ripening, yield reduction and overall stress on grapevines. Research suggests blackleaf is induced by high levels of UV radiation and overall light intensity, which induce color changes (purple-brown-black) in exposed leaves, resulting in $>50 \%$ reduction in photosynthesis. The ability to detect blackleaf symptoms before expression can provide insight into metabolic stresses and the possibility of the use and/or timing of management practices to reduce its impact. Remotely sensed imagery and spatial analysis may elucidate reflectance-related processes and symptoms not apparent to the un-aided eye. In this research we mapped canopy growth (leaves/shoot and shoots/vine), metabolic triggers (photosynthesis, leaf water potential, soil moisture), and percent blackleaf expression within vineyards using global positioning system (GPS), infrared gas analyzer, and digital remotely-sensed images. Each image and data record was stored as an attribute associated with specific vine location within a geographical information system (GIS). Spatial maps were created from the GIS coverages to graphically present the progression of blackleaf across vineyards throughout the season. Analysis included summary statistics such as minimum, maximum, and variation of green reflectance, within a vineyard by image capture date. Additionally, geostatistics were used to model the degree of similarity between blackleaf values as a function of their spatial location. Continuing research will be aimed at identifying spectral characteristics of early season stresses due to UV light, water stress, and reduced photosynthetic capacity. Spatial relationships between early season stress and later blackleaf expression will be assessed using joint spatial dependence measures. Overall, information obtained through digital image and spatial analysis will supplement site level information for growers.

\section{8}

\section{Practical Applications of Site-specific Management-An} Industry Perspective

John LeBoeuf*; 8398 North Ninth Street, Fresno, CA 93720

The initial surge of interest in precision agriculture technologies exhibited by innovators and early adopters involved in crop production appears to have crossed over an important threshold and made a significant development. As valuable field experience increases and learning by doing advances, successful applications of management practices are being identified. Access to accurate information pertaining to practical applications of site-specific management would be expected to motivate more producers to incorporate technology uses with crop production. This next group of producers has been watching technology developments as they preferred to avoid risk and wait for identifiable benefits. Waiting for detailed case studies involving high value fruit and vegetables may be the wrong approach to take. Fierce competition and strict confidentiality are expected, especially in the freshmarket industry that places quality attributes high on the list of desired features. Practical applications of technology that pertain to manageable factors will be the impetus to implementation of site-specific management. High resolution remote sensing imagery from digital aerial and satellite sensors has been used to identify plant stress, direct plant tissue and soil sampling efforts to identifiable soil variability, and provide valuable information for analysis and interpretation of crop growth. Examples of remote sensing imagery that has provided val uable in season progress reports will be identified. Imagery can then be used in a geographic information system along with field maps based on soil properties and physical characteristics determined by on-the go tractors using various sensors. The focus will be on practice, not theory, as seen from an industry perspective.

\section{9}

\section{Summary of the Status of Precision Agriculture}

\section{Douglas C. Sanders* ; North Carolina State University, Raleigh, NC 27695}

The diversity of site-specific management opportunities is demonstrated by the list of topics and speakers we have in the colloquium. These techniques will help use to better understand, adapt, and adjust horticultural management to the benefit of producers, researchers, and the consumer. With these technologies we will be able to reduce costs, environmental impacts, and improve production, and quality. Horticulture will use more both remote and manually operated devices that allow more intensive planning and management of our production systems. This colloquium has just scratched the surface of the potential of these techniques in horticulture. We hope that the sampling will whet your appetite for great depth of study of the opportunities that are just around the corner.

\section{COLLOQUIUM 4 (Abstr. 650-652) 30+ Years of Molecular Genetics: How Far Have We Come and What Are the Major Challenges and Opportunities for Advancement?}

\section{0}

How are Molecular Maps and DNA Libraries Being Used for Genetics and Germplasm Research of Horticultural Crops? Norman F. Weeden ${ }^{*}$, Dept. Horticultural Sciences, Cornell Univ. Geneva, NY 14456 Molecular maps and DNA libraries are now possible to construct in nearly 
every horticultural crop. Comparison of linkage relationships both within and among families of flowering plants is giving us the capability to predict where genes will be even in crops lacking linkage maps. The dissection of quantitative traits into Mendelian components has been successfully performed in many crops, and candidate genes have occasionally been matched with QTLs or morphological mutations on the basis of map position. Breeders are now able to predict what combination of traits will be difficult to achieve as a result of repulsion phase linkage and what traits might be associated with problems due to linkage drag. Maps and libraries also help in identification of homologous genes in different species and gene-rich regions within a chromosome. More generally, DNA libraries are giving us access to every gene in a genome, leading to much more powerful studies concerning the anatomy, ontogeny and physiology of horticultural crops.

\section{1}

\section{Important Genes that Have Been Transferred or Are Avail-} able for Transfer

D.M. Tricoli*, K.J. Carney, L.J. Nea, J.M. Palys, J.F. Reynolds, and C.E. Green; Seminis Vegetable Seeds, Woodland, CA 95695

Many seed companies are using plant biotechnology as a valuable extension of conventional plant breeding with the goal of providing breeders with novel biological traits. The application of biotechnology allows scientists and breeders to make precise changes during the process of germplasm improvement. Many of the first improvements achieved using transgenic plants have involved the transfer of input traits. Some of these traits include, insect resistance, nematode resistance, disease resistance, and herbicide tolerance. For example, the insertion of a gene that produces the crystalline toxin from Bacillus thuringeinsis has led to the production of transgenic plants that are resistant to insects from the Order Lepidoptera. The transfer of coat protein genes from plant viruses has lead to the development of transgenic crops that are resistant to the virus from which the gene or genes were isolated. Various strategies have been developed that allow transgenic plants to tolerate applications of herbicides that allows for improved weed control. In addition to input traits, other strategies are now being used that are directed at improving output traits. These include such traits as enhanced shelf life, ripening control, altered oils, and superior processing characteristics. At Seminis Vegetable Seed Co., we are currently developing transgenic plants with enhanced input as well as output traits. We have an active program using pathogen derived genes to develop virus resistance cultivars in a range of crops including, tomato, cucurbits, and peppers. Using this approach, we have been able to develop plants with multiple virus resistance by transforming germplasm with constructs containing stacked genes. Seminis is currently marketing a hybrid squash variety with resistance to two major virus pathogens. Another major goal for Seminis is implementing biotechnology to improve various aspects of fruit quality including viscosity, color, softening, and shelf life. Through our collaboration with Zeneca we have developed a high viscosity tomato, which was produced by suppressing endogenous levels of polyglacturonase. This processed food product is currently on the market in the United Kingdom.

\section{2}

\section{Challenges and Opportunities for Application of Genetic} Engineering to Horticultural Crop Improvement

David A. Somers* , Department of Agronomy and Plant Genetics, University of Minnesota, St. Paul, MN 55108

Genetic engineering offers numerous potentially useful genetic manipulations for the improvement of horticultural crops. Nevertheless, there are several impediments to the efficient integration of genetic engineering into plant improvement programs. The ability to regenerate plants from tissue cultures and, therefore, to genetically engineer most plant species is limited to specific genotypes. This may constrain introduction of genetically engineered traits into crops that have complex genetics, are highly heterozygous, or are propagated by asexual reproduction. Even in crops that are self-compatible, diploids, genotypic specificity of the transformation process often necessitates backcrossing for transfer of genetically engineered traits into elite lines and to reduce problems associated with tissue culture-induced genetic variation. This limits progress in improving other traits compared to other breeding strategies. Other challenges to applying genetic engineering exist. The major genomics initiatives currently underway for gene discovery from a broad range of organisms will provide plant improvers access to most genes. Yet there remains a dearth in tissue-specific, developmentally timed, and environmentally responsive promoters for appropriate expres- sion of introduced genes (transgenes). Furthermore, transgene expression is not as controllable as desired due to transgene silencing. Transgene integration is a random process and further refinements of targeted DNA integration will likely enhance the stability of expression of transgenic traits. The availability of other tools, such as selectable marker genes, will becomelimiting as multiple transgenic traits are combined within a species. In addition to technical problems, there likely will be problems of access to proprietary technology and testing to meet federal regulations and public acceptance. While these various challenges and limitations currently may constrain progress in application of genetic engineering to horticultural crop improvement, it is foreseeable that with further improvements of genetic engineering technology and development of the appropriate molecular tools, genetic engineering will become a component of most plant improvement programs.

\section{3}

\section{Use of Beneficial Rhizobacteria to Enhance Growth and Induce Systemic Disease Protection in Transplants}

Joseph W. Kloepper*, M.S. Reddy, Choon-min Ryu, and John F. Murphy; Department of Plant Pathology, Auburn Univeristy, Auburn, AL 36849

Use of beneficial rhizobacteria to enhance growth and induce systemic disease protection in transplants. Plant associated bacteria have been studied for the capacity to provide plant growth enhancement and biological disease control. "Rhizobacteria" are bacteria from the rhizosphere that have the capacity to colonize plant roots following introduction onto seeds or into soil. Effects of rhizobacteria on plants may be deleterious, neutral, or beneficial. Beneficial rhizobacteria are termed "PGPR - plant growth-promoting rhizobacteria." In developmental studies aimed at reducing to practice the concept of induced systemic disease protection mediated by PGPR, we discovered that mixtures of PGPR and an organic amendment into the soilless media used to prepare tomato transplants resulted in highly significant and reproducible plant growth promotion. Time for development of transplants was typically reduced from 6 weeks for controls receiving industry standard fertility and growth regimes to 4 weeks for seedlings grown in soilless mix into which the PGPR had been incorporated. This marked growth promotion was also associated with systemic protection against pathogens. When transplants were inoculated with the tomato spot pathogen, significantly fewer lesions developed on plants grown in the biological system than on control plants. Similar effects on plant growth and systemic disease protection were seen with cucumber, bell pepper, and tobacco, suggesting that the benefits are not highly crop or cultivar specific. Results of recent field studies will be presented. We conclude that incorporation of PGPR into soilless mixes is a technologically useful and feasible way to deliver benefits to transplants.

\section{4}

\section{Vegetable Transplant Biological Control Amendments}

Charles S. Vavrina* ${ }^{* 1}$ N. Kokalis Burrell, and J. Kloepper; ${ }^{1}$ Horticultural Sci. Dept., Univ. of Florida, Immokalee, FL 34142; ' $U S D A$, Plant Pathology, Auburn Univ., Auburn, Ala.

Bell pepper (Capsicum annuum) seedlings treated with various biological preparations exhibited increased root and shoot growth both in the greenhouse and during subsequent field establishment. Early fruit set and pod development showed signs of possible yield improvement by the treatments, but treatment differences were not apparent at first harvest. Data from subsequent harvests did show yield increases with some preparations. Treatment organisms appeared to activate or induce systemic resistance to bacterial spot (Xanthomonas campestris) infestation though not to the level shown by Actigard (Novartis). Crop/treatment response under soil solarization, fumigation, and compost amended conditions will be discussed. 


\section{5}

Commercial Biological Products for Reducing Plant Disease and Enhancing Plant Establishment in Flowers and Ornamental Crops

Robert Wick*; Department of Microbiology, Morrill Science Center N-203, University of Massachusetts, Amherst MA 10003

Several biological control agents for the control of fungal diseases have recently been commercialized. Do the claims of pest control meet the expectations of the growers? Do the biocontrol agents perform consistently? How do they compare to chemicals? These questions have yet to be answered but recent trials indicate mixed results. In Massachusetts, Mycostop worked well against fusarium stem rot but not against fusarium wilt. Deny ( Burkholderia cepacia) did not perform well against Rhizoctonia or Pythium root rot of poinsettia. The following information was taken from the 1997 and 1998 Biological and Cultural Tests for Control of Plant Diseases. In Maryland, zinnia damping-off was controlled by both SoilGard (Gliocladium virens) and Bio-Trek (Trichoderma harzianum). The biocontrols performed as well as the conventional fungicide. In North Carolina, GlioGard (Gliocladium virens) and SoilGard gave only partial control against Pythium and Rhizoctoniadamping-off of bedding plants. In Pennsylvania, Greygold (mixture of four microorganisms) did not provide adequate control of Botrytis on geranium. In Georgia, Pythium and Rhizoctonia diseases of a variety of plants were evaluated with SoilGard and RootShield (Trichoderma harzianum). Disease pressure was low and the results varied from inconclusive to both positive and negative. In addition, SoilGard apparently reduced fresh weight of several plant species. RootShield was reported to both increase root weight in one case and decrease root weight in another. In Connecticut, Rhizoctoniaroot rot of poinsettia was not significantly suppressed with SoilGard, RootShield, or Earthgro, a suppressive growing medium. However, the authors stated that the results indicated that the biocontrols had promise. Results of additional trials will be presented.

\section{WORKSHOP 3 (Abstr. 656) Seed Quality Issues in Medicinal Herbs}

\section{6}

Improving Seedling Establishment of Medicinal Herbs

Baine M. Grassbaught ${ }^{*}$ Mark A. Bennett, and Andrew F. Evans; The Ohio State Univ., Dept of Horticulture and Crop Science, 2021 Coffey Road, Columbus, OH 43210

Successful crop production and optimum yields, regardless of the species, can beaccomplished only when maximum stand establishment is achieved. Stand reduction after planting typically results in reduced yields and lower crop quality. Several classes of factors (environmental, edaphic, biotic) contribute to successful stand establishment in crop production and should be considered in growing medicinal plants. Environmental factors (e.g., temperature and moisture extremes) as well as pathogens and insect pests that attack seeds and seedlings may contribute to reduced stands. Soil related factors such as $\mathrm{pH}$, nutrient availability, and crusting may also restrict seedling growth. Understanding the requirements for optimum seed germination and the environmental conditions into which the seed is sown is essential for uniform crop establishment. Vigor tests can aid growers in determining the optimum temperature range for seed germination. Many cultural practices may also influence soil related factors and contribute to successful stand establishment in the field. Seed vigor tests (SSAA, thermogradient results) along with seed treatments and enhancements can assess seed vigor, improve germination and lead to more reliable stands of medicinal species.

\section{WORKSHOP 6 (Abstr. 657-661) Manipulation of Flowering with PGRs}

\section{7}

Relationship between Intensity of Flowering and Cropping in Fruit and Nuts

EW. Stover"; Indian River Res. \& Edu. Center, Univ. of Florida, Ft. Pierce, FL 34945

The relationship between intensity of flowering and various aspects of crop- ping will be reviewed for fruit and nuts. Clearly, relatively light flowering can limit yield in most fruit and nut species. This commonly occurs before mature bearing commences and in "off" years for varieties that display alternate bearing. During mature bearing, many species will carry fruit numbers that exceed commercially desired levels, resulting in excessively small fruit and accentuating alternate bearing. The economic disadvantages of excess cropload have resulted in considerable research on fruit thinning and widespread commercial application of this practice. Heavy flowering intensity in some crop species results in economic disadvantages beyond the problems of excessive cropload and resultant small fruit size. Many species flower profusely and have initial fruit set far in excess of final tree capacity, resulting in abscission of numerous flowers and fruitlets. Abscised organs can represent a substantial investment in carbohydrates and nutrients, compromising availability at critical periods in flower and fruit development. The potential implications of this process are best exemplified in navel orange, where an increase in flowering beyond intermediate intensity results in a reduction in both initial fruit set and final fruit yield at harvest. In several crops, there is evidence that fruit size may be reduced by excessive flowering, even when cropload is quickly adjusted to an acceptable level. These data suggest that further research on the advantages of controlling flowering intensity is warranted.

\section{8}

Processes Influencing Floral Initiation and Bloom: The Role of Phytohormones in a Conceptual Flowering Model

Thomas L. Davenport" ; University of Florida, Trop. Res. \& Ed. Ctr., 18905 SW 280 St., Homestead, FL 33031

The reproductive phenology of temperate tree fruit species, such as apple and peach, will be briefly introduced and compared to the reproductive phenologies of several tropical and subtropical tree fruit species. Conceptual models of citrus and mango flowering will be described which help to understand the physiological mechanisms of flowering and vegetative flushes in trees growing in subtropical and tropical environments. Possible roles for auxin and cytokinins in shoot initiation and for gibberellins and a putative florigenic promoter in induction will be discussed as they relate to the physiology of flowering and vegetative flushes of tropical species. Successful application of these conceptual flowering models in controlling flowering of citrus, mango, lychee, and longan through the use of growth regulators and other horticultural management techniques will be described.

\section{9}

Reducing Floral Initiation and Return Bloom in Fruit TreesApplications and Implications in Fruit Production: Pome Fruit

Duane W. Greene*, Department of Plant and Soil Sciences, Univ. of Massachusetts, Amherst, MA01003

Pome fruit display a biennial bearing tendency that is characterized by heavy flowering and fruit set one year followed by a year with reduced bloom and fruit set. This tendancy results in a year with heavy cropping with small fruit, and a subsequent year with large fruit and a small crop. Both situations are undesirable. Chemical thinners in the "on" year are frequently used to modify this cropping behavior. Alternative methods to control cropping by flower bud inhibitions will be discussed. Gibberellin application in the "off" year at or soon after bloom will inhibit flower bud formation and encourage moderate flowering. This method of crop regulation has been used infrequently. Gibberellins differ in their ability to inhibit flowering. Therefore, selection of a specific gibberellin and an effective concentration range may provide greater flexibility in controlling flowering. The cytokinins CPPU and thidiazuron inhibit flower bud formation, increase fruit size, and also thin fruit. Appropriate application of these cytokinins will be discussed where beneficial effects on fruit size may be achieved while maintaining a moderate level of flower bud formation.

660

Reducing Floral Initiation and Return Bloom in Stone Fruit Trees: Applications and Implications in Fruit Production Stephen M. Southwick*; Pomology Department, University of California, Davis, CA 95616, USA

Commercially grown apricots ( Prunus armeniaca), peaches (Prunus persica), nectarines (Prunus persica), plums (Prunus salicinaand Prunus domestica), and pluots (Prunus salicina x Prunus armeniaca) have a tendency to produce high numbers of flowers. These flowers often set and produce more fruit than trees can 
adequately size to meet market standards. When excessive fruit set occurs, removal of fruit by hand-thinning is common to ensure that fruit size meets market standards. Over the years there have been numerous attempts to find chemical or physical techniques that would help to reduce costs associated with and improve efficiencies of hand-thinning; however, using alternate strategies to handthinning have not been widely adopted in stone fruit production. In the past 10 years, through the continuing efforts of scientists throughout the world in public and private institutions and business, it appears that there are chemical sprays capable of reducing the need for hand-thinning in stone fruit. Management of flowering by reducing the number of flowers on apricot, peach, nectarine, plum, and prune has shown promise under climatic conditions such as those found in the San Joaquin Valley of California. By applying gibberellins during May through July, flowers in many stone fruit cultivars can be reduced in the following season. The reduction in flower number does not generally lead to an increase in fruit set. As a result, fruit numbers are reduced, the need for hand thinning can be reduced, and in some cases eliminated. There are risks associated with reducing flower number before climatic conditions during bloom or final fruit set are known. However, given the changes in labor costs and market demands, especially in the developed world, the benefits may outweigh the risks. The application and implications of these summer gibberellin applications toward reducing flower numbers will be discussed as it relates to commercial stone fruit growing.

\section{1}

\section{Encouraging Flowering and Cropping in Slow-to-bear Tree Fruit with Bioregulators}

D.C. Efving ${ }^{\star}$; WSU Tree Fruit Research \& Extension Center, Wenatchee, WA 98801

Some cultivars of deciduous tree fruit, especially in apple and pear, tend to come into bearing slowly. Bioregulators have been used to stimulate flowering and cropping in slow-to-crop cultivars, but success has been variable. Improved flowering may not necessarily lead to increased cropping. Reduction in vegetative vigor as a result of bioregulator treatment is often, but not always, associated with increased flowering. Bioregulators that act by interfering with gibberellin biosynthesis or that generate ethylene in plant tissues have proven effective for increasing flowering under a variety of conditions. Few studies have demonstrated that exogenous bioregulator applications to poorly cropping fruit trees can be used to produce sustained and economically significant improvement in fruiting while maintaining satisfactory fruit quality.

\section{WORKSHOP 9 (Abstr. 662-666) Ornamental Plant Breeding in the Midwest}

\section{2}

Genetics and Physiology of Postharvest Cut Flower Longevity

Dennis P. Stimart* and Kenneth R. Schroeder; Department of Horticulture, University of Wisconsin, 1575 Linden Drive, Madison, WI 53706

Efforts to improve postharvest longevity of fresh-cut flowers has only recently turned toward selection and breeding. Conventional methods to extend keeping longevity of cut flowers depend on use of chemical treatment placed in holding solutions. Postharvest longevity studies were initiated with Antirrhinum majus L. (snapdragon) to determine: if natural genetic variation existed for cut-flower longevity, the inheritance of the trait, heritability, and associated physiology. Evaluation of commercial inbreds held in deionized water revealed a range in cutflower longevity from a couple of days to 2.5 weeks. The shortest- and longestlived inbreds were used as parents in crosses to study the aforementioned areas of interest. Information will be presented on inheritance of cut flower longevity based on populations evaluated from matings for generation means analysis and inbred backcross method. Also presented will be information on stomata, transpiration, carbohydrate, fresh-weight change, and forcing temperature relative to postharvest longevity.

\section{3}

Breeding of Woody Landscape Plants at the Univ. of Minnesota Harold Pellett*; University of Minnesota, Dept. of Horticultural Science, Chanhassen, MN 55317

Breeding, selection and evaluation of woody landscape plants has been an active project at the Univ. of Minnesota for many years. The goal of the project is to develop and or identify superior plants that are well adapted to the climatic conditions of Minnesota and other northern areas. About 20 cultivars of many species have been introduced to the nursery trade through this program in the past 20 years. These introductions result from selections made from populations arising from controlled crosses and from open-pollinated populations and native plant populations. One of the primary efforts has been development of the cold hardy, "lights series" of deciduous azaleas. These possess flower bud hardiness of from -35 to $-40^{\circ} \mathrm{C}$. Other current breeding activities include efforts with Viburnum, Acer rubrum, Rosa, and intergeneric hybridization in the Pomoidaea subfamily of Rosaceae. An integral part of the project is development and use of techniques to screen for tolerances to various environmental stresses. Approaches used will be discussed and plants currently under evaluation will be described and illustrated with slides.

\section{4}

\section{Breeding and Development of Cold-hardy Roses}

Campbell G. Davidson*; Agriculture and Agri-Food Canada, Morden Research Center, Morden, Manitoba, Canada R6M 1 Y5

Without a doubt, roses have been and continue to be an important landscape and greenhouse plant. From the early records, dating back to Egyptian, Roman, and Greek times, roses have played an important societal role. Early attempts at growing roses in Prairie Canada were frequently unsuccessful. The extreme cold in winter, where temperatures of -30 to $-40^{\circ} \mathrm{C}$ are common, and droughts and heat in the summer greatly reduced the range of plant material, including roses that could be grown. As a result, the Morden Research Centre, part of Agriculture and Agri-Food Canada's Research Branch in southern Manitoba, initiated a series of projects on the development of hardy landscape plants including roses. Since1929, we have introduced over 130 new landscape plant cultivars to the nursery trade, including 18 cultivars of roses. One of the keys to the success of the program was the incorporation of cold tolerance originally obtained from Rosa arkansana, a prairie native. This has led to the development of the 'Parkland' rose series. This group of plants flowers repeatedly, are hardy to USDA zone 3, root from softwood cuttings, and are available in a variety of colors. Highlights of these will be presented. More recently, emphasis has been placed on developing breeding strategies to improve disease resistance. Major diseases affecting roses include black spot (Diplocarpon rosea), powdery mildew (Sphaerotheca pannosa), and rust (Phragmidium sp.). Details of the current breeding protocols will be outlined as well as results from a series of trials established to elucidate the influence of environment and genotype on disease expression. Cooperative disease monitoring trials (Canada and Sweden) were established and results will be presented.

\section{5}

Selection, Domestication, and Breeding Native Herbaceous Prairie Plants

D.T. Lindgren ${ }^{*}$; West Central Research and Extension Center, Univ. of Nebraska, North Platte, NE 69101

There has been a large increase in the use of native herbaceous prairie plants for ornamental purposes. They are also being used for cut flowers, medicinal purposes, and in restoration projects. To discuss the subject of breeding and selecting herbaceous plants for landscaping, it is convenient to divide the topic into three areas of interest: 1) selecting native ecotypes for use on specific sites; 2) selecting and breeding for nonnative/native plants for wildflower mixes; and 3) selecting, breeding and developing specific individual plants for ornamental/ garden use. Native plant traits that are being evaluated at the Univ. of Nebraska West Central Center include competitiveness, pest tolerance, regional adaptation, flowering characteristics, foliage characteristics, proportionality of plants, ease of propagation, ease of establishment, and moisture requirements. In addition, research is being conducted at the West Central Center regarding genetic variation. For example, Dalea purpureum varies in height, foliage color, stems per plant, stem lodging, and time of flowering. Similar variation has been documented in Lithospermum, Calylophus, Penstemon, Liatris, and Echinacea, to name a few. Botanically, genetic variation has been documented within many native herbaceous species. However, plant breeders have done very little with these variations in genotypes, thus allowing considerable opportunity for breeding research with native herbaceous plants. 
666

Trends in Floriculture Plant Breeding and the Seed Industry Grace R. Price*; PanAmerican Seed Co., 1 S861 Green Road, Eburn, IL 60119

This presentation describes market demands and breeding methodologies that in combination drive development of new floriculture products. In recent years, radical shifts in the direction and pace of product innovation have taken place. New product introductions and development in petunias will be reviewed to demonstrate how breeders approach these new challenges. Parameters of product performance and selection will be discussed as these apply to the midwest, as well as to the rest of the world.

\section{WORKSHOP 10 (Abstr. 667-668)}

\section{Tree Fruit Rootstocks: Current Materials} and Future Trends

667

Apple Rootstocks for the Next Century

Terence L. Robinson* and William C. Johnson; Dept. of Hort. Sciences, New York State Agricultural Experiment Station, Cornell University and USDA-ARS Geneva, New York, 14456 USA

Rootstock breeding programs in the United States, the United Kingdom, Germany, Russia, Poland, the Czech Republic, and Japan have all released apple rootstocks in the recent past that are potentially important to the worldwide apple industry in the next century. Several of these programs are continuing to breed new rootstocks. Each program has focused on different breeding objectives, thus giving a wide range of horticultural characteristics among this new group of rootstocks. All programs have focused on the horticulturally important traits of productivity, dwarfing and precocity but certain programs have also emphasized other characteristics such as propagability, stress tolerance, disease resistance or insect resistance. Commercialization of this new group of rootstocks is proceeding at an extremely fast pace due to the worldwide networking of fruit tree nursery companies and the use of plant patents. This presents a large job for research and extension personnel to properly test rootstocks for adaptability to different growing areas before they are planted on a large scale. The national rootstock testing project (NC-140) composed of researchers from most apple growing states and provinces in the U.S. and Canada is collecting rootstocks from around the world and conducting uniform field trials that give performance data from a wide variety of climates and soils. This information becomes the basis for local rootstock recommendations in North America. This presentation reviews the most promising rootstocks from around the world and summarize the research information from North American and worldwide trials.

\section{8}

Precocious, Dwarfing, and Productive-Will New Rootstocks Ruin the Sweet Cherry Industry?

Gregory A. Lang*; Irrigated Agriculture Research and Extension Center, Wash : ington State University, Prosser, WA 99350

Sweet cherries (Prunus avium) can be one of the most profitable tree fruit cultivated in temperate climates. While cherry trees grow naturally to relatively tall heights, new size-controlling cherry rootstocks similar to those used in highdensity apple orchards are now a reality. The Gisela series from Germany, the Gran Manier series from Belgium, the Weiroot series, the P-HL series, Tabel Edabriz, and others of international origin are at various stages of scientific and field testing in North America, with some now moving into commercial fruit production. These stocks confer several highly advantageous traits besides vigor control, including precocious fruiting and high productivity. While these obvious traits are exciting, serious problems have also been documented, on occassion, with such phenomena as small fruit size and tree decline. As many of these rootstocks are interspecific Prunus hybrids, might there be significant limitations for fruit quality and orchard longevity? What is known about their susceptibilities to pathogens and pests? What is known about their tolerance to various soil types and/or climatological stresses? Further, with the U.S. and worldwide orchard area planted to fresh-market sweet cherries already expanding to record levels throughout the 1990s and a time-honored agricultural trend toward overproduction until grower profits are minimized (see recent international apple markets), what might be the future impact of such precocious, productive rootstocks on sweet cherry profitability and sustainable production? This overview will address these topics, providing some answers and some areas for future scientific investigation and discussion.

101 WORKSHOP 13 (Abstr. 669-674) Long-term Recovery Dynamics of Perennial Species Following Tropical Cyclone Damage

\section{9}

The Impact of Gulf Coast Hurricanes on Pecans, Ornamental Trees, and Invasive Exotic Species

Edward L. McWilliams*; Dept. of Horticultural Sciences, Horticulture and Forest Building, College Station, TX 77843-2133

Hurricanes strike the Gulf Coast of the United States every few years. We briefly describe generalized hurricane tracks for the Gulf Coast and vegetation damage using NDVI satellite imagery as well as slides of damaged urban trees in Florida. The impact of recent hurricanes on both pecan defoliation and production and on initial damage and subsequent recovery of various ornamental trees is described. Pecan harvests were greatly reduced by hurricanes that struck late in the season in both Alabama and Texas. Varieties of pecans varied in their susceptibility to various stresses. Pine forests were sometimes devastated by certain hurricanes while live oaks, various shrubs, and important insects often survived the same storms with little damage. Many exotic ornamental plants including Chinese tallow are either adventive or invasive along the Gulf Coast. Species escape from cultivation over a long period of time and exhibit different invasion lag phases. In Texas and Louisiana, hurricane damage to native trees allowed Chinese tallow seedlings and saplings to subsequently dominate some areas as a result of the disturbance. One delayed ecological response to hurricanes and typhoons is an acceleration of ongoing exotic plant invasions.

\section{0}

Long-term Impacts and Recovery of Perennial Tropical Fruit Crops from Hurricanes in South Florida

Jonathan H. Crane ${ }^{* 1}$, Bruce Schaffer', and Richard J. Campbel/2, 'University of Florida, IFAS Tropical Research and Education Center, 18905 S.W. 280 St., Homestead, FL 33031-3314; ' ${ }^{2}$ airchild Tropical Garden, 11935 Old Cutler Road, Miami, FL 33156

Southern Florida has experienced numerous hurricanes, of which Hurricane Andrew was the most recent. Six years after this storm, nearly one-third of the 8093 ha of tropical fruit that existed in Miami-Dade County before the storm has never been replanted. The damage, reaction, and recovery from the storm varied among fruit species. The effect of heat stress and high light intensity was minimal on avocado, 'Tahiti' lime, carambola, mamey sapote, guava, sapodilla, and longan. In contrast, mango trees experienced severe heat stress. Root damage caused by toppling and subsequent re-setting of sugar apple, atemoya, mango, and grafted 'Tahiti' lime trees was severe; thus, trees not re-set were less likely to recover than trees left toppled or leaning. The extent and rate of recovery from hurricanerelated wind stress also varied among species. Avocado, carambola, guava, and Iongan refoliated within 3 to 4 weeks after Hurricane Andrew. In contrast, mango, sugar apple, and atemoya trees went through two or more cycles of refoliating and dying back until tree death occurred. Iron and nitrogen deficiencies were common for mango, sugar apple, atemoya, and guava. Other consequences of hurricanes in south Florida include increased weed and vine growth and increased susceptibility to drought stress and insect infestations. Recovery to prehurricane crop production levels has varied among crops. For example, avocado and carambola production is near and exceeds pre- 1992 levels, respectively. In contrast, 'Tahiti' lime and mango production are about $20 \%$ pre- 1992 levels. The long-term effect of the most recent hurricane on fruit production in south Florida has been a change in the crop species and/or cultivars planted. 


\section{1}

Impact of Southeastern Hurricanes on Peach and Pecan Orchards Gregory Reighard ${ }^{* 1}$, Bruce Wood ${ }^{2}$, Thomas Beckman ${ }^{2}$, Michael Parker ${ }^{3}$, and Gerard Krewer'; ' 'Dept. of Horticulture, Box 340375, Clemson, SC 29634; ${ }^{2}$ USDAARS Southeastern Fruit \& Tree Nut Lab., 21 New Dunbar Road, Byron, GA 31008: ${ }^{3}$ Dept. of Horticultural Science, North Carolina State Univ., Raleigh, NC 27695; ${ }^{4}$ Horticulture Dept., Univ. of Georgia, Tifton, GA 31793

Southeastern peach and pecan orchards weathered hurricanes in the 1980 s and 1990s that left long-term effects on tree health and productivity. Pecan trees were affected the most, due to being blown down from strong winds and wet soils or suffering considerable damage to branches and immature nuts resulting in massive nut drops. Premature nut drop triggered or enhanced alternate bearing problems. Cultivar differences were evident in the ability of trees to withstand wind damage, with open-canopy trees being most resistant, but essentially all trees were damaged when they exceeded $\approx 17 \mathrm{~m}$ in height. Hurricanes in older, alternate-bearing orchards sometimes broke enough limbs to induce sufficient vegetative regrowth to reestablish an equilibrium between sink (nuts) and source (foliage), thus enhancing yields in subsequent years. Peach trees which were less than $4.5 \mathrm{~m}$ tall and already harvested usually did not blow over unless the soil was very wet. However, peach trees were often twisted about the tree axis from the change in wind directions as the hurricane passed over. Afterwards, many trees leaned more than $30^{\circ}$, especially trees less than 6 to 7 years of age. Root damage was significant and increased when trees were manually repositioned as additional root breakage occured from which these trees often later died. Trees not repositioned but instead retrained to vertical by pruning lived longer. Ambrosia beetles also attacked wind-stressed trees and caused a longterm decline. Slow moving hurricanes significantly damaged peach trees by waterlogging the soil, which killed roots and helped primary pathogens such as Phytophthorasp. to attack the tree crown. This was followed by secondary pathogens like Oxyporous sp., which attacked the internal woody cylinder. Initial trunk damage appeared localized; however, trees continued to die over a number of years. Experience showed that whole orchard removal on severe waterlogged sites was the best economical response.

\section{2}

\section{The Impact of East Coast Hurricanes on Apples}

Richard P. Marini*1, John Barden', and James Schupp 2; 'Dept. of Horticulture, Virginia Polytechnic Institute\& State University, Blacksburg, VA 24061; ${ }^{2}$ Highmore Farm, P.O. Box 179, Univ. of Maine, Monmouth, ME04259

Hurricanes or strong winds occasionally damage apple trees in the northeastern and mid-Atlantic regions of the U.S. Following the wind event, trees may be leaning or may be lying flat on the ground with extension root damage. Commercial growers generally pull trees upright while the ground is still moist and support the tree or just the trunk with various types of posts providing support to a height of about 60 to $200 \mathrm{~cm}$ above ground. In some cases the trees are pulled partially upright and propped up with boards or sand bags may be placed on the upwind side of the tree. Research data are not available for comparing various methods of treating the trees following wind damage, but field observations indicate that trees perform well if trees are pulled upright within 2 or 3 weeks after the wind event. Data from rootstock research plantings from several states indicate that tree anchorage is influenced by the combination of scion cultivar and rootstock. In Virginia in 1989, Hurricane Hugo brought wind gusts of about $95 \mathrm{~km} \cdot \mathrm{h}^{-1}$ when the ground was completely saturated by heavy rains. Trees in several plantings designed to evaluate rootstocks or cultivars were evaluated for the extent of leaning following the storm. The percentage of leaning trees on M.26 EMLA was $<10 \%$ for 'McIntosh' and 'Golden Delicious' and 40\% for 'Delicious'. Susceptibility of trees on M.7A was also influenced by scion cultivar, with $\% \%$ for 'Golden Delicious' and 'Empire', 2\% for 'Redchief Delicious', and 88\% for 'TripleRed Delicious'.

\section{3}

\section{Resistance and Resilience of Native Forests to Disturbance by Hurricane Iniki}

James H. Fownes ${ }^{* 1}$, Robin A. Harrington', and Darrell A. Herbere; ${ }^{1}$ Dept. Forestry and Wildlife Management, Univ. of Mass., Amherst, MA 01003; ${ }^{2}$ The Ecosystems Center, Marine Biology Laboratory, Woods Hole, MA 02543

Two studies were established in upland native forest of northwestern Kauai before Hurricane Iniki (Sept. 1992). One study was a gradient study in Acacia koa forest in the leeward rain shadow and the second study was a replicated fertiliza- tion experiment in mesic Metrosideros polymorphaforest. Both studies escaped devastation by high-intensity microbursts. Removal of LAI (from 3\% to $80 \%$ ) was proportional to pre-hurricane LAl, suggesting that resistance to damage was higher in low LAl, low-productivity sites. LAl recovered to prehurricane levels within 2 years, except in plots with major limb and stem loss. In the Acaciaforest, damage to overstory trees was less than to understory trees, whereas in Metrosideros forest, larger trees were more damaged than smaller trees. During 2 years of recovery, both forests lost LAl in winter storms nearly equivalent to the hurricane damage. Disturbance is more frequent than previously known, which suggests that chronic disturbance needs to be better understood as a force regulating ecosystem structure and function. In both studies, the relative rate of recovery was faster in the more productive but more disturbed plots, suggesting that ecosystem resistance and resilience were traded off. These results have application to land use planning, agroforestry systems management, and other perennial crop management decisions following damage by a tropical cyclone.

\section{4}

The Impact of Tropical Cyclones on Perennial Species in the Mariana Islands

Thomas E. Marler"1 and Mark A. Lander ${ }^{2} ;{ }^{1}$ College of Agriculture \& Life Sciences, Univ. of Guam, Mangilao, GU 96923; ${ }^{2}$ Water and Environmental Research Institute, Univ. of Guam, Mangilao, GU 96923

The frequency of tropical cyclones is a major factor affecting the vegetation of the Mariana Islands, where these storms are called typhoons. An average of about one typhoon per year has passed within $\approx 100 \mathrm{~km}$ of Guam during the past 50 years. The physiognomy of Guam's natural and urban forests is largely determined by these typhoons. The impact of each typhoon is determined by a long list of interacting factors such as species characteristics; environmental and horticultural conditions preceding the typhoon; the intensity, direction, and duration of winds; the amount of rainfall associated with the typhoon; and the environmental and horticultural conditions following the disturbance. Many species survive typhoons by reducing aerodynamic drag of the canopy by abscising inexpensive leaves or breakage of small stems which results in an intact major structural framework. Speed of recovery for nonlethal damage following disturbance depends on nonlimiting conditions during recovery. Thus, the most destructive typhoons are those that occur in sequence with other environmental stresses. The most common of these may be heat and high-light stress, associated with subsequent high pressure systems, and severe drought conditions. For example, the $230-298 \mathrm{~km} \cdot \mathrm{h}^{-1}$ winds of Typhoon Paka in Dec. 1997 were followed by the driest year on record for Guam. Typhoon debris and drought generated 1400 forest and grassland fires from Jan. through May 1998. Sequential typhoons are also severely damaging. For example, Guam experienced three direct eye passages and two more typhoons within $113 \mathrm{~km}$ during the months Aug. to Nov. 1992. Damage susceptibility and recovery dynamics will be discussed in relation to these and other physical, chemical, biological, and human-induced factors.

\section{WORKSHOP 21 (Abstr. 675) Measuring the Impact of Environmental Horticulture Programs}

\section{5}

Program Evaluation Resources and Reporting Methods

Mary Hockenberry Meyer"; University of Minnesota, St Paul, MN 55108

Several traditional print extension resources have been published on program evaluation, including Evaluating Impact of Extension Programs, by R. Rennekamp, P. Warner, and R. Maurer, 1996, Univ. of Kentucky; and Evaluation for Accountability, by B. Sawer, 1992, Oregon State Univ. Additional resources from other agencies, such as the Minnesota Department of Human Services' publication Measuring the Difference Volunteers Make can aid in the evaluation of extension programs. New reporting methods are now being used to present information and program evaluation such as Minnesota Impacts http://www3. extension.umn.edu/mnimpacts/index.asp, and Oregon Invests. This workshop session will define terms important in evaluation reporting, suggest resources to use, and propose a method of reporting evaluation information of similar projects in environmental horticulture programs throughout the United States. 


\section{WORKSHOP 25 (Abstr. 676-680) Phosphorus Management in Horticultural Crops}

676

Overview of Phosphorus Research in Horticultural Crops

Laurence A. Sistrunk*; Dept. of Hort. Sci., Texas A\&M University, College Station, TX 77843-2133

Ulsing phosphorus in horticultural crops has been researched for along time, almost since it was discovered in 1669 by Hennig Brand in Germany. Recent advances in phosphorus application, involving using precision placement of coated fertilizers and by inoculating crops with mycorrhizae, have provided-more efficient uptake and increase in plant yields. By reviewing the key discoveries and current work going on, we can better design our future projects as nutrition scientists. While this approach will not encompass all horticultural crops, results with vegetables and ornamentals should provide concepts for work with other commodities.

677

\section{Phosphorus Soil Transformations and Management for Vegetables}

C.A. Sanchez" ; University of Arizona, Yuma Agric. Center, Yuma, AZ 85364

The amount of phosphorus $(P)$ accumulated by vegetable crops is relatively small compared to nitrogen and potassium. However, large amounts of $P$ fertilizer are often required for optimal yield and quality. Typically $\mathrm{P}$ added to soils is quickly converted to unavailable forms resulting in low crop utilization efficiencies. These low $P$ uptake efficiencies have long been of economic concern and a major focus of agronomic and horticultural research. Additionally, in certain regions where crop production areas are hydrologically linked to wetland ecosystems, P fertilization is also of environmental concern. This presentation will summarize important $P$ soil transformations, biotic and abiotic factors influencing the availability of $\mathrm{P}$ to crops, and $\mathrm{P}$ fertilizer management strategies for improved crop utilization efficiency and reduced environmental impact.

\section{8}

\section{Turfgrass Response to Phosphorus Applications}

N.E. Christians ${ }^{*}$; lowa State University, Ames, IA 50011

Phosphorus $(P)$ applications to turfgrasses vary with the development stage of the plant. At establishment, it is common to use "starter fertilizers," such as $12 \mathrm{~N}-25 \mathrm{P}-10 \mathrm{~K}$, that are high in $\mathrm{P}$ and relatively low in nitrogen (N). Mature grass plants, however, are very efficient users of $P$. As the root system develops, the amount of $\mathrm{P}$ added as fertilizer decreases, unless the soil is very deficient in P. A common analysis for mature turf would be a $20 \mathrm{~N}-2 \mathrm{P}-15 \mathrm{~K}$. The reason for this change is the relative immobility of $P$ in the soil. At the time of establishment, the limited root system is unable to obtain sufficient $P$ to meet the plant's needs for this element. The P does not readily move in the soil solution to the vicinity of the plant and it must be placed on the surface in close proximity to the developing root. At maturity, the fibrous, multibranched root systems of grasses make them some of the most efficient species at removing $P$ from the soil. A major concern over the use of $P$ fertilizers on turf in recent years has been the possibility of movement of this element into surface waters. Excess $P$ in surface water may result in algal blooms and other environmental problems. While there is some reason for concern where fertilizers are applied on sidewalks and streets in urban areas, $\mathrm{P}$ movement from most turf areas is very limited and properly applied fertilizer results in little damage to the environment.

\section{9}

Intelligent Media: Use of Buffered Phosphate for Production of Ornamentals in Soilless Media

Jonathan Lynch* and Kathleen Brown; Dept. of Horticulture, Penn State, University Park, PA 16802

We have developed solid-phase $\mathrm{P}$ buffers capable of maintaining $\mathrm{P}$ concentrations in soiless media much lower than conventional fertilizers, in the range of available P levels found in natural soil. In addition to substantially reducing PGH reaching into the environment, these buffers can have a number of useful effects on crop growth. Using various floriculture and ornamental species, plants grown in media buffered at low P levels have stimulated root branching and growth, increased drought resistance, better transplant establishment, better shoot form, better vegetative growth, increased flowering, and continued development of buds in the postharvest environment. Phosphorus availability regulates many aspects of root architecture including adventitious rooting, lateral branch density, root gravitropism, and root hair formation. It appears that many of the effects of $P$ on root growth may be mediated by ethylene. We hypothesize that the high P concentrations used in many horticultural systems are detrimental to optimal plant growth, and that buffered media represent an opportunity to improve production systems while also reducing environmental pollution from nutrient effluents.

\section{0}

\section{Use of Mycorrhiza for Selected Horticultural Crops}

Ed Bloodnick*; PREMIER HORTICULTURE, 326 Main Street, Red Hill, PA 18076

In undisturbed soil environments, certain bacteria and fungi help plants by transforming organic compounds, surpressing diseases, and acquiring nutrients. A strong interest has developed in the identification and culture of beneficial soil microorganisms. Complex groups of fungi, called mycorrhizae, grow in association with roots of many plant species. These fungi show promise as growth and quality enhancers for agriculture crops. However, farmlands that are subjected to excessive chemical fertilizers, pesticides, and soil fumigants contain low levels of indigenous mycorrhizae and other beneficial microorganisms. The re-introduction of endo-mycorrhizae populations has proven to be valuable for improvement of soils and vegetable crop culture. Peat-based substrates are generally used for germination and production of vegetable transplants. In this case, endo-mycorrhizae species (Glomus intraradices) was incorporated into a peat-based growing medium as a means of introducing inoculum to vegetable transplants. Bell pepper (Capsicum annuum) seeds were germinated and grown-on inoculated and noninoculated growing medium inside of a polyhouse for a period of 8 weeks. Fertilizer applications of $50 \mathrm{ppm}$ of $\mathrm{N}$ were given weekly. Seedlings were subsequently outplanted into field soil where incidence of root disease, fertilizer requirements, and pesticide applications were recorded. At fruit maturity, each harvest was evaluated for fruit quality and yield. At the end of the growing season, results indicated an improvement of fruit quality and a yield increase of $>16 \%$. 